Portland State University

PDXScholar

\title{
Social Support in an Urban Moroccan Neighborhood: the Effects of Social Networks, Mediation and Patronage on the Physical Health and Psychological Adjustment of Women
}

Carla Ann Green

Portland State University

Follow this and additional works at: https://pdxscholar.library.pdx.edu/open_access_etds

Part of the Family, Life Course, and Society Commons, and the Gender and Sexuality Commons Let us know how access to this document benefits you.

\section{Recommended Citation}

Green, Carla Ann, "Social Support in an Urban Moroccan Neighborhood: the Effects of Social Networks, Mediation and Patronage on the Physical Health and Psychological Adjustment of Women" (1995). Dissertations and Theses. Paper 1335.

https://doi.org/10.15760/etd.1334

This Dissertation is brought to you for free and open access. It has been accepted for inclusion in Dissertations and Theses by an authorized administrator of PDXScholar. Please contact us if we can make this document more accessible: pdxscholar@pdx.edu. 
SOCIAL SUPPORT IN AN URBAN MOROCCAN NEIGHBORHOOD:

THE EFFECTS OF SOCIAL NETWORKS, MEDIATION AND PATRONAGE

ON THE PHYSICAL HEALTH AND PSYCHOLOGICAL

ADJUSTMENT OF WOMEN

by

CARLA ANN GREEN

A dissertation submitted in partial fulfillment of the requirements for the degree of

DOCTOR OF PHILOSOPHY

in

SYSTEMS SCIENCE:

SOCIOLOGY

Portland State University

(C) 1995

All Rights Reserved 
OMI Number: 9526359

Copyright 1995 by

Green, Carla Ann

All rights reserved.

UMI Microform 9526359

Copyright 1995, by UMI Company. All rights reserved.

This microform edition is protected against unauthorized copying under Title 17, United States Code.

\section{UMI}

300 North Zeeb Road

Ann Arbor, MI 48103 


\section{DISSERTATION APPROVAL}

The abstract and dissertation of Carla Ann Green for the Doctor of Philosophy in Systems Science: Sociology were presented January 26, 1995, and accepted by the dissertation committee and the doctoral program.

COMMTTTEE APPROVALS:

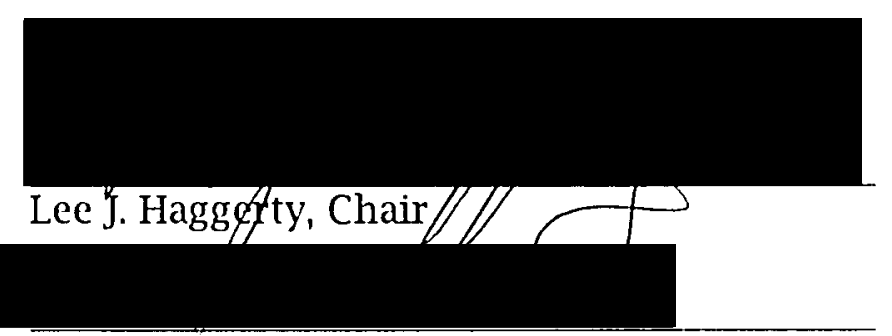

Kathryn A. Farr

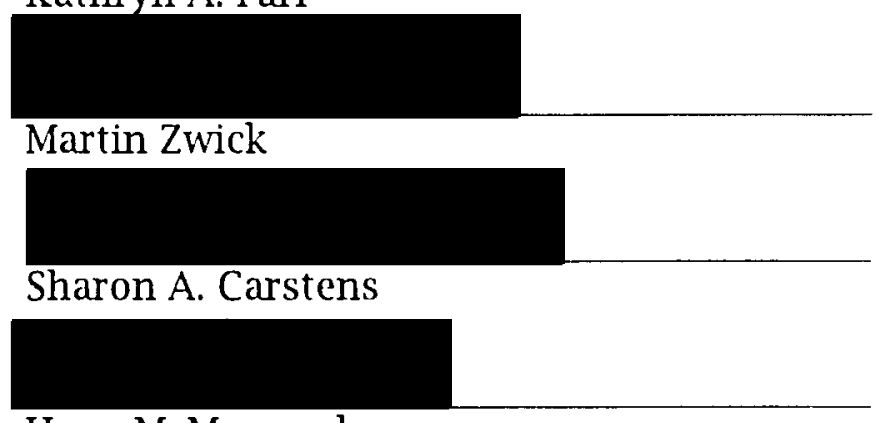

Hugo M. Maynard

Representative of the Office of Graduate Studies

DOCTORAL PROGRAM APPROVAL:

Beatrice Oshika, Director

Systems Science Ph.D. Program

ACCEPTED FOR PORTIAND STATE UNIVERSITY BY THE LIBRARY

by

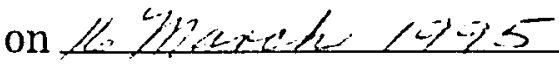




\begin{abstract}
An abstract of the dissertation of Carla Ann Green for the Doctor of Philosophy in Systems Science: Sociology presented January 26, 1995.

Title: Social Support in an Urban Moroccan Neighborhood: The Effects of Social Networks, Mediation and Patronage on the Physical Health and Psychological Adjustment of Women.
\end{abstract}

Although there has been a great deal of research in the areas of social networks, social support and well-being over the past two decades, little of that research has been cross-cultural, and virtually none has been carried out in countries outside the West. The present study attempted to describe the structure and functioning of the social networks of a group of relatively modern urban Moroccan women, and the associations among their social networks, social support, physical health and psychological well-being. Extensive interviews were conducted with 108 married or previously-married women who were living in a middle-class neighborhood in Rabat, Morocco. Subjects were asked to identify social network members, defined as friends, family or others who provided various types of support in typically encountered 
life situations, or with whom the subject had negative interactions. Standardized self-report instruments were used to assess physical and psychological well-being, and to assess the occurrence of stressful life events. Additional observational data were collected on respondents' neighborhoods and immediate physical surroundings. A model describing the interactions between well-being, network structure and network function was tested using factor-analytic and set-regression techniques. Stressful life events predicted reduced physical well-being. Enhanced psychological functioning was predicted by reciprocity in relationships, marital satisfaction, and to a lesser degree, practical and emotional support. Contrary to predictions, patronage support was associated with both enhanced physical and psychological well-being. Results were generally consistent with Conservation of Resources (COR) theory, which predicts that the uniformly large and well-functioning networks found in this study would produce effect sizes that were small, but consistent with Western research findings. 


\section{DEDICATION}

I dedicate this work to my family, who have been the best possible social support network I could have hoped for. To my husband, Darien Fenn, who has kept the house standing and the animals fed, to my daughter Dessa, who has put up with more academic life than anyone her age should ever have to, to my mother for always being available when I need her, and to my late father, Carl Green, for inspiring me to achieve and teaching me how to think. And lastly, to Sofia Harmaoui, the best "ustad" of them all. 


\section{ACKNOWLEDGMENTS}

Many people have helped and supported me from the early conceptualizations of this project to its finish. Most importantly, I could not have completed this project without the gracious hospitality of the Moroccan women who welcomed me into their homes and told me of their lives. I cannot thank them adequately for what they have so unselfishly given to me.

My dear friends Amina Al Zemmouri and Taib Amrani provided support and information that helped me to negotiate daily life in Morocco and assisted me directly with my fieldwork. Both worked on translations of the questionnaires, Taib gave me Moroccan Arabic lessons, and Amina first interpreted for me, then later completed interviews on her own. I cannot thank them enough for their help and companionship during our stay. I especially want to thank Dr.

Mohammed Guessous, my field advisor in Morocco, who gave me time out of an extremely busy schedule and who helped me to overcome difficulties when they arose in my fieldwork.

Rkia Montassir reviewed the Arabic questionnaires and gave me language lessons, Badia El Abassi and Noureddine Bouchtia helped with early changes to the questionnaire. Christine Deery and Claudine Fischer provided excellent French language instruction, and Christine helped me create the French versions of my questionnaires. Mostafa 
Jawadi contributed many of the details necessary to develop the early questionnaires and provided aid well beyond the call of duty in helping us get settled in Morocco.

I would like to express my gratitude for the grant provided by the Fulbright Foundation, and their liaison in Morocco--the MoroccanAmerican Commission for Educational and Cultural Exchange--without which this research would have been impossible. In particular, I want to thank Ed Thomas and Saadia Meski for their help and support throughout my fieldwork and after.

I want to thank my committee--Lee Haggerty, Sharon Carstens, Kathryn Farr, Hugo Maynard and Martin Zwick--for their thoughtful work, constructive criticism and helpful suggestions. I particularly want to thank Hugo Maynard and Lee Haggerty who helped me ruthlessly eliminate mountains of data when I was drowning in complexity.

Darien Fenn deserves more thanks than I can possibly give for helping me think my ideas through, providing comments, criticism and not a few meals. Dessa Fenn did more than her share of the house- and barnwork, and in addition, helped me to both find and keep in order, the enormous number of references and articles I needed. 
TABLE OF CONTENTS

DEDICATION $\ldots \ldots \ldots \ldots \ldots \ldots \ldots \ldots \ldots \ldots \ldots \ldots \ldots \ldots \ldots \ldots \ldots \ldots \ldots$

ACKNOWLEDGEMENTS $\ldots \ldots \ldots \ldots \ldots \ldots \ldots \ldots \ldots \ldots \ldots \ldots \ldots \ldots \ldots \ldots$

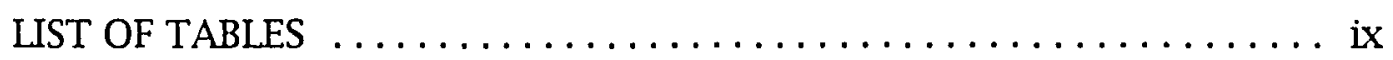

LIST OF FIGURES $\ldots \ldots \ldots \ldots \ldots \ldots \ldots \ldots \ldots \ldots \ldots \ldots \ldots \ldots \ldots \ldots \ldots \ldots$

INTRODUCTION $\ldots \ldots \ldots \ldots \ldots \ldots \ldots \ldots \ldots \ldots \ldots \ldots \ldots \ldots$

Social Support and Well-Being in Western Research ........ 2

Review of the Literature $\ldots \ldots \ldots \ldots \ldots \ldots \ldots \ldots \ldots \ldots$

Social Networks $\ldots \ldots \ldots \ldots \ldots \ldots \ldots \ldots \ldots \ldots$

Using Social Networks to Study Social Support ........ 5

Social Networks in Non-Western Settings . ..........6 6

Women's Social Networks ...................11

Social Network Structure . . . . . . . . . . . . . . . . . I1

Social Support Functions ................... 18

The Detrimental Effects of Relationships . ......... 27

Stressful Life Events ...................... 28

Antecedent and Control Measures .............. 30

Social Support and Well-Being in a Cross-Cultural Setting:

A Conceptual Framework ..................... 34

Assessment of Social Networks, Social Support, Physical Health

and Psychological Well-Being: Research Hypotheses . . . . . 36

Hypotheses Associated with Network Structure . . . . . . 37

Hypotheses Associated with Network Functions . . . . . . . 39

Hypotheses Unique to Moroccan Patterns of Interaction . . 41

THE RESEARCH SETTING $\ldots \ldots \ldots \ldots \ldots \ldots \ldots \ldots \ldots \ldots \ldots+2$

Morocco: Location and Character of the Country ......... +2

Climate................................ 43

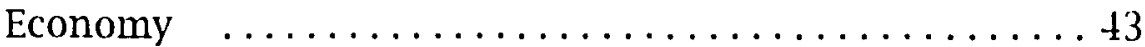

Government ..........................4

Ethnicity and Language . . . . . . . . . . . . . . . . . . . . 44

Education and Literacy $\ldots \ldots \ldots \ldots \ldots \ldots \ldots \ldots+\ldots \ldots$

Capital City: Rabat ........................ t7

Local Research Setting: History and Characteristics of the Agdal

Neighborhood ........................... 48

Geography and Population of the Neighborhood ..... . 50

Daily Life for Middle-Class Moroccan Women ........... 51 


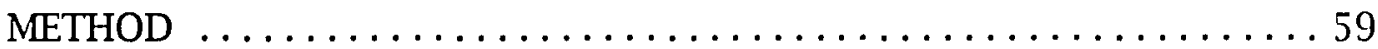

Instrumentation ............................. 59

Antecedent Variables .......................6 60

Measure of Recent Life Events . . . . . . . . . . . . . 65

Measures of Network Structure $\ldots \ldots \ldots \ldots \ldots \ldots 68$

Measures of Social-Support Functions ............. 74

Measures of Physical Illness and Psychological

Adjustment .......................... 77

Interviewer and Refusal Questionnaires $\ldots \ldots \ldots \ldots 81$

Procedure ..............................82

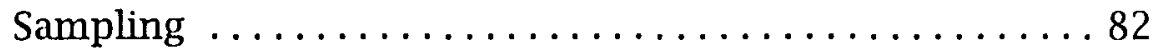

Administration of the Questionnaire $\ldots \ldots \ldots \ldots \ldots 84$

Respondent Characteristics ................. 86

Refusals and Refusers .................... 92

Characteristics of Family Structures and Social

Networks in the Sample .................. 96

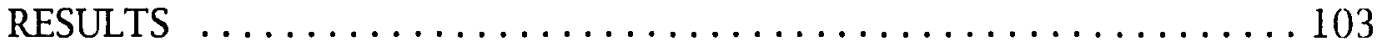

Factor Analysis of Network Structure and Function Variables 103

Descriptions of the Factors ................. 106

Relevance of Factors to Western Theoretical Concepts .. 112

Antecedent Measures, Life Events, Social Network Structures

and Functions, and Well Being: Breakdown of the Model .. 113

Antecedent Measures and Life-Events ............ 115

Antecedent Measures, Life Events and Network

Structures ......................... 118

Antecedent, Life-Events, Network Structures and Network

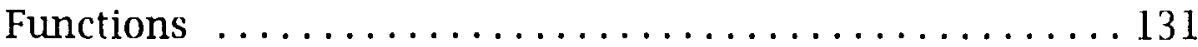

Global Measures of Network Function ............ 134

Frequency of Contact with Network Members ......... 139

Frequency of Support Received from Network Members . 140

Reciprocity .............................. 14

Negative Interactions ........................ 149

Joint Analyses of All Independent Variables With Brief

Symptoms Inventory Subscales . . . . . . . . . . . . . . 154

General Severity Index . . . . . . . . . . . . . . . . . . 155

Positive Symptom Distress Index . . . . . . . . . . 157

Positive Symptom Total ..................... 160

Joint Analyses of All Independent Variables With Physical

Illness Measures .......................... 162

Number of Recent Illnesses (Six Months Prior to

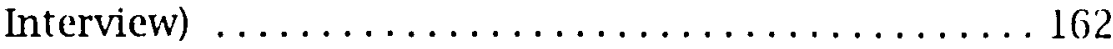

Illness-Severity Index (Six Months Prior to Interview) . . . 163 
Joint Regression Analyses of All Independent Variables On Well-Being Measures, Sample Split for Respondents' Level of Stress ............................. 164

Regressions of Antecedent and Network Measures on Health and Psychological Dependent Measures for Recent High and Low Stress Levels . . . . . . . . . . . . . . . . . . . . . 165

Regressions of Antecedent, Life-Events and Network

Measures on Health and Psychological Dependent

Measures for Remote High and Low Stress Levels . . . . 170

Summary of Analyses .........................174

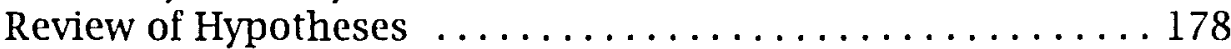

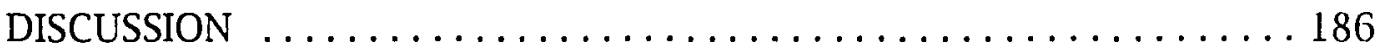

Patterns in the Prediction of Well-Being . . . . . . . . . 186

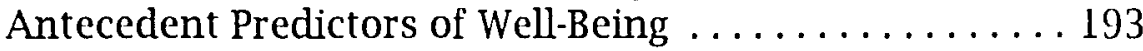

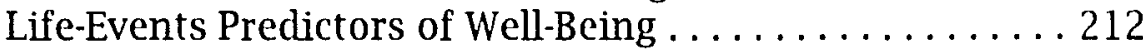

Network Structure Predictors of Well-Being . . . . . . . 220

Network Function Predictors of Well-Being . . . . . . . 233

Limitations of the Study . . . . . . . . . . . . . . . 238

Summary of the Most Important and Interesting Conclusions 241

Network Factors ........................ 241

Predictive Ability of the Overall Model . . . . . . . . 242

Interesting and Unexpected Findings $\ldots \ldots \ldots \ldots \ldots 245$

REFERENCES ............................... 251

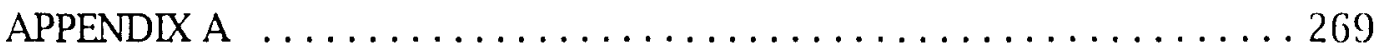

Questionnaire: English Version . . . . . . . . . . 270

APPENDIX B . . . . . . . . . . . . . . . . . . . . . . . . . . . 292

Reliability Analysis of the Socio-Economic Status (SES) Scale . 293

Reliability Analysis of the Traditionality-Modernity (T-M) Scale 294

APPENDIX C . . . . . . . . . . . . . . . . . . . . . . . . . . . 295

Interviewer Questionnaire .................. 296

Refusal Questionnaire .......................... 301

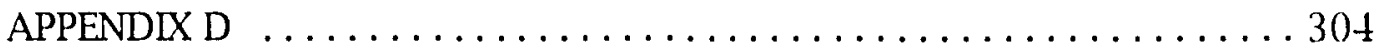

Brief Symptoms Inventory $(\mathrm{BSI}) \ldots \ldots \ldots \ldots \ldots \ldots \ldots \ldots \ldots \ldots$

APPENDIX E . . . . . . . . . . . . . . . . . . . . . . . . . . . 309

Modified Life Experiences Survey (LES) . . . . . . . . . . . . 309 
APPENDIX F ................................. 313 Index of Marital Satisfaction (IMS) $\ldots \ldots \ldots \ldots \ldots \ldots \ldots \ldots \ldots \ldots$

APPENDIX G ...................................... 315 Modified Severity of Illness Rating Scale-Revised (SRS-R) . . . 315 
TABLE

\section{LIST OF TABLES}

I Frequencies and Percentages of Agdal Respondents for Each Socio-economic Status and Modernity-Traditionality Quartile Constructed with the Larger Sample ......... 92

II Participation as a Function Of French-speaking Ability . . 94

III Results of Cross-Tabulations of Sex by Kinship for Respondents' Network Members ............... 101

IV Factor Loadings of Network Structure And Function Variables ............................. 104

$\mathrm{V} \quad$ Eigenvalues and Percentages of Variance Accounted for by Network Structure and Function Factors . . . . . . 105

VI Factor Correlation Matrix for Network Structure and Function Factors ..................... 106

VII Results of Regression Analyses of Antecedent Measures on Life-events During the Year Preceding Participation .. 115

VIII Results of Regression Analyses of Antecedent and Life-Events on Network Structure . . ............. 119

IX Correlations Between Average Dispersion in Networks, Berber-Speaking Ability, and Length of Time Lived in Rural Areas ........................... 130

$\mathrm{X}$ Results of Regression Analyses of Antecedent, Life-Events, And Network Structure Measures on Network Functions .................... 132-133

XI Correlations Between Education Level, Employment Status And T-M And SES Scale Scores .. 
TABLE

XII Reciprocity as a Function of Respondent's Age and Whether or Not Network Member Is Her Child

XIII Results of Regression Analysis of Antecedent, Life-Events, Network Structure and Network Function Measures on the GSI ................ 156

XIV Results of Regression Analysis of Antecedent, Life-Events, Network Structure and Network Function

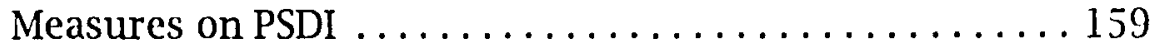

XV Results of Regression Analysis of Antecedent, Life-Events, Network Structure and Network Function Measures on PST .................... 61

XVI Results of Regression Analysis of Antecedent, Life-Events, Network Structure and Network Function Measures on Number of Recent Illnesses . . . . . . . . 162

XVII Results of Regression Analysis of Antecedent, Life-Events, Network Structure and Network Function Measures on Recent Illness-Severity Index . . . . . . . . . 164

XVIII Results of Regression Analyses of Antecedent, Network Structure and Network Function Measures on Well-Being with Sample Split for Respondents' Recent Stress Level . . 166

XIX Results of Regression Analyses of Antecedent, Network Structure and Network Function Measures on Well-Being, Sample Split for Respondents' Remote Level of Stress . . 171

XX Summary of Antecedent And Network Variables Predictive of Psychological Adjustment or Physical Health in All Regression Analyses . . . . . . . . . 175

XXI Summary of Literature Review of Network Structure

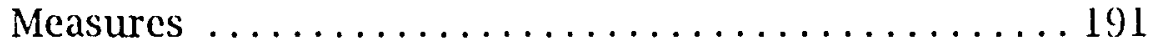




\section{TABLE}

XXII Summary of Literature Review of Network Function

Measures ............................. 192

XXIII Results of Cross-tabulations of Patron Vs. Non-Patron

Network Members by the Reciprocity of Their

Relationships with Respondents $\ldots \ldots \ldots \ldots \ldots \ldots 24$

XXIV Item-Total Statistics For SES Scale Reliability Analysis . . 293

XXV Item-total Statistics For T-M Scale Reliability Analysis . . 294 


\section{LIST OF FIGURES}

FIGURE

1. Conceptual Model of Factors Affecting Well-Being ...... 35

2. Question used for measure of reciprocity. ......... 77

3. Respondents' Education Level with $n$ of each group

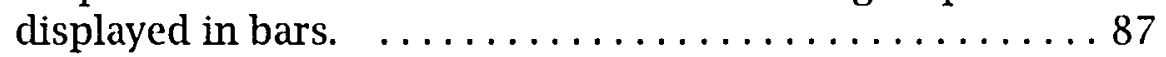

4. Respondents' Literacy Level with $n$ of each group displayed in bars. $\ldots \ldots \ldots \ldots \ldots \ldots \ldots \ldots \ldots . \ldots . \ldots . \ldots 8$

5. Monthly household revenue (Note: at the time of the survey, $\$ 1.00=$ approximately $8 \mathrm{Dhs}) \quad \ldots \ldots \ldots \ldots \ldots 89$

6. Respondents' family classification. .............. 97

7. Respondents' relationships to persons with whom they had only negative interactions. . . . . . . . . . . . 102

8. Relationship between recent negative life events and education level, grouped by the number of additional languages spoken. ....................... 117

9. Relationship between age and network size, grouped as members of the Agdal sample or the larger sample. ... 121

10. Time lived in rural areas and network dispersion, grouped by Berber-speaking ability . ............ 131

11. Relationship between satisfaction with friends and traditional vs. modern cultural orientation grouped by socio-economic status. ..................... 136

12. Total frequency of support received as a function of $\%$ kin in networks, grouped by respondents' SES levels. . . 143 


\section{FIGURE}

13. Respondent's assessment of reciprocity with network members as a function of her age, and grouped by whether or not member is her child.

14. Relationship between traditionality-modernity and average frequency of negative interactions grouped by employment status. ..................... 152

15. Percentage of variance accounted for by the full model in regression analyses with physical health and psychological functioning dependent measures. . . . . . 2 243 


\section{INTRODUCTION}

The purpose of this research was to examine and describe types of social network structure and functions as well as their associations with physical health and psychological functioning in a non-Western setting. This was exploratory work: I wanted to learn whether or not the associations among social networks, social support and well-being found by Western researchers held true in a different society. In addition, I hoped to illuminate aspects of the social support process which might be unique in the Moroccan setting. In order to achieve these goals, I conducted a randomly sampled survey of a middle-class Moroccan neighborhood, interviewing women about their social networks, the social support they received, their recent life experiences and health problems, and their level of psychological functioning at the time of the interview.

The sections which follow review Western findings about the associations between social networks, social support and well-being as well as relevant work that has been carried out in the Middle East and North Africa. 


\section{Social Support and Well-Being in Western Research}

During the last two decades, many studies in the Western world have established a link between social support and physical health, psychological well-being, morbidity and mortality (see Argyle, 1992; Berkman, 1983; Cohen \& Syme, 1985a; House, Umberson, \& Landis, 1988; and Israel, 1982 for reviews). Researchers have also studied the roles played by social networks and their associated structure in providing the social support related to these outcomes, and have explored such support in a wide variety of situations (see Boswell, 1969; Cohen, 1992; Gottlieb, 1981; Hall \& Wellman, 1985; House, Umberson, \& Landis, 1988; Lieberman, 1982; Wills, 1983; Wilcox \& Birkel, 1983; for just a few). At the same time, these results have sometimes been contradictory and many researchers have found only weak effects. Additionally, considerable controversy still exists in this literature about whether social support has a direct effect on overall health and well-being, aids network members only when they experience adverse life circumstances, or if social support improves health outcomes in both of these ways (Cohen \& Syme, 1985b).

At this time, a number of major inadequacies in the social support literature remain. To date, most researchers have measured either network structure or social support variables alone, even though their interaction is believed to be critical to an understanding of social 
support processes (Cohen \& Syme, 1985b; Schulz \& Rau, 1985). Because of this unidimensional focus, relatively little information exists about the interactions between measures of structure like network size and density, and functions such as types and amount of support provided, or the well-being outcomes with which these interactions are associated. In addition, little is currently known about how social networks and social support function and affect well-being in non-Western contexts.

\section{Review of the Literature}

Research exploring social networks and social support has become a complicated undertaking in recent years, with a variety of social network concepts believed to interact with a number of different support types, all influenced by demographic and lifestyle elements as well as recent life experiences. This interacting system of factors has been shown to influence both mental ard physical health in a number of ways and in a variety of circumstances. Because of the complexity of the system, I have organized the literature review in sections corresponcling to the major areas of focus of these research efforts. These include: (a) social networks in Western and in non-Western settings, (b) social network structure, (c) social support functions, (d) the detrimental effects of relationships, (e) stressful life events, and (f) antecedent and control factors. 


\section{Social Networks}

Social networks have been conceptualized in several different ways by different researchers. Mitchell (1969) distinguishes between the metaphorical usage of networks (as in, "a network of social relationships") and the "notion of a social network as a specific set of linkages among a defined set of persons, with the additional property that the characteristics of these linkages as a whole may be used to interpret the social behaviour of the persons involved" (p. 2). Knoke and Kuklinski summarize Mitchell's definition of networks as follows: "a specific type of relation linking a defined set of persons, objects, or events" (1982, p. 12). Hall and Wellman (1985) define networks as a "set of nodes [in most health research, nodes are "persons"], tied together by at least one specific type of relation" (p. 25). In addition, they further clarified these relationships as follows:

...ties are defined by the flow of resources from one node (or network member) to another. These resources can vary in quality (whether the tie provides emotional aid or companionship), quantity (whether it provides much emotional aid, frequent companionship), multiplexity (whether it provides only emotional aid or both emotional aid and companionship), and symmetry (whether both parties to a tie exchange roughly equivalent amounts of 
emotional aid or whether the resource tends to flow only in one direction) (Hall \& Wellman, 1985, p. 25).

Although not an exhaustive list of specific types of ties, this delineation gives an overview of some of the more commonly measured structural and functional variables, and I found it to be the most useful conceptualization for this research project.

\section{Using Social Networks to Study Social Support}

Hall and Wellman (1985) have argued that social network analysis is the most appropriate method for the systematic study of the "composition, structure and content of interpersonal ties in naturally occurring settings" and for "relating these network descriptions to the study of stress, social support and other health-care issues" (p. 25). Their argument comes after many years of research conceptualizing ties as supportive, dyadic relationships, and support as a global and unidimensional phenomenon (p. 24). Hall and Wellman argue that it may not even make sense to think of social support as a set of coherentlyrelated phenomena. Irrespective of the way social support has been conceptualized thus far, the social network model provides a series of tools which can be used to systematically describe and understand the structure of support systems without reducing complex ties and interrelationships to dyads, and social support to a construct lacking depth (Hall and Wellman, 1985). These tools include graphical 
presentations of networks as well as a group of descriptive variables like density (the proportion of actual ties in a network to total ties possible) and multiplexity (the number of types of support provided by an individual member) as well as many others.

\section{Social Networks in Non-Western Settings}

Social networks have been studied by anthropologists in nonWestern contexts, but this work has been primarily concerned with describing membership in particular networks, the pervasiveness of networks in specific settings, and their economic and cultural functions (see Davis, 1978; Eisenstadt and Roniger, 1984; Geertz, Geertz, \& Rosen, 1979; Maher, 1974; Maher, 1976; Rassam, 1980; Rosen, 1984; Sabah, 1984; Sabah, 1987, for some specifically Moroccan examples). To date, the roles these networks play with respect to health and adjustment have not been examined. Because of indigenous conditions and traditions, Islamic countries are a particularly fertile ground for studying social support and its effects on health and well-being. For example, people living in this part of the world continue to have more limited access to health care (see Bowen, 1985; Maazouzi, 1989; Sabah, 1984 for work in Morocco), and recent public health advances have not yet eliminated problems with sewage, water and food supplies (Abu-Lughod, 1980; Haddad, 1988; Maazouzi, 1989). These factors have the potential to increase the likelihood that the sometimes subtle effects of social 
support on health found in Western settings will be more pronounced. Most importantly, Islam promotes the provision of ongoing support to others by requiring almsgiving as one of its five pillars, in addition to making mutual assistance a normative expectation for believers (Bates \& Rassam, 1983). Moreover, family ties and social networks remain very strong and cohesive in Islamic countries (Abdal-Ati, H., 1974; Al-Thakeb, 1985; Barakat, 1985; Bates \& Rassam, 1983; CERED, 1991; Davis \& Davis, 1989; Gram, 1974; Geertz, 1979; Kramer, 1970; Lubeck, 1981; Maher, 1976; Rassam, 1980; Rosen, 1984; Sabah, 1984; Sixième Colloque de Démographie Maghrebine, 1985).

\section{Networks and the Role of Kinship}

In combination with religious traditions of help-giving, the continuing importance of kin, family, and tribal history in Islamic countries yield large well-established social networks that have significant proportions of kin as members (Al-Thakeb, 1985). Research in the West suggests that kin relations are often characterized by increased frequencies of mutual assistance as well as the willingness to provide forms of help which may involve personal sacrifices for those giving the help (Amato, 1990; Gerstel; 1988; Leslie \& Grady, 1985; Milardo, 1987; Wellman \& Wortley, 1989; Zimmer \& Aldrich, 1987). Al-Thakeb (1985) found the same (if not more extensive) pattern among his Kuwaiti respondents. At the same time, greater involvement of kin may be 
associated with negative outcomes as a result of increased interference in other affairs, detrimentally influencing well-being (Gerstel, 1988; Milardo, 1987; Spanier \& Hanson, 1981). Several researchers working in Morocco have reported case studies which provide evidence for both increased helping as well as interference by kin (see for example: Davis, 1983; Geertz, 1979; Mernissi, 1989).

\section{Patronage and Brokerage}

Many, if not all, Islamic countries have well-developed exchange structures called systems of patronage or brokerage. Patronage relations often play very important roles in the lives of their participants (Maher, 1976), yet the exchanges which characterize these types of connections may create alliances that are unbalanced and where reciprocity-in-kind is not possible. Patrons or brokers are most often people of higher socioeconomic status, persons who are well-placed in bureaucracies or play gatekeeping roles in such organizations, or those who have access to such persons. These patrons use their power and resources to provide services, goods, information and contacts to those who do not have other means of access to these assets (Agier, 1981; Gellner, 1977; Maher, 1974 \& 1976; Sabah, 1984 \& 1987; Stuart, 1972). In exchange, their clients may place themselves in subordinate positions, often only able to return labor, obedience, power and prestige to the patron/broker. Because the exchanges in these relationships are not of the same type, exchange 
theorists would consider them non-reciprocal ties. In addition, past research on exchange and helping relationships suggests that such nonreciprocal ties may be detrimental to the well-being of one or both parties in the exchange (Belle, 1982; Greenberg \& Westcott, 1983; Hatfield \& Sprecher, 1983; Kelley, 1979). In Morocco, these relationships are pervasive in social, economic and government life (Sabah, 1984 \& 1987; Waterbury, 1970), and viewed in the context of Western research and theory, such inherent asymmetries would be expected to have negative effects on well-being, irrespective of and/or overwhelming any functional aspects of the exchange.

\section{Mediation}

Unlike most Western societies, networks in Middle Eastern and Islamic communities frequently contain people who function as mediators when disputes arise (Ayoub, 1965 \& 1966 ; Bates \& Rassam, 1983; Geertz, 1979; Gram; 1974; Huxley, 1978; Sabah, 1984). Although a formal court system exists and is used for some purposes, families and communities more frequently ask family members, friends, or particularly pious individuals to act as informal mediators. These mediators often help to resolve small economic disputes, problems between husbands and wives and/or other family members, disputes with neighbors, or other difficulties that present themselves. Al-Thakeb (1985) found that only two percent of conflicts were resolved in court, 
while the rest were resolved with the help of relatives and friends. Almost unknown in Western societies, these mediators play a critical role in the everyday lives of people in the Islamic world, and informal mediation by friends and/or family members provides an important resource for ensuring fairness (Bates \& Rassam, 1983).

I was interested in these mediation techniques because I felt that they might enhance informal dispute resolution processes, perhaps increasing network solidarity. If mediation reduces conflict or resolves problems that otherwise might continue to create strained relations, then involved network members should benefit. In addition, if Moroccan marriages are more likely to survive because of the mediation and intervention of others, and if marital relationships in Morocco are as important to physical and mental health as they are in the West (Argyle, 1992), the availability of mediators could be an important predictor of well-being. In addition, if serious disputes are more easily resolved in Moroccan culture than in the West, then both health and psychological benefits should accrue to all disputants.

Consistent with my assertions about the potential benefits of mediation, Jones and Vaughan (1990) have argued that intervention programs designed to strengthen networks in the West should focus on conflict-management rather than on friendship initiation, facilitating the 
continuation of existing (and therefore stronger) network relationships rather than new (and weaker) ties.

\section{Women's Social Networks}

The importance of women's social networks as well as their structure, composition, and functioning in a wide variety of settings has only recently been granted significant attention (March \& Taqqu, 1986). In addition to providing daily social support and help, women's networks provide a variety of services for their members. As is true of men's networks, women's networks often help improve economic power and conditions by making loans to participants, increasing political organization and strength, and establishing important institutional linkages (Waltz, 1990; March \& Taqqu, 1986). To date, these networks have been understudied (March \& Taqqu, 1986).

\section{Social Network Structure}

Researchers have identified a number of important features that describe the structure of networks. They include the overall size of a person's network as well as the sizes of subnetworks associated with providing particular forms of support. In addition to size, network density, multiplexity, homogeneity and dispersion are all considered important descriptors. 


\section{Density}

Network density is the ratio of the number of persons who know each other directly in a network to the number of possible ties available within that network. Density measures can provide particularly important information about how integrated a network is and about its possibilities for coordination. For example, in a very dense network, most people are likely to know if the respondent has a problem, and can coordinate methods for providing aid among themselves. However, if the network is not dense, individuals are less likely to know about others' problems in the first place, and secondly, are less likely to be able to coordinate help with others. When this is the case, those individuals who do have the information must bear the burden of providing aid themselves, or choosing to reject requests for help.

Several studies have found that density may have differential effects dependent upon needs (see House \& Kahn, 1985; and Schulz \& Rau, 1985, for reviews). For those persons needing a great deal of support related to identity formation or maintenance, small dense homogenous networks are often more beneficial. Conversely, larger, less dense heterogenous networks are more helpful when information is needed, contacts must be made, or when people must adjust to life transitions and changes in roles and identities. Fischer (1982) found some interesting (and complicated) relationships between density, the 
"psychological mood" of respondents, and how they felt about the support they received. Density was generally associated with feelings of contentment about the numbers of people respondents had available to talk to or have fun with. However, as density moved above $70 \%$, he found that respondents began to wish they knew more people with whom to interact. Additionally, psychological mood improved with increasing network density for low income respondents, while for affluent participants it deteriorated.

\section{Network Size}

Fischer (1982) found that the larger a respondent's network the greater their reported happiness. However, in a review of the effects of social networks throughout the life course, Schulz and Rau (1985) found conflicting evidence about associations between network size and physical health and psychological functioning. At the same time, House and Kahn (1985) have shown that increasing network size has a positive effect on health but that the effect diminishes significantly after a certain point (diminishing returns begin to occur somewhere between 5 and 10 persons). That is, as long as a person has a core group of people who can be relied upon, increasing numbers of people in the network do not proportionately improve its functioning. This finding may explain the aforementioned conflicting results reported by Schulz and Rau. If diminishing returns occur when networks reach a size between five and 
ten, the population under study would have to include respondents with very small networks to find any size effect.

\section{Dispersion}

Dispersion is a spatial measure, indicating the distance between the homes of respondents and their network members, and is important because it reflects the difficulty associated with having face-to-face contact with those network members. Dispersion is normally assessed as the amount of time it takes the respondent to travel from his or her own home to the home of the network member. Fischer (1982) found that dispersion was related to education level, with more highly educated respondents naming more distant network members. In addition, most participants rated distant members among those with whom they felt "especially close".

Dispersion can be seen as an important factor in social exchanges. Obviously, increasing distance between friends or kin makes interactions more costly-in terms of both travel time and cost of transportation. As would be expected, researchers have found differences in the types of typical exchange relationships people maintain as a function of a combination of the distance between them and their intimacy levels (Fischer, 1982). Fischer found, as had Wellman (1979) before him, that when nearness is important for an exchange, nearby network members are preferred, but in more important situations where intimacy, sacrifice 
and faith are critical to the interaction, people show no preference based on distance. In fact, Fischer (1982) suggests that knowing that very intimate friends and family can be relied upon if necessary may make people feel more confident, even if the distance between them is great.

\section{Multiplexity}

Multiplexity can be defined as the "extent to which relationships involve more than one type of content or transaction" (House \& Kahn, 1985, p. 92). Fischer (1982) found that several factors were related to the presence of multiplex relations (what he called "multistrandness"): Younger, more highly educated and employed individuals tended to have both larger and more multiplex networks, while those with fewer activities (older, retired individuals as well as homemakers) had smaller networks with fewer multiplex relations.

The multiplexity of network relationships has continued to be of interest to researchers, yet in their reviews considering the effects of multiplex relations on well-being (both physical and psychological) House and Kahn (1985) as well as Israel (1982) have found conflicting results: Some studies have shown clear effects of multiplexity on health while others have not. At this time it is not yet clear whether multiplexity affects well-being, or how it does so if it is a causal factor. 


\section{Composition and Homogeneity}

Homogeneity is a broad term which is used to describe how similar network members are to one another. It is frequently measured by questioning respondents about how similar they are to their network members in terms of personality or character, although gender and kinship are also dimensions of similarity that are commonly included in social network research. Although the socio-economic status (SES) of network members might also be an important homogeneity indicator, the difficulties associated with assessing SES levels for large numbers of network members is probably responsible for its lack of consideration in this aspect of social network research.

The homogeneity of networks has been found to affect health in different ways in different circumstances. Consistent with findings about density in networks, increasing homogeneity in networks can be very important for people adjusting to events which produce needs for maintaining or recovering social identity and well-being (House \& Kahn, 1985). Conversely, heterogeneity (and low density) in networks may be helpful during life transitions that require changes in roles and/or identities (House \& Kahn, 1985). Measures of homogeneity typically used in social network research provide methods for assessing both of these factors along a continuum. 
Gender and Social Networks. Differences in the gender composition of networks can be critical for understanding their supportive qualities. Several studies in Western settings have found that gender composition is an important factor in determining health outcomes, with female network members providing more beneficial assistance than males (Belle, 1982), yet gender-based role differences within social networks have been neglected. In general, we know that marital partners are often critical members of social networks, providing support which reduces both physical and mental illness (Argyle, 1992; Cleary, 1987; House \& Kahn, 1985), although this pattern is almost always more true for men than it is for women (Belle, 1983; Gove, Hughes, \& Style; 1983). In fact, some studies have even shown married women to be at increased risk for both mental and physical health problems (see Radloff, 1975; and Belle, 1983 for a review), although this may vary with income level (Cox \& Radloff, 1984). Bernard (1981) argues that these differential findings for men and women can be best explained by men's lack of training in "supportive functions". This lack of expertise results in an increased likelihood for both men and women to turn to women for support, creating a situation where women give more help and support than they receive, and resulting in imbalanced exchanges with potentially harmful effects. There is not yet any other 
information about specific trends in the types of support or help provided by either men or women in social networks.

Kinship and Social Networks. The proportion of kin to kith in a network often provides an important index of the commitment of the people in the network and of the level of support which can be expected from them. Although a few studies have found negligible effects of kin on support received, most find that family members provide a great deal more aid than do friends and acquaintances (Wellman, 1979; Wellman \& Wortley, 1989).

\section{Social Support Functions}

In recent years, researchers have identified a number of social support functions which they believe influence well-being. They include different types of social support (e.g. emotional, informational, etc.) as well as frequency of contact with network members, frequency of supportive interactions, and reciprocity within the network.

\section{Types of Social Support}

A number of types of support have been identified in recent years. In an early review of the literature, House (1981) identified four general areas of support: (a) emotional, (b) instrumental, (c) informational, and (d) appraisal. As he defined it, emotional support involves interaction which provides empathy, caring, love, trust and concern. Instrumental (or practical) support includes behaviors that directly help the person in 
need, e.g. money, labor, time, and aid-in-kind. In contrast, informational support is defined as access to needed data, advice, and directives which help people cope with their situations. Finally, appraisal support involves providing information which allows self-evaluation, such as feedback about beliefs and behavior, affirmation, and social comparison. In other research, Vaux, Riedel and Stewart (1987) found evidence consistent with a five-factor model of social support. They proposed the following distinctions for support type: (a) emotional, (b) socializing, (c) practical assistance, (d) financial assistance, and (e) advice/guidance. In a more recent effort, Vaux (1992) reviewed the literature and found that although other types of support have been suggested (including (a) social integration, (b) attachment, (c) motivational, (d) love, (e) esteem, and (f) belonging, among others), most researchers have consistently stayed with definitions similar to the House (1981) and Vaux, Riedel and Stewart (1987) formulations (Vaux, 1992).

Wellman (1985) found that instrumental aid (which he defined as information, domestic help and financial assistance) helped to reduce stress when people had problems, and in his 1985 review, Wills found that instrumental support had beneficial effects on well-being in a number of different circumstances. Others have found that emotional support is a crucial factor in preventing both physical and mental illness 
(Cohen, 1992) although some forms of emotional support may increase depression in certain circumstances (Argyle, 1992).

The importance of informational support in preventing or reducing illness has yet to be established. Wills (1985) argues that informational support should influence health outcomes only during times of stress, because under normal circumstances, most people have the information they need to function adequately. From a public health perspective, lack of information about health problems (both mental and physical) can result in increased illness because treatment regimens are not carried out and/or appropriate referrals for mental health problems are not forthcoming (Kiesler, 1985). However, these types of information are of the formal rather than informal type because they arise out of communication with health professionals rather than within the informal support networks of concern in this project. Dakof and Taylor (1990) found that for victims of cancer, informal informational and tangible support were less frequently perceived as helpful than was emotional support.

\section{Frequency of Contact and Supportive Functions}

It is not clear how different levels of contact with and/or support by network members affect health outcomes. Berkman and Syme (1979) found that greater frequencies of contact reduced mortality, irrespective of age, sex, SES, lifestyle and initial health status of respondents. 
However Lieberman, in his 1982 review, found that frequency of contact was unrelated to either physical or mental-health outcomes. Consistent with Lieberman's findings, others (Thomas, Milburn, Brown \& Gary, 1988) found that frequency of interaction did not influence depressive symptoms. At the same time however, Schultz and Rau (1985) report that numerous studies show that positive assessments of life satisfaction are related to frequency of social interaction (i.e. frequency of contact). And, in their meta-analysis of the effects of social support on physical morbidity and mortality, Schwarzer and Leppin (1992) found a weak (but, they argue, important) negative effect of social integration (which included frequency of contact) on these outcomes.

In one of the few cross-cultural works on the subject, Imamoğlu, Küller, Imamoğlu, \& Küller (1993) found significant differences in the average frequency of interaction reported by Turks (like Moroccans, Turks are also Muslims) and Swedes. Turkish people interacted more frequently with their network members than did Swedish people, and the researchers found that increased interaction reduced feelings of loneliness and worries about aging in both cultures. In particular, increased interaction was associated with increased life- and selfsatisfaction among Turks, although this measure was not predictive of satisfaction among Swedish participants who reported being more satisfied than their Turkish counterparts. 


\section{Reciprocity}

Many researchers and theorists have been interested in the reciprocity of relationships. Some have explored the norms associated with reciprocity; others have examined how people determine whether their relationships are reciprocal or what people do when they perceive their associations are not balanced. Social support theorists have also argued for the importance of reciprocity in interpersonal relationships, and exchange theorists have provided some methods for understanding how it influences such ties.

Social Exchange Theory and Reciprocity In Relationships. Exchange theory provides an excellent framework for understanding networks of mutual assistance, their norms and functioning. As Cook (1982) notes, "Various network theorists, predominantly anthropologists, have commented on the natural affinity between exchange theory and the analysis of social networks." (p. 178).

Blau $(1954,1964)$ was one of the first to recognize the importance of the social (as opposed to material) aspects of exchange. He also outlined how power becomes differentiated in ongoing exchange relationships and noted the importance of both ideas to an adequate understanding of the workings of social networks. Blau also argued that people would continue in exchange relationships only if the reward for remaining was either high enough in and of itself, or if there were no 
alternatives available to provide for the fulfillment of a particular need. Thibaut and Kelley (1986 [1959]) and Kelley (1979) further refined these concepts in terms of interpersonal interdependency and social comparison, and showed how exchange partners determine the adequacy of a relationship as well as the availability of alternatives to a particular exchange.

Social network theorists have differentiated between those relationships they term "balanced" (symmetric) or "unbalanced" (asymmetric) in terms of reciprocity (House \& Kahn, 1985). These constructs correspond nicely to exchange theory's concepts of equity and interdependence. Social relationships that are balanced are characterized by equitable exchange and reciprocity over the long term and would be characterized as "equitable" and "interdependent" by exchange theorists, while affiliations which are imbalanced are those characterized by the lack of ability of one party to reciprocate (in kind) over time. In these latter types of exchanges, a dependency relationship is created wherein the person who cannot reciprocate becomes dependent on the party participating in the transaction(s). Such relationships are consistent with situations analyzed by Blau (1964), Thibaut \& Kelley (1986), and Kelley (1979), where recipients of aid are then required to give power to the benefactor and relinquish at least some control over their own behavior in order to balance the exchange. 
Exchange theorists predict that people will avoid such relations if at all possible, and social support theorists argue that such associations predispose their members (perhaps only the receiver) to negative health consequences (see for example, Belle, 1982). However, even though the consequences of these unbalanced, inequitable exchange relationships may be unfavorable for participants, Thibaut and Kelley (1986) suggest that when people compare their own relationships to those of similar others, and find that those alliances are not significantly different from their own, they will remain in the exchange. This would be particularly likely if few or no other alternatives exist, or if those alternatives involve similar costs. In addition, it is not clear what the effects of such exchanges would be if they were normative. That is, in Western settings where this research has been carried out, participants in exchange relationships expect that their relationships should be reciprocal, while such expectations may not exist in societies where imbalanced exchanges are common. In this context the comparison may produce an assessment that such relationships are not only consistent with similar others but that exchanges of this type are appropriate to the situation.

Reciprocity and Social Support. In the social support literature, reciprocity refers to perceptions of how balanced exchanges are between a focal person and a particular member of his or her network. Antonucci (1985), in her summary of reciprocity-related findings, suggests that lack 
of reciprocity in networks makes people feel that their networks are inadequate, overly demanding and less satisfying. Additionally she found that those with non-reciprocal networks reported fewer positive outcomes than did those with reciprocal relationships. Interestingly however, it appears that it is the perceived reciprocity rather than the actual reciprocity which is predictive of such outcomes.

Israel and Antonucci (1987) found that the effects of reciprocity in emotionally supportive relationships were an important determinant of psychological functioning but that reciprocity in instrumental exchanges (or the lack of it) had no effect. At the same time, Ingersoll-Dayton and Antonucci (1988) found that the effects of reciprocity were different for interactions with children compared to those with spouses, in part as a function of expectations for those relationships. Those respondents who expected to confide in and provide care for their adult children in an unreciprocated manner were likely to perceive that their networks were more demanding than those who did not. For spouses however, they found that those who overbenefited in terms of confiding (i.e. confided more to their spouses than their spouses confided in them) and underbenefited in terms of being cared for when sick (i.e. provided more care than they received) felt that their networks were less demanding.

Stevens (1992) found that reciprocity in American family relationships was an important predictor of satisfaction in later life 
among elderly respondents. In particular, those elderly who were able to give as well as receive support, particularly of the instrumental type, fared the best. Levitt, Guacci, \& Weber (1992) found that relationship quality was tied to reciprocity-in-support for younger mother-daughter dyads but not for that of older dyads. In addition, they found that reciprocity levels were different for women at different phases in the life cycle, with younger women being overbenefited, middle-aged women underbenefited, and older women again overbenefited. These latter results suggest that the needs and responsibilities of women of different ages influence the reciprocity in their relationships and perhaps the effects of those exchanges as well. In a longitidunal study of Dutch retirees, van Tilburg (1992) found that reciprocity was an important factor in the continuation of relationships, with overbenefiting relationships more likely to be discontinued than those that were underbenefiting. These results provide evidence which is at least partly consistent with exchange theoretic predictions for non-reciprocal relationships.

Other researchers have found few effects of reciprocity. Jones and Vaughan found that of four reciprocity measures, none was predictive of satisfaction with best friends in their sample of the elderly, although there may be little variance in reported satisfaction with best friends. Additionally, this finding may reflect the fact that best friendships are 
more likely to continue when they are reciprocal. In other research, Thomas et al. (1988) found no association between reciprocity in network ties and depressive symptoms among a population of African-American respondents. Such inconsistencies in reciprocity-related results suggest that there may be different reciprocity-related expectations or behaviors for different cultural groups or among the same people at different times in their life-cycles.

\section{The Detrimental Effects of Relationships}

Recent research has also made it increasingly clear that receiving help may actually be harmful in some situations. These investigations show that help may be detrimental to others if it is the wrong kind, the wrong amount, given at an inappropriate time, withheld when expected, or if norms or persons require a level of reciprocity which is not desired (Hatfield \& Sprecher, 1983; Harris, 1992; Rook, 1992; Rook \& Pietromonaco, 1987). Additionally, there is evidence that persons giving help which is not reciprocated may also be detrimentally affected, and that this may be a particularly important phenomenon to study in women, who may routinely provide more help than they receive (Belle, 1982; House \& Kahn, 1985).

Other factors that may be important because of their potential for detrimental impact are associated with the presence of nonsupportive ties in networks. To date, many researchers have ignored these types of 
relationships (Wellman, 1981). Nonsupportive ties are those which are disruptive or characterized by the presence of conflict (Marsden, 1990). Barrera (1981), Jones and Vaughan (1990), and Rook (1984) have found evidence which suggests that the absence of conflicted or nonsupportive ties may be more important than the presence of supportive ties. In combination with these findings, Wellman's (1981) argument shows the necessity of considering both supportive and nonsupportive ties in social support research.

\section{Sîressful Life Events}

Stressful events have been associated with increases in both physical and mental illnesses in both the West and in Islamic communities (see Cleary, 1987; Holroyd \& Lazarus, 1982; Rabkin, 1982; Selye, 1982 for reviews; El-Islam, Mohsen, Demerdash \& Malasi, 1983; Hays, 1987; Sendiony, Abou-El-Azaem, \& Luza, 1977 for Middle Eastern works). Most models of the stress process have included the effects of both personal and situational variables as either mediators or attenuators of stress and its mental and physical health outcomes (Gore, 1985). Additionally, many researchers have recognized the role that social networks and social support should play in coping with such stressful events. These observations have led to two hypotheses engendering much conflict among researchers: the "buffering" and "direct-effect" hypotheses. The first was adopted by those who believed 
that social support was beneficial only when stressful life events were present, the second by those who postulated that social support was beneficial at all times (Cohen \& Syme, 1985; Gore, 1985). Cohen and Syme (1985b) have argued that sufficient evidence now exists to support a combination of theoretical premises--that is, networks may provide both ongoing support in normal circumstances as well as increased support during times of stress, and that current research should move toward testing more specific hypotheses which establish "how social support relates to various behavioral, emotional, and physiological mediators of health" (p. 6). Researchers have begun to study these relationships as well as the process of coping with stress and of the mobilization of the support network during stressful situations (see Gore, 1985 for a review). Irrespective of conflict over the direct vs. buffering effects of social support systems, the role of stressful life events in social support research has been well established (Cohen \& Syme, 1985), and a number of measures have been developed in recent years to produce reliable indicators of the presence and strength of different life events. The first of these was the Social Readjustment Rating Scale [SRRS]), developed and tested by Holmes and Rahe (1967). Since that time, the SRRS and other similar scales have been commonly used to measure stress levels (Perkins, 1982) and to test hypotheses 
about the buffering effects of social support during adverse life circumstances (Kessler \& McLeod, 1985).

\section{Antecedent and Control Measures}

As with most sociological research, demographic factors have been included in the social support research paradigm for purposes of description as well as control. In addition, there are a number of factors that have clear effects on well-being (e.g. physical exercise, smoking, etc.) that have been incorporated in research exploring support influences on health. Other factors (such as chronic illness) are often included for purposes of control and to reduce the possibilities of reverse causation (see below).

\section{Reverse Causation and Prior Chronic Physical and Mental Illness}

A number of investigators have discussed the problem of reciprocal causation in social support research (Dooley, 1985). The problem arises because most of this research is correlational and therefore subject to alternative causal explanations (Dooley, 1985). That is, in non-longitudinal social support research, different causal explanations for the same association may be reasonable. For example, some evidence suggests that severe and/or chronic illness (both mental and physical) may directly affect network structure, and perhaps other aspects of physical health and psychological adjustment as well (Dooley, 1985; Kiesler, 1985; Wortman \& Conway, 1985). Depression often 
produces social withdrawal which influences, at the least, network size. Terminal diseases, especially cancer, may make network members fearful and more likely to avoid the sick person, also influencing network structure and perhaps function as well (Dooley, 1985). Other research has shown that the networks of chronically mentally ill patients are more likely to be smaller and contain more non-reciprocal relationships, and that they have lower levels of intimacy (Gottlieb, 1985). Chronic and/or severe mental or physical illness may affect life events as well. For example, these conditions may place people in circumstances different from those that healthier individuals might experience (such as hospitals) or have serious effects on relationships (e.g. severe mental illness might cause a divorce). All of the above examples could easily be interpreted in a different fashion if they were not statistically controlled. That is, researchers might conclude that reduced network size caused increased depression when the reverse was true.

\section{Marriage and Marital Satisfaction}

According to House and Kahn (1985), "Of all social relationships, marital status has been the most studied and most consistently related to health." (p. 89). In general, married people fare better than unmarrieds when it comes to physical health, and this appears to be a function of three factors: (a) spouses take care of one another, (b) married people engage in more healthy behaviors (better diets, less 
drinking etc.), and (c) the immune systems of married people seem to function better than those of their unmarried counterparts (Argyle, 1992). In their review of the subject, Schultz and Rau (1985) also found that there was consistent evidence showing that being married is associated with lowered rates of morbidity and mortality as well as increased well-being. Argyle's review (1992) confirms the beneficial effects of marriage on mental health as well as increases in reported happiness.

Although it is generally true that being married improves both mental and physical health, several researchers have found that differences in overall marital satisfaction can affect the enhanced protection against illness (both physical and psychological) generally provided by marriage (see Argyle, 1992 and Schulz \& Rau, 1985 for reviews). Those married people who have low marital satisfaction are less likely to experience this beneficial protection than are more satisfied couples.

\section{Lifestyle Variables}

Lifestyle variables are commonly included for purposes of control in research exploring the effects of social support on health. They include the frequency of regular exercise as well as consumption of caffeine, alcohol abuse and cigarette usage. The roles of these behaviors in promoting health and/or illness have been well-documented 
(American Psychiatric Association, 1987; Barker \& Whitfield, 1991;

Bigelow \& Haines, 1991; Thamer, Stewart, \& Barker, 1991).

\section{Social Support and Modernization}

The roles of modernization and urbanization and their effects on social networks and social support have been of great interest to sociologists. Some researchers and theorists have argued that as people move from rural to urban settings, their relationships with others suffer, interpersonal ties weaken, and social networks become both smaller and less helpful (Durkheim, 1964[1893] \& 1966[1897]; Fischer, 1982; Kadushin, 1982; Korte, 1978; Wirth, 1938). These theorists expected that such social disintegration in urban settings would create situations compelling people to turn to more formal organizations for the help they need rather than to the family and/or friends who would have helped in the past (Korte, 1983). There has, however, been a great deal of dispute about whether or not these notions are correct (See Korte, 1978 for a review). More recent research and theories suggest that urbanization itself is not the problem but that other factors, such as the overcrowding and high housing density found in some types of urban settings, are responsible for perceptions of the presence of social disintegration in these areas (Fischer, 1984). At the same time, others have suggested that city life may provide a necessary critical mass for some groups (such as ethnic groups), encouraging cohesion among their 
members (Fischer, 1984; Gans, 1962). In addition, there is evidence that certain types of urban spatial environments may lead to conditions which discourage helping and encourage crime, fear and isolation, while other spaces encourage neighborly involvement and support (Cohen \& Felson, 1979; Fischer, 1982; Korte, 1978; Jacobs, 1961; Newman, 1973; Whyte, 1982). In particular, Jacobs (1961) has suggested that neighborhoods which are heterogenous in composition (composed of a variety of residential types plus small businesses and restaurants) are more likely to produce defensible spaces and provide environments where people interact with each other. These spaces supply opportunities for people to get to know, trust, and help one another, and have the potential to produce significant changes in network structure.

Social Support and Well-Being in a Cross-Cultural Setting:

\section{A Conceptual Framework}

In order to integrate the factors reviewed above in a manner which would facilitate both the understanding of their interaction and help to organize the design of this survey, I created a basic conceptual model of the social support process. Figure 1 represents that model, as well as the approach I used to determine what data would be collected and how analyses associated with the research project would be conducted. Other, more complicated, models of social support exist (c.f. Cohen, 1992; Israel, 1982); however, because they have been based on research 


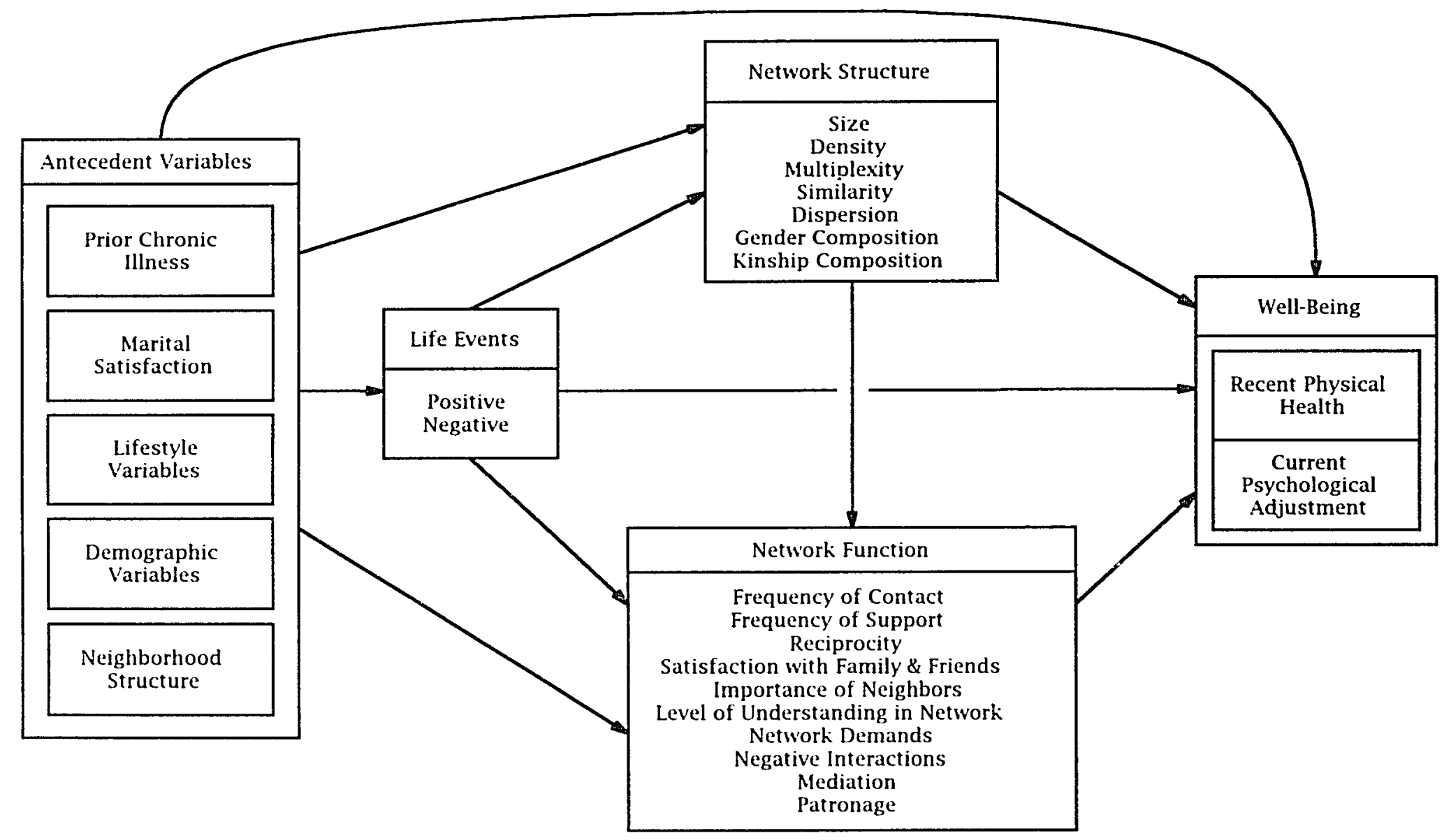

Figure 1. Conceptual Model of Factors Affecting Well-Being 
that may reflect cultural patterns of support, relating, and network structures unique to Western environments, I decided such models were inappropriate as a basis upon which to build an exploratory research project in Morocco. Instead, I felt I should begin with a general model that would provide a logically consistent framework, allowing me to explore the relationships among a group of interrelated variables and to test a number of initial hypotheses in the Moroccan setting. This model, based on a combination of social network research from Morocco and other Islamic countries as well as work on social-support in the West, was intended to function as a general heuristic for use in understanding and exploring these processes.

Assessment of Social Networks, Social Support, Physical Health and Psychological Well-Being: Research Hypotheses

There were five primary questions around which this research project was structured. They were: (a) Do the social network and social support concepts used in the West apply in the Moroccan cultural context? (b) What are the associations between the antecedent and other variables of the conceptual model in the Moroccan setting? (c) Do social networks and social support in Morocco have the same effects on the health and psychological adjustment of their members as do social networks in Western countries? (d) Does social support have a direct 
effect on well-being among Moroccan women, and/or does it function as a buffer during times of stress? and (e) How do network and support characteristics specific to Morocco (mediation and patronage) influence health and psychological adjustment?

I developed a set of hypotheses within these broad guidelines, keeping in mind the results of Western social-support research. The confirmation of the first groups of hypotheses (which follow), would indicate that the pattern of social network and social support effects, found in many Western locales, generalizes to a vastly different setting. If disconfirmed, such results would imply that Western findings may not be applicable in other environments.

\section{Hypotheses Associated with Network Structure}

\section{Network Size: Global and Subnetworks}

Increasing network size will be associated with enhanced well-being to the point of diminishing returns (between five and ten persons). In particular, larger numbers of persons available (up to about 10) to provide practical- and emotional-support (practical and emotional subnetworks) will be most beneficial. Additionally, larger numbers of people with whom the respondents had negative interactions (negative subnetwork) will be associated with diminished well-being. 


\section{Multiplexity}

Increased multiplexity will be associated with greater well-being. In addition, female network members will be more likely to have multiplex relationships with respondents than will male members.

\section{Similarity}

The more similar respondents perceive their network members to be (to themselves) the greater the respondent's well-being will be.

\section{Percentage Female}

The more women there are in a network (proportionally) the greater the amount of received support will be. Additionally, the larger the percentage of females, the greater the well-being of the respondent.

\section{Percentage of Kin}

Larger percentages of kin in networks will be associated with increased social support and negative relationships. In addition, there will be an interaction between support received from kin, negative relationships with kin, and the well-being measures. Greater amounts of support will enhance well-being while increases in negative relationships will be associated with reduced well-being. 


\section{Dispersion}

Networks with greater levels of dispersion will be associated with less frequent contact and help, and therefore, lowered well-being scores.

Hypotheses Associated with Network Functions

\section{Contact with Network Members}

Increased contact with network members will be associated with enhanced well being.

\section{Received Support}

Increases in the average amount of support received will be associated with greater well-being.

\section{Reciprocity}

The greater the percentages of reciprocal relationships in networks the greater the well-being of respondents. At the same time, increases in non-reciprocal relationships will be associated with reduced well-being scores.

\section{Satisfaction with Family and Friends}

Satisfaction with family as well as with friends will improve well-being, and family satisfaction will be the more important of the two predictors. 


\section{Feeling that Others Understand}

Those respondents who feel that the most important people in their networks understand them will have enhanced well-being when compared to those who do not feel that way.

\section{Negative Interactions}

Larger average frequencies of negative interaction will be associated with reduced well-being.

\section{Feeling that Others in the Network Demand Too Much}

Those women who report that their network members demand too much of them will have reduced well-being when compared to women who do not feel this way. The following hypotheses reflect an integration of expectations based on Western research as well as related work in Islamic countries. Confirmation of the predictions associated with patronage would indicate that the Western conceptualizations of patronage as nonreciprocal and harmful are correct, while lack of confirmation would indicate a need to re-think previous conclusions. Verification of the mediation hypothesis would indicate that mediation is a relevant factor in research on social support and well-being in the Middle East, and that it might be considered for inclusion in research carried out in other cultures. 
Hypotheses Unique to Moroccan Patterns of Interaction

\section{Patronage}

Patronage relationships will be non-reciprocal, and

increasing proportions of such relations in networks will be associated with decreased well-being.

\section{Mediation}

Increased numbers of available mediators will be associated with enhanced well-being. 


\section{THE RESEARCH SETTING}

\section{Morocco: Location and Character of the Country}

Morocco is a large country in North Africa $(725,730$ square

kilometers including the disputed Western Sahara region--slightly larger than the State of California) with a 1990 population of between 25 and 26 million people (Britannica, 1988, 1991; Centre d'Etudes et de Recherches Démographiques [CERED], 1990a). It is strategically located with coastlines and ports on both the Atlantic ocean and the Mediterranean sea, a characteristic shared with only one other country-Spain. The country's potential control of the Strait of Gibraltar during times of war has attracted Western interests, and Morocco's politically and religiously moderate government has received a great deal of aid, in particular from the United States (Damis, 1991). Although most of Morocco lies at rather high altitudes (average altitude 800 meters), it has a long coastline, and much of the population lives in the lower altitudes with some moderately dense areas in the interior (Brittanica, 1988; CERED, 1990a). The majority of the population is still rural (53.5\% in 1990), but the proportion of inhabitants living in urban areas has been increasing at a very rapid rate (in 1960, 70.9\% were inhabitants of rural 
areas) and should reach a majority in the next few years (CERED, 1990a).

\section{Climate}

Morocco has a climate similar to that of California, with a combination of arid regions as well as fertile plains and rich valleys having warm summer temperatures which allow the production of a wide variety of fruits, vegetables and grains (Parker, 1987). Although, agricultural production has been good in the past and continues to expand, the country's rapid population growth has exceeded the ability of its farmers to feed its people, and it has moved from being a net exporter of grains before 1960 to a net importer at the present time (Parker, 1987).

\section{Economy}

Morocco's natural and industrial resources are seriously limited (Parker, 1987). Although it has the world's largest deposits of phosphate, market fluctuations in both the demand and price have made the income from these products undependable. Other potential resources include the fishing industry, which has yet to be fully developed, and potential oil and uranium production, which have not yet reached economic viability. This lack of development of key resources leaves Morocco dependent on a combination of agriculture, light industry and phosphate export. Alone, these industries do not bring the country anywhere near economic sustainability, and it relies heavily on foreign 
aid, tourism, and income sent home by Moroccans working in foreign countries, to fuel its economy (Parker, 1987). In addition, although statistics are difficult to find (and perhaps to trust), unemployment and underemployment among some groups of potentially active members of the population may have reached more than 40\% (CERED, 1990c; CombsSchilling, 1989). Morocco remains a third-world country with serious economic and social problems.

\section{Government}

Morocco's government is an Islamic constitutional monarchy with King Hassan II at its head. He functions as the legitimate political and spiritual leader of the country, and is a powerful ruler whose father, Mohammed V, was responsible for ousting the French from their colonial position in the period between 1955 and 1956. Although many have predicted Hassan's fall because of his repressive policies and the country's economic problems, he has survived more than three decades of rule, including two coup attempts, and has consolidated his power in recent years, leaving others to argue that he is unlikely to be unseated in the near future (Combs-Schilling, 1989; Parker, 1987).

\section{Ethnicity and Language}

Classical Arabic is the official language of Morocco, and French is the official second language. Most Moroccans, however, speak either an unwritten dialectical version of Arabic or one of three unwritten Berber 
dialects as their true first language, while classical Arabic and French are learned primarily in school (Bentahila, 1983). Berber-speaking peoples were the original inhabitants of the country but were not a homogenous group--they seem to have had ancestors who came from Western Asia as well as southwestern Europe and other areas (Combs-Schilling, 1989). After Arabs began arriving in Morocco in the 600's B.C.E., there were close contacts between the original inhabitants and newcomers, and virtually all Moroccans have both Arab and Berber ancestors. The question then becomes one of group identification, and this is most often determined by mother tongue or the presence of Berber-speaking ability (Rosen, 1984). Those who grew up in Berber-speaking areas are considered Berber, irrespective of cultural practices or the particular Berber dialect they speak. Therefore, although most Moroccans define themselves as either Berber or Arab or a combination of the two, the distinction is mostly one of language (Combs-Schilling, 1989; Rosen, 1972). Combs-Schilling (1989) described the ethnic situation well when she said:

The Arab-Berber division in Morocco is linguistic rather than social and cultural. . For over a thousand years Berber speakers and Arabic speakers have intermingled and intermarried, obfuscating any clear-cut division. Many Moroccans are bilingual, and it is not uncommon to have a 
family in which one parent speaks mostly one language and one parent mostly the other, and the children move easily through both. (p. 280)

\section{Education and Literacy}

Illiteracy continues to be a severe problem for Morocco. Although improvements in literacy rates are continuing, the most recent data (1982) suggest that there is much yet to be done to improve access to schooling as well as parents' willingness to send their children to school. This is particularly true in rural areas, where girls are frequently prevented from attending school or are removed by parents once they near puberty out of fear that their honor will be compromised (i.e. through contact with boys or just the potential for such contact), particularly if they have to travel any distance to the school facility (Steinmann, 1993). CERED (1990a, 1990b) reports that the rural illiteracy rate (in 1982) for males over the age of nine was 62.8 percent, with females 96.7 percent illiterate. In the urban areas, the rates are significantly better yet still high, with male illiteracy at 35 percent and female illiteracy at 65.7 percent. At the same time, Rabat had a much lower illiteracy rate for both men and women during the same period: 46.7 percent of women and 23.1 percent of men remained illiterate. 


\section{Capital City: Rabat}

The seat of government is in the capital city of Rabat, where this research was conducted. Rabat was originally named Ribat Al-Fath, meaning "Monastery of Conquest", because of its initial construction as a fortified monastery in 1150 (Abu-Lughod, 1980). The city is divided into "quartiers", the French term for quarters, districts, or neighborhoods. These quarters have distinct characteristics which developed as the consequence of the urban planning policies instituted by French protectorate Résident Général Louis Hubert Lyautey between 1912 and 1925 and continue to this day. His goal was to modernize the country by building new and up-to-date "European style" cities (called "nouvelles villes" or new cities) while almost completely preserving traditional Moroccan areas, unfortunately consigning these zones to a lack of modern infrastructure and services available in the new cities: running water, electricity, sewage and transportation systems. Abu-Lughod (1980) argues that these separate cities within cities produced an "apartheid" character in urban areas which continues to the present day. The vast differences in lifestyles, architecture, wealth, and population density that remain between these areas reflect similar social distinctions in the country as a whole. Lower-income uneducated Moroccans are over-represented in the traditional "medina" (old city) areas, in low-cost government-created housing, and in illegal "bidonvilles" 
(literally "tin-can cities," in which housing is assembled by residents from available materials), where living conditions remain the worst in the country.

\section{Rabat's Population}

Although the most recent census was carried out in 1982, projections place the Rabat population for 1992 at approximately 689,098, up from 523,344 in 1982. This represents both an increase in births as well as large numbers of migrants who come from rural areas looking for work. An estimated 31.5 percent of the city's 1992 population was under the age of $15 ; 64.9$ percent were between the ages of 15 and 64 , and 3.6 percent over the age of 65 (CERED, 1990b). This distribution reflects the fact that Rabat has had the lowest birth-rates in the country (CERED, 1990b). The overall Moroccan population distribution by age in 1989 was as follows: 40.6 percent under the age of $15,55.4$ percent between the ages of 15 and 64 years, and four percent over the age of 65 (CERED, 1990a).

\section{Local Research Setting: History and Characteristics of the Agdal}

\section{Neighborhood}

Agdal, named after the gardens which once existed there, is now a transitional urban neighborhood in Rabat's nouvelle ville. It has recently come to be one home of the newly developing Moroccan middle class (M. Guessous, personal communication, August 11, 1992). The 
neighborhood was constructed by the French during the years of the Protectorate but became populated by Moroccan Jews beginning in the late 1940's and ending rather abruptly around the time of the 1967 war in Israel. After the war, most Jews left Morocco, and Agdal began to change from a neighborhood composed primarily of foreign Christians and Moroccan Jews to its present-day composition of a few foreigners intermixed with Moroccan Muslims. This Islamization was given its greatest boost when a law requiring Moroccanization of all businesses (Moroccans had to control at least $51 \%$ of all business interests) was passed in 1973. Since that time, more and more Moroccans have moved into the neighborhood, and increasing numbers of the French-built villas have been replaced with high-density housing (i.e. high-rise apartment buildings) to accommodate these new residents. Those who moved to Agdal in the 1970's were upwardly-mobile, well-educated Moroccans, but as the number of villas decreased and the density of the area increased, many wealthy Moroccans and foreigners began to leave the area. Newer residents still tend to be somewhat upwardly mobile, but at the same time are more likely to have lower and more stagnant income levels than those who moved to the neighborhood in the recent past (M. Guessous, personal communication, August 11, 1992).

Despite these changes, Agdal remains a neighborhood of highly educated individuals. Its residents include a combination of the more 
wealthy families who have lived in the neighborhood for many years (since the early years of Moroccanization), those who moved in as the first apartments were finished, as well as the more recent arrivals who tend to have increasingly lower socio-economic status than do residents who arrived in the period between 1970 and the early 1980's (M. Guessous, personal communication, August 11, 1992). Agdal is now a diverse, middle-class neighborhood which maintains its ties to Moroccan culture and traditional practices.

I chose Agdal as a research site for a number of the reasons outlined above. From a practical standpoint, the general level of education made it possible for me to conduct the majority of the interviews myself using French. From a methodological and theoretical point of view, the middle-class nature of the sample insured that the group was more likely to be comparable to previous Western samples in terms of education, SES, and access to adequate health care and nutrition. Additionally, I was interested in differences in social networks and social support that might be associated with modernization, so I needed a group that would include more modern individuals.

\section{Geography and Population of the Neighborhood}

The Agdal neighborhood is located south of Rabat's city center, and runs at an angle roughly northwest to southeast. It is rather long and thin in shape, increasing in width on the end furthest from 
downtown Rabat, and is oriented on a gradual slope. This has created a natural distinction, used by residents, between areas in the neighborhood which are lower (lower Agdal) or higher (upper Agdal), with lower Agdal being nearest the city center. These geographic differences also carry a socio-economic distinction. Those areas closest to the city center have seen increasingly more apartments, fewer remaining villas, higher population density and lower standards of living. The uppermost portions of the neighborhood remained almost completely untouched by this transformation, with no apartment buildings present at the time of survey was completed. In total, the neighborhood covers an area of approximately 30 square kilometers.

\section{Daily Life for Middle-Class Moroccan Women}

For middle-class urban women in Morocco (as is true of other Moroccans) daily life is fairly regimented, with the vast majority of inhabitants sharing common activities at typical times. For the most religious persons (typically the older members of society) the daily calls to prayer (5 times each day) signal the cessation of whatever activity is in process (including sleeping) and the commencement of the rituals associated with prayer. However, most members of the population do not pray daily, and this is especially true of busy younger and middleaged women, particularly those who are employed. 
A typical day for any grown woman in Morocco revolves around her husband, children and her family responsibilities, although many traditional household tasks are reduced or eliminated for middle- and upper-class women because they hire maids to cook, clean and care for children. The role of maids is important to any understanding of daily life in middle-or upper-class households. Maids are most often younger, uneducated women with darker skin (although Islam specifically states that bias on the basis of such differences is unacceptable, those people with lighter skin have distinct advantages in Moroccan society). Because they are young and uneducated, they are perceived as inept, and are frequently treated poorly--as the "lower-class citizens" which they truly are (from a sociological point of view). In addition, although maids provide important services, they also reduce privacy in homes, damage possessions, and may be seen as a threat to the stability of the family because they may become involved with the male(s) of the household. In fact, two of the women I interviewed reported that their husbands had had affairs with maids, one of whom had become pregnant and then became the second wife.

Given these potential problems, one must ask why maids are hired at all. I believe that there are several important reasons for their prevalence. First and most important, household labor is extremely difficult and time-consuming in Morocco. The majority of all cooking is 
based upon the use of raw foods that take long periods of time to prepare, washing machines are extremely rare (and expensive) as are other mechanical devices used in the kitchen and elsewhere in households, and shopping for necessities can be a lengthy process in the traditional markets. In addition, the high standards for appropriate food preparation, entertaining, and housekeeping require a great deal of work, and visitors who would notice any lapses are frequent. These factors are compounded by the fact that women's worth (at least to a certain extent) is measured on the basis of how well they maintain these practices, so women may feel compelled to abide by these standards.

Another important contribution to the prevalence of maids is unemployment, which remains extremely high in Morocco and creates a large pool of potential low-wage workers. The pressures created by such high unemployment rates are particularly likely to affect poor women who desperately need to work. Maids were generally paid between 150 and 250Dh's per week (between about \$19 and \$30) for full-time (often seven days a week, live-in) services: a very low wage compared to the mean income of the Agdal residents I sampled--approximately $10,000 \mathrm{Dh} /$ month (about $\$ 1250$ ). This difference between middle-class incomes and wages earned by maids, in combination with the difficulties associated with housekeeping, creates a situation where the increased income produced by a woman working outside the home more than 
offsets the costs of hiring a maid. In the end, most middle- and upperclass families choose to have a maid or maids to help them around the house, and daily life for the women in these families includes the management and supervision of these maids.

For a working mother living in Agdal, the day most often starts between 6:00 and 7:00 a.m. when breakfast is prepared (often with the help of a maid), children are readied for school ${ }^{1}$ if they are school-aged, and husbands and wives prepare themselves for work. Most Agdal women wear European-style clothing to work (many wear only European clothing) except during Ramadan--the Muslim month of fasting--when they were more likely to wear traditional garb than during the rest of the year.

School starts at 8:00 a.m., and children either walk or are transported by parents (school buses are generally not provided), who then go on to work--usually arriving between 9:00 and 10:00 a.m. when most offices and stores open. Many Agdal residents own cars or have them provided by their employers (usually the government) but buses and taxis are frequent and cheap for those who do not, and many young people ride mopeds. Therefore, transportation is generally not a problem except during the noon hours when everyone (including

\footnotetext{
'It is unusual for Moroccans to have no children-even infertile couples find ways to have children in their households through adoption or fostering.
} 
transportation providers) is eating and sleeping, and late at night, when most people are at home.

Parents and children remain at work or school until noon, when everyone goes home for lunch. If the family has a maid, lunch is usually waiting and is eaten, followed by a short siesta and a return to work/school between 2:00 and 3:00 p.m. where people remain until 5:00 or 6:00 p.m. If there is no maid, the women prepare lunch upon arrival, and clean the kitchen and dishes rather than taking a siesta after lunch. These practices hold true except on Fridays (the Islamic religious day) when people work only until 11:00 a.m. and most often do not return in the afternoon. In the evenings, people frequently visit each other (particularly relatives), watch television, or go shopping. Dinner is prepared (often by or with the help of the maid) and eaten late (8:00-9:00 p.m. in winter, later in summer). Children tend to go to bed when they are tired, not on a particular schedule, so often stay up late, watching television and sitting with adults.

On weekends, visiting is the norm and visiting with close relatives particularly important. In addition, paying visits to the husband's kin is often a necessity in many families. Such visits are worked around school schedules for those households whose children attend school on Saturdays, but visiting activities are not restricted to weekends alone. Mothers, sisters and mothers-in-law are common daily drop-in visitors 
(during lunch or in the evenings for families where both husband and wife are employed) and frequently visit for periods of days or weeks if they live at any distance (i.e. an hour's travel or more). Such visits are often the source of both support and strain, depending upon who is visiting (mothers-in-law are frequently perceived as overly critical and demanding). Whether the visitors are supportive or not, they increase the number of persons who must be cared for in the household, and correspondingly, the woman's responsibilities.

In general, women are responsible for keeping the household running smoothly--that is, meals must be prepared, guests served, the maid's duties managed--while men have few household responsibilities, even those whose wives are employed. I believe that these divisions of labor are a carryover from times when women did not work outside the home, although some women report that their husbands have begun to help around the house a little. In any case, there are clear pressures on both women and men to maintain these traditional activities, and the availability of maids allows couples to continue to manage their houscholds in these established ways.

In terms of recreational activities, social interactions such as visiting family and friends are given the most importance. In fact, men often spend their weekday free time in cafés drinking coffee with their friends. Some people do exercise and play sports and games in their 
spare time (children in particular), although these practices are more common among men than women because men have more free time.

An additional aspect of women's daily lives is the regular occurrence of harassment by men when they are in public places-particularly on the streets. This harassment can take a number of forms. Men driving automobiles often drive up to women walking alone and try to solicit their services as prostitutes, while men standing along the streets or in cafés frequently stare and make disparaging and/or sexual comments which women find offensive. These activities are so pervasive--even when traditional modest clothing is worn-that women restrict their own movements. They try not to be on the streets alone because the harassment is worse in such situations (a friend reported being harassed even when she was nine-months pregnant), and women feel more comfortable walking on the side of the street opposite from the direction that automobiles travel in order to reduce solicitations from drivers. In addition, a number of respondents and acquaintances told me that their self-esteem and sense that others respected them were undermined by such degrading encounters, even though most women I asked said that they were relatively inured to the harassment. This harassment leads to a general uncomfortableness in public places, particularly outdoors, and women tend to sit inside restaurants and cafés rather than in outside areas which are more pleasant. 
Overall, women's daily lives involve caring for their family members--both nuclear and extended--and the majority of their activities reflect this priority. Whether they work outside the home, have maids, or neither of the two, women are expected to manage and control daily household activities and ensure that they run smoothly. Although these responsibilities are great, particularly for women who are employed and/or have no maid, I believe the control they exercise in the home has important positive consequences. Women who regulate the daily activities of their families build self-confidence as well as many competencies. I saw these qualities regularly reflected in their powerful approaches to dealing with family members, employment-related activities, and the problems they encountered in their lives. 


\section{METHOD}

\section{Instrumentation}

In the past, researchers have often measured variables associated with either network structure or network function alone, in order to determine how each of these factors individually affect physical health and psychological adjustment. However, Cohen \& Syme (1985b) have noted the importance of looking at a combination of structure and function measures in order to understand how networks perform as systems. For this reason, I designed the questionnaire to collect data about both network structure and network function. In addition, I included a variety of demographic measures, an inventory of marital satisfaction (the Index of Marital Satisfaction [IMS]), a recent history of stressful life events, an inventory of physical health problems, and an assessment of current psychological functioning.

I used a number of resources to construct the questionnaire. Several of the demographic and lifestyle questions were modified versions of those asked by Fischer (1982) and others were borrowed from NORC-Roper's General Social Surveys (Davis \& Smith, 1989). Fischer's (1982) survey also provided most of the questions I included to assess the interviewer's perceptions of the respondent and the interview 
process, as well as many of those questions assessing neighborhood type and structural properties.

I also constructed a short version of the questionnaire (a subset of the full questionnaire) for those women who wanted to participate but who did not have the time to complete the full questionnaire. It included all demographic information and questions assessing the respondent's perceptions of the general functioning of her network, an assessment of the people who were most important in the network, and all four self-report measures. See Appendix A for an example of the completed questionnaire, in English. ${ }^{2}$

\section{Antecedent Variables}

Among the antecedent variables, I included measures of a number of demographic factors which have been found to be predictive of either physical or psychological health, as well as standard descriptive characteristics including age, education, marital status, and number of children. I also incorporated measures appropriate to this particular project such as marital satisfaction, length of time lived in rural areas and Berber-speaking ability. In addition, I constructed scales for socioeconomic status and traditional versus modern cultural orientation.

\footnotetext{
${ }^{2}$ I wish to thank Christine Deery (Centre d'Etudes Lingustiques d'Avignon, France) Taib Amrani (Department of English, Universite Mohammed V, Rabat) and Rkia Montassir (U.S. Peace Corps Language Instructor, Morocco) for their help in translating the main questionnaire. Ms. Deery worked with me on the French translation, and Mr. Amrani was responsible for translating the questionnaire into Moroccan Arabic--a particularly difficult task because Moroccan Arabic is not normally a written language and must be phonetically transliterated into the Classical Arabic alphabet. Ms. Montassir helped edit and revise the Mloroccan Arabic version.
} 
Several measures were included because of their potential relationship to the health component of the study (e.g. caffeine and cigarette consumption--alcohol consumption was so rare that I eliminated it at the analysis stage). The following section describes the more complex measures.

\section{Measures of Socio-Economic Status and Traditionality vs. Modernity}

I constructed two scales: one for socio-economic status (SES) and a second which assessed respondents' traditional vs. modern cultural orientation (T-M). Items for both scales were selected by factor analyzing sets of likely items selected a priori. Both SES and T-M factors were obtained from a subset of those items using principal components extraction and a varimax rotation. The items in each factor were then analyzed for reliability, and only those with the highest item-total correlations with the scales were retained. The final SES scale contained six items and had a Chronbach's alpha of 0.77 . The final T-M scale contained $19 \mathrm{items}$ and had a reliability coefficient of 0.94 . See Appendix B for a list of the items included in each scale and their corresponding item-total correlations.

During the data-collection process, I became concerned that measures such as these would be based on a sample which was much more homogenous than the actual Moroccan population and artificially inflated by the characteristics of the group with which I chose to work. I 
knew that Agdal residents were in a much better economic position than average Moroccans, and as my experience in the neighborhood and other areas of the country increased, I also felt that its residents were much more likely to have modern beliefs and to lead more modern lifestyles. I wanted to more closely place the respondents in the urban context of Morocco--that is, I wanted to compare their SES and traditionalitymodernity to urban women living in other settings. To achieve this goal, I decided to use two different tactics. The first was to take a small random sample of Rabat's medina (old city). Residents of this area are known to be both poorer and have greater diversity in family composition (Abu-Lughod, 1980) than do Agdal residents. Based on my experiences and observations in these parts of the city, I believe that residents in this area also live more traditional lives and have more traditional beliefs. Second, additional participants were solicited at a wedding ceremony in Tetouan (know as a very traditional small city) and through acquaintances in Casablanca. For the purposes of this dissertation, the combined sample of Agdal residents as well as these other participants (140 total) was used only to create these two scales. All other analyses include only the Agdal interviews, although each Agdal respondent has a scaled score for SES and T-M situated in the broader context of the larger sample. 


\section{Measures of Neighborhood Characteristics}

Two of the antecedent measures were calculated from geographic subsets of the sample, then applied to all respondents who lived in each particular area. Descriptions of the methods I used to calculate the variables--neighborhood heterogeneity and activity level--follow.

Neighborhood Heterogeneity. Neighborhood heterogeneity was a measure designed to reflect the types of buildings and activities carried out within each section of the Agdal neighborhood. For example, a neighborhood which was solely residential would have a low heterogeneity score, while a neighborhood with residences, businesses and institutional structures like mosques or governmental buildings would have a high heterogeneity score.

To develop this measure, I started with the neighborhood subsections specified during the sampling procedure. Each section was relatively distinct geographically (separated by major arteries in the neighborhood) and of roughly equal size. To describe each area, I started by counting the number of neighborhood heterogeneity variables recorded for each respondent in the specified area. These included the presence of the following, on either side of the street on each respondent's block: high-rise apartments (greater than two stories), lowrise apartments (two stories or less), du- and tri-plexes, commercial facilities, institutional structures (government buildings, mosques, 
schools, etc.), single family attached and detached villas, government housing, and parks. To create the index of neighborhood heterogeneity, I divided the total number of heterogeneity variables recorded for each section by the number of contacts in that section (both respondents and refusals were included because the same information was available for both). The appropriate score for each section was then recorded for each respondent residing in that section.

Neighborhood Activity Level. As with neighborhood heterogeneity, I treated the geographic subsections of Agdal as distinct areas. I took the average level of street activity (cars and people, ranging from "almost none" to "a great deal"), recorded at the time of each interview, for each sub-section, and assigned that value to all respondents from that section. The majority of interviews were completed during the afternoons and evenings, and although there was some variability in activity level associated with the time of day interviews were completed, street activity is remarkably consistent during these hours, even during weekends. When interviews required more than one session (many did), the later sessions provided additional information for making the rating. In cases where there was a change during the period of the interview (i.e. quiet upon arrival and busy upon leaving, or the reverse) or a difference between the first and later sessions, interviewers always chose the response that matched the highest level of observed activity. 


\section{Measure of Marital Satisfaction}

As a measure of marital satisfaction, I chose the Index of Marital Satisfaction (IMS) created by Hudson (1982). The advantages of this selfreport questionnaire were (a) its length (a relatively short 25 questions), (b) its lack of cultural specificity, and (c) its focus as an assessment tool, measuring only the extent of marital problems rather than including items which might suggest particular therapeutic options as do many other instruments of this type (Hudson, 1982). In addition, the English version of the IMS has high internal consistency $(\propto \geq .90$, IWalmyr Publishing Co., 1992, p.22]) in combination with a low standard error of measurement and high concurrent validity with another well known marital satisfaction inventory (the Locke-Wallace Marital Adjustment Test) as well as the ability to discriminate between known groups in Western populations (Corcoran \& Fischer, 1987, p. 443). For Moroccan respondents, I used versions of the IMS which had been translated into both French and Classical Arabic. ${ }^{3}$

\section{Measure of Recent Life Events}

Holmes and Rahe's (1967) Social Readjustment Rating Scale (SRRS) was the first systematic scale designed to assess the level of stress and adjustment associated with a variety of life events. Although it received

\footnotetext{
${ }^{3}$ For help with the translation of the IMS into French, I am indebted to Christine Deery and Amina Al Zemmouri. Taib Amrani graciously completed the translation of the Arabic version of the measure.
} 
wide usage for many years, it was criticized for treating both potentially positive and negative events similarly with respect to the expected amount of readjustment required, and more recent efforts have included a measure of the perceived negativity or positivity of each event in question (Sarason, Johnson, \& Siegel, 1978). Additionally, these researchers have shown that a measure of overall negative events is a better predictor of health and adjustment than the original SRRS, which treated both positive and negative experiences as stressful.

I chose to use Sarason, Johnson and Siegel's (1978) Life Experiences Survey (LES) as a measure of recent life events in this project. This questionnaire includes an assessment of the respondent's positive or negative evaluation of each life event experienced (Sarason, Johnson, \& Siegel, 1978), providing a more sensitive index of stress because it gives respondents the opportunity to rate their experiences based on their perceptions of the event's positivity or negativity using a Likert scale ranging from negative three to positive three. Other scales (like the SRRS) allow respondents only a binary choice for the presence or absence of an event. The LES asks respondents to make an intensity rating which includes an option for zero impact, eliminating the need for the researcher to determine which events are stressful and which are not. This system allows for a more valid representation of the actual event itself (e.g. the death of a young person in an accident may be perceived 
much differently than the death of an older person who has been suffering) as well as the response of the individual who has experienced the event. I felt that the ability to allow respondents to evaluate events based on their own experience was particularly important in the case of this research, since the LES is an instrument developed for use in the West. To assume that the stressfulness of events would be the same across both individuals and cultures could undermine validity.

I modified the LES in several ways in order to tailor it to the population I was studying. I eliminated all questions which were appropriate only for men, as well as all references to U.S. dollar values. I removed examples which I felt would not be understood by Moroccans, and changed religious references so that they would be meaningful in an Islamic country. I also added some questions about stressful experiences I believed might be more commonly found in Morocco than in the United States (e.g. death of a child), and included (out of personal interest) an additional life event: the intentional physical injury of the respondent by her spouse (both minor and severe). The instrument, in its final form, was translated into both French and Arabic. ${ }^{4}$

For this project, the LES allowed me to control for the effects of stressful life events as well as to differentiate between respondents who

\footnotetext{
${ }^{4}$ Christine Deery graciously helped me with the translation of the LES into French, and Taib Amrani was kind enough to translate it into Arabic.
} 
had recently experienced high levels of stressful events and those who had not. This latter differentiation was important for testing the directversus buffering-effect of social support hypotheses. Scoring the LES produces six potential measures of recent life events. They include negative, positive and total life events (a sum of positive and negative events) for the six months prior to the interview and the six to twelve months before that. I chose to use only the positive and negative measures for what I have termed the "recent" (prior six months) and "remote" (prior six to twelve months) periods.

\section{Measures of Network Structure}

I measured a number of the structural characteristics associated with each participant's larger helping network as well as the structures of specific subnetworks defined functionally (see Network Boundaries below). Some of these variables were network graph theoretic (e.g. density \& size) and were calculated from data matrices, while others were measured variables, but not graph theoretic in origin (e.g. dispersion, proportion of rural ties).

\section{Network Boundaries}

In order to collect data on networks, those networks must be defined, and part of that definition arises from boundary specification. For the purposes of this study I took a nominalist approach, defining network boundaries by their functions, i.e. by the types of support 
and/or assistance network members provided (Knoke and Kuklinski, 1982). Cook (1982) provides the logic for conceiving of networks of exchange relations in this manner when she says:

Exchange domains within social network theory are often referred to as different relational "contents." For example, sentiment relations, information-exchange relations, and advice-giving and influence relations represent separate domains of social interaction or activity (that is, different types of ties) and thus separate networks (p. 179).

Following this tradition, I defined network functions after House (1981) who reviewed the social support literature and identified four general types of assistance provided by network members. They were: emotional, instrumental, informational, and appraisal support. I used three of these categories (emotional, instrumental and informational support) to delineate subnetwork boundaries and added two additional categories which I felt were appropriate in the Moroccan context. I eliminated the appraisal category because I was both concerned about the length of my questionnaire and because I believe appraisal more appropriately represents a form of emotional support. This change is consistent with the work of other authors in the field (see Cohen \& Syme, 1985 a for a review). The two additional categories reflected Moroccan patterns of patronage and mediation discussed previously (see Davis, 
1989; Geertz, 1979; Sabah, 1984). Those individuals identified by the respondent as providers of each of these types of help defined the subnetworks of emotional aid, instrumental help, informational assistance, patronage, or mediation.

\section{Network Size and the Pilot-Testing Procedure}

Although a great deal of this type of network research has been completed in the West, little or none had been completed in the cultural setting in which I planned to work. In order to ensure that the questionnaire was practicable and its design valid, I incorporated a pilottesting phase into my project. Of particular concern was a potential problem associated with network size.

I measured network size in two ways. First, I collected the names of network members who were most important to respondents, then asked for the names of people who provided emotional, instrumental, informational, mediational and/or patronage support. The number of people reported for each of these groups made up specific functionrelated subnetwork sizes. I also asked for the names of members with whom respondents had negative interactions (negative subnetwork). The second size measure, global network size, consisted of the sum of all people mentioned in all contexts.

Measuring network size seems to be straightforward until the researcher contemplates the problems associated with eliciting and 
recording accurate accounts of network membership and the characteristics associated with each network member mentioned. My final questionnaire included 10 questions about each person listed by respondents, so every additional network member significantly increased the length of time required to complete the interview. One obvious solution was to limit the size of the networks I was studying, but this posed a crucial problem. I believed that average network size would be larger in Morocco than in the West, and additionally, that more people might play influential roles in those networks. If this had been true, then limiting the number of names a respondent could provide would create an artificial upper ceiling for network and subnetwork size and seriously confound any measures of network structure or function that were size-related. Conversely, failure to place a limit on size had the potential to make interviews impossible to complete.

I chose to deal with this problem in a series of steps. First, I pilottested the questionnaire (with no limits for the number of people that could be named as network members) upon arrival in Morocco. After completing several interviews, I concluded that network sizes were manageable in the interview setting, but that a number of the questions initially included to assess respondents' relationships with those members were too repetitious and cumbersome. In the end, although I did not need to place a limit on network size, I did have to eliminate 
some questions about the relationships respondents had with their network members.

Other problems also became apparent during the pilot-testing period. I found that several questions needed to be reworded in order to make them more easily understandable or to obtain useful information. For example, one of the original questions was "Are there any people (in your network) that you really can't count on?" I found that the most common response was "I can't count on anyone." I therefore reversed the question so it became "Are there any people (in your network) that you can really count on?" This usually elicited one to three people rather than an "everyone already mentioned" response. In addition, there were two other questions that had the same type of problem and several questions which I eliminated because they did not address the social support function I had intended. For example, I had originally inquired "Is there someone you could ask to give you a ride in case of an emergency?" This commonly produced the response "a taxi," because taxis are inexpensive and pervasive forms of transportation. This response obviously did not provide any information about social support processes.

\section{Density}

Density was measured by asking whether or not network members knew one another. I recorded the data for the question using a diagonal 
matrix with network members' names arrayed vertically along the left side, using a strip with corresponding names arrayed horizontally that I moved from the top to the bottom of the matrix. I asked if a particular network member was acquainted with the rest of the network members, placing a check in the appropriate box where the two names intersected when they were acquainted. The final measure was the ratio of actual ties between network members to all possible ties.

\section{Dispersion}

I measured dispersion by asking each respondent to indicate the travel time between her home and the home of each of her network members. Although I originally intended to assess the method of travel (i.e. on foot vs. automobile, train, etc.) to determine the difficulty associated with visiting that network member, I found during pilottesting that respondents were bored and frustrated by the repetitive nature of this question, so I ignored type of travel.

\section{Multiplexity}

To determine the level of multiplexity within each respondent's network, I counted the number of general types of support (e.g., emotional, practical) that each network member provided, then averaged those sums across network members. This gave me a measure of the average multiplexity of each respondent's network. 


\section{Homogeneity}

Although many characteristics could conceivably be measured in order to describe the homogeneity of networks, I collected data on the following: sex of the network member, whether or not the person listed was a family member, and the respondent's perception of the similarity (with respect to character) between herself and each of her network members. I then calculated the percentages of women and kin in each respondent's network as well as the average similarity of members to respondents, across the network.

\section{Measures of Social-Support Functions}

Consistent with other research projects discussed previously, I measured a number of network functions, ranging from global descriptions and perceptions of networks to frequencies of contact and support provided by each network member. Unlike other efforts, I included patronage and mediation as social-support functions. The following section describes these measures.

\section{Global Measures of Perceived Network Functioning}

Global measures of respondents' perceptions of support are important because such perceptions have been shown to affect wellbeing even when they are inconsistent with the actual amounts of support received (see Review of the Literature). I chose to measure relationships with family ("How satisfied are you with your relationships 
with your family, the time you spend with them and your common activities?"), with friends ("How satisfied are you with your relationships with your friends and the activities you do together?"), and with neighbors ("In your everyday life, how important are your neighbors?"). I also inquired about how demanding the network was ("How often do you feel that the people in your life demand too much from you?") as well as how often respondents felt understood by the most important members of their networks ("Thinking about the people that count the most in your life, do you think they understand you most of the time, some of the time, or rarely?").

\section{Frequency of Contact}

I used two measures of frequency of contact in my analyses. The first was total frequency of contact, calculated as the number of persondays each month the respondent saw network members. For example, if a respondent had three network members and saw them once a week (four times a month), her total frequency of contact would be $3(4)=12$. The second measure I used was the average frequency of contact across the network, calculated as the total frequency of contact divided by the number of network members.

\section{Frequency of Received Support}

As with frequency of contact, I had two measures of frequency of received support, and the calculations paralleled those for the 
aforementioned measure. Total frequency of support was calculated as the number of days each month that support was received, summed across network members. The average frequency of support was the total frequency of support divided by the number of network members mentioned.

\section{Frequency of Negative Interactions}

I calculated two measures of negative interaction. The first was the average frequency of negative interactions, and was calculated in the same way that average frequencies of contact and received support were calculated. The second measure was a weighted measure of negativity within the network. This was the average, across the network, of the product of the frequency of negative interactions with the number of types of negative interaction the respondent had with each network member. This measure provided an indication of the amount of ongoing negative interactions weighted by a combination of the frequency of those interactions and the number of different types of negative interactions associated with each network member.

Level of Reciprocity

I used a Likert scale to assess respondents' general perceptions of the level of reciprocity in their relationships with network members in order to assess reciprocity on a continuum (See Figure 2). Respondents were asked to rate the reciprocity of each relationship they had 
mentioned, and from these responses I calculated the percentages of all network relationships which respondents had reported at each level of reciprocity.

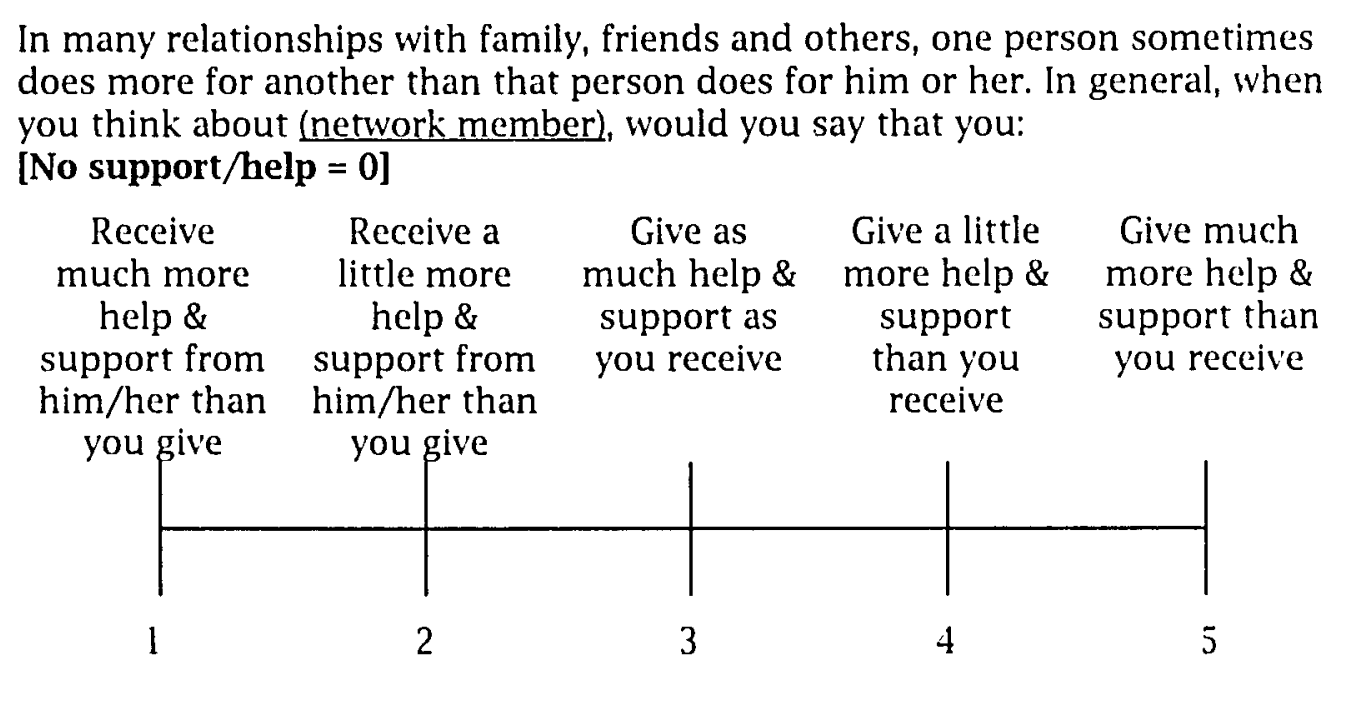

Figure 2. Question used for measure of reciprocity.

\section{Measures of Physical Illness and Psychological Adjustment}

As a measure of recent and chronic illnesses, I used the Seriousness of Illness Rating Scale-Revised (SIRS-R), a list of common medical problems developed in the United States and ranked according to their severity. The original SIRS was developed by Wyler, Masuda, and Holmes (1968) and then revised by Rosenberg, Hayes, and Peterson (1987). The SIRS-R is a ranked ordinal scale of the seriousness of 137 different illnesses. The scale was calculated from the geometric means obtained from the rankings of severity of illness made by groups of 
physicians, medical residents, and $3^{\text {rd }}$ and $4^{\text {th }}$ year medical students. Inter-rater reliability for the ranks was high (Kendall's $W=0.716, p<$ 0.00001) (Rosenberg et al., 1987, p. 87).

I originally modified the ranked list in several ways. Some items were not appropriate to this particular study because they were either assessed elsewhere (e.g., mental health-related illnesses) or because I felt that they were not appropriately considered an illness (e.g., abortion). I eliminated all items of this type. In addition, I added several physical conditions after researching common health problems in Morocco (Hartley, 1985; Maazouzi, 1989) and after consulting my Moroccan adviser.

When I pilot-tested the SIRS-R, I discovered several problems with its construction. Respondents reported having had a number of illnesses that did not appear in the SIRS-R, and in addition, respondents had difficulty filling out the form (a list of illnesses in order of their ranking with a series of boxes specifying the time period in which they had the problem). Finally, most respondents were not familiar with many of the illnesses on the list. Moroccan physicians apparently give only general information about illnesses, telling a patient, for example, that she has a "lung problem" rather than giving the illness its proper name (pneumonia, tuberculosis, etc.). In addition, very little health-related information is available through other sources with the exception of a 
recent anti-smoking campaign started by the government and a focus in the news on cholesterol problems. This constituted a major impediment to the accurate assessment of respondents' health statuses.

In order to try and resolve these problems I made a number of changes. I grouped the illnesses according to categories (e.g., ear, nose \& throat problems, infectious diseases) and added an "other illness, specify" space to each category, to be completed if an illness had occurred but did not appear on the original list. In addition, I added several other disorders to the list which had been reported repeatedly by respondents in the pilot phase of the project. The final instrument consisted of 141 items (including the "other, specify" blank items for health problems that were not included in the original scale).

To improve understanding of the specific illnesses, I added symptom descriptions to the names of illnesses which were not commonly known. The Rabat American Embassy Health Unit nurse reviewed and verified the accuracy of the questionnaire to ensure complete and correct symptom descriptions (E. Farrington, personal communication, November 4,1991$)$. The final form was translated into both French and Classical Arabic. ${ }^{5}$

\footnotetext{
${ }^{5}$ Christine Deery, Amina Al Zemmouri, and Taib Amrani helped with French translations, while Taib Amrani and Karim Al Zemmouri completed the Arabic version.
} 
For those diseases which do not appear on the SIRS-R but were mentioned by respondents, I asked two physicians (in the U.S.) to rank the seriousness of those illnesses in comparison to the original SIRS-R items. The mean of these ranks was used to place the illnesses within the SIRS-R scale. When this was complete, I calculated two measures of recent illness. The first was a count of the number of illnesses reported by each respondent for the six months prior to their participation, irrespective of the severity of those illnesses. The second measure the Illness-Severity-Index [ISI) was weighted by the severity of the problem. In order to create this index, I used the assigned ranks for the modified SIRS-R as an approximation of the seriousness of the illness and summed the ranks of all reported health problems for each respondent.

As a measure of psychological adjustment I used Derogatis' (1975) Brief Symptom Inventory (BSI), a subset of the Symptom Checklist-90Revised (SCL-90-R). The instrument generates scales of nine primary symptom dimensions and three global indices of distress. For the purposes of this research, I used the three main indices of distress which "represent summary measures of psychological disorder that, although correlated, have been shown to display distinct aspects of psychopathology" (Derogatis, 1983, p. 1). The General Severity Index reflects both the number of symptoms and their intensity; the Positive Symptom Total is a measure of the total number of symptoms; the 
Positive Symptom Distress Index is a measure of intensity alone, adjusted for the number of symptoms present (Derogatis, 1983).

The BSI had been translated into both French and Classical Arabic, although published norms exist only for Western samples at this time. Internal consistency and test-retest reliability are high for the English version (Derogatis, 1983), and comparisons with the Minnesota Multiphasic Personality Inventory (MMPI) produced "very high convergent and discriminant valiclity" (Derogatis, 1983, p. 2; Derogatis, Rickels, \& Rock, 1976) between the two measures. The advantages of the BSI over the MMPI and the SCL-90-R for this project were significant. The BSI is much shorter (53 compared to 567 and 90 items respectively), and it does not have the translation problems associated with items on the MMPI, many of which are based on culturally constrained forms of behavior. The BSI questions are based solely on specifically described symptoms of psychological disorders.

\section{Interviewer and Refusal Questionnaires}

In order to describe the living situation of respondents as well as their neighborhoods, and to determine if there had been any problems or abnormalities during the interview process, I designed a questionnaire which was completed by the interviewer at the end of each interview. It contained some questions used by Fischer (1982), some modified versions of his questions, and others which I developed myself. 
In addition to questions about the interview (e.g. "Was anyone else present during the interview? If yes, who?"), I included questions designed to describe both the area in which each respondent lived and her living conditions.

A similar questionnaire was completed by interviewers for each refusal (to the best of the interviewer's ability) in order to determine if participants were different from non-participants on key variables such as age, SES, type of neighborhood, etc. See Appendix C for examples of both forms.

\section{Procedure}

\section{Sampling}

When I chose my sampling strategy I had several concerns. I wanted to collect a representative sample of Agdal residents, but at the same time I believed that traditional randomizing techniques might be difficult to use. In Morocco, there are two factors which impede a researcher's ability to select a random sample. First, access to sources such as telephone lists and census data is limited, and second, even if access were possible, what exists is frequently out-of-date, incomplete and/or inaccurate. At the same time, I was concerned that nonrandomized techniques such as snowball methods (Sudman, 1976) would produce serious overlaps among the social networks of respondents, producing multiple measures of the same group of people, and severely 
biasing results. An additional problem was that these kinds of socialnetwork overlaps may also be caused by proximity (Festinger, Schachter \& Back, 1950), that is, the closer you live to someone, the more likely you are to know that person and the other people in that person's network. If the overlap in either of these cases were large, the potential confounds were significant for the types of across-network measures I was using.

In order to achieve a representative sample of the neighborhood using the available information while minimizing the aforementioned confounds, I took the one piece of quality information I could obtain--a detailed government-produced map of Agdal--and divided it into blocks of approximately equal spatial size. I then measured the area within each block on the map, in millimeters, and using a random-number table, selected one point in each specified block (the random number corresponding to the millimeter), marking the point on the map. Then, throughout the survey, interviewers (most often the author) went to each particular block and determined the area which corresponded to the mark on the map. If the mark corresponded to a villa (a single family dwelling constructed by the French during the colonial period, most often detached), an attempt was made to contact the residents. If it corresponded to an apartment house or multiple-family dwelling of some kind, a random number table was used to select the appropriate apartment or family. In cases where potential participants could not be 
found or in the case of refusals, the interviewer began at the nearest apartment or family unit to the one originally selected, in an effort to use the overlap of social networks to advantage (Sudman, 1976) by including those most likely to be a part of the same network (Festinger, Schachter \& Back, 1950). In the case where a villa was originally sampled, the interviewer moved to the nearest villa and continued. If there were no other villas in the block, the nearest apartment house was sampled.

\section{Administration of the Questionnaire}

The questionnaire was presented in an interview format with four separate paper-and-pencil components by one of two interviewers (the author and Amina Al Zemmouri) or by the author and an interpreter. I completed 82 interviews myself using French and an additional 20 using one of two interpreters that I hired (Amina Al Zemmouri and Rkia Montassir) or someone present at the interview site, most often a daughter (eight interviews). An additional six interviews were completed by Ms. Al Zemmouri, who had interpreted for me previously. In total, 86 of the interviews were carried out using French exclusively, and the remaining 22 were completed in Arabic.

The interview began with respondents either reading or being read (for those who could not read) the "Instructions to Participants" segment of the questionnaire. This informed respondents of the broad purposes of the research and of their absolute right to discontinue participation, 
at any time during the process, for any reason. After respondents indicated their understanding of their rights and any questions had been answered, the interview began with a series of demographic questions. Upon completion of this introductory section, interviewers began to elicit the names of network members. Respondents were asked to provide the first name (and last initial if there was a duplication of first names) of each network member they named. After each name was recorded, the interviewer circled a number which corresponded to the name-eliciting question. If the same person was mentioned subsequently, it was only necessary to circle the question number corresponding to the type of interaction which had been specified. At the end of the network-eliciting section, the data sheet was unfolded, revealing blanks opposite the names, to be filled in with a variety of data corresponding to each previously-named network member.

The interview was followed by the paper-and-pencil instruments. For those women who could read and write, the interviewer explained how to fill out the forms, and let the respondent work on them. For illiterate respondents, the interviewer read each question aloud and marked the appropriate response. For literate respondents, the interviewer took the time available during the self-report questionnaires to complete the matrices for the density question. Interviewers wrote the network members' names on the left size of the density matrix and 
again on a corresponding strip of paper. When the respondent had finished the four paper-and-pencil questionnaires, interviewers filled out the density matrix with the respondent's help. The interviewer then eliminated the names on all parts of the questionnaire for those respondents who were concerned about confidentiality. Respondents were thanked for their participation and the interviewer left.

In cases where the respondent could not complete the questionnaire in one sitting, an appointment was made to finish the interview at a later date. Most of the interviews were finished in one or two sessions, with a few taking three or more meetings for completion. The total length of interviews ranged from a minimum of one-half hour (for a short form) to nearly seven hours for one particularly difficult interview. The mean time necessary to complete the interviews (both short- and long-forms) was 2.19 hours with a standard deviation of .96 hours; most respondents reported no problems with the amount of time required to complete the interview.

\section{Respondent Characteristics}

Respondents were married (98), divorced (6), widowed (2), or separated (2) women (total $N=108$ ) who agreed to be interviewed for the study and who were living in Agdal (excluding those used in the scaleconstruction sample). I chose only ever-married women because marriage changes a woman's life-style and responsibilities in ways that I 
felt would influence both their social networks and the social support they received. Respondents' ages ranged from 20 to 69 years, with a mean age of 37.17 years. The length of time married ranged from six months to 40 years for those married at the time of the interview, with a mean of 14.39 years and a standard deviation of 10.43 years.

\section{Education}

There was a wide range in levels of education within the sample-from either no school at all to respondents having completed graduate

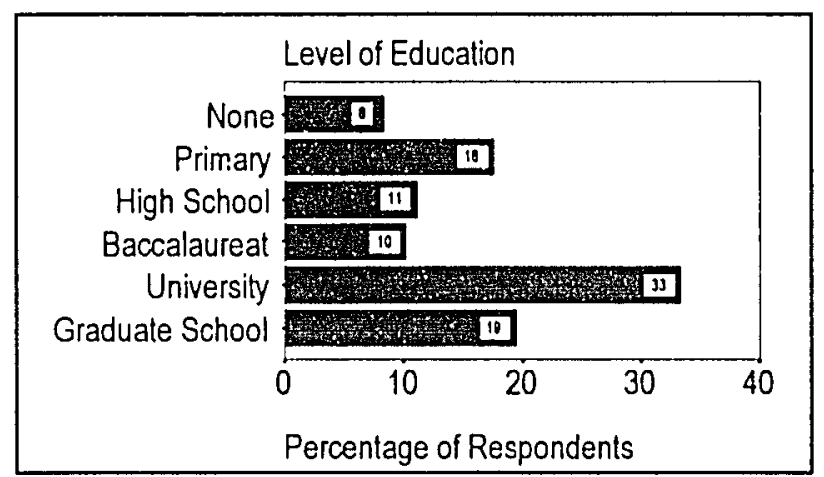

Figure 3. Respondents' Education Level with $n$ of each group displayed in bars. degrees. Figure 3 shows the percentages of respondents who had completed at least some education at the level specified. The baccalaureat refers to the standardized college entrance exam originated in Europe and

brought to Morocco by the French when they initiated their educational system there. Its passage is a requirement for admission to college, and because many students do not pass, it is a significant step above a highschool education, both in terms of knowledge and because of the status associated with having passed the exam. 
Although many of the women in the sample were well-educated, a relatively good cross-section of all educational levels was achieved. However, the sample is not proportionally representative of Moroccan society or even the relatively more educated Rabat area as a whole. In keeping with the respondents' relatively high level of education, Figure 4 shows the number of

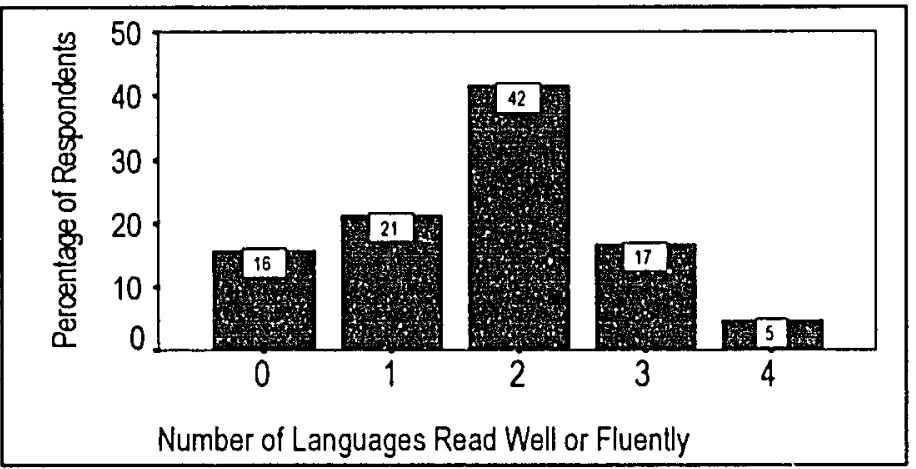

Figure 4. Respondents' Literacy Level with $n$ of each group displayed in bars. languages

respondents were able to read well or fluently. Most participants $(80.1 \%)$ reported speaking

French either fluently or rather well, while $55.5 \%$ reported the same ability with classical Arabic. Fluency rates were lower for English (19.5\%) and Spanish (10.2\%). Overall, $92.6 \%$ of respondents reported speaking at least one language well or fluently in addition to their native Arabic or Berber dialect.

\section{Employment Status and Household Responsibilities}

Over half of the women were currently employed (55.6\%) and most (87\%) had children $(M=2.364, S D=1.959)$ with a range from no children to a maximum of eight. Although most women reported having at least one maid (74.1\%) to help with household chores and childcare, 12.1\% 
reported having two or more maids regularly, and employed women were more likely than housewives to have a maid $\chi^{2}(1, N=108)=4.05, p$ $<.04$. This result is not particularly surprising because increased income (expected in households with two incomes) was associated with having more maids $F(1,3)=4.90, p<.003$, and because working women have less time to devote to household responsibilities. In addition, as noted previously, low-cost female labor is readily available, and time-saving devices (like washing machines and prepared foods) are both rare and extremely expensive.

\section{Household Size and Monthly Income}

Respondents lived in households with a large range of monthly incomes (See Figure 5). From a low of 700Dh (about \$90) to a high of 40,000Dh (about \$5000), these incomes reflect the economic diversity and inequality present in Morocco (exchange rate at the time of the

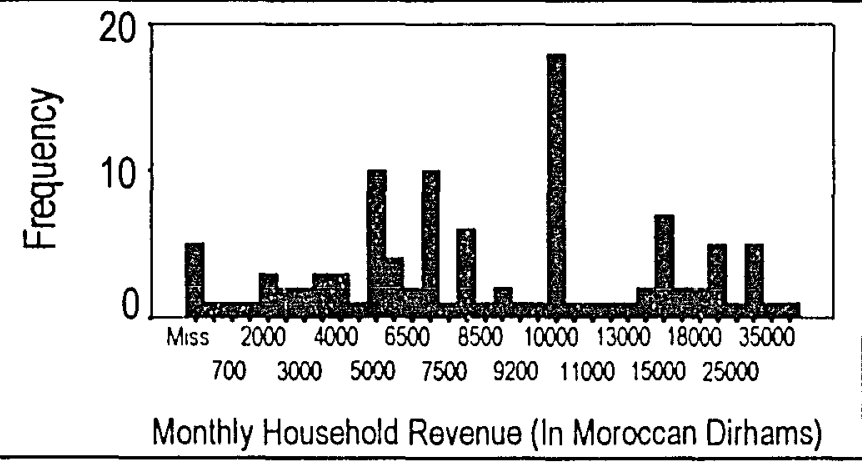

Figure 5. Monthly household revenue (Note: at the time of the survey, $\$ 1.00=$ approximately 8Dhs) research was

approximately equal to $8 \mathrm{Dh} / \mathrm{S1.00)}$. The

median monthly income for the sample was $9,000 \mathrm{Dh}(\$ 1,125)$, and the mean 
$10,514 \mathrm{Dh}$, with a large standard deviation of 7,713Dh.

Unfortunately, because of difficulties collecting information about household revenue in Morocco, there are no equivalent statistics available for comparison with Moroccans' average incomes. However, CERED does collect data about yearly household expenditures which provide some indirect information about income for households of differing sizes. In the present survey, the mean household size was 4.97 $(S D=1.93)$ with a range of from two to eleven people living in the same residence. CERED (1992) reports that the mean yearly expenditures in 1990-1991 reported by urban households with 4.73 to 5.75 members (including food, beverages, clothing, housing costs, utilities, houschold equipment, health care, transportation, communication, domestic servants, and leisure activities) range between 25,529Dh and 55,396Dh, or approximately $\$ 266$ to $\$ 577$ per month. Although these amounts are generally considered to be under-reported because of fear of taxation, they do provide some important indicators for understanding the economic placement of the current sample. Expenditures are by definition less than or equal to income (at least in Morocco, whose inhabitants have informal, if any, access to credit), so CERED's figures would still be somewhat lower than those of the current sample if it were to be considered representative of urban populations. However, the large differences between these figures provide support for my 
assertion that the Agdal neighborhood is a middle- and upper-class area whose inhabitants are generally in a better economic position than the majority of Moroccan citizens.

\section{Socio-Economic Status and Traditionality-Modernity}

As discussed previously, both the SES and T-M scales were constructed from a broader sample, including respondents who came from lower-class and more traditional areas. As can be seen from the results presented in Table I, which reflect the SES and T-M scale scores for the Agdal neighborhood alone, higher SES and Modernity scores were over-represented in this group. Because both variables were scaled and standardized with the larger and more diverse sample, I would have expected a relatively equal representation of respondents in all quartiles if Agdal was representative of the larger sample as a whole. However, the fact that the lowest quartile of both scales is underrepresented provides further evidence that the residents of this neighborhood have higher SES levels and are more modern in their outlook than are other Moroccans. In fact, because the scales were based upon a sample of which the majority were Agdal residents, it is reasonable to assume that even with the extended sample, they remain artificially high with respect to average urban Morocco. 
TABLE I

\section{FREQUENCIES AND PERCENTAGES OF AGDAL RESPONDENTS FOR EACH SOCIO-ECONOMIC STATUS AND MODERNITY-TRADITIONALITY QUARTILE CONSTRUCTED WTTH THE LARGER SAMPLE}

\begin{tabular}{|c|c|c|c|c|}
\hline \hline Quartiles & \multicolumn{2}{|c|}{ Socio-Economic Status } & \multicolumn{2}{c|}{ Modernity-Traditionality } \\
\hline & Frequency & Percentage & Frequency & Percentage \\
\hline 1 (lowest) & 17 & 15.7 & 16 & 14.8 \\
\hline 2 & 28 & 25.9 & 31 & 28.7 \\
\hline 3 & 27 & 25.0 & 28 & 25.9 \\
\hline 4 (highest) & 30 & 27.8 & 33 & 30.6 \\
\hline Missing & 6 & 5.6 & 0 & 0.0 \\
\hline Total & 108 & 100.0 & 108 & 100.0 \\
\hline
\end{tabular}

\section{Refusals and Refusers}

Of the 145 women contacted for participation in Agdal 37 (25.5\%) refused, producing an overall participation rate of $74.5 \%$. The most frequent reasons for refusing were: (a) lack of time [11], (b) did not want to participate [7], and (c) family would not allow participation [3]. Interviewers estimated refusers' age (within a range of 10 years) for comparison with the known ages of respondents. There were no significant differences between the two groups $\chi^{2}(4, N=140)=3.28, p=$ n.s. However, with regard to French-speaking ability, there were some important differences. Women who did not speak French were 
significantly more likely to refuse while those who spoke French fluently were much more likely to participate $\chi^{2}(3, N=142)=13.54, p<.004$.

These differences in French-speaking ability can be explained in two ways. Most obviously, those women who did not speak French could not understand the interviewer when approached for participation. If no other French-speaking person was present, a later effort was made to contact the woman with a translator. Upon return, contact may or may not have been made with the woman, this inability to contact being subsequently coded as a "refusal". Alternatively, women who did participate and who did not speak French were also more likely to be uneducated $(r=.41)$ and older $(r=.38)$ than those who did. If this was true for refusers as well, then uneducated women might have been more likely to be among refusers than among participants. And, although there were no significant differences between the ages of participants and refusers, older uneducated women appeared to be more suspicious when approached to participate than did those who were younger and/or educated. Frequently, in cases where older uneducated women did consent, a younger French-speaking person explained the project to the potential participant and assuaged fears about the possible dangers and ramifications associated with participation. Most often, fears were related to confidentiality or the potential dangers associated with granting an interview to a foreigner. During the study period, a 
prominent labor leader was prosecuted for giving an interview critical of the government to a foreign newspaper, and while the trial was in progress, all attempts to interview failed. In other cases, interpreters provided this service, answering any questions about the research project. However, the refusals represent small numbers with respect to the overall sample size, and a number of women who did not speak French did participate. See Table II for a summary of participation by French-speaking ability.

TABLE II

\section{PARTICIPATION AS A FUNCTION OF FRENCH-SPEAKINC: ABILITY}

\begin{tabular}{||c|c|c|c||}
\hline $\begin{array}{c}\text { French- } \\
\text { Speaking } \\
\text { Ability }\end{array}$ & Refusals & Participants & Total Contacts \\
\hline None & $10(58.8 \%)$ & $7(41.2 \%)$ & $17(12 \%)$ \\
A Little & $5(25 \%)$ & $15(74 \%)$ & $20(14.1 \%)$ \\
Fairly Well & $3(23.1 \%)$ & $10(76.9 \%)$ & $13(9.2 \%)$ \\
Fluently & $16(17.4 \%)$ & $76(82.6 \%)$ & $92(64.8 \%)$ \\
Unknown & $3(100 \%)$ & & \\
\hline \hline Total & $37(25.5 \%)$ & $108(74.5 \%)$ & $145(100 \%)$ \\
\hline
\end{tabular}

In order to compare the refusers to the total sample on SES, I used two approximate (observable) measures: (a) type of dwelling and (b) condition of the building. There were no differences between the types of buildings in which refusers and participants lived $\gamma^{2}(6, N=145)=$ 
$4.36, p=.63$, nor were there any differences in the conditions of these same buildings $\chi^{2}(4, N=145)=1.37, p=.85$.

I was also able to assess some observable items from the T-M scale to determine if there were differences between the groups with respect to their traditionality or modernity. In Morocco, there are a variety of clothing items which tend to be associated with more traditional lifestyles. Refusers were more likely to wear the Djellaba (a traditional Moroccan full-length long-sleeved modest dress) and less likely to wear European style clothing $\chi^{2}(1, N=136)=8.63, p<.003$, indicating that refusers may have been more likely to be traditional women than were participants. Additionally, two out of the three women who had facial tattoos also refused to participate. These tattoos have been applied rarely in recent years and are almost exclusively worn by rural women of Berber origin. This provided an additional indication that older, less educated and more traditional women were less likely to participate. There were no differences on any of the other clothing variables, including the wearing of the hijeb. This garment, a carefully folded scarf which covers the hair and neck but leaves the face visible, has become a symbol of adherence to Islamic fundamentalist beliefs (Hessini, 1991).

To determine if refusers were made more uncomfortable by the request for participation than were participants, interviewers recorded whether any signs or tension or stress were present during the contact 
period. I found no differences between refusers and participants on these assessments $\chi^{2}(2, N=141)=3.88, p=$ n.s.

To summarize, although respondents were not significantly different from refusers in terms of their discomfort with the request for participation, their age or with respect to a rough approximation of SES, those who refused participation appear to have been more traditional in outlook with less education than respondents.

\section{Characteristics of Family Structures and Social Networks in the Sample}

The following section contains an overview of the types of family structures in which respondents lived (nuclear, extended, etc.). In addition, I have briefly outlined the general characteristics and composition of their social networks.

\section{Respondents' Family Structures}

The majority of respondents were living in nuclear family units $(86$ or $79.6 \%)$ with an average family size of $3.36(S D=1.74)$ persons (See Figure 6). Of these nuclear families, only one was headed by a divorced female. In order to make a distinction between older and younger families, I classified 15 of this group as "aging nuclear" in structure-having three-fourths or more of the children in the family older than age 18. This is an important category because it reflects an increasingly pervasive social problem in Morocco: High rates of unemployment have 
resulted in the inability of many younger people to find jobs, and therefore to support either independent living and/or a family.

Additionally, unmarried

Classification of Family Types

Younger Nuclear $61.1 \%$

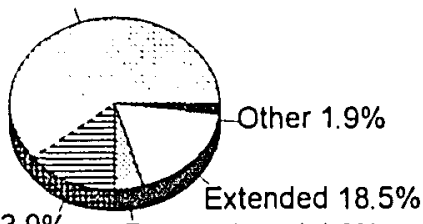

Aging Nuclear $13.9 \% \quad$ Reconstituted $4.6 \%$ women in their mid- to latetwenties increasingly find that men of their age, who are finally self-sufficient enough to support a family, prefer younger women as wives. This

Figure 6. Respondents' family classification. have little hope of marriage, many of whom are just old enough to have missed the recently improved educational opportunities available to younger women, and who therefore remain dependent upon their family of origin. I believe that, because of the relatively high SES, level of education and modernity of the group I studied, occurrences of this problem were less severe than what I would expect to find elsewhere in Morocco. However, it was clear that these younger family members did place a strain on aging parents and family finances. Such problems can only be expected to grow worse over time, and these types of situations can become particularly severe when parents die. In traditional families, unmarried women such as these would be expected to move into their brothers' homes, or might be 
taken on as the second wives of their sisters' husbands. However, the economic strain currently being experienced by most families precludes their taking on any additional members, and the educational background and modern beliefs held by many of these younger women make them completely unwilling to become second wives. Such situations may leave these women destitute as there is no equivalent to a social security or welfare system in Morocco.

Five other respondents lived in what I called "reconstituted" nuclear families. These were divorced (4) and separated (1) women who had moved back into their family of origin. I classified these families differently from the other nuclear families because the respondent had moved back into her role as daughter in the household, rather than living in a nuclear family where she was the principal female.

Extended families were fairly uncommon among the sample, with only 20 (18.5\%) classifiable as such. Additionally, the majority of these families were not "extended" in the traditional sense. In typical traditional Moroccan extended families, couples live with their parents-frequently those of the husband-creating large complex families with several generations living in the same houschold. Only one of the respondents I surveyed lived in a family of this type. The other 19 families categorized as "extended" had a structure quite similar to nuclear families, but which appeared to have taken on an additional 
family member (or sometimes two). The most common additions were mothers, mothers-in-law, brothers and sisters. Of the respondents living in all types of extended families, 18 of the 20 were married at the time of the interview, one was widowed and one separated.

Finally, two respondents lived in situations which were not classifiable within the above system. One was a divorced woman who lived with her sister, the other a widow who lived with a friend and a distant member of her husband's family who played the role of the respondent's servant.

\section{Respondents' Social Networks}

The lists of respondents' social networks used in this survey were elicited in response to a series of questions which included inquiries about those persons who lived with respondents, the people respondents felt were most important in their lives, persons who provided any of a variety of types of support (practical, emotional, informational, mediational, and patronage $e^{6}$, and those persons with whom respondents had negative interactions. Network members were listed whether they provided a great deal of aid and support or only a little. I also included as network members those people mentioned in association with problem interactions alone.

\footnotetext{
${ }^{6}$ See Appendix $A$ (the English questionnaire) for further information about the specific types of support included in the survey.
} 
In general, participants reported networks that were large (average size over 18 members), and which were composed primarily of kin (over $70 \%$ on average). Respondents also listed an interesting variety of relationship types in addition to kin members. These relationships most frequently included friends, neighbors, acquaintances, and colleagues as well as persons paid for their help such as maids, gardeners, household guards, and hired drivers. Less frequent mentions included physicians, psychologists/psychiatrists, attorneys, professors, apartment concierges, and governesses. Interestingly, of all network members mentioned by all respondents ( 1881 total), only 268 (14.2\%) were friends. The majority of participants were married at the time of the interview (over 90\%), and $91.66 \%^{7}$ of these women named their husbands as network members. Of all husbands listed (99), 88 were listed as among the people who "counted the most" in respondents' lives. Overall, family members were most commonly listed as among those who counted the most. Close kin were most likely to be cited in this category: (a) 232 children, (b) 188 sisters, (c) 140 brothers, (d) 71 mothers, and (f) 46 fathers. Only 100 friends were classified as among those most important to respondents.

The majority of network members were female (approximately 55\%), and there were differences in the types of relationships

\footnotetext{
${ }^{7}$ The latter value is higher than the former because some respondents named their exhusbands/separated husbands as people with whom they had negative interactions.
} 
TABLE III

\section{RESULTS OF CROSS-TABULATIONS OF SEX BY KINSHIP FOR RESPONDENTS'} NETWORK MEMBERS

\begin{tabular}{|c|c|c|c|}
\hline & Female & Male & $\begin{array}{l}\text { Row } \\
\text { Total }\end{array}$ \\
\hline Non-Kin & $\begin{array}{c}366 \\
(36.5 \%)\end{array}$ & $\begin{array}{c}184 \\
(22.0 \%)\end{array}$ & $\begin{array}{c}550 \\
(29.9 \%)\end{array}$ \\
\hline Kin & $\begin{array}{c}637 \\
(63.5 \%)\end{array}$ & $\begin{array}{c}652 \\
(78.0 \%)\end{array}$ & $\begin{array}{c}1289 \\
(70.1 \%)\end{array}$ \\
\hline & $\begin{array}{c}1003 \\
(54.5 \%)\end{array}$ & $\begin{array}{c}836 \\
(45.5 \%)\end{array}$ & $\begin{array}{c}1839 \\
(100.0 \%)\end{array}$ \\
\hline
\end{tabular}

respondents had with their male and female network members. A chi-square analysis (See Table III) of the sex of network members by kinship (non-kin vs. kin) shows that male network members were much more likely to be kin than were females in respondents'

networks $\chi^{2}(1, N=1839)=45.61, p<.0000$. While $57.7 \%$ of female nonkin network members were friends, only $31 \%$ of non-kin male network members were classified in the same way. Male network members were more likely to be identified as acquaintances (12\%), husbands' friends (12\%) or colleagues (19\%). Only $2.7 \%$ of female non-kin network members were identified as acquaintances, $8.2 \%$ as colleagues, and none as friends of husbands.

Overall these percentages point to the importance of kin as network members in comparison to non-kin members. In particular, the gender differences associated with the type of relationships respondents had with male and female members were marked. These differences are likely to reflect respondents' unwillingness to classify male members in 
ways which could be perceived as intimate even though the French "ami" or "friend" does not carry the same connotations of intimacy associated with the Moroccan Arabic word. ${ }^{8}$

For network members with whom respondents had only negative interactions (receiving no support whatsoever), the majority again were

Relationships of Network Members With Only Negative Interactions

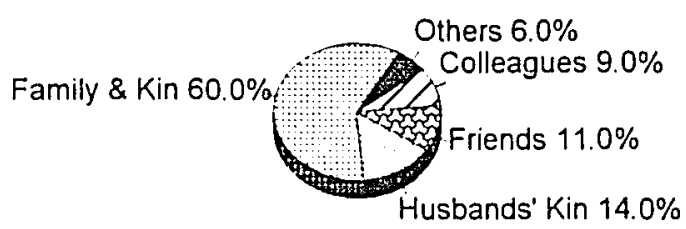

Figure 7. Respondents' relationships to persons with whom they had only negative interactions. acquaintances as well as a few others. kin: $60 \%$ were members of the respondents' families (including husbands, children, and grandchildren), $14 \%$ were members of the respondents' husbands' families, $11 \%$ were friends and $9 \%$ were colleagues (See Figure 7). The remainder included neighbors, maids and

\footnotetext{
${ }^{8}$ The Moroccan Arabic word for "my friend" when used by a woman speaking of a man (sahebti) means "boyfriend" rather than "friend," and there is no single word which conveys the meaning of "friend" in this context.
} 


\section{RESULTS}

\section{Factor Analysis of Network Structure and Function Variables}

Because there had been no prior research of this type in Morocco, the items in my questionnaire and variables constructed for their subsequent analysis were necessarily a reflection of theoretical constructs generated in Western settings. In order to assess the validity and applicability of these constructs within the Moroccan research setting, I factor analyzed those variables which were most theoretically relevant. Two general questions guided this analysis: (1) would the structure and function measures fall into separate and distinct factors, indicating that these two broad categories were independent with respect to one another, and (2) would the composition of the factors reflect Western theoretical constructs or would the interrelationships between the variables describing the factors suggest a different underlying structure.

Because this analysis was meant to be a basic test of the applicability of Western constructs in a North African setting, I used principal components analysis to extract the initial factors. This method achieves an economy of representation, and avoids introducing assumptions about underlying factors in the data (Kim \& Mueller, 1978). 
Additionally, because I expected that the concepts represented by the variables used in this analysis might overlap one another, I utilized an oblique rotation to produce the set of final factors. This method of rotation does not constrain factors to be orthogonal, producing factors which are intercorrelated.

Table IV describes the outcome of the factor analysis. Variable loadings less than .30 have been omitted in order to improve the clarity

TABLE IV

FACTOR LOADINGS OF NETWORK STRUCTURE AND FUNCTION VARIABLES

\begin{tabular}{|c|c|c|c|c|c|c|c|c|}
\hline & Factor 1 & Factor II & $\begin{array}{c}\text { Facior } \\
\text { III }\end{array}$ & Factor IV & Factor $v$ & Factor $\mathrm{Vl}$ & Factor vil & Factor Sill \\
\hline Items Included in Each Factor & $\begin{array}{c}\text { Social } \\
\text { Embeddedness }\end{array}$ & $\begin{array}{c}\text { Communication } \\
\text { Quality }\end{array}$ & Density & Reciprocity & \begin{tabular}{|} 
Satisfaction \\
with Friends
\end{tabular} & $\begin{array}{l}\text { Restrieted } \\
\text { Networks }\end{array}$ & $\begin{array}{l}\text { Low- } \\
\text { Demand } \\
\text { Vetworks }\end{array}$ & $\begin{array}{c}\text { Importance } \\
\text { of } \\
\text { velghbors }\end{array}$ \\
\hline $\begin{array}{l}\text { Average Freq of Contact } \\
\text { Average Freq of Support } \\
\text { Received }\end{array}$ & $\begin{array}{l}904 \\
856\end{array}$ & & & & & & & \\
\hline $\begin{array}{l}\text { Sum of Monthly Contuct with } \\
\text { all Network Members }\end{array}$ & 731 & & & & & .577 & & \\
\hline $\begin{array}{l}\text { Weighted Negativity } \\
\text { Freq. of Ningative Interactions } \\
\text { Feels that Important Network } \\
\text { Members Undersiand Her } \\
\end{array}$ & & $\begin{array}{r}.788 \\
.780 \\
695\end{array}$ & & & & & & \\
\hline $\begin{array}{l}\text { X kin in Network } \\
\text { Density }\end{array}$ & & & $\begin{array}{l}-872 \\
.834 \\
\end{array}$ & & & & & \\
\hline $\begin{array}{l}\text { 76 Reciprocal or Nearly } \\
\text { Reciprocal } \\
\text { \% Of Network to Whom } \\
\text { Respondent Gives Much } \\
\text { Less }\end{array}$ & & & & $\begin{array}{r}935 \\
.614\end{array}$ & & & & \\
\hline $\begin{array}{l}\text { \%o Of Network to Whom } \\
\text { Respondent Gives Much } \\
\text { More }\end{array}$ & & & $\cdot 303$ & .526 & 481 & & & $\cdot 332$ \\
\hline Satisfiled with Friends & & & & & 808 & & & \\
\hline $\begin{array}{l}\text { Network Size } \\
\text { 6of Network Female } \\
\text { Mulluppexily } \\
\end{array}$ & 370 & & .306 & & & $\begin{array}{r}-823 \\
566 \\
463 \\
\end{array}$ & & .449 \\
\hline $\begin{array}{l}\text { Feels Others Ask Too Much } \\
\text { Satisfied with Family } \\
\text { Network Disperston } \\
\text { Average Similarliy of Network } \\
\text { Members } \\
\end{array}$ & $\cdot 448$ & $\begin{array}{r}380 \\
\cdot 302\end{array}$ & $\begin{array}{r}-333 \\
345\end{array}$ & 399 & 320 & & $\begin{array}{l}-658 \\
601 \\
506 \\
482\end{array}$ & .398 \\
\hline $\begin{array}{l}\text { Nelghbors are important in } \\
\text { Daily L.1fe }\end{array}$ & & & & & & & & .761 \\
\hline
\end{tabular}


of the presentation. The principle components procedure extracted eight factors which exceeded the conventional eigenvalue cutoff of 1.0 and accounted for just over $71 \%$ of the variance. Two of the factors ("Satisfaction with Friends" and "Importance of Neighbors") loaded primarily on a single variable, although there was some variance shared with variables contained in other factors.

Table V shows the eigenvalues and the percentage of variance accounted for by each factor. Eigenvalues for final factors show that no single factor dominated the analysis, indicating that all of the factors are important in describing the networks of these subjects. Table VI lists the

TABLE $V$

EIGENVALUES AND PERCENTAGES OF VARIANCE ACCOUNTED FOR BY NETWORK STRUCTURE AND FUNCTION FACTORS

\begin{tabular}{|c|c|c|c|}
\hline Factor & Eigenvalue & $\begin{array}{c}\text { x of Variance } \\
\text { iccounted for } \\
\text { by Each Factor }\end{array}$ & $\begin{array}{c}\text { Cumulative } \% \text { of } \\
\text { Variance } \\
\text { Accounted For } \\
\text { by dill Factors }\end{array}$ \\
\hline $\begin{array}{c}\text { Social } \\
\text { Embeddedness }\end{array}$ & 2.894 & 14.5 & 14.5 \\
\hline $\begin{array}{c}\text { Communication } \\
\text { Quality }\end{array}$ & 2.429 & 12.1 & 26.6 \\
\hline Density & 2.167 & 10.8 & 37.5 \\
\hline Reciprocity & 1.750 & 8.7 & 46.2 \\
\hline $\begin{array}{c}\text { Satisfaction with } \\
\text { Friends }\end{array}$ & 1.489 & 7.4 & 53.6 \\
\hline $\begin{array}{c}\text { Restricted Networks } \\
\text { Lowr-Demand } \\
\text { Networks }\end{array}$ & 1.258 & 6.3 & 59.9 \\
\hline $\begin{array}{c}\text { Importance of } \\
\text { Neighbors }\end{array}$ & 1.211 & 6.1 & 66.0 \\
\hline
\end{tabular}


correlations between the factors. Only three of the correlations

exceeded 0.10 , with the largest at -0.18 , indicating that the factors

representing these concepts were, for the most part, independent of one another.

TABLE VI

FACTOR CORRELATION MATRIX FOR NETWORK STRUCTURE AND FUNCTION FACTORS

\begin{tabular}{|c|c|c|c|c|c|c|c|}
\hline & $\begin{array}{c}\text { Social } \\
\text { Embedded- } \\
\text { ness }\end{array}$ & $\begin{array}{c}\text { Communication } \\
\text { Quality }\end{array}$ & Density & Reciprocity & $\begin{array}{c}\text { Satisfaction } \\
\text { with } \\
\text { Friends }\end{array}$ & $\begin{array}{l}\text { Restricted } \\
\text { Networks }\end{array}$ & $\begin{array}{c}\text { Low: } \\
\text { Demand } \\
\text { Network } \\
\end{array}$ \\
\hline $\begin{array}{l}\text { Communication } \\
\text { Quality }\end{array}$ & .055 & & & \multirow[b]{4}{*}{.054} & \multirow[b]{5}{*}{.005} & & \\
\hline Density & -.180 & .039 & & & & & \\
\hline Reciprocity & .003 & .065 & 005 & & & & \\
\hline $\begin{array}{l}\text { Satisfaction with } \\
\text { Friends }\end{array}$ & -.032 & .030 & -.023 & & & & \\
\hline $\begin{array}{l}\text { Restricted } \\
\text { Networks } \\
\end{array}$ & .018 & .069 & -.100 & .017 & & & \\
\hline $\begin{array}{l}\text { Low-Demand } \\
\text { Networks }\end{array}$ & .047 & .120 & .018 & .004 & .050 & .075 & \\
\hline $\begin{array}{l}\text { Importance of } \\
\text { Neighbors }\end{array}$ & -.046 & .032 & .060 & .063 & -.121 & .027 & .023 \\
\hline
\end{tabular}

\section{Descriptions of the Factors}

\section{Factor 1: Social Embeddedness}

The variables that combined to produce Factor I included frequency of contact, total contact with all network members, and average frequency of help received. The factor also loaded positively on multiplexity, and negatively on network dispersion, although these loadings were weak in comparison. Therefore, respondents with high scores on this factor were those who had a great deal of contact with, 
and received much help from, their network members. To a lesser degree, the network members of these subjects helped them in a wide variety of ways and tended to live in close proximity. I named this factor "social embeddedness" because it appears consistent with Laireiter and Baumann's (1988, in Laireiter \& Baumann, 1992) definition of social integration/embeddedness: "participation and involvement of a person in his or her social life in the community and in society." (pp. 34).

\section{Factor II: Communication Quality}

The three variables that comprised Factor II were all related to the quality of interactions with network members. "Feeling that others understand" loaded positively on this factor, while two variables that described negative interactions with network members loaded in a negative direction. These loadings indicate that those respondents who had the most negative interactions with their network members also felt the most misunderstood. Conversely, respondents who felt understood had few negative interactions with their network members. If feeling misunderstood results from an inability to make oneself understood, then the quality of interaction might itself be a function of communication. I find this factor one of the more interesting produced by this analysis. The combination of negativity and ability to communicate with important others may represent an underlying dimension (i.e., communication)--a conceptualization that marital 
therapists might not find surprising, but which I have not seen previously in the social support literature. For the purposes of this research, it remains consistent with theoretical conceptions of the importance of negative and positive interactions in networks.

\section{Factor III: Density}

Factor III was composed of mainly two variables: network density and percentage of kin in networks. It clearly corresponds to the theoretical concept of density, for kin in networks would be much more likely to know one another than other network members.

\section{Factor IV: Reciprocity}

Factor IV was composed of the reciprocity measures. Percentage of reciprocal relationships in the network loaded positively on the factor, while both types of non-reciprocal relationships loaded negatively (giving more than receiving and receiving more than giving). The factor corresponds nicely to the exchange theoretic construct of reciprocity, which does not specify the direction of non-reciprocal relationships, but requires only that they be non-reciprocal.

\section{Factor V: Satisfaction With Friends}

Factor $V$ was one of two which loaded primarily on a single variable: respondents' satisfaction with their friends. Two other variables which loaded primarily on other factors, were also moderately related to this factor. The first of these variables, a reciprocity measure, 
coded percentage of people in the network to whom respondents gave much more than they received. The second of these variables coded similarity among network members. Overall, this factor indicated that satisfaction with friends was an important network construct, but also that those who gave more to their friends and who were similar to them, tended to be more satisfied with those friendships. This conclusion is consistent with theoretical predictions that relationships are better among people who are similar, and also suggests that satisfaction with friends may be greater among those who have a greater commitment to their friendships.

\section{Factor VI: Restricted Networks}

The variables that loaded on Factor VI included network size, percent of the network that was female, and the multiplexity of the network. The amount of contact with network members (from Factor I) also loaded highly on this factor. Generally, the networks of respondents who scored highly on this factor were small and composed mostly of women with whom participants had low levels of contact, but who provided them with many different kinds of support. These networks therefore appeared "restricted" in terms of number, contact, and gender, subsequently obliging network members to play more multiplex support roles. 
In order to better understand the characteristics of this factor, I computed zero-order correlations between regression factor scores for the factor and a number of the demographic variables. Respondents who had highly restricted networks were younger $(r=-.38, p<.000)$, had fewer children $(r=-.51, p<.000)$ and were more traditional $(r=-.25, p<$ .01). This latter correlation was computed with the T-M factor with employment removed--the correlation with the T-M factor itself (which included employment status) did not attain statistical significance. Together, the loadings on the factor and the correlations of the factor scores with the demographic variables paint a picture of marginalized women--younger, more traditional women who work, but who find themselves living in a modern neighborhood that may be less accepting of their beliefs. These more traditional beliefs may cause them to restrict their interactions with men, and the fact that they have had fewer children may increase their feelings of marginality because of the importance placed upon childbearing in Morocco. Feelings of failure associated with having had either no children or too few children may be particularly likely among individuals with more traditional belief systems, and may increase fears that husbands will take an additional wife as has been typical in the past. 


\section{Factor VII: Low-Demand Networks}

Factor VII contained a combination of variables that coded both structure (dispersion, similarity) and function (feeling others ask too much, family satisfaction). Of these, feeling that "others asked too much" loaded negatively while family satisfaction, similarity and dispersion loaded positively. This indicates that respondents whose network members demanded less of them were more satisfied with their families, perceived themselves as more similar to their network members, and lived at greater distances from the people who provided them support than did respondents with more demanding networks. Note that the three variables which loaded positively on this factor also shared their variance with several of the other factors, indicating that these aspects of networks have broad importance beyond the concept of high or low network demand.

In order to further evaluate this factor, I computed the same analyses as described for Factor VI. I found that women who scored high on this factor were less likely to be employed $(r=. .19, p<.05)$, had better relationships with their husbands (lower IMS scores) $(r=-.26, p<$ $.007)$, spoke fewer languages $(r=-.21, p<.03)$, were less modern $(r=-.25$, $p<.01)$, and had lower SES levels $(r=-.21, p<.03)$ than did women who scored low on the factor. In combination with the factor loadings, these women appear to have a less-demanding lifestyle-perhaps because they 
are more traditional and they and their families are both comfortable with their traditional roles (as evidenced by the positive loading on family satisfaction).

\section{Factor VIII: Importance of Neighbors}

Factor VIII was the second factor that was described primarily by a single variable: the importance of neighbors in respondents' networks. Three other variables also had weak loadings on this factor: Decreased similarity among network members, smaller percentages of female network members and lower proportions of network members to whom respondents gave much more than they received all loaded in the same direction as importance of neighbors.

\section{Relevance of Factors to Western Theoretical Concepts}

Overall, the factors corresponded to constructs suggested by Western researchers. The function-related factors (i.e. Social Embeddedness, Communication Quality, Reciprocity, Satisfaction With Friends and Importance Of Neighbors) as well as the Density factor are quite similar to Western theoretical conceptions and are relatively distinct and easily interpretable. Conversely, Factors VI (Restricted vs. Non-Restricted Networks) and VII (Low- vs. High Demand Networks), which reflected primarily network structure measures, were composed of variables (such as network size, multiplexity, similarity, dispersion, and gender) that combined in ways that were not always easily 
interpretable. Additionally, the presence of structure and function measures together in these two factors suggests that such measures might be better understood as structure/function dimensions rather than as one or the other, at least among these Moroccan women.

Antecedent Measures, Life Events, Social Network Structures and Functions, and Well Being: Breakdown of the Model

In order to describe network structures and functions as they existed in this sample, I completed a series of regression analyses consistent with the general model I proposed in the Introduction. I entered sets of independent variables into the regression equations one set at a time, corresponding to the model structure (antecedent followed by recent life-events, etc.), using stepwise backwards elimination techniques (the criterion for removal was 0.10 , the default setting in SPSS [Norušis, 1992]). I chose the backwards elimination technique because it is a more inclusive technique and I wanted to best describe the associations between the antecedent, life-events and network measures. I felt that the less stringent criteria employed in this elimination process might provide more suggestive directions for future research, and in addition, this technique would allow me to discover any suppressor relationships which might exist in the data (Darlington, 1990). Due to the use of sets in the analysis, some variables which were retained as significant after a set had been entered, later became non- 
significant during the processing of subsequent sets. Even though these variables were no longer statistically significant, SPSS retains the variables in the final equation. I have indicated variables such as these with the "n.s." (non-significant) code in all tables.

In order to reduce unacceptable experiment-wide error rates resulting from the number of regression analyses I completed, I have reported only regression analyses attaining an overall significance level less than or equal to 0.01 as statistically significant results. Results of those analyses which did not reach this level of significance are included in their respective tables solely for purposes of hypothesis generation for future research.

In order to explore the general theoretical model I proposed in the Introduction, I decomposed the model into each of its related segments and analyzed the relationships among the components of each segment. Each component of the model corresponded to a set which was entered into the regression analyses in the order proposed by the model: (a) antecedent variables, followed by (b) life-events variables, (c) network structure variables, (d) network function variables, and finally (e) wellbeing variables (either psychological or health). The results of those analyses follow. 


\section{Antecedent Measures and Life-Events}

This section and Table VII describe the results of regression

analyses of antecedent measures on the recent life events (positive and negative changes during the year prior to the interview). The distributions of all life-events variables were skewed, so I used the log-

\section{TABLE VII}

\section{RESULTS OF REGRESSION ANALYSES OF ANTECEDENT MEASURES ON LIFE-EVENTS DURING THE YEAR PRECEDING PARTICIPATION}

\begin{tabular}{|c|c|c|c|c|}
\hline Antecedent Variables & \begin{tabular}{|c|} 
Recent Negative \\
Changes \\
$(0-6$ Months \\
Before Interview)
\end{tabular} & \begin{tabular}{|} 
Remote Negative \\
Changes \\
(6-12 Months \\
Before Interview)
\end{tabular} & $\begin{array}{c}\text { Recent Positive } \\
\text { Changes } \\
\text { (0-6 Months } \\
\text { Before Interview) }\end{array}$ & $\begin{array}{c}\text { Remole Positive } \\
\text { Changes } \\
\text { (6-12 Months } \\
\text { Before Interview) }\end{array}$ \\
\hline Age & 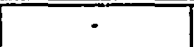 & .254 & -.339 & $\cdot$ \\
\hline Number of Chronic llinesses & $.176+$ & $\cdot$ & $\cdot$ & $-251^{*}$ \\
\hline Level of Education & $.307^{+\infty}$ & . & $\cdot$ & $.305^{* \bullet}$ \\
\hline Employment Status & - & $\cdot$ & $\cdot$ & - \\
\hline Length of Time Lived in Rural Area & $\cdot$ & $\cdot$ & $\cdot$ & - \\
\hline Works in Public Sector & - & - & - & $\cdot$ \\
\hline Neighborhood Heterogeneity & $\cdot$ & $\cdot$ & $\cdot$ & - \\
\hline Size of Household & - & $\cdot$ & $\cdot$ & $\cdot$ \\
\hline IMS Score & $.187+$ & - & .189 & $\cdot$ \\
\hline Number of Languages Spoken & $.300^{* *}$ & - & - & - \\
\hline Length of Time Lived in Neighborhood & - & .194 & $\cdot$ & - \\
\hline Marital Status & - & - & $\cdot$ & $\cdot$ \\
\hline M-T Scale & $\cdot$ & - & - & - \\
\hline Neighborhood Activity Level & $\cdot$ & - & - & $.197^{*}$ \\
\hline Number of Children & $\cdot$ & - & .316 & $.267^{\circ}$ \\
\hline SES & $\cdot$ & $\cdot$ & $\cdot$ & - \\
\hline Berber Speaking Ability & - & - & - & - \\
\hline Student & $\cdot$ & - & $\cdot$ & - \\
\hline Multiple R & .40 & 24 & .31 & .41 \\
\hline$p$ & .0041 & .0673 n.s. & $.0310 \mathrm{~ns}$ & .0031 \\
\hline
\end{tabular}


transform of the variables in computing the analyses. However, means and standard deviations reported for the measures reflect the untransformed variables.

\section{Recent Negative Change (Six Months Prior to Participation)}

The average recent negative change was $5.82(S D=6.38)$ and ranged from 0 to 36. Two of the antecedent measures were predictive of recent negative events. Higher levels of education were associated with fewer stressful events while speaking more languages predicted greater numbers of such events (Multiple $R=.40$ ). These results seemed inconsistent, since I knew that education level and number of languages spoken (not including native tongues) were correlated $(r=.49, p<.000)$. In order to explore this contradiction, I created a graph of education level and recent negative events grouped by number of additional languages spoken.

The differences among the groups appear in Figure 8. For women who spoke one other language in addition to their native tongue, increasing education was associated with fewer negative life events, while for those who spoke more than one additional language, more languages and additional education were associated with increases in the numbers of negative life events reported. Although the positive relationship between education and negative change may hold true for women who only spoke their native language, the size of this group is 


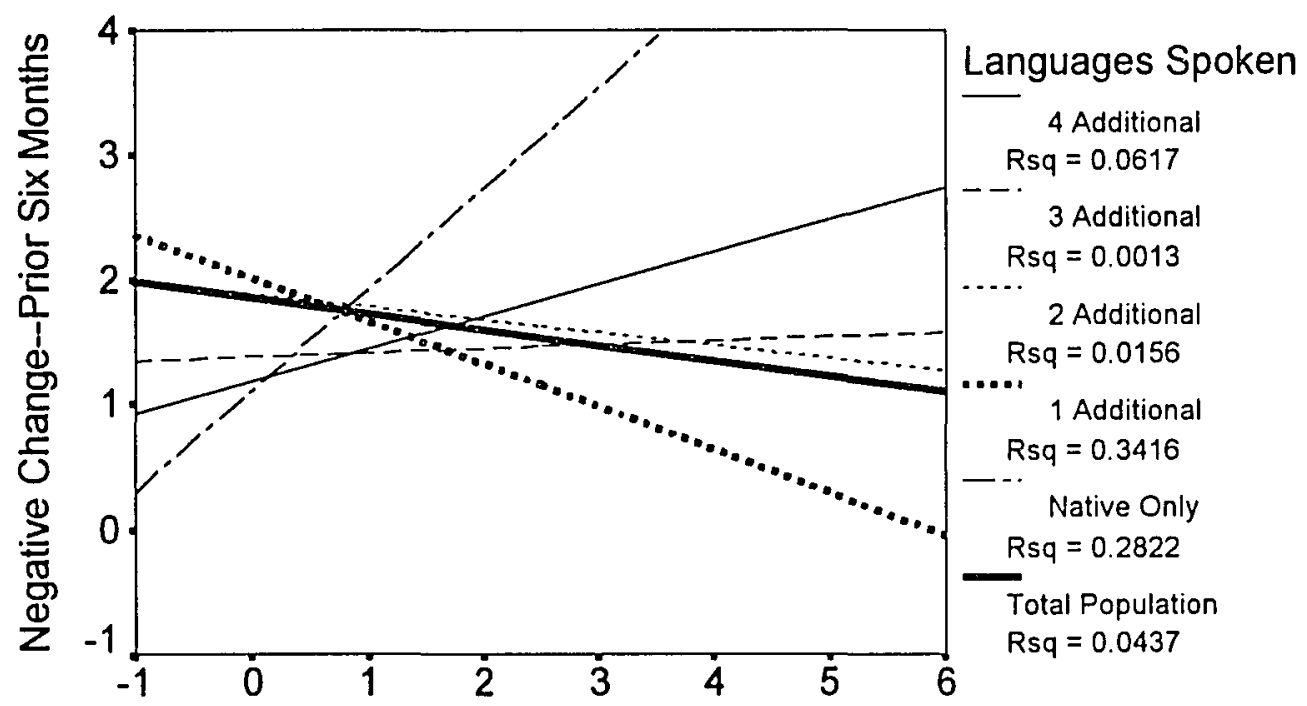

\section{Education Level}

Figure 8. Relationship between recent negative life events and education level, grouped by the number of additional languages spoken. Note: $\mathrm{Rsq}=r^{2}$; data points have been omitted to improve clarity.

too small (almost by definition, because Moroccan dialects are neither written at all nor taught in schools) to draw any conclusions. In any case, the graph shows that the relationship between education level and negative change during this period varied as a function of the number of languages spoken by respondents. The origin of this relationship is not clear from these analyses and, if it is not a statistical artifact, this finding may require further study to elucidate its nature.

\section{Remote Negative Change (Six to Twelve Months Prior to Participation)}

The average remote negative change was $4.19(S D=5.39)$ and ranged from 0 to 30 . Because the overall $F$-test for the equation was not 
significant at specified 0.01 level, the results of this analysis were inconclusive (Multiple $R=.24, p=$ n.s.).

\section{Recent Positive Change (Six Months Prior to Participation)}

The average reported positive change during the six months prior to participation was $4.96(S D=5.47)$ and ranged from 0 to 28 . The overall F-test of this analysis did not reach the selected criterion of .01 , so results associated with it should also be considered inconclusive (Multiple $R=.31, p=$ n.s.).

\section{Remote Positive Change (Six to Twelve Months Prior to Participation)}

The average positive change reported during the period six to twelve months prior to the interview was $3.58(S D=5.52)$ and ranged from 0 to 37. Three of the antecedents were associated with increases in positive change during this period. They were (a) increases in respondents' levels of education, (b) having had more children and (c) higher levels of activity in the respondent's neighborhood. Not surprisingly, having more chronic illnesses was associated with experiencing fewer positive changes (Multiple $R=.41$ ).

\section{Antecedent Measures, Life Events and Network Structures}

The sets in this group of regressions again reflected the proposed model. The first set entered included all the antecedent variables except those theoretically unrelated to network structure (e.g. frequency of exercise; caffeine and cigarette consumption), followed by the recent 
TABLE VIII

RESULTS OF REGRESSION ANALYSES OF ANTECEDENT AND LIFE-EVENTS ON NETWORK STRUCTURE

\begin{tabular}{|c|c|c|c|c|c|c|c|c|c|c|c|c|c|}
\hline Independent Variables & $\begin{array}{c}\text { Global } \\
\text { Network } \\
\text { Size }\end{array}$ & $\begin{array}{c}\text { Size } \\
\text { Practical } \\
\text { Subnetwork }\end{array}$ & $\begin{array}{c}\text { Size } \\
\text { Emotional } \\
\text { Subnetwork }\end{array}$ & $\begin{array}{c}\text { Size } \\
\text { Information } \\
\text { Subnetwork } \\
\end{array}$ & $\begin{array}{c}\text { Size } \\
\text { Mediation } \\
\text { Subnetwork }\end{array}$ & $\begin{array}{c}\text { Size } \\
\text { Patronage } \\
\text { Subnetwork }\end{array}$ & $\begin{array}{c}\text { Size } \\
\text { Negative } \\
\text { Subnetwork }\end{array}$ & Density & Multiplexity & Similarity & Percent & $\begin{array}{c}\text { Percent } \\
\text { Kin }\end{array}$ & $\begin{array}{c}\text { Average } \\
\text { Dispersion }\end{array}$ \\
\hline Age & $.243^{2}$ & - & - & -1 & -1 & $-\quad$ & - & $\overline{-}$ & $=$ & $\overline{-}$ & $=$ & $-.291^{\prime}$ & $.338^{6 \pi}$ \\
\hline \# of Chronic Illnesses & - & - & - & - & - & - & - & - & - & - & - & - & - \\
\hline Level of Education & - & - & - & .191 & $-.498^{* \pm *}$ & - & - & - & - & - & - & - & - \\
\hline Employment Status & - & - & $\cdot$ & $\cdot$ & $\cdot$ & - & $\cdot$ & - & -.279 & $\cdot$ & - & - & - \\
\hline Time Lived in Rural Area & - & - & - & - & - & $392^{n+\infty}$ & - & - & - & $\cdot$ & - & - & $-.313^{* *}$ \\
\hline Public Sector Employ. & $.177+$ & - & - & - & - &. & - & - & - & - & $-.219^{*}$ & $-.162+$ & - \\
\hline $\begin{array}{l}\text { Neighborhood } \\
\text { Heterogeneity }\end{array}$ & - & $.182+$ & - & - & - & - & - & - & - & -341 & - & $.184^{*}$ & - \\
\hline Size of Household & $.310^{* *}$ & $388^{* \ldots *}$ & 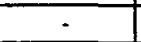 & $\cdot$ & - & - & .199 & - & - & - & - & - & $-.264^{\text {nt }}$ \\
\hline IMS Score & $\cdot$ & - & - & - & $.330^{\text {st* }}$ & - & - & - & - & -.149 n.s. & - & - & - \\
\hline Languages Spoken & - & $\cdot$ & -.236 & - & $\cdot$ & - & - & $-.275^{\text {th }}$ & $\cdot$ & $-\cdot$ & - & $-.269^{* \star}$ & - \\
\hline \begin{tabular}{|l} 
Time Lived in \\
Neighborhood
\end{tabular} & - & - & - & - & - & - & - & - & - & - & - & - & - \\
\hline Marital Status & $\cdot$ & - & - & - & - & - & - & $-.152+$ & - & $-.194+$ & $.195+$ & $.187+$ & $-.220^{*}$ \\
\hline M.T Factor & - & - & - & $\cdot$ & - & - & $\cdot$ & - & .288 & - & - & - & - \\
\hline Neighborhood Activity & - & - & 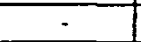 & - & - & - & - & - & $\cdot$ & - & - & - & - \\
\hline Number of Children & $\cdot$ & 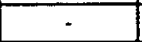 & $\cdot$ & - & $\cdot$ & $\cdot$ & $\cdot$ & $.333^{* *}$ & - & $.282^{\text {*t }}$ & $-.343^{+40+t}$ & $.363^{\circ * t}$ & - \\
\hline Network Size & nis & Ni & ni & $\mathrm{n} / \mathrm{i}$ & $\mathrm{n} / \mathrm{i}$ & $\mathrm{ni}$ & $n \sqrt{1}$ & $-.361^{\text {tant }}$ & - & ni & ni & $n \sqrt{i}$ & $\mathrm{n} / \mathrm{i}$ \\
\hline SES & - & $\because$ & $\cdot$ & - & $.392^{* *}$ & $.345^{* * * *}$ & $\cdot$ & \begin{tabular}{|l|}
- \\
\end{tabular} & $\cdot$ & - & $-.240^{ \pm}$ & $\cdot$ & - \\
\hline Fluency in Berber & - & - & - & .194 & - & $\cdot$ & - & - & - & - & - & - & $.348^{* *}$ \\
\hline Student & - & - & 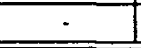 & $\cdot$ & $-249^{* *}$ & - & - & - & - & $\cdot$ & - & $\cdot$ & $\cdot$ \\
\hline Recent Neg. Change & $\overline{-}$ & 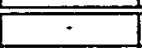 & - & 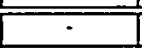 & - & $=$ & $\overline{-}$ & $\overline{-}$ & 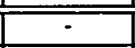 & $-.197^{4}$ & $=$ & $=$ & - \\
\hline Remote Neg. Change & - & - & - & - & - & - & - & - & - & - & - & - & - \\
\hline Recent Pos. Change & - & - & - & $\cdot$ & $.179+$ & - & - & - & - & - & - & - & - \\
\hline Remote Pos. Change & $165+$ & $\cdot$ & $\cdot$ & $\cdot$ & $.251^{\text {th }}$ & - & $\cdot$ & - & $\cdot$ & - & - & $\cdot$ & - \\
\hline Mulfole R & 49 & 21 & 24 & 22 & 59 & 43 & 20 & 51 & 25 & 49 & 45 & 55 & 55 \\
\hline 0 & 0001 & 0004 & $0279 n s$ & 1201 & 0000 & 0002 & $0612 n s$ & 0000 & $0589 \mathrm{~ns}$ & 0004 & 0008 & 0000 & 0000 \\
\hline
\end{tabular}

Note. $+p<.10 . " p<.05 . * p<.01 . * * p<.001 . n / \mathrm{i}=$ not included in the analysis. 
life events measures. These two sets were regressed on each network structure measure, and the results appear in Table VIII. I included global network size with the set of antecedent variables (as a control) in the analyses of network density and multiplexity for two reasons. First, I expected that increases in network size would reduce the likelihood that members of networks would know one another, therefore reducing measures of density. Second, I also felt that larger networks would be more likely to contain more unidimensional-support relations, therefore decreasing multiplexity.

\section{Global Network Size}

Global network size ranged from a minimum of nine persons to a maximum of 43 , with a mean of $18.36(S D=5.41)$. The total number of network members mentioned by all respondents was 1881 . Two of the antecedent measures were significant predictors of global network size although none of the life-events measures were predictive. Increases in respondents' age and household size were both associated with increases in network size, although Figure 9 uses a quadratic regression line to show that network size appears to drop off for the oldest women. This figure combines both the Agdal sample as well as the larger sample used to construct the T-M and SES scales because, although the relationship remained the same, the larger sample made the relationship more 
apparent: It included proportionally more older women (Multiple $R=$ .49).

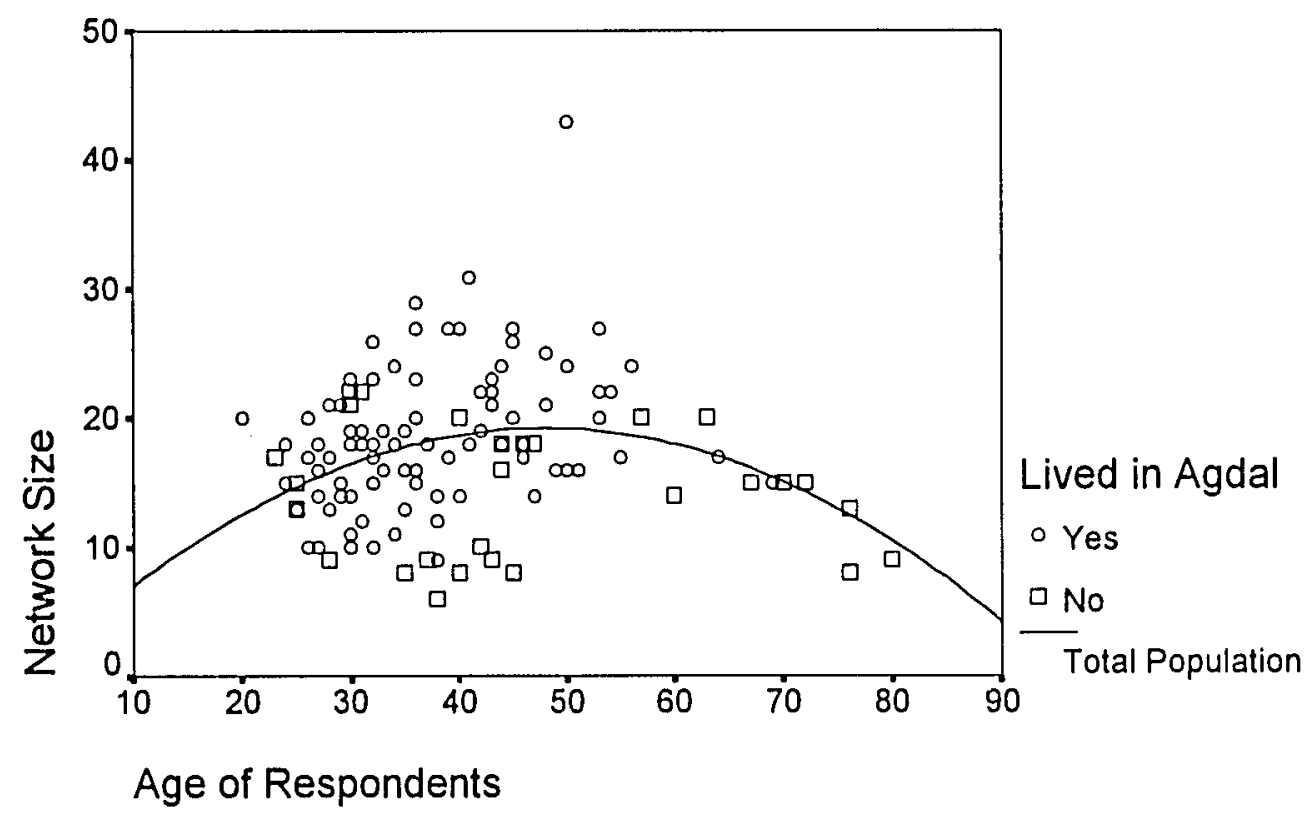

Figure 9. Relationship between age and network size, grouped as members of the Agdal sample or the larger sample.

Size of the Practical Support Subnetwork. The number of practical support providers ranged from 3 to 21 with a mean of $8.65(S D=3.35)$. None of the life-events measures were associated with practical support, and only one of the antecedent variables was a significant predictor of the number of people available to respondents for practical help: Larger households were associated with more people available to provide practical support (Multiple $R=.41$ ).

Size of the Emotional Support Subnetwork. The number of emotional support providers ranged from 1 to 28 with a mean 
subnetwork size of $6.30(S D=3.94)$. The overall significance test for the equation did not attain the 0.01 level, so there were no significant predictors of the number of people available to provide emotional support. The fact that none of the independent variables were predictive would suggest that other factors, such as traits of either respondents or network members, would provide more reasonable explanations for the availability of emotional support (Multiple $R=.24, p=$ n.s.).

Size of the Information Support Subnetwork. The average size of the information subnetwork was $5.23(S D=2.59)$ and ranged from 0 to 13. As with the emotional subnetwork, the overall significance level for the equation did not attain the specified level, so the results of this analysis were inconclusive. It is interesting to note that education level (and the increased access to more informed people that should be associated with it) was not a strong predictor of knowing people who could provide information when needed. However this may be related to the fact that, for many Moroccans, life remains relatively simple, and information may not be as necessary as it is in the West. For example, when asked who might provide information to them, a number of women (mostly older) replied with something similar to "why would I need information?." I was normally able to provide a scenario ("perhaps you might need someone to teach you how to make a new recipe") which would elicit a response, yet it was clear that a number of participants felt 
they knew as much as they needed to know in their lifetimes. This perception that no further information is needed could account for the inability of the equation to predict the sizes of the informational subnetwork (Multiple $R=.22, p=$ n.s.).

Size of the Mediational Support Subnetwork. The average size of this subnetwork was $5.47(S D=3.62)$ with respondents reporting from 0 to 20 potential mediators. Several factors were predictive of the size of this subnetwork. Increasing education was negatively associated with the number of persons available for dispute mediation, as was being a student. Consistent with these results, many of the more educated women I interviewed reported feeling uncomfortable asking others to help them resolve disputes, and a number of these women were unwilling to use such mediators even in the most serious circumstances. I also noticed during a number of the interviews that, in circumstances where respondents did feel mediation was appropriate, more educated women tended to be more discriminating when choosing whom to approach as a potential mediator. For these reasons, I believe the results were a function of more educated women either refusing to use mediators or being extremely reluctant about their use, rather than that such women did not know potential mediators.

Although education was inversely related to the size of the mediation subnetwork, increasing SES was associated with knowing more 
potential mediators as was greater marital dissatisfaction. Women of higher SES may be in a better position to access successful mediators because they may be more likely to associate with higher SES mediators who have more prestige and are therefore considered to have more potential as helpers than would lower SES mediators. The fact that women who have marital problems know more mediators may be a function of having needed a mediator in the past and therefore knowing who is helpful, or just of having spent time thinking about who might help in particular marital situations. Additionally, remote positive changes were predictive of larger mediation subnetwork sizes (Multiple $R$ $=.59)$.

Size of the Patronage Support Subnetwork. The average size of the patronage subnetwork was $3.52(S D=2.75)$, smaller than for the other subnetworks, with sizes ranging from 0 to 21 . Two variables were highly predictive of the number of potential patrons with whom respondents had contact. Both higher SES and the length of time lived in rural areas were associated with larger networks of patrons. Most likely, higher SES network members have both the prestige and the power to influence others, and by definition, interaction between members of the same SES level is more common than between different levels. Therefore, the SES of the respondent ought to predict, at least to a certain degree, the SES of her network members and therefore their higher economic power and 
prestige--both of which are factors that describe useful patrons. Additionally, those who have lived in rural areas should have been more likely to be a party to the traditional means of overcoming problems which characterize patronage relationships, than would their urban counterparts (Multiple $R=.43$ ).

Size of the Negative Interaction Subnetwork. The average size of this subnetwork was five $(S D=3.05)$, ranging in size from 0 to 13 members. Interestingly, no factors were statistically significant predictors of the number of people with whom respondents had negative interactions. As with the size of the emotional subnetwork, these types of interactions may be more a function of traits of respondents and network members than the social factors I measured (Multiple $R=.20, p=$ n.s.).

\section{Density}

The density of respondents' networks was high: on average, $80.2 \%$ of respondents' network members knew one another $(S D=14.82 \%)$ while percentages ranged from 42 to $100 \%$. As would be expected, increasing numbers of children were associated with greater density in the network while larger global networks were less dense. In addition, women who spoke more languages had less dense networks than did those who spoke fewer, perhaps because they were able to interact with people who spoke only languages that other members of their network did not. 
Conversely, respondents who spoke more languages may have been interested in having friends that were more diverse, with the result that such people would be less likely to know one another (Multiple $R=.57$ ).

\section{Multiplexity}

The mean multiplexity of the networks was $1.59(S D=.46)$, and the values ranged from 0.57 to 3.07 (out of a possible range of $0-5$ ), indicating that for networks as a whole, the average number of types of support functions provided by individual members was low. Out of curiosity, I computed the multiplexity of network members who were not defined by respondents as people who were most important in their lives, and compared the mean for these more distant members to the mean for members who were identified as very important. The most important network members provided significantly more types of support to respondents $(M=2.13, S D=1.61)$ than did less important members $(M=1.10, S D=0.95), F(1,1877)=223.16, p<.0000$.

With respect to the regression of the antecedent and life-events measures on network multiplexity, the overall $F$-test of the equation did not reach the required significance level, so the betas shown in the table should be considered only for hypothesis generation purposes (Multiple $R=.25, p=n . s$.$) .$ 


\section{Homogeneity}

Similarity of Character. The average similarity of network members to respondents was $1.78(S D=.38)$ and ranged from 1.06 to 2.69 (3 corresponded to "very similar"). The most important predictor of network similarity was the heterogeneity of the neighborhood. Women who reported having many network members who were similar to them were likely to live in more homogenous neighborhoods, while those living in heterogenous neighborhoods reported fewer similar network members. This seems to provide support for the notion that proximity plays the same kind of important role in friendship development in Morocco as it does in the West. In addition, recent negative change was associated with lower levels of similarity, in an unexpected way providing support for the assertion that similarity in networks is beneficial. That is, perhaps the effect of similarity is truly a function of the negative events which may arise in networks that are less similar. An alternative explanation for the association between similarity and negative change may be that such changes lead women to look for support from different kinds of people, therefore reducing the average similarity in their networks. Lastly, having more children was associated with increased similarity in the network (Multiple $R=.49$ ).

Percent Female. The average percentage of women in respondents' networks was $55.5(S D=11.91)$, and ranged from 17.6 to 80.0 percent. 
Three factors played important roles in explaining the proportion of women in networks. Increasing numbers of children (young as well as adult), higher SES and working in the public sector were all associated with decreases in the proportion of women in respondents' networks (Multiple $R=.45$ ).

Percent Kin. The average percentage of kin in respondents' networks was high, $71 \%(S D=15 \%)$, and ranged from 25 to 100 percent. Four factors were significant predictors of these percentages. Not surprisingly, women who had more children had proportionately greater numbers of kin in their networks. At the same time, women living in more heterogenous areas also had proportionately more kin than did respondents who lived in homogenous neighborhoods. Conversely, older respondents and women who spoke many languages had fewer kin as network members, and the relationship between age and percentage of kin in networks contradicted the zero-order correlation between the two variables as well $(r=.0009, p=n . s$.$) . Additionally, I knew that age$ was highly correlated with number of children $(r=.67, p<.000)$, another variable in the equation, but one which was positively associated with percentage of kin. In order to explore these results, I computed a partial correlation coefficient for respondents' age and percentage of kin in networks, controlling for the number of children respondents had. Consistent with the regression analysis, this analysis indicated that when 
number of children was controlled for, increasing age was associated with lower proportions of kin in networks $(r=-.28 p<.006)$. It is possible that this may be a function of older respondents being more likely to have lost non-child kin to death as they aged.

\section{Dispersion}

The average dispersion in networks was 1.83 hours $(S D=2.38$ hours), and ranged from 0.14 hours to 15.74 . Because the distribution for dispersion was skewed, I log-transformed the variable before conducting the following regression analysis.

There were several factors which were associated with the average amount of time it took respondents to travel the distance between their own homes and the homes of their network members. First, increasing age was a strong predictor of greater dispersion. The most plausible explanation for these increases in dispersion was that children move away as they grow older, leaving for college or jobs and/or getting married. However, follow-up analyses indicated that dispersion and respondents' age were positively associated for children and other network members when I compared the associated correlations: (a) age and dispersion for children $(r=.51, p<.000)$ and (b) age and dispersion of other network members $(r=.34, p<.000)$. In addition to these results, increases in household size were associated with lower average dispersion levels. 
Two other factors were important predictors of average network dispersion: (a) the length of time the respondent had lived in a rural area, and (b) Berber-speaking ability (Multiple $R=.55$ ). I expected that both of these measures would be positively associated with network dispersion because most Berber-speaking areas are rural, but in fact, although Berber-speaking ability was positively associated with dispersion, length of time spent living in rural areas was negatively associated with the distance measure in the regression analysis.

Because of these contradictory results, I performed some further analyses. Zero-order correlations between average dispersion, Berberspeaking ability and length of time lived in the country appear in Table IX. Although these correlations remained consistent with the regression

TABLE IX

CORRELATIONS BETWEEN AVERAGE DISPERSION IN NETWORKS, BERBERSPEAKING ABILTY, AND LENGTH OF TIME LIVED IN RURAL AREAS

\begin{tabular}{||c|c|c|}
\hline & $\begin{array}{c}\text { Time lived } \\
\text { in Rural } \\
\text { Area }\end{array}$ & $\begin{array}{c}\text { Berber- } \\
\text { Speaking } \\
\text { Ability }\end{array}$ \\
\hline $\begin{array}{c}\text { Berber- } \\
\text { Speaking } \\
\text { Ability }\end{array}$ & .5309 &.. \\
\hline $\begin{array}{c}\text { Average } \\
\text { Network } \\
\text { Dispersion }\end{array}$ & .1111 & .1930 \\
\hline
\end{tabular}

analyses, the effect sizes were small and the direction of those effects remained inexplicable. I decided to examine dispersion and length of time lived in the country using Berberspeaking ability as a 
grouping variable. Figure 10 shows the interactions among these variables. There were no differences between any of the groups (i.e. $r \approx$ .00) except for those women who spoke Berber fluently. However, the relationship between dispersion and length of time lived in rural areas for fluent Berber speakers was extremely strong $(r=.85)$.

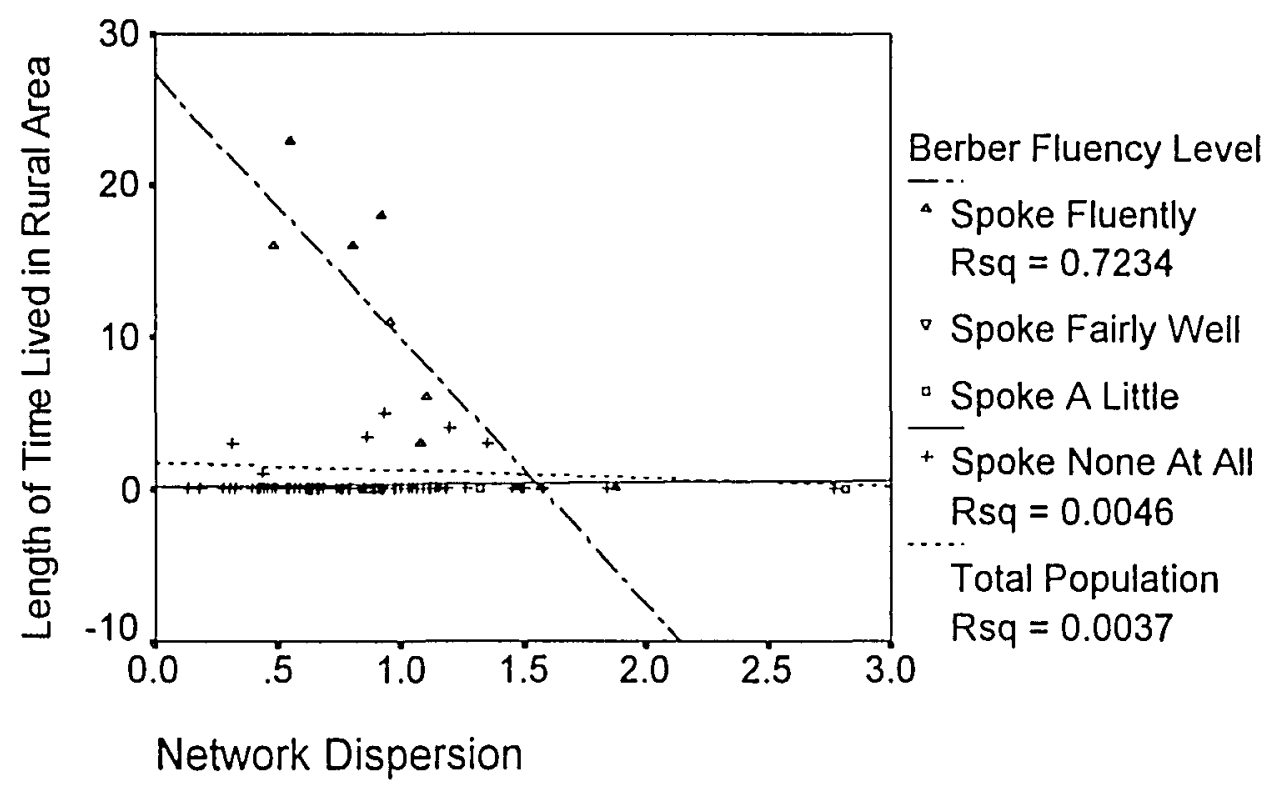

Figure 10. Time lived in rural areas and network dispersion, grouped by Berber-speaking ability (Note: $R s q=r^{2}$, and $R^{2} s$ which do not appear are equal to population statistics.)

\section{Antecedent, Life-Events, Network Structures and Network Functions}

Table X summarizes the results of all regressions of antecedent, life-events and network structure measures on network functions. The regression techniques used for these analyses were the same as those 
TABLE X

RESULTS OF REGRESSION ANALYSES OF ANTECEDENT, LIFE-EVENTS, AND NETWORK STRUCTURE MEASURES ON NETWORK FUNCTIONS

\begin{tabular}{|c|c|c|c|c|c|c|c|c|c|c|c|c|c|c|}
\hline Independent Variables & $\begin{array}{c}\text { Family } \\
\text { Satisfaction }\end{array}$ & $\begin{array}{c}\text { Satisfactio } \\
\mathrm{n} \text { with } \\
\text { Friends }\end{array}$ & $\left|\begin{array}{c}\text { Importance } \\
\text { of } \\
\text { Neighbors }\end{array}\right|$ & $\begin{array}{l}\text { Feeling } \\
\text { Under- } \\
\text { stood }\end{array}$ & $\begin{array}{c}\text { Average } \\
\text { Frequency } \\
\text { fof Contact }\end{array}$ & $\begin{array}{l}\text { Total } \\
\text { Contact } \\
\text { Days } \\
\text { Month } \\
\end{array}$ & $\begin{array}{l}\text { Average } \\
\text { Frequency } \\
\text { of Support }\end{array}$ & $\begin{array}{c}\text { Total } \\
\text { Support } \\
\text { Days/ } \\
\text { Month }\end{array}$ & $\begin{array}{l}\text { Percent } \\
\text { Reciprocal } \\
\text { \& Neariy }\end{array}$ & $\begin{array}{l}\% \text { Non- } \\
\text { Reciprocal: } \\
\text { Gave More }\end{array}$ & \begin{tabular}{|c|}
$\%$ Non- \\
Reciprocal \\
Received \\
More
\end{tabular} & $\begin{array}{l}\text { Weighted } \\
\text { Negativity }\end{array}$ & $\begin{array}{c}\text { Ave. } \\
\text { Freq. } \\
\text { Negative } \\
\text { Interaction }\end{array}$ & $\begin{array}{c}\text { People } \\
\text { Demand } \\
\text { Too } \\
\text { Much }\end{array}$ \\
\hline \multicolumn{15}{|l|}{ Antecedent Measures: } \\
\hline Age & - & - & $\cdot$ & - & -.043 n.s. & $\cdot$ & $-247^{\star}$ & - & - & - & - & .100 n.s. & - & - \\
\hline Number of Chronic Illnesses & - & - & .115 n.s. & - & - & - & - & - & - & - & - & - & - & - \\
\hline Level of Education & - & $.594^{* *}$ & - & - & - & - & - & - & - & $.312+$ & - & - & - & $\cdot$ \\
\hline Employment Status & - & $.286^{*}$ & - & - & - & - & - & - & - & - & $.183+$ & - & $.349^{m+4}$ & $.321^{1+10 *}$ \\
\hline Time Lived in Rural Areas & - & .151 n.s. & $412^{\text {ntwn }}$ & $-.195+$ & - & - & - & - & - & $.179+$ & - & - & - & - \\
\hline Public Sector Employment & - & - & - & - & - & - & - & - & $-.274^{* \star *}$ & $\cdot$ & - & - & - & - \\
\hline Neighborhood Heterogeneity & - & - & - & - & - & - & - & - & - & - & - & - & - & $-.213^{*}$ \\
\hline Size of Household & $.339^{\text {wa** }}$ & $.348^{* *}$ & $.202^{*}$ & - & $.348^{*+1+\infty}$ & $.350^{* *}$ & $.350^{* *}$ & $.411^{1 \ldots+1}$ & - & $245^{*}$ & - & $.373^{* * *}$ & $.370^{* *+}$ & - \\
\hline IMS Score & $-.365^{\text {ntmenten }}$ & $\cdot$ & - & $-.178+$ &. & - & - & $\cdot$ & $-.197^{*}$ & $\cdot$ & - & $.439^{m+m e n}$ & - & - \\
\hline Languages Spoken & - & - & - & .163 n.s. & - & - & - & - & - & - & - & - & - & - \\
\hline Time Lived in Neighborhood & - & - & $.106 \mathrm{~ns}$ & - & - & - & - & - & - & - & - & - & - & - \\
\hline Marital Status & - & - & - & - & - & - & - & - & - & $\cdot$ & - & $.357^{\star \star * \ldots+1}$ & - & - \\
\hline M-T Scale & - & $.572^{* *}$ & - & $.334^{*}$ & - & .153 n.s. & - & - & $\cdot$ & $-.389^{*}$ & $\cdot$ & - & $-.491^{* *}$ & - \\
\hline Neighborhood Activity & - & - & $.353^{\text {t+mk }}$ & - & - & - & $-201^{*}$ & $-.176^{*}$ & - & - & - & - & - & - \\
\hline Number of Children & - & - & - & $.305^{*}$ & - & $.280^{*}$ & - & - & - & - & - & $-.553^{*+1+1}$ & $-.420^{* *}$ & - \\
\hline SES & - & $-.491^{* *}$ & $\dot{-}$ & - & - & $\cdot$ & - & $222^{2 * t}$ & $.177+$ & - & - & - & - & - \\
\hline Fluency in Berber & $\cdot$ & $\cdot$ & $.289^{\circ *}$ & $\cdot$ & -.144 n.s. & $\cdot$ & $\cdot$ & $\cdot$ & $-.261^{10 *}$ & - & $\cdot$ & - & - & - \\
\hline Student & - & & & $\dot{.}$ & - & - & $\therefore$ & 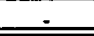 & - & & $458 \cdots$ & $-514^{*}$ & . & - \\
\hline
\end{tabular}


TABLE X

(Continued)

RESULTS OF REGRESSION ANALYSES OF ANTECEDENT, LIFE-EVENTS, AND NETWORK STRUCTURE MEASURES ON NETWORK FUNCTIONS

\begin{tabular}{|c|c|c|c|c|c|c|c|c|c|c|c|c|c|c|}
\hline Independent Variables & $\begin{array}{c}\text { Family } \\
\text { Satisfaction }\end{array}$ & $\begin{array}{c}\text { Satisfaction } \\
\text { with } \\
\text { Friends }\end{array}$ & $\begin{array}{c}\text { Importance } \\
\text { of } \\
\text { Neighbors }\end{array}$ & $\begin{array}{l}\text { Feeling } \\
\text { Under- } \\
\text { stood }\end{array}$ & $\begin{array}{l}\text { Average } \\
\text { Freq. of } \\
\text { Contact }\end{array}$ & \begin{tabular}{|c|} 
Total \\
Contact \\
Days \\
Month \\
\end{tabular} & $\begin{array}{l}\text { Average } \\
\text { Frequency } \\
\text { of Support }\end{array}$ & $\begin{array}{l}\text { Total } \\
\text { Support } \\
\text { Days/ } \\
\text { Month }\end{array}$ & $\begin{array}{l}\text { Percent } \\
\text { Reciprocal } \\
\text { \& Nearly }\end{array}$ & $\begin{array}{l}\text { \% Non- } \\
\text { Reciprocal: } \\
\text { Gave More }\end{array}$ & $\begin{array}{c}\% \text { Non- } \\
\text { Reciprocal: } \\
\text { Received } \\
\text { More }\end{array}$ & $\begin{array}{l}\text { Weighted } \\
\text { Negativity }\end{array}$ & $\begin{array}{l}\text { Ave. Freq. } \\
\text { Negative } \\
\text { Interaction }\end{array}$ & \begin{tabular}{|c|} 
People \\
Deman \\
too \\
Much
\end{tabular} \\
\hline \multicolumn{15}{|l|}{ Life-Events Measures: } \\
\hline Recent Neg. Change & 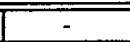 & . & $\overline{-}$ & $=$ & $\overline{-}$ & - & 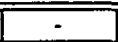 & - & $\overline{-}$ & - & - & $-.225^{+\hbar \hbar}$ & 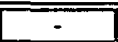 & 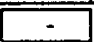 \\
\hline Remote Neg. Change & - & - & - & - & - & - & - & - & - & - & - & - & - & 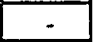 \\
\hline Recent Pos Change & .129 n.s. & - & $.166+$ & - & - & - & - & - & - & - & - & - & - & $-244^{\text {th }}$ \\
\hline Remote Pos. Change & $.298^{\circ \cdots}$ & $\cdot$ & $-.235^{*}$ & .147 n.s. & - & - & - & - & - & - & - & $-.297^{+\cdots+1}$ & $-.199^{*}$ & - \\
\hline \multicolumn{15}{|l|}{ Network Structure Measures: } \\
\hline Size Practical Subnetwork & - & 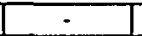 & - & $\cdot$ & - & $.207^{*}$ & - & $.197^{*}$ & - & - & - & - & - & - \\
\hline Size Emotional Subnetwork & - & $.247^{*}$ & - & $.323^{m+m}$ & - & - & - & - & - & - & - & - & - & - \\
\hline Size Information Subnetwork & - & - & - & - & $-.187+$ & - & $-.237^{*}$ & - & $.204^{*}$ & - & - & - & $-.178^{*}$ & - \\
\hline Size Mediation Subnetwork & $-.169+$ & $\cdot$ & - & - & $-.276^{\circ *}$ & - & $-.189+$ & - & $\cdot$ & $\therefore$ & - & - & 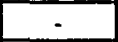 & - \\
\hline Size Patonage Subnetwork & - & - & - & - & - & - & - & - & - & - & - & - & - & - \\
\hline Size Negative Subnetwork & $.175+$ & - & - & $-197^{*}$ & - & - & - & - & - & $.173+$ & - & $253^{* t}$ & $226^{*}$ & $.189^{*}$ \\
\hline Density & $.190^{\circ}$ & - & $\dot{-}$ & - & $\cdot$ & - & $.375^{\text {t*t }}$ & $.365^{*}$ & - & $\cdot$ & - & $.292^{\cdots+1}$ & $\cdot$ & $\cdot$ \\
\hline Multiplexity & - & $\cdot$ & - & - & $.297^{* x+}$ & - & $.357^{\mathrm{mon}}$ & - & - & - & - & - & + & - \\
\hline Similarity & $\cdot$ & - & $.194^{*}$ & - & - & - & - & - & $.245^{* *}$ & - & - & - & - & - \\
\hline$\%$ Female & $.152+$ & - & - & - & - & $-.139+$ & $-.243^{* *}$ & $-.163+$ & $\cdot$ & - & - & $-168^{*}$ & - & $\cdot$ \\
\hline$\% \mathrm{Kin}$ & - & - & - & - & - & $-.293^{* * t}$ & $-.251+$ & $-.306^{\star *}$ & - & - & - & - & $.212^{\prime \prime}$ & - \\
\hline Dispersion & 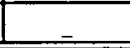 & - & - & - & $-258^{* *}$ & $-216^{* *}$ & - & - & - & - & - & $372^{\text {mant }}$ & - & - \\
\hline Multiple R & 0.64 & 0.5 & 0.61 & 0.56 & 0.57 & 0.72 & 0.63 & 0.7 & 0.49 & 0.47 & 0.48 & 0.77 & 0.62 & 0.52 \\
\hline$p$ & 0 & 0.0011 & 0 & 0.0001 & 0 & 0 & 0 & 0 & 0.0007 & 0.0007 & 0 & 0 & 0 & 0 \\
\hline
\end{tabular}

Nole. $+\rho<.10 .{ }^{*} \rho<.05 . " \rho<.01 . \cdots p<.001$ 
used in the previous regression analyses and were described in depth in the introduction to the results section.

\section{Global Measures of Network Function}

\section{Family Satisfaction}

Respondents' satisfaction with their families was high. On a scale from one (not at all satisfied) to four (completely satisfied), it averaged $3.55(S D=.65)$. Several factors combined to predict respondents' overall family satisfaction. Increasing household size was a strong predictor of increased satisfaction, while marital dissatisfaction was strongly associated with reduced overall satisfaction with the family. Remote positive changes were also significant predictors of increased satisfaction, while of the network structure variables, only density was predictive. Consistent with other researchers' findings that density is associated with enhanced well-being (e.g. Fischer, 1982), those respondents having more dense networks reported feeling more content with familial relationships than did those with less dense networks (Multiple $R=.64$ ).

\section{Satisfaction with Friends}

Respondents' satisfaction with their friends ranged from one (not at all satisfied) to four (completely satisfied) with a mean of $3.20(S D=$ $.84)$, slightly lower than that of family satisfaction. Of the antecedent variables, higher levels of education were strongly predictive of feeling 
satisfied with friends as was being employed, while living in larger households was predictive of lower levels of such satisfaction. At the same time, women with higher SES and more modern cultural orientations appeared to be less satisfied with friends than were their more traditional and lower SES counterparts. These results seemed inconsistent because I knew that higher education and employment were both positively associated with increases in SES and T-M scale scores (see

TABLE XI

CORRELATIONS BETWEEN EDUCATION LEVEL, EMPLOYMENT STATUS AND T-M AND SES

SCALE SCORES

\begin{tabular}{|lccc|}
\hline & $\begin{array}{c}\text { Level of } \\
\text { Education }\end{array}$ & $\begin{array}{c}\text { Employment } \\
\text { Status }\end{array}$ & $\begin{array}{c}\mathrm{T} \cdot \mathrm{M} \\
\text { Scale }\end{array}$ \\
Employment & .54 & & \\
Status & $p=.000$ & & \\
T-M Scale & .78 & .60 & \\
& $p=.000$ & $p=.000$ & \\
SES & .72 & .61 & .53 \\
& $p=.000$ & $p=.000$ & $p=.000$ \\
\hline
\end{tabular}

Table XI). I expected

that because of these

relationships, any of

these measures

remaining in the

equation should have

predicted satisfaction in the same direction rather than in both

directions (i.e.

positive and negative). For this reason, I decided to explore the relationships between these variables further. Consistent with expectations but inconsistent with the regression analysis, Figure 11 shows the relationship between traditionality-modernity and satisfaction with friends, grouped by SES. There is an interaction with SES, with 


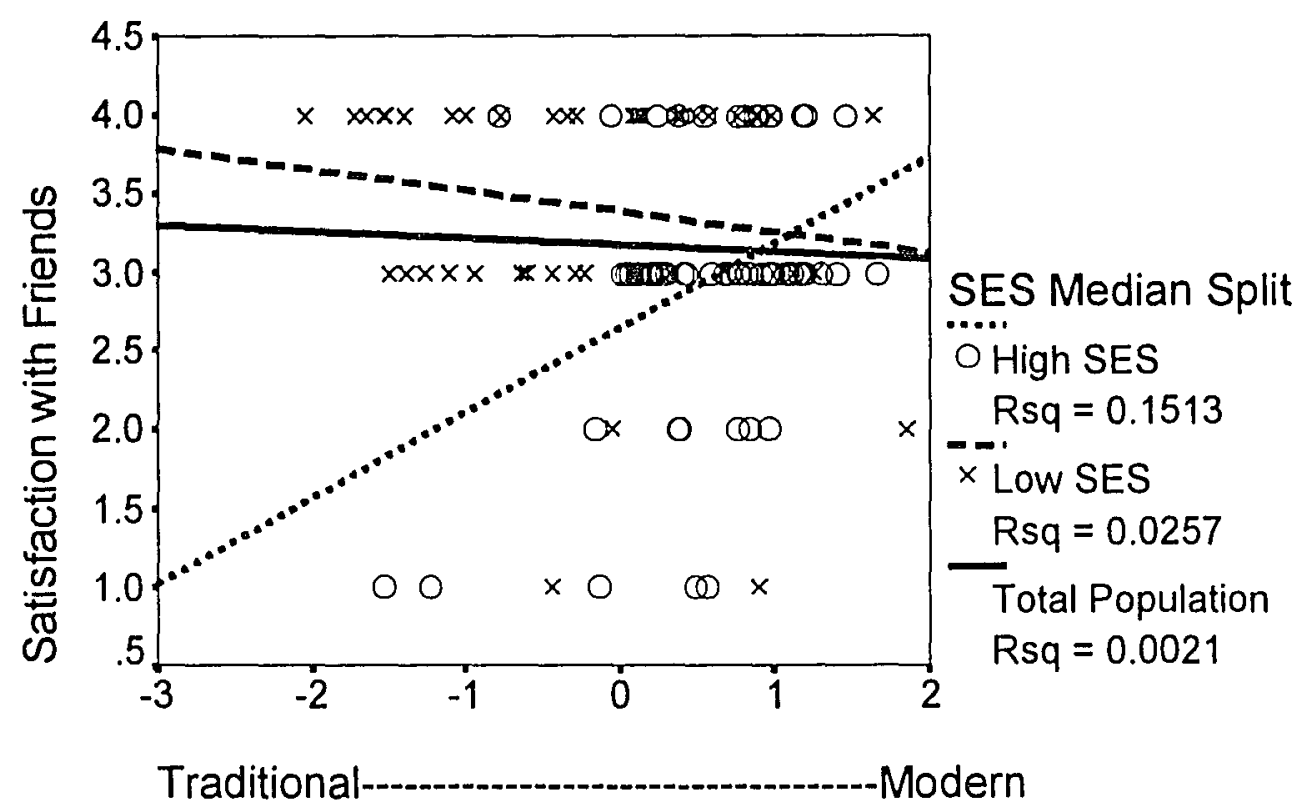

Figure 11. Relationship between satisfaction with friends and traditional vs. modern cultural orientation grouped by socio-economic status.

respondents of higher SES increasingly satisfied with friends as their T-M scale score increased, while lower SES respondents reported being slightly less satisfied with friends, the more modern their cultural orientation. Although it must be kept in mind that the distribution for satisfaction with friends is skewed and therefore these results are strongly influenced by a small number of respondents, this figure generally indicates that, after level of education and employment status have been entered into the equation, some of the remaining variance may have been explained by lower SES and more traditional women, who were less satisfied with their friends. 
Of the network structure measures, the size of the emotional subnetwork was the only predictor of greater satisfaction with friends. As expected, having more people who could provide emotional support was associated with increased satisfaction (Multiple $R=.50$ ).

\section{Importance of Neighbors}

Respondents' average rating of the importance of neighbors in their daily lives was low, $1.31(S D=.54)$, and ranged from one (not at all important) to three (very important). Because this distribution was so skewed, I recoded the variable for the regression analyses into just two levels (not at all important or somewhat/very important). Women who had lived in rural areas for longer periods were more likely to report that their neighbors were more important in their daily lives, as were women living in larger households and in areas with higher rates of neighborhood activity. However, those women who spoke Berber were more likely to report that neighbors were not as important as their nonBerber speaking counterparts, perhaps because of prejudice against Berbers, or ethnic and/or language differences that create barriers between Berbers and Arabs.

Of the life-events measures, remote positive change was associated with lower levels of importance ascribed to neighbors, while of the network structure measures, increasing similarity of network members 
to respondents was associated with feeling that neighbors were more important (Multiple $R=.61$ ).

\section{Feeling Understood by Network Members Deemed Most Important}

The average rating for feeling understood by the most important network members was $2.34(S D=.55)$ and ranged from one (rarely) to three (most of the time). Women scoring on the more modern end of the traditional-modern continuum reported feeling understood more frequently than their traditional counterparts, as did those women who had more children (young and adult). This latter result is interesting for it could be a result of respondents' feeling that their children understood them better than did other important members, and/or a function of the fact that in Morocco, women's identities are strongly tied to childbirth, and women who have given birth to more children may be more respected (particularly among more traditionally oriented people).

Consistent with expectations about the effects of emotional support and negative interactions, respondents who had larger emotional subnetworks also reported feeling understood more frequently than did women with smaller emotional subnetworks, while increasing size of the negative subnetwork was associated with feeling understood less frequently by those people deemed most important. 


\section{Frequency of Contact with Network Members}

\section{Average Frequency of Contact with Network Members Each Month}

The average frequency of contact across respondents' networks was 13.17 days/month $(S D=4.30)$ and ranged from 5.35 to 30.00 . That is, respondents saw each member of their network, on average, 13.17 days each month. Of the antecedent factors, size of the household was the only significant predictor of average frequency of contact across respondents' social networks. Increasing household size was associated with increased frequencies of contact.

Three of the structure variables were predictive of average frequency of contact in the network. Increasing multiplexity was a strong predictor of greater average levels of contact with network members. Conversely, as the size of the mediation subnetwork increased, the average frequency of contact in the network decreased, perhaps because mediators are most often older members with high prestige with whom respondents interact rarely. Although I did not have a measure of the status of network members, I was able to test the hypothesis that mediators were more likely to be older than other network members. The mean age for mediators was 44.01 years $(S . D .=$ 15.28), fully ten years older than the average age of other network members $(34.67$ years, S.D. $=17.06)$, a statistically significant difference $F$ $(1,1825)=120.85, p<.0000$. Lastly, as would be expected, increased 
physical distance between respondents and their network members (dispersion) was associated with reduced levels of contact.

\section{Total Frequency of Contact with Network Members Each Month}

The total contact with all members during the average month was 234.38 days/month $(S D=85.57)$ and ranged from 76.50 to 494.50 . That is, on average, respondents had contact with 7.8 of their network members each day.

Several of the antecedent measures were significantly associated with increased total contacts with network members. Household size and number of children were important positive predictors of total frequency of contact as was increasing size in the practical support subnetwork. Conversely, increased dispersion was again associated with lower levels of contact as were increased proportions of kin in the network.

\section{Frequency of Support Received from Network Members}

\section{Average Frequency of Support Received Each Month}

The mean of the average frequency of support received across respondents' networks from all network members was 9.69 days/month $(S D=4.74)$ and ranged from 1.76 to 22.36 days. That is, on average, respondents received support 9.69 days/month from each network member. Of the antecedent variables, increasing age was associated with the receipt of less help, perhaps because women need less help as their 
children grow older. In addition, increases in neighborhood activity level and Berber-speaking ability were also associated with lower support levels. Again, either language and ethnic differences or discrimination against ethnic Berbers may account for their receipt of less help. Not surprisingly, larger household sizes were associated with increased frequencies of help, most likely because of both the increased need for support associated with maintaining larger households and the expanded availability of potential helpers.

Interestingly, although it seemed reasonable to expect that the amount of support received by respondents would change as a function of recent life events, particularly those which were negative, none of the recent life events variables were predictive of the average amount of support received from network members. However, several of the network structure variables were associated with differing levels of provided support. Multiplexity and density were strong positive predictors of the average frequency of help received each month, while larger information support subnetworks were associated with reduced levels of support. This may be because those from whom one can ask informational help are more educated or have higher prestige, and are for these reasons less likely to provide the ongoing day-to-day support assessed by this measure. In addition, an unexpected result was that greater proportions of women in networks were associated with lower 
average frequencies of received support. The latter result contradicted the hypothesis that increasing proportions of women in networks would be associated with corresponding increases in received support.

\section{Total Frequency of Support Received Each Month}

The average of the total frequency of help received each month was 168.51 days/month $(S D=95.61)$ and ranged from 34.25 to 486.50 . That is, respondents received support from approximately 5.62 network members each day on average.

Consistent with results from the analysis of the average frequency of support received, the number of people living in the houschold was positively associated with increased support, while increased levels of neighborhood activity were associated with less support. This latter finding is curious. Increases in neighborhood activity may mean that more goods and services are available, therefore reducing the need for support, or it is possible that such activity levels make it more difficult for network members to provide the support in some way-e.g., more difficult to find and/or use transportation. Higher SES was associated with more received support as were larger practical support subnetworks. Additionally, increasing density was predictive of increased support while having more kin in the network was predictive of reduced help and support. The latter result was unexpected because it contradicted the hypothesis that kin would provide more support than 
non-kin. In addition, because networks with large proportions of kin are more dense $(r=.70, p<.000)$ and increasing density was predictive of increased support, I decided to further explore these relationships.

Figure 12 shows the relationship between percentage of kin in networks and total frequency of support received, grouped by SES. I used SES as a grouping variable because it was predictive of support levels and I suspected that respondents with higher socio-economic statuses might have access to paid-for support that lower SES respondents could not afford (e.g., maids, gardeners, guardians, drivers). The figure provides tentative support for this hypothesis, indicating that for respondents in the highest SES level, support declines as the

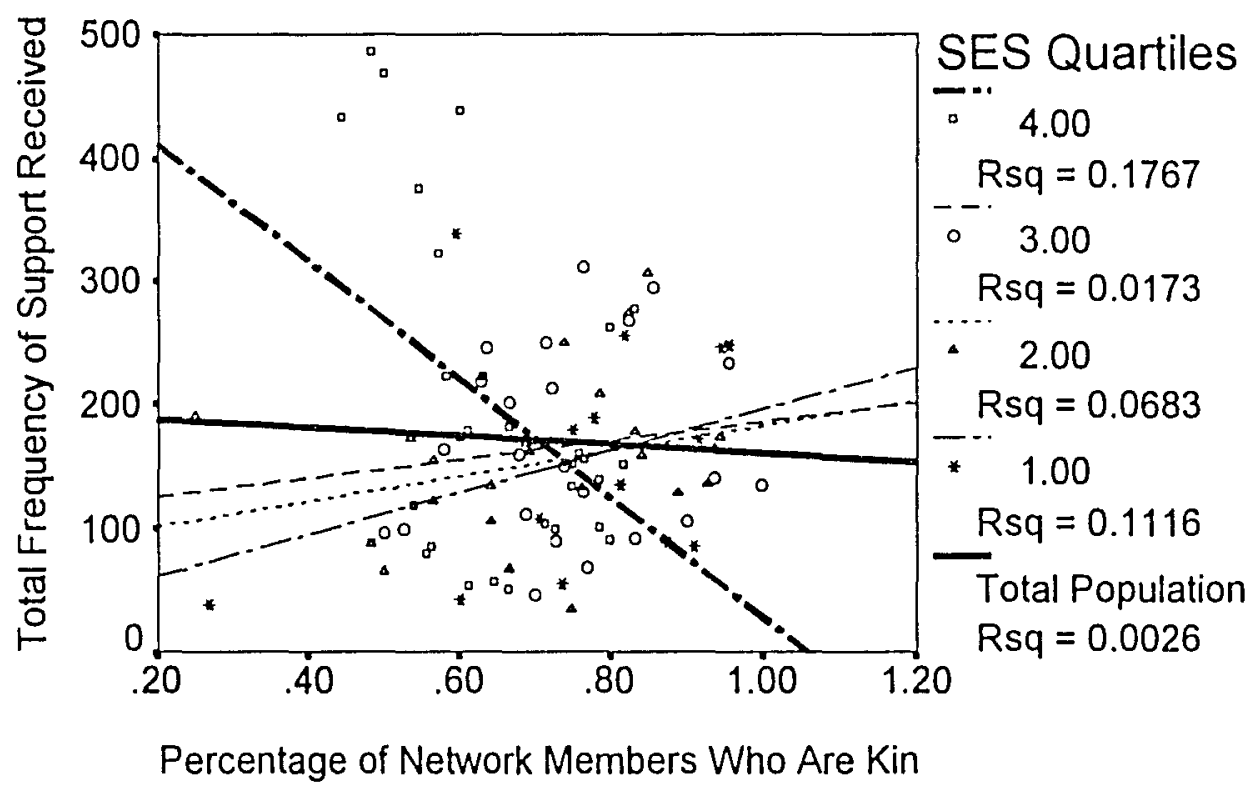

Figure 12. Total frequency of support received as a function of $\%$ kin in networks, grouped by respondents' SES levels. 
percentage of network members that are kin increases. At the same time however, members of this group with low proportions of kin have the highest levels of support received of all respondents. These differences may reflect either beliefs on the part of kin that support is not needed for kin who are well-off, that such support is supplied by paid providers, or a combination of the two. Interestingly and consistent with the hypothesis that kin would provide more aid, support for the other SES groups increased slightly with larger proportions of kin in networks. The Multiple $R$ for the regression analysis was .70.

\section{Reciprocity}

\section{Percentage of Reciprocal and Nearly Reciprocal Relationships}

The average percentage of reciprocal and nearly reciprocal relationships in networks was $59 \%(S D=22)$ and ranged from no reciprocal relationships to $100 \%$ reciprocity. The most important predictor of the percentage of reciprocal and nearly reciprocal relationships in networks was employment in the public sector. Those women who worked in this sector were more likely to have fewer reciprocal relationships with network members than were homemakers and women who worked in the private or semi-private sectors. This result seemed unusual, so I explored the data to see if I could find the reason(s) for this finding. I wanted to determine whether or not the gender composition in networks of women who worked in the public 
sector was different from those who worked elsewhere or who were not employed. I felt this might be a reasonable place to begin because Belle (1987) has noted the propensity of Western women to provide different types of social support when compared to their male counterparts. I hypothesized that such a difference might influence respondents' assessments of reciprocity. In fact, women who worked in the public sector had somewhat lower proportions of female network members $(r=$ $-.26, p<.01)$, so I hypothesized that if respondents had more reciprocal relationships with women than with men, then lower proportions of women in networks would decrease the average level of reciprocity. However, chi-square analyses of reciprocity by sex for all network members $\chi^{2}(1, N=1665)=1.82, p=n$.s., as well as only for those women who worked in the public sector $\chi^{2}(1, N=1166)=.89, p=$ n.s., failed to confirm this explanation. At this time, I can provide no other explanations of the lack of reciprocity present in the networks of women working in the public sector.

Two other antecedent measures were predictive of reciprocity in networks. Women who spoke Berber had networks with lower average reciprocity levels than did non-Berber speaking women, as did those women who were dissatisfied with their marriages. Of the network structure variables, women with larger information support subnetworks also had proportionately more reciprocal relationships as did women 
who's networks were, on average, more similar to them (Multiple $R=.49$ ).

I was curious about the failure of respondents' age to predict proportions of reciprocal relationships because there have been some suggestions that people eliminate non-reciprocal relationships as they grow older--at least until old age where needs are expected to increase. In addition, it seemed reasonable to expect that reciprocity would change across the life cycle, particularly as children grow older. For these reasons I decided to explore the lack of relationship between age and reciprocity. The zero-order correlation between age and reciprocity was consistent with the regression analysis and showed no relationship between the variables $(r=.02, p=n$.s.). In order to determine if reciprocity was affected by child-rearing responsibilities, I performed an ANOVA with age as a function of reciprocity and whether network members were children or not.

Table XII indicates that there were main effects for both children and age on reciprocity, as well as a children-by-age interaction, while Figure 13 shows the main effects of, and interactions between, these variables. There was a clear difference in reciprocity for respondents' relationships with their children when compared to their relationships with other network members. Relationships with network members other than children were very nearly reciprocal across the range of ages (1002/1425 or $70 \%$ were reciprocal or nearly so). 
TABLE XII

\section{RECPROCITY AS A FUNCTION OF RESPONDENT'S AGE AND WHETHER OR NOT NETWORK MEMBER IS HER CHUD}

\begin{tabular}{||l|c|c|c|c|c||}
\hline Source of Variation & $\begin{array}{c}\text { Sum of } \\
\text { Squares }\end{array}$ & $d f$ & $\begin{array}{c}\text { Mean } \\
\text { Square }\end{array}$ & $F$ & $p$ \\
\hline Within + Residual & 497.40 & 1655 & .30 & & \\
\hline Member is Child & 11.15 & 1 & 11.15 & 37.09 & .000 \\
\hline Respondent's Age & 6.31 & 4 & 1.58 & 5.25 & .000 \\
\hline Child x R's Age & 11.99 & 4 & 3.00 & 9.97 & .000 \\
\hline (Mlodel) & 79.25 & 9 & 8.81 & 29.30 & .000 \\
\hline (Total) & 576.65 & 1664 & .35 & & \\
\hline
\end{tabular}

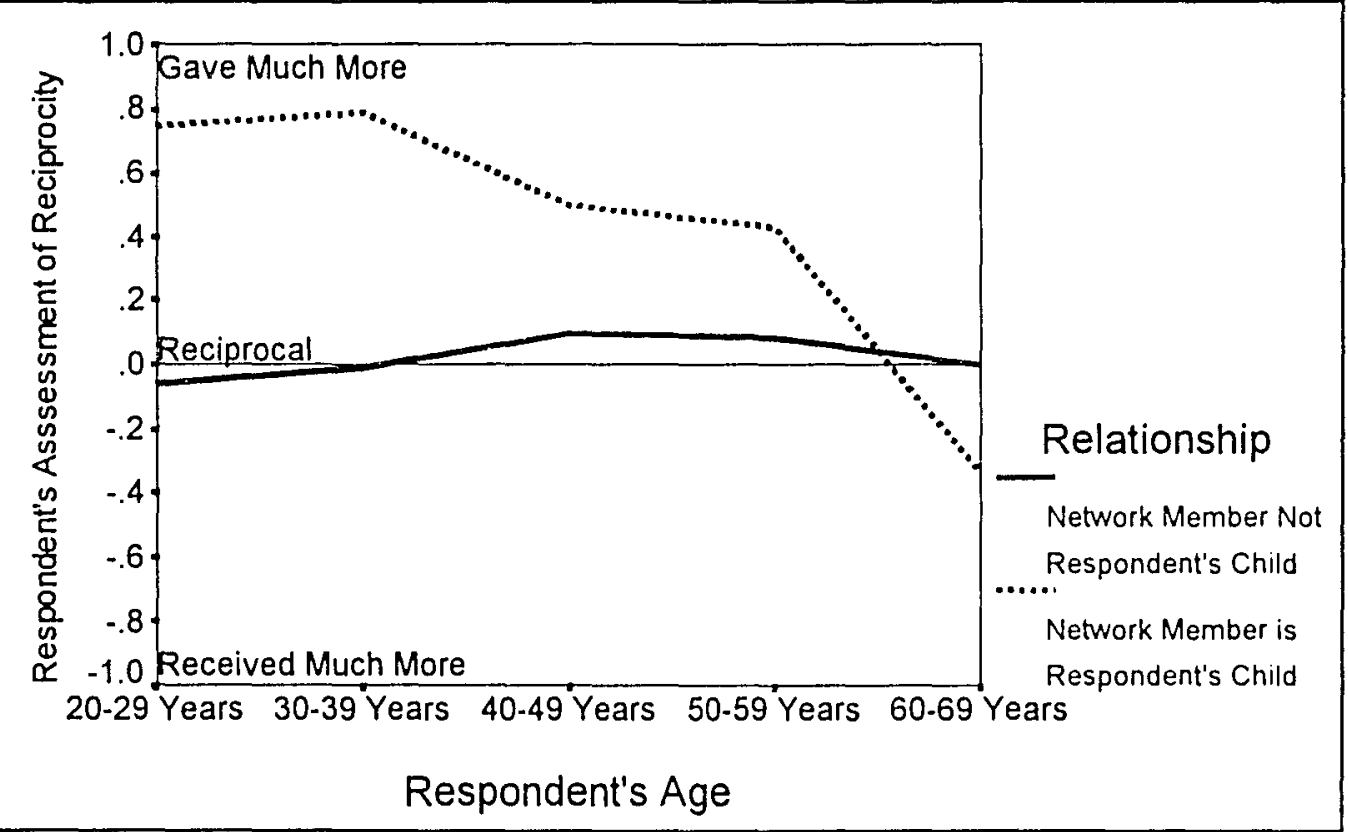

Figure 13. Respondent's assessment of reciprocity with network members as a function of her age, and grouped by whether or not member is her child. 
Conversely, for relationships with children, the youngest respondents were most likely to give much more than they received and the oldest respondents were more likely to receive much more than they gave. It is noteworthy that relationships with children appear to move from giving much more than receiving to receiving much more than giving as age increases, with virtually no age range characterized by reciprocity (only $70 / 240$ or $29 \%$ of relationships with children were reciprocal). Age 60 appears to have been the approximate cross-over point from giving more to receiving more. For women under age forty, relationships with children were the least reciprocal.

\section{Percentage of Relationships in which the Respondent Gave Much More}

\section{than She Received}

The average percentage of relationships where respondents gave much more than they received was $20 \%(S D=16 \%)$ and ranged from $0 \%$ to $80 \%$. The T-M factor was the most important predictor of these types of relationships, with more modern women reporting fewer nonreciprocal relationships of this type. Conversely, women living in households with more people reported many more of these nonreciprocal relationships, most likely because other household members are more likely to be children (Multiple $R=.47$ ). 
Percentage of Relationships in which the Respondent Received Much More than She Gave

The average percentage of relationships in which respondents received much more than they gave to network members was $12 \%(S D=$ $13 \%)$ and ranged from $0 \%$ to $59 \%$. The only predictor of this type of nonreciprocal relationship was student status. Those respondents who were students were much more likely to receive more help than they gave, than were non-students (Nultiple $R=.48$ ).

\section{Negative Interactions}

\section{Weighted Negativity in the Network}

The average negativity of respondents' networks was $5.15(S D=$ 10.03) and ranged from 0 to 90 . As with previous skewed variables, I logtransformed the weighted-negativity measure before using it in the regression analyses. Within this analysis, several of the antecedents were strongly predictive of average negativity in networks. Increasing numbers of people living in respondents' homes were associated with greater negativity, as was being married and marital dissaltisfaction. Conversely, having more children and being a student were associated with less negativity.

For the life-events variables, increasing negative change during the six months prior to the interview and increasing positive change cluring the period six to twelve months prior 10 participation were both 
associated with lower average negativity. Perhaps negative life events were associated with reduced negativity because network members moderated their negative behavior knowing the respondent was under stress. At the same time, it is possible that the same positive life events which affected respondents also affected their network members positively, increasing positive feelings and reducing the likelihood of negative interactions.

A number of the network structure variables were also predictive of weighted negativity as well. Not surprisingly, increasing sizes of the negative interaction subnetwork were associated with increased average negativity, as were increased density and dispersion. Conversely, having proportionately more women in the network was associated with lower levels of negativity. This latter result suggests that one possible explanation for the positive effects of social support provided by women may be actually a function of reduced negative interactions (Multiple $R=$ $.77)$.

\section{Average Frequency of Negative Interactions}

The mean of the average frequency of negative interactions in respondents' networks was $2.82(S D=2.39)$ and the range was from .02 to 10.07. That is, respondents had negative interactions with each network member, on average, 2.82 days out of each month. 
Several of the antecedent factors were predictive of the average frequency of negative interactions within respondents' networks. Employed women reported more negative interactions in their networks than did women who did not work outside the home, perhaps because of the role conflicts associated with being a working woman in a society where women were until fairly recently secluded within their homes. As was true of average negativity in the network, increasing numbers of people living in one household were associated with increased frequencies of negative interactions, while at the same time, women who were more modern in cultural orientation reported less negativity in their networks, as did women who had more children.

I was curious about the relationship between the T-M scale, employment status, and negative interactions, because I knew that more modern women were more likely to be employed, yet employment predicted increases in negative interactions while modernity predicted decreases in the same measure.

Figure 14 shows the relationship between these variables. Employed women clearly had more frequent negative interactions, but these interactions decreased with increasingly modern cultural orientations. However, most interestingly, the decrease was far greater for employed women than it was for women who did not work outside the home. Perhaps, because of role strain, negative interactions are 


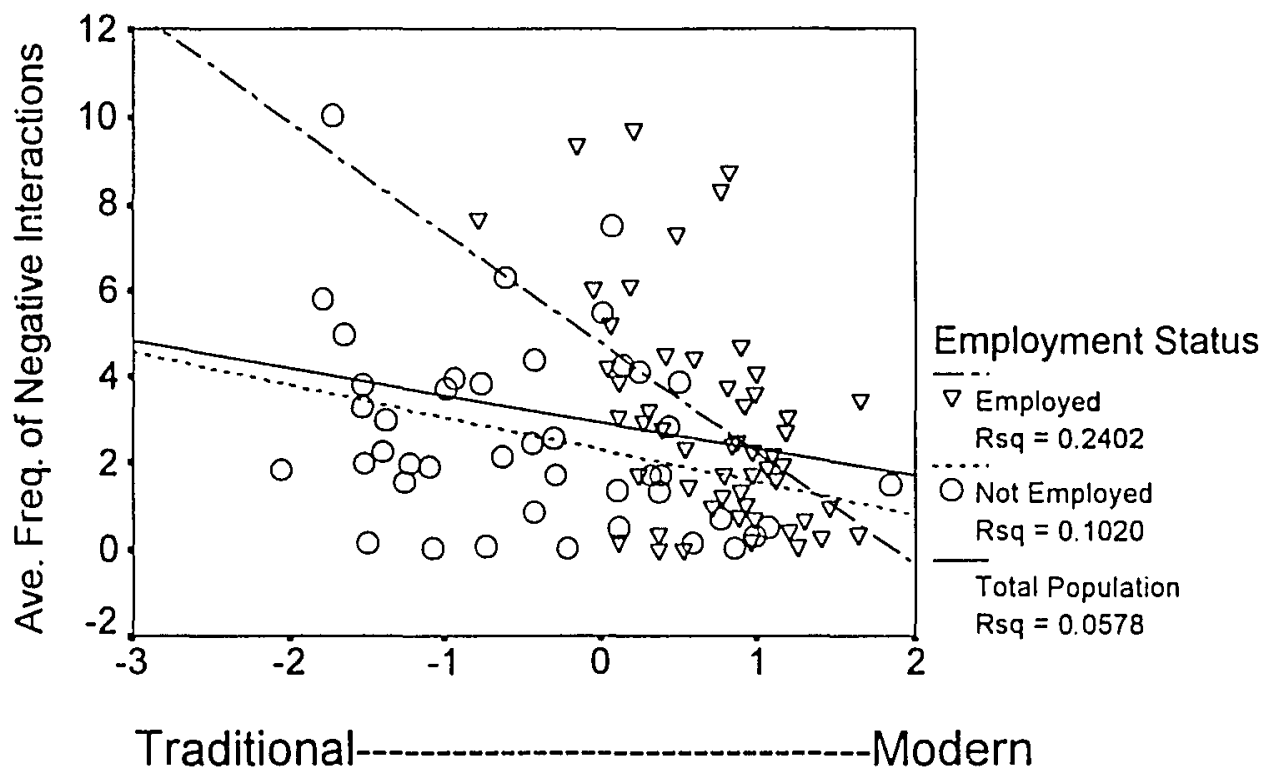

Figure 14. Relationship between traditionality-modernity and average frequency of negative interactions grouped by employment status.

highest among those women who are employed but whose cultural orientation is neither particularly modern nor particularly traditional. It is possible that those women who are most modern in orientation feel less strain because they are personally comfortable with their role as employed women and/or because their friends and family share their beliefs and therefore support their employment status.

Of the recent life-events measures, remote positive change was associated with reduced average frequencies of negative interactions, consistent with the influence of positive life events on the weighted negativity measure. Of the network structure measures, several were predictive of negative interactions as well. Those women who had larger 
information support subnetworks reported fewer negative interactions while those with larger negative interaction subnetworks had more negative encounters with network members. Consistent with expectations, those women who had larger proportions of kin in their networks reported increased levels of negative interactions (Multiple $R=$ $.62)$.

\section{Respondent Feels that Others Demand Too Much}

On average, respondents reported feeling that the people in their lives frequently demanded too much of them. The mean rating was 3.15 $(S D=.89)$ and ranged one (never) to four (often). Employed women were more likely to feel that others demanded too much than were other respondents, perhaps because of the role strain previously hypothesized or perhaps the "supermom" phenomenon (women who work but who are expected to be responsible for most or all of housework and childcare) exists in Morocco as well as in the West. My observations during the time I spent in Morocco would suggest that a combination of these factors would provide the best explanation. In addition, respondents who lived in more heterogenous areas reported fewer demands from their network members, while positive changes during the six months prior to the interview were associated with feeling that others were less demanding and increasing sizes of the negative interaction subnetwork were associated with feelings of increased demands (Multiple $R=.52$ ). 


\section{Joint Analyses of All independent Variables With Brief Symptoms Inventory Subscales}

This section describes the results of a series of regression analyses of all antecedent, life-events and network measures on psychological distress dependent measures (subscales derived from the Brief Symptoms Inventory [BSI]). For these analyses, I used stepwise set regression techniques (entry criterion $=.05$, removal criterion $=.10$ ) because I was more interested in determining strong predictors of wellbeing than in describing the relationships as inclusively as possible as had been true with the previous analyses of network structures and functions. In addition, I have reported results with the subnetwork sizes (as opposed to the global network size measure) as independent variables in this section for three reasons. First, because they are specific indicators of the availability of network members who provide particular types of support, they yield more information about the support process. Second, because respondents' networks were so large, I expected that there would be no effect associated with global network size because such effects are normally found in small networks. Lastly, in order to test this last assumption, I performed the same analyses with global network size included in the equation and subnetwork sizes eliminated, and the global size measure was not predictive of any of the well-being variables. 


\section{General Severity Index}

The General Severity Index provides the most sensitive index of a respondent's psychological distress level, because it combines both information about the intensity as well as the number of symptoms in one measure (Derogatis, 1982). The average GSI scale score for the sample was $.92(S D=.63)$ and ranged from .09 to 3.15 . The mean of the GSI scores corresponds to an American-normed, female, non-patient tscore of 65 . In comparing the Moroccan sample to the provisional criterion of BSI "caseness" (that is, the score beyond which a person is no longer considered within the normal range) in American non-patient samples, the group mean exceeds the required $t$-score of 63 . In fact, only $47.5 \%$ of the sample fall below the case criterion. This contrast between the groups indicates that this sample of normally-functioning women either experienced more and/or were more willing to report the psychological distress symptoms measured by the BSI than were American women, or that cultural factors produced differences in the interpretation of, or responses to, the BSI items.

\section{Predicting the General Severity Index}

Table XIII shows the results of the regression analysis of all antecedent, life-events and network measures on the GSI. Consistent with the model proposed in the introduction, the first set entered contained the antecedent variables, the second the life-events variables, 
TABLE XIII

RESULTS OF REGRESSION ANALYSIS OF ANTECEDENT, LIFE-EVENTS, NETWORK STRUCTURE AND NETWORK FUNCTION MEASURES ON THE GSI

\begin{tabular}{|c|c|c|}
\hline Antecedent Measures & Beta & $p$ \\
\hline Works in Public Sector & 0.294 & .0014 \\
\hline IMS Score & 0.369 & . 0000 \\
\hline SES & -0.444 & .0000 \\
\hline Smokes & .167 & .0513 \\
\hline \multicolumn{3}{|l|}{ Network Structure Measures } \\
\hline $\begin{array}{l}\text { Average Similarity of Network } \\
\text { Members }\end{array}$ & -.177 & .0310 \\
\hline \multicolumn{3}{|l|}{ Network Function Measures } \\
\hline $\begin{array}{l}\text { Feels that Others Demand Too } \\
\text { Mluch }\end{array}$ & .264 & .0022 \\
\hline Multiple R & .70 & .0000 \\
\hline
\end{tabular}

followed by network structure measures and finally network function variables. These same regression techniques were used in the remainder of analyses reported in this section.

Three of the antecedent variables were statistically significant predictors of the GSI. Working in the public sector was associated with more psychological distress, as was increasing marital dissatisfaction (as measured by the IMS). At the same time, increasing SES was associated with better psychological well-being. None of the life-events variables 
were predictive of GSI level, but two of the network measures played significant roles predicting well-being.

Of the structural measures only average similarity of network members to respondents was predictive, and it was increasing similarity, as expected, that was associated with enhanced well-being. With respect to network function and consistent with theoretical predictions, those respondents who felt that their network members demanded too much of them reported more and more severe symptoms of psychological problems that did those women who did not feel that way (Multiple $R=$ $.70)$.

\section{Positive Symptom Distress Index}

The PSDI is a measure of the intensity of symptoms reported, irrespective of the number of those symptoms (Derogatis, 1982). The average scaled score for the PSDI was $0.03(S D=0.01)$ and ranged from

0.02 to 0.07 . The average PSDI score is extremely low, corresponding to a $t$-score of 28 . This indicates that although respondents reported being bothered by symptoms, the intensity of their distress was very low in comparison to American norms. There are several potential explanations for these differences: (a) Moroccan women may be more aware of their symptoms than American women, therefore reporting low-level symptoms that American women do not report, (b) they may be more willing to report symptoms in general, (c) they may minimize the 
distress they feel and therefore report being less bothered than are American women with the same symptoms, or (d) they may understand the questions differently than their American counterparts. In any case, although GSI scores were high when compared to American norms, PSDI scores were extremely low in comparison.

\section{Predicting the Positive Symptom Distress Index}

As can be seen from Table XIV, two of the antecedent measures were significant predictors of PSDI scores. Increasing marital dissatisfaction was strongly associated with higher PSDI scores while being married, in general, was associated with lower levels of psychological distress. Consistent with the hypothesized relationship between practical support and well-being, increased size of the practical subnetwork was predictive of better psychological functioning. For network functions, hypotheses that increasing frequency of contact and greater proportions of reciprocal relationships would be associated with improved well-being were confirmed. Contradicting the hypothesized relationship that increased support would be associated with enhanced well-being, it appeared that increased frequencies of received support were associated with more psychological symptoms. However, I believed a more plausible explanation was that this result was a function of the collinearity between the frequency of contact and frequency of support measures $(r=.70, p<.000)$. If this were true, the residual, after variance 
TABLE XIV

RESULTS OF REGRESSION ANALYSIS OF ANTECEDENT, LIFE-EVENTS, NETWORK STRUCTURE AND NETWORK FUNCTION MEASURES ON PSDI

\begin{tabular}{||c|c|c||}
\hline Antecedent Measures & \multicolumn{1}{c|}{ Beta } & $p$ \\
\hline IMS Score & .366 & .000 \\
\hline Marital Status & -.267 & .002 \\
\hline SES & -.168 & .054 \\
\hline Network Structure Measures & -.207 & .020 \\
\hline Size of the Practical Subnetwork & \\
\hline Network Function Measures & -.402 & .001 \\
\hline Average Frequency of Contact & .288 & .018 \\
\hline Average Frequency of Support &. .302 & .000 \\
\hline \% of Reciprocal or Nearly & .68 & .000 \\
\hline Multiple R
\end{tabular}

associated with frequency of contact was removed, might account for the fact that this measure was predictive in the opposite direction from that of the expected result. In order to test this hypothesis, I computed the same regression analysis twice, each time including only one of the collinear variables. When the equation included the frequency of contact measure only, the above results were repeated with the exception of the frequency of support variable. However, when the variables were reversed, the frequency of support measure was no longer predictive of PSDI, indicating that the average frequency of contact was the stronger 
predictor of the two. The final multiple $R$ for the results reported in Table XIV was .68.

\section{Positive Symptom Total}

The PST represents a count of the number of reported psychological distress symptoms, and is not weighed by the severity of those symptoms. The average PST of the sample was $26.14(S D=12.61)$ and ranged from 2 to 48 . The average of the PST scores corresponds to a t-score of 63 when compared to the normed population of American female non-patients, indicating that on average this sample of Moroccan women reported more symptoms than do American women. In fact, only $10.8 \%$ of the Moroccan sample had symptoms at the level of or below the $50^{\text {th }}$ percentile of the American group. Therefore, in combination with the GSI and PSDI results, these results indicate that these particular Moroccan women reported, on average, many more symptoms of psychological distress than their American counterparts, but that the severity of their distress with respect to those symptoms was much lower than would be expected based on American norms. Because the women interviewed in Morocco appeared to represent a group of women who function normally in everyday life, these results indicate the need to develop norms appropriate to this culture before conclusions about caseness can be drawn. 


\section{Predicting the Positive Symptom Total}

Table XV represents the final results of regressions of all variables on the PST scale. As was true of the other BSI measures, marital dissatisfaction was a strong predictor of increased psychopathology, and working in the public sector was also associated with more reported symptoms. Conversely, increasing SES was predictive of fewer psychological problems.

Two of the network variables were predictive of PST. As hypothesized, having more people available for emotional support was associated with reduced numbers of symptoms, while fecling that

\section{TABLE XV}

RESULTS OF REGRESSION ANALYSIS OF ANTECEDENT, LIFE-EVENTS, NETWORK STRUCTURE AND NETWORK FUNCTION MEASURES ON PST

\begin{tabular}{||c|c|c||}
\hline \hline Antecedent Measures & \multicolumn{1}{c|}{ Beta } & $p$ \\
\hline Works in Public Sector & .252 & .0109 \\
\hline IMS Score & .385 & .0001 \\
\hline SES & -.361 & .0003 \\
\hline Network Structure Measures & \multicolumn{2}{|c||}{} \\
\hline $\begin{array}{l}\text { Size of the Emotional } \\
\text { Support Subnetwork }\end{array}$ & -.228 & .0125 \\
\hline $\begin{array}{c}\text { Network Function Measures } \\
\text { Feels that Others Demand } \\
\text { Too Much }\end{array}$ & .258 & .0067 \\
\hline Nultiple R & .60 & .0000 \\
\hline
\end{tabular}


network members demand too much was associated with increased pathology (Multiple $R=.60$ ).

Joint Analyses of All Independent Variables With Physical IIIness Measures Number of Recent IIInesses (Six Months Prior to Interview)

The average number of medical problems reported during the six months before the interview was $11.75(S D=6.59)$ and ranged from 0 to 29. As can be seen in Table XVI, of the antecedent measures, only frequency of exercise was a statistically significant predictor of number of reported illnesses, with women who exercised more reporting fewer illnesses than women who exercised rarely or not at all. Consistent with the relationship hypothesized between life events and illness, recent

TABLE XVI

RESULTS OF REGRESSION ANALYSIS OF ANTECEDENT, LIFE-EVENTS, NETWORK STRUCTURE AND NETWORK FUNCTION MEASURES ON NUMBER OF RECENT ILLNESSES

\begin{tabular}{||c|c|c|}
\hline Antecedent Measures & \multicolumn{1}{|c|}{ Beta } \\
\hline Age & .175 & .0609 \\
\hline Frequency of Exercise & -.351 & .0003 \\
\hline Life-Events Measures \\
\hline \begin{tabular}{c|c||} 
Recent Negative Change \\
Network Function Measures
\end{tabular} \\
\hline $\begin{array}{l}\text { Feels That Others Demand } \\
\text { Too Mluch }\end{array}$ & .184 & .0462 \\
\hline \begin{tabular}{c} 
Multiple R \\
\hline
\end{tabular} & .56 & .0000 \\
\hline
\end{tabular}


negative life events were positively associated with the number of reported illnesses during the same period.

Although none of the dimensions of network structure were predictive of number of illnesses during this period, the perception that others in the network demanded too much was positively associated with the total number of illnesses reported by respondents (Multiple $R=$ $.56)$.

\section{IIIness-Severity Index (Six Months Prior to Interview)}

The average of the reported illnesses weighted by severity was $430.83(S D=274.60)$ and ranged from 0 to 1350.00 . In order to make these statistics more comprehensible, I created a list of common illnesses, which, when compiled for a period of six months, would approximately equal the mean. If a respondent reported having each one of these health problems at least one time during the six months prior to the interview, she would have had an ISI score of 426: (a) knee pain, (b) migraine, (c) muscle tension, (d) painful intestinal gas, (e) sore throat, (f) vaginal infection, (g) varicose veins, (h) high cholesterol, (i) the flu, (j) constipation, and (k) toothache. Those women who scored highest on this scale either had to have had many illnesses during the period, or very serious illnesses. 


\section{Predicting the Illness-Severity Index}

As can be seen in Table XVII, antecedent variables as well as one of the negative change variables were predictive of the ISI. Increasing age was associated with having had more illnesses, while increasing exercise was associated with fewer illnesses. At the same time, the only other variable which remained in the equation was recent negative change, which was associated with higher ISI scores, as predicted. None of the network structure or function variables were predictive of this physical health measure (Multiple $R=.53$ ).

TABLE XVII

RESULTS OF REGRESSION ANALYSIS OF ANTECEDENT, LIFE-EVENTS, NETWORK STRUCTURE AND NETWORK FUNCTION MEASURES ON RECENT ILLNESS-SEVERTTY INDEX

\begin{tabular}{||c|c|c||}
\hline \hline Control Variables & \multicolumn{1}{c|}{ Beta } \\
\hline Age & .243 & .0112 \\
\hline Frequency of Exercise & -.291 & .0026 \\
\hline Life-Events Variables & \\
\hline Recent Negative Change & .286 & .0035 \\
\hline Nultiple R & .53 & .0000 \\
\hline
\end{tabular}

Joint Regression Analyses of All Independent Variables On Well-Being Measures, Sample Split for Respondents' Level of Stress

In order to determine if social network structures and/or functions had differential associations for women who had experienced 
high or low stress levels (i.e. to test the "buffering hypothesis"), I computed the same stepwise set regressions of antecedent and network measures on health and psychological functioning variables, split for respondents with high or low stress levels. To compute these analyses, I began by determining the median stress level for each six-month period (the most recent six months prior to the interview is labeled "Recent," while the period six to twelve months prior to participation is labeled "Remote"). I used this median (of the negative change LES measures) to split the sample, and then computed the same stepwise regressions using the same sets as I had previously used (with the exception of the life-events measures) for both high and low levels of stress reported during the two six-month periods prior to the interviews. Associations between social network, social support and well-being measures under only high-stress conditions would provide evidence for the hypothesis that social support is important only as a "buffer" during times of high stress (i.e. many negative events), while associations between the same support and well-being measures for periods of high and low stress would indicate that social support is generally beneficial.

Regressions of Antecedent and Network Measures on Health and Psychological Dependent Measures for Recent High and Low Stress Levels

Table XVIII summarizes regression analyses of all antecedent, lifeevents, and network variables on well-being measures for those women 


\section{TABLE XVIII}

RESULTS OF REGRESSION ANALYSES OF ANTECEDENT, NETWORK STRUCTURE AND NETWORK FUNCTION MEASURES ON WELL-BEING WITH SAMPLE SPLIT FOR RESPONDENTS' RECENT STRESS LEVEL

\begin{tabular}{|c|c|c|c|c|c|c|c|c|c|c|}
\hline \multirow[b]{2}{*}{ Stress Level } & \multicolumn{2}{|c|}{ GSI } & \multicolumn{2}{|c|}{ PSDI } & \multicolumn{2}{|c|}{ PST } & \multicolumn{2}{|c|}{ Number of Recent linesses } & \multicolumn{2}{|c|}{ Illness-Severily Index } \\
\hline & High & Low & High & Low & High & Low & High & Low & High & Low \\
\hline \multicolumn{11}{|l|}{ Antecedent Measures } \\
\hline Age & - & - & - & - & - & - & - & $62 \sigma^{* \cdots}$ & - & $.524^{\cdots}$ \\
\hline Employment Status & - & - & . & - & - & $.510^{*}$ & - & & - & - \\
\hline Level of Education & - & - & - & - & - & - & - & $-349^{* *}$ & - & - \\
\hline Frequency of Exercise & - & - & - & - & - & - & -318 & $-.523^{\cdots \cdots}$ & - & $-.427 \cdots$ \\
\hline Neighborhood Heierogenerty & - & - & - & - & - & - & - & - & - & $.241+$ \\
\hline IMS Score & $344^{*}$ & $363^{* *}$ & $318^{\circ *}$ & - & $364^{* *}$ & - & - & - & - & - \\
\hline Number of Languages Spoken & - & - & $-289^{\circ}$ & - & - & - & - & - & - & - \\
\hline Length of Time Lrved in Neighborhood & - & - & $288^{\circ}$ & - & - & $-407^{\circ}$ & - & - & - & - \\
\hline Married & $-377^{*}$ & - & $-245+$ & - & - & - & - & - & - & - \\
\hline T-M Scale & - & $-464^{\cdots \cdots}$ & - & I. & - & $-.728^{\cdots \cdots}$ & - & - & - & - \\
\hline Nerghborhood Activity & - & $412^{* *}$ & - & - & - & - & - & & - & \\
\hline Number of Childen & - & 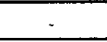 & - & - & - & - & - & $-591 \cdots$ & - & - \\
\hline \multicolumn{11}{|l|}{ Petwork Structure Measures } \\
\hline$\%$ Female & - & $-212 n s$ & - & - & $\overline{-1}$ & $-\overline{-}$ & - & $\overline{-}$ & - & $\overline{-}$ \\
\hline Size of the Patronage Subnetwork & - & - & - & - & - & - & - & - & - & $-285^{\circ}$ \\
\hline Size of the Ilegative Subnetwork & - & . & - & - & - & 262 & - & - & - & - \\
\hline Similanity & - & 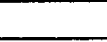 & - & $249+$ & - & - & - & - & - & - \\
\hline \multicolumn{11}{|l|}{ Network Function Measures } \\
\hline $\begin{array}{l}\text { \% Reciprocal or Nearly Reciprocal } \\
\text { Relationships }\end{array}$ & - & - & - & $456^{* *}$ & - & - & - & - & - & - \\
\hline Neighbors are Important & - & - & - & - & - & 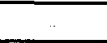 & - & - & 290 & - \\
\hline Feels that Important Members Understand Her & - & & - & - & . & $-287^{\circ}$ & $\cdots$ & - & - & - \\
\hline Feels that Others Demand Too Much & & $278^{\circ}$ & 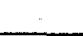 & $312^{\circ}$ & 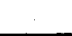 & & & $253^{\circ}$ & - & - \\
\hline Multiple R & 54 & 71 & 66 & 65 & 36 & 73 & 32 & 79 & 29 & 70 \\
\hline$p$ & 0005 & 0001 & 0001 & 0002 & 0118 & 0001 & $0296 \mathrm{~ns}$ & 0000 & $0482 \mathrm{~ns}$ & 0001 \\
\hline
\end{tabular}


reporting both high and low stress levels during the six months just prior to their participation in the research project.

\section{General Severity Index}

High Stress Level. As can be seen in Table XVIII the only variables predictive of the GSI scores of respondents with high-stress levels during this period were marital status and marital satisfaction. Consistent with expectations, being married appears to have protected women from the effects of stressful conditions--GSI scores for married women were lower than for widowed, separated and divorced women. Conversely, women who were dissatisfied with their husbands were more psychologically distressed than women with happier marriages (Multiple $R=.54$ ).

Low Stress Level. As can be seen in the summary table, several of the measures were predictive of GSI scores among those respondents reporting low levels of stress during the period six months prior to the interview. Marital dissatisfaction was associated with increased psychological distress as was increased neighborhood activity level. More modern women on the T-M scale had fewer psychological problems than did their more traditional counterparts, and lastly, those women who felt that other network members demanded too much from them were more psychologically distressed than women who did not feel that way (Multiple $R=.71$ ). 


\section{Positive Symptom Distress Index}

High Stress Level. Only antecedent measures were predictive of PSDI (the intensity measure) for women experiencing high stress levels during this period. As with the GSI, being married was associated with lower PSDI scores, while speaking more languages was also predictive of lower PSDI levels. Conversely, increasing marital dissatisfaction was predictive of more severe psychological distress as were increases in the length of time respondents had lived in the neighborhood (Multiple $R=$ $.66)$.

Low Stress Level. For the low-stress group, several network measures were predictive of PSDI scores. Increases in the average similarity of network members to respondents were associated with less distress, as were increases in the proportion of reciprocal relationships in networks. Conversely, respondents who felt that others demanded too much of them reported increased psychological distress (Multiple $R=$ $.65)$.

\section{Positive Symptom Total}

High Stress Level. As can be seen from the table, the only predictor of PST for women who had experienced high stress during this period was marital dissatisfaction, which was associated with increased numbers of symptoms of psychological distress. (Multiple $R=.36$ ). 
Low Stress Level. The table also shows that both antecedent and network member variables were predictive of PST in the low-stress level group. Employed respondents reported more psychological symptoms than did women who did not work outside the home, with more modern women reporting far fewer of the same problems. In addition, women who had lived in the same neighborhood for longer periods reported fewer symptoms than newer residents. Of the network measures, size of the negative interaction subnetwork was associated with more psychological symptoms while women who felt that the most important members of their networks understood them reported fewer of the same symptoms (Multiple $R=.73$ ).

\section{Number of Reported IIInesses during the Six-Months Prior to the Interview}

High Stress Level. The only measure that was predictive of the number of reported illnesses for the high-stress group was frequency of exercise, with those respondents reporting more frequent exercise schedules having fewer illnesses during the period (Multiple $R=.32$ ).

Low Stress Level. Several of the antecedent measures were strong predictors of illness in the low-stress group. Increasing age was associated with more illnesses, while higher levels of education, greater frequencies of exercise and having had more children were associated with fewer illnesses. Of the network measures, only feeling that network members demand too much was predictive of number of illnesses, with 
those women who felt that way reporting more illnesses than those who did not (Multiple $R=.79$ ).

\section{Illness-Severity Index: Six Months Prior to Interview}

High Stress Level. Table XVIII shows that the only predictor of illnesses weighted by their severity for women who had experienced high stress levels, was the importance of neighbors in daily life (Multiple $R=.29)$

Low Stress Level. As can be seen in Table XVIII, increasing age was associated with increases in the Illness-Severity Index for the low-stress group as were increases in neighborhood heterogeneity. As was true of the other regressions for the health measures, increased frequency of exercise was associated with fewer and less severe illnesses (Multiple $R=$ $.70)$

Regressions of Antecedent, Life-Events and Network Measures on Health and Psychological Dependent Measures for

\section{Remote High and Low Stress Levels}

This section presents results of stepwise sets regression analyses for all antecedent, life-events and network measures on both physical health and psychological well-being outcomes, for respondents who experienced either high or low stress levels during the six to twelve months prior to being interviewed for this project. Table XIX provides a summary of all results presented in this segment of the Results section. 


\section{TABLE XIX}

RESULTS OF REGRESSION ANALYSES OF ANTECEDENT, NETWORK STRUCTURE AND NETWORK FUNCTION MEASURES ON WELL-BEING, SAMPLE SPLIT FOR RESPONDENTS' REMOTE LEVEL OF STRESS

\begin{tabular}{|c|c|c|c|c|c|c|c|c|c|c|}
\hline & \multicolumn{2}{|c|}{ GSI } & \multicolumn{2}{|c|}{ PSDI } & \multicolumn{2}{|c|}{ PST } & \multicolumn{2}{|c|}{ Number of Recent lithesses } & \multicolumn{2}{|c|}{ lllness-Severity Index } \\
\hline Stress Level & High & Low & High & LOW & High & Low & High & LOW & High & Low \\
\hline \multicolumn{11}{|l|}{ Antecedent Measures } \\
\hline Age & - & - & - & - & $=$ & - & - & $.444^{\circ \cdots}$ & - & $.449^{\mathrm{ma}}$ \\
\hline Frequency of Exercise & - & - & - & - & - & - & $-366^{* *}$ & $-.502^{*-*}$ & $-.280^{\circ}$ & $-.506^{\circ \cdots}$ \\
\hline Works in Public Seclor & - & 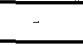 & - & - & $\dot{-}$ & - & - & - & - & - \\
\hline lins Score & $492^{\cdots *}$ & $.379^{* *}$ & + & $290^{\circ}$ & $398^{*}$ & $305^{\circ}$ & - & - & - & - \\
\hline Number of Languages Spoken & - & - & - & - & - & $-.382^{\circ}$ & - & - & - & - \\
\hline Married & $-196 n s$ & - & $-433^{\circ}$ & - & - & - & $=$ & - & $-.278^{*}$ & - \\
\hline SES & - & $-348^{\circ *}$ & - & - & - & - & - & - & - & - \\
\hline Smokes & - & - & - & $235+$ & - & - & - & - & - & - \\
\hline \multicolumn{11}{|l|}{ Network Siruclure Measures } \\
\hline Density & $=$ & $\overline{-}$ & - & - & - & - & $\overline{-}$ & $-361^{*}$ & - & $-.342^{-\infty}$ \\
\hline Size Emolional Subnetwork & - & - & - & - & $-411^{\circ-}$ & - & - & - & - & - \\
\hline Size Patronage Subnetwork & $-.380^{n}$ & - & - & - & - & - & $-325^{\circ}$ & - & $-.334^{\circ}$ & - \\
\hline Similanty & - & - & - & $-148 n s$ & 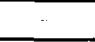 & - & - & - & - & - \\
\hline$\%$ fenale & $-290^{\circ}$ & - & - & - & - & - & - & - & - & - \\
\hline \multicolumn{11}{|l|}{ Network Funclion Measules } \\
\hline \% Reciprocal or Wearly Reciprocal & - & $\overline{-}$ & $-347^{\circ+}$ & $392^{\circ}$ & $\overline{-}$ & - & $=$ & - & $\overline{-}$ & - \\
\hline Satısfaction with Family & - & - & $-283^{\circ}$ & - & - & - & - & - & - & - \\
\hline Salisfaction with Friends & - & - & - & - & - & - & - & $262^{\circ}$ & - & - \\
\hline Feels Others Undersland Het & - & 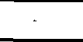 & - & - & . & $-398^{* *}$ & - & - & 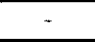 & - \\
\hline Ave Freq liegatwe Interactions & - & $322^{\circ}$ & & & & $\cdot$ & 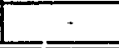 & - & - & - \\
\hline MultipleR & 62 & 64 & 65 & 71 & 51 & 62 & 51 & 70 & 57 & 64 \\
\hline 0 & 0008 & 0001 & 0005 & 00000 & 0,028 & 0002 & 0026 & 0000 & 0014 & 0001 \\
\hline
\end{tabular}

Nole. $+p<.10 . " p<.05 . " p<.01 . " * * p<.001$ 


\section{General Severity Index}

High Stress Level. As can be seen in Table XIX, increasing marital dissatisfaction was associated with increased psychological distress for the high stress group, while as expected, having proportionately more women in networks was associated with enhanced well-being. Unexpectedly, increases in the size of the patronage subnetwork were also associated with better psychological outcomes (Multiple $R=.62$ ).

Low Stress Level. Increased marital dissatisfaction was again predictive of more psychological problems in the low stress group, while higher SES women were less distressed. Of the network measures, more frequent negative interactions were predictive of reduced well-being (Multiple $R=.64$ ).

\section{Positive Symptom Distress Index}

High Stress Level. Being married was associated with lower levels of psychological distress among respondents with high stress levels during the period, as were feeling satisfied with family relations and increasing proportions of reciprocal relationships in networks (Multiple $R=.60)$.

Low Stress Level. Increasing marital dissatisfaction was again associated with more psychological distress for the low-stress group, while as expected, increasing numbers of reciprocal relationships were associated with enhanced psychological well-being (Multiple $R=.71$ ). 


\section{Positive Symptom Total}

High Stress Laval. As can be seen from the table, marital dissatisfaction was associated with increased numbers of psychological symptoms for the high-stress group, while consistent with the hypothesized relationship between emotional support and well-being, increasing sizes of the emotional subnetwork were predictive of reduced numbers of symptoms (Multiple $R=.51$ ).

Low Stress Level. Respondents' dissatisfaction with their husbands was again associated with increased numbers of psychological symptoms while women who spoke more languages reported fewer such problems. In addition, those women who felt that their most important network members understood them reported fewer symptoms than did those who did not feel understood (Multiple $R=.62$ ).

Number of Reported IIInesses during the Six-Months Prior to the Interview

High Stress Level. Increased frequencies of exercise were associated with reduced numbers of illnesses among respondents who experienced high stress levels during the period. In addition, and contrary to the hypothesized relationship between patronage relationships and well-being, increasing sizes of the patronage subnetwork were associated with fewer reported illnesses (Multiple $R=$ $.51)$ 
Low Stress Level. For those women with low stress levels during the period six to twelve months prior to being interviewed, both antecedent and network measures predicted frequency of illness. Increasing age was predictive of more illnesses, while those who exercised again reported lower illness levels. For network measures, increased density was associated with fewer illnesses, while unexpectedly, feeling satisfied with friends was associated with more health problems (Multiple $R=.70$ ).

\section{IIIness-Severity Index: Six Months Prior to Interview}

High Stress Level. As can be seen in the summary table, increased exercise and being married were associated with enhanced health outcomes for the high-stress group. In addition, larger patronage subnetwork sizes were again predictive of enhanced physical well-being (Multiple $R=.57$ ).

Low Stress Level. Among respondents with low stress levels, older women reported more illnesses of greater severity while those women who exercised reported fewer such problems. As expected, increasing density in networks was associated with better health outcomes (Multiple $R=.64$ ).

\section{Summary of Analyses}

Table XX represents a summary of all predictors from regression analyses of antecedent, life events, and network structure and function 
TABLE XX

\section{SUMMARY OF ANTECEDENT AND NETWORK VARIABLES PREDICTTVE OF PSYCHOLOGICAL ADJUSTMENT OR PHYSICAL HEALTH IN ALL REGRESSION ANALYSES}

\begin{tabular}{|c|c|c|c|c|c|c|c|c|c|c|c|c|c|c|c|c|c|c|c|}
\hline \multirow{3}{*}{$\begin{array}{c}\text { Predictive Variables in Sections } \\
\text { Corresponding to the Proposed } \\
\text { Model: } \\
\text { Antecedents } \\
\text { Life-Events } \\
\text { Network Structures } \\
\text { Network Functions }\end{array}$} & \multicolumn{4}{|c|}{ GSI } & \multicolumn{3}{|c|}{ PSDI } & \multicolumn{4}{|c|}{ PST } & \multicolumn{4}{|c|}{$\begin{array}{l}\text { Number of } \\
\text { Illnesses }\end{array}$} & \multicolumn{4}{|c|}{$\begin{array}{l}\text { Illness/ } \\
\text { Severity } \\
\text { Index }\end{array}$} \\
\hline & \multicolumn{3}{|c|}{0.6} & $6 \cdot 12$ & \multicolumn{2}{|r|}{0.6} & $6 \cdot 12$ & \multicolumn{3}{|c|}{0.6} & $6 \cdot 12$ & \multicolumn{3}{|c|}{$0 \cdot 6$} & $6 \cdot 12$ & \multicolumn{3}{|c|}{0.6} & $6 \cdot 12$ \\
\hline & $G$ & 11] & $\begin{array}{lll}\mathrm{L} & \mathrm{H} \\
\end{array}$ & 15 & \begin{tabular}{|l|l|l}
$G$ & 1 \\
\end{tabular} & \begin{tabular}{l|l}
11 & $\mathrm{~L}$ \\
\end{tabular} & 115 & G & 11 & & i. 1 & $G$ & \begin{tabular}{l|l}
11 & 1 \\
\end{tabular} & $\begin{array}{lll}1 . & 11 \\
\end{array}$ & $\begin{array}{ll}11 & 1 \\
\end{array}$ & $\mathrm{G}$ & \begin{tabular}{|l|l|}
111 \\
\end{tabular} & $\mathbf{L}$ & H] \\
\hline Age & & & & & & & & & & & & & & + & + & + & & + & + \\
\hline Level of Education & & & & & & & & & & & & & & - & & & & & \\
\hline Exercise Frequency & & & & & & & & & & 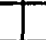 & & - & $-1-$ & - & -1 & - & & - & - \\
\hline Employed & & & & & & & & & & + & & & & & & & & & \\
\hline Works in Public Sector & + & & & & & & & + & & & & & & & & & & & \\
\hline IMIS score & + & + & ++ & + & + & + & + & + & + & + & +1 & & & & & & & & \\
\hline Number of Languages Spoken & & & & & & - & & & & & -1 & & & & & & & & \\
\hline Length of Time Lived in Neighborhood & & & & & & + & & & & - & & & & & & & & & \\
\hline Married & & - & & & -1 & & - & & & . & & & & & & & & & - \\
\hline$T$-M Scale & & & - & & & & & & & - & & & & & & & & & \\
\hline Neighborhood Activity Level & & & + & & & & & & & & & & & & & & & & \\
\hline Number of Children & & & & & & & & & & & & & & - & & & & & \\
\hline SES & & & & $\square$ & & & & -1 & & & & & & & & & & & \\
\hline Recent Viegative Change & & & & & & & & & & & & & & & & & & & \\
\hline Size-Practical Subnetwork & & & & & - & & & 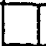 & & & & & & & & & & & \\
\hline Size-Emotional Subnetwork & & & & & & & & - & & - & - & & & & & & & & \\
\hline Size-Patronage Subnetwork & & & - & & & & & & & & & & & - & & & & - & - \\
\hline Size-Negative Subnetwork & & & & & & & & & & + & & & & & & & & & \\
\hline Density & & & & & & & & & & & & & & & & & & & \\
\hline Similarity & - & & & & & & & & & & & & & & & & & & \\
\hline ZFemale & & & & 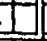 & & & & & & & & & & & & & & & \\
\hline Average Frequency of Contact & & & & & - & & & & & & & & & & & & & & \\
\hline Average Frequency of Support & & & & & + & & & & & & & & & & & & & & \\
\hline X Reciprocal or Nearly & & & & & - & - & - & & & & & & & & & & & & \\
\hline Satisfied with Family & & & & & & & - & & & & & & & & & & & & \\
\hline Satisfled with Friends & & & & & & & & & & & & & & & + & & & & \\
\hline Importance of Neighbors & & & & & & & & & & & & & & & & & + & & \\
\hline Average Freq of Negative Interactions & & & & + & & & & & & & & & & & & & & & \\
\hline Feels that Others Demand Too Much & t & & + & & & + & & + & & & & + & & + & & & & & \\
\hline $\begin{array}{l}\text { Feels that Most Important Network } \\
\text { Members Understand Her }\end{array}$ & & & & & & & & & & - & & & & & & & & & \\
\hline
\end{tabular}

Note. In the table, 0-6 and 6-12 refer to time periods for which stress levels were measured (six months prior to interview and six to twelve months prior to interiew, respectively). "G" refers to global analyses including all respondents, "H" refers to respondents with high stress levels during the specified period, and "L" refers to respondents with low stress levels during the period. Plus signs indicate a positive association between the variables while ninus signs indicate a negative relationship. 
measures on physical health and psychological adjustment, including those analyses with the sample split for high- and low-stress levels. A number of patterns among the variables can be clearly seen, and the results of this part of the study can be summarized as follows:

Antecedent Measures. A number of the antecedent measures were important predictors of physical health and/or psychological distress. Of these factors, the most consistent were age, frequency of exercise, marital satisfaction, marital status and SES.

Life-Events Measures. In general, the life-events measures were not predictive of well-being with the exception of the recent negative change measure (negative life-events during the six months prior to the interview).

Network Structure Measures. A number of network structures were predictive of well-being, although their predictive ability was not consistent across analyses, with the exception of the size of the patronage subnetwork. This subnetwork was predictive of the greatest number of wellbeing measures, but was associated with improved wellbeing rather than the expected reduced well-being. The majority of the predictive structural measures were subnetwork sizes, while a number of theoretically important 
structure measures (i.e. multiplexity, dispersion, global network size, and percentage of kin) were not predictive of any of the outcome measures. Theoretically important measures of network structure that were predictive (i.e. density, similarity and percentage female) did not have consistent associations with well-being across analyses. Network Function Measures. Like the network structure measures, measures of network function were not consistent predictors of well-being across analyses, with one exception. Feeling that network members demanded too much was predictive of both physical health and psychological distress. Other function measures were most often predictive of only one or two of the outcome measures, although reciprocity was consistently predictive of the intensity of psychological symptoms.

\section{Buffering vs. Direct Effect of Social Support Hypotheses.}

With respect to the buffering and direct-effect hypotheses, the results of these analyses suggest that different structural and functional aspects of networks may best be understood as having differential associations with health outcomes under different stress levels. That is, some measures were predictive in low-stress conditions, others during periods of 
high stress, while a few were predictive of well-being outcomes for both high and low stress groups. I believe that these results indicate that some network characteristics should be classified as buffers while others function irrespective of stress level, the results providing support for both hypotheses about the workings of the social support process. Additionally, it appears that some of the antecedent characteristics share these same qualities, only predictive of well-being at particular levels of stress.

\section{Review of Hypotheses}

In this section I review the results associated with the hypotheses outlined in the Introduction. More extensive explanations for these results appear in the Discussion section.

\section{Hypothesis \#1: Network Size: Global and Subnetworks}

Increasing network size will be associated with enhanced well being to the point of diminishing returns (between five and ten persons). In particular, larger numbers of persons available to provide practical-and emotional-support (practical and emotional subnetworks) will be most beneficial. Additionally, larger numbers of people with whom the respondents had negative interactions (negative subnetwork) will be associated with diminished well-being. 
There was no evidence of an association between global network size and well-being. However, all networks sampled exceeded the number at which diminishing returns would be expected to begin. There was tentative support for the positive associations between well-being and the practical and emotional support subnetworks as well as the negative association with the negative interaction subnetwork.

\section{Hypothesis \#2: Multiplexity}

Increased multiplexity will be associated with greater wellbeing.

There was no evidence of an association between multiplexity and any of the well-being measures.

\section{Hypothesis \#3: Similarity}

The more similar respondents perceive their network members to be (to themselves) the greater the respondent's well-being will be.

Tentative support was found for an association between increased similarity of network members and enhanced well-being, although similarity was predictive of only one of the main psychological measures. Hypothesis \#4: Percentage Female

The more women there are in a network (proportionally) the greater the amount of recenved support will be. Additionally, 
the larger the percentage of females, the greater the wellbeing of the respondent.

Unexpectedly, having proportionally more women in networks was associated with reduced average frequencies of support provided by network members to respondents, disconfirming the first part of this hypothesis. However, there was tentative evidence of an association between the proportions of women in the network and enhanced wellbeing, but the association held true in only one of the subsidiary analyses and therefore should be considered questionable at this time.

\section{Hypothesis \#5: Percentage of Kin}

Larger percentages of kin in networks will be associated with increased social support and negative relationships. In addition, there will be an interaction between support received from kin, negative relationships with kin, and the well-being measures. Greater amounts of support will enhance wellbeing while increases in negative relationships will be associated with reduced well-being.

Having proportionally more kin in networks was associated with lower frequencies of contact with respondents as well as reduced total support, contrary to the first part of hypothesis \#5, although having more kin in networks was associated with increased average frequencies of negative interactions, as hypothesized. With respect to kin and well- 
being, there was no evidence found of any association between the two measures, although this may be a function of the consistently high numbers of kin present in respondents' networks.

\section{Hypothesis \#6: Dispersion}

Networks with greater levels of dispersion will be associated with less frequent contact and help, and therefore, lowered well-being scores.

Respondents with more dispersed networks did report reduced frequencies of contact with their network members although contrary to expectations, dispersion was not associated with reduced levels of support. It is possible that for such dispersed networks, support was provided during most contacts rather than only from a smaller subset of contacts, therefore producing this somewhat unusual result. Contrary to the second part of the hypothesis, dispersion itself was found to have no association with respondents' well-being.

\section{Hypothesis \#7: Contact with Network Members}

Increased contact with network members will be associated with enhanced well being.

Tentative support for this hypothesis was found, with increased frequencies of contact associated with reduced intensities of reported psychological symptoms. 


\section{Hypothesis \#8: Received Support}

Increases in the average amount of support received will be associated with greater well-being.

No evidence was found to support the hypothesis that increased support was associated with enhanced well-being. In fact, average frequency of support was predictive of increased intensity of psychological symptoms, although I believe this result was a statistical artifact.

Hypothesis \#9: Reciprocity

The greater the percentages of reciprocal rela:ionships in networks the greater the well-being of respondents. At the same time, increases in non-reciprocal relationships will be associated with reduced well-being scores.

Increased proportions of reciprocal relationships were consistently associated with reduced intensities of reported psychological symptoms, providing support for the first part of the hypothesis. However, neither type of non-reciprocal relationship (i.e. giving more than receiving nor receiving more than giving) was associated with well-being, suggesting that the presence of many reciprocal relationships is more important than the presence of non-reciprocal ties. 


\section{Hypothesis \#10: Satisfaction with Family and Friends}

Satisfaction with family as well as with friends will improve well-being, and family satisfaction will be the more important of the two predictors.

Neither of these measures were important or consistent predictors of well-being. Satisfaction with family was associated with reduced psychological symptom levels in one of the subsidiary analyses while satisfaction with friends was predictive of increased numbers of physical illnesses in another subsidiary analyses. The lack of consistency across analyses and between these results suggests that they may be due to chance fluctuations. At this point, there is little evidence supporting this hypothesis.

\section{Hypothesis \#11: Feeling that Others Understand}

Those respondents who feel that the most important people in their networks understand them will have enhanced wellbeing when compared to those who do not feel that way.

Tentative support was provided for this hypothesis. Those respondents who were in the low stress groups and reported feeling understood by their most important network members also reported fewer psychological symptoms than did those who did not feel that way. 


\section{Hypothesis \#12: Negative Interactions}

Larger average frequencies of negative interaction will be associated with reduced well-being.

In general, there was little support for this hypothesis across

analyses. Average frequency of negative interaction was associated with reduced well-being in only one of the subsidiary analyses, suggesting that among this population it is not the important predictor it was expected to be.

Hypothesis \#13: Feeling that Others in the Network Demand Too Much

Those women who report that their network members demand too much of them will have reduced well-being when compared to women who do not feel this way.

This hypothesis was well substantiated by the analyses. Women whe felt that others demanded too much of them consistently reported both more (and more intense) psychological symptoms as well as increased physical health problems. It is possible, however, that women with such emotional and/or physical problems might have been more likely to feel overburdened by the demands of their network members. Hypothesis \#14: Patronage Relationships

Patronage relationships will be non-reciprocal, and increasing proportions of such relations in networks will be associated with decreased well-being. 
Relationships with patrons were more likely to be characterized by respondents as relationships where they received more than they gave when compared to relationships with other network members, but the majority of relationships with patrons were unexpectedly perceived as reciprocal in nature. These results both provide support for the first hypothesis and contradict it. The second part of the hypothesis was not supported. In fact, in one of the most interesting findings of this study, patronage relationships were associated with enhanced well-being, particularly for those women who experienced high stress during the periods measured.

\section{Hypothesis \#15: Mediation}

Increased numbers of available mediators will be associated with enhanced well-being.

No support for this hypothesis was found among the analyses of this study. The possible reasons for the lack of support for this hypothesis are discussed in the Discussion section. 


\section{DISCUSSION}

\section{Patterns in the Prediction of Well-Being}

Within the range of variation in this sample of Moroccan women, network structure and network function were not consistent predictors of well-being. At the same time, it is nevertheless true that the majority of associations I reported were supportive of the hypotheses applicable to the interactions between social support and well-being. It is the lack of ability of most of these measures to consistently predict well-being across the range of dependent measures which indicates that the initial conceptualization of the social support process within this cultural setting needs to be revised.

I believe that the best possible explanation for these results, and revision of the model, may be found in the application of Hobfall's "conservation of resources (COR) theory" (Hobfall, 1989; Hobfall \& Lilly, 1993; Hobfoll, Lilly, \& Jackson, 1992). In addition, this theory can also be used to account for the patterns found in the predictive abilities of some of the antecedent measures included in the model. Although COR theory involves a complex set of principles and corollaries, it relies on a few basic assumptions which I have abstracted (primarily) from Hobfall and Lilly (1993, pp. 129-132) and summarized below: 
(a) Resources are those things that "individuals strive to obtain, retain, and protect", and such resources are essential tools for living.

(b) Hobfall and Lilly argue that these resources include "objects" such as a home, a car etc. as well as "conditions" such as having a good marriage, tenure or seniority on the job, "personal characteristics" such as self-esteem, problemsolving abilities and social competence, and "energies" such having money and credit to "fuel" a particular lifestyle. (c) People have basic needs for these resources in the same sense suggested by Maslow in his argument for deficiencybased motivation in human behavior (1968). He argued that individuals become motivated only when they experience shortages, and that until basic requirements are met, motivational attention cannot be focused on higher-level needs. Hobfall (1989) has suggested that people have basic needs for social support resources. It follows from this premise that psychological stress occurs when these resources are either threatened with loss, actually lost, or when individuals invest in the development of such resources but fail to achieve the gains that they originally sought. 
(d) Both acute and chronic stress conditions result in resource loss, although acute stressors result in more rapid resource loss while chronic stressors deplete resources more slowly. Such losses to the pool of resources produce additional stress. In the wake of a stressful event, well-being should then be predictable as a function of the initial condition of the resource pool and the magnitude of the stressor.

(d) An individual's ability to cope with stressful events is a function of the resources available to that individual. Those with greater resource pools are able to cope with difficulties more easily than are those with fewer resources. Because of this, some groups may be particularly vulnerable to stress because they are disenfranchised in some way (e.g. the poor, the elderly, or members of minority groups).

(e) Resource loss is both a more powerful and more potent process than resource gain, and it is more difficult to prevent loss than to obtain gains in the resource pool. Additionally, losses are more depleting than resource gains are resource generating.

(f) Individuals must invest resources in order to generate more resources and/or to prevent the loss of resources, and 
therefore, those who begin with more resources are able to produce more resources more easily than those with fewer resources.

In the following sections, I apply COR theory to the general pattern of results I outlined previously. I will argue that the results of these analyses suggest three global interpretations. First, that for the most part, life events, social networks, social support and well-being were related in ways consistent with previous work in the field and with principles of exchange theory where applicable. Second, I believe that the fact that few of the predictors were consistently associated with the measures of well-being (even though when they were predictive they were most often theoretically consistent) suggests that respondents in this sample had relatively rich resource pools which both protected them from stressful life events and enhanced their lives in other ways. Third, I believe that the inability to consistently predict well-being from life events, social networks and social support measures found in this project and others can be understood as a combination of sampling resource-rich networks and the effects of restricted variance. That is, results are more likely to be found (or have been found) where respondents represent a range from those who are resource poor for some reason to those who are resource rich; i.e., where the variance is greater within the sample. The opposite is also true. In samples of 
networks that are characterized by relatively rich resources pools (such as this one), researchers will be less likely to find associations between life events, social network and social support measures, and well-being outcomes.

In order to explore the validity of these assertions, I reviewed a subsample of the social network and social support literature in an effort to find measures which could be compared with those I used. I have included network and support measures in an effort to situate the current data in the context of previous work, but have left a more complete review including well-being outcomes for a later time. Tables XXI and XXI provide summaries of what I found. What is at first evident within these tables is the lack of measures of many of the concepts deemed most important in the literature, as well as the lack of consistency in their measurement when they have been included in research protocols. These problems make it more difficult to clearly determine whether evidence exists for the perspective I have suggested, although I feel that the tables provide some initial support for the COR conceptualization.

Table XXI shows that network size exceeded the level expected to produce diminishing returns (five to ten network members) in this study as well as in all of the reviewed articles. Consistent with my argument that networks in this Moroccan sample were more rich in resources than 


\section{TABLE XXI}

SUMMARY OF LITERATURE REVIEW OF NETWORK STRUCTURE MEASURES

\begin{tabular}{|c|c|c|c|c|c|c|c|c|c|c|}
\hline Author(s) & Type of Sample & $\begin{array}{l}\text { Average Global } \\
\text { It thetwork Size }\end{array}$ & $\begin{array}{l}\text { Ave Size Pracical } \\
\text { Subnetwork }\end{array}$ & $\begin{array}{l}\text { Ave Sze } \\
\text { Emotional } \\
\text { Subnetwork } \\
\end{array}$ & $\begin{array}{l}\text { Ave Size } \\
\text { Information } \\
\text { Subnetwork }\end{array}$ & Average Densty & $\begin{array}{l}\text { Average } \\
\text { Mulipplexty }\end{array}$ & Average Similanty & $\begin{array}{c}\text { Average Percent } \\
\text { Femat }\end{array}$ & $\begin{array}{l}\text { Average } \\
\text { Percont Kin }\end{array}$ \\
\hline $\begin{array}{l}\text { Present } \\
\text { Siudy }\end{array}$ & $\begin{array}{c}\text { Random Sample of Women in Hiddie. } \\
\text { Cars librocan thaghbortiood } \\
n=108\end{array}$ & 1836 & 865 & 630 & 523 & $\begin{array}{c}802 \% \\
\text { (included } \\
\text { xquantances) }\end{array}$ & $\begin{array}{c}1.59 \\
\text { (out of } 5 \text { support } \\
\text { categones) }\end{array}$ & $\begin{array}{c}1.78 \text { (on 3.point } \\
\text { ikert scate mith } 3= \\
\text { very smiar) }\end{array}$ & $55.5 \%$ & $71 \%$ \\
\hline $\begin{array}{l}\text { Wefiman \& } \\
\text { Welman } \\
(1992)\end{array}$ & $\begin{array}{c}\begin{array}{c}\text { Smal Subsample of } 845 \text { Randomly } \\
\text { Sected Toronto Restents } \\
n=20\end{array} \\
\end{array}$ & $\begin{array}{l}\text { ranged from } 85 . \\
144 \text { network } \\
\text { members }\end{array}$ & $\begin{array}{l}\text { average for three } \\
\text { groups ranged } \\
\text { from } 45.144 \\
\end{array}$ & $\begin{array}{l}\text { average for three } \\
\text { groups ranged } \\
\text { from } 15.176 \\
\end{array}$ & $\begin{array}{l}\text { average fox throe } \\
\text { groups ranged } \\
\text { from 0.36 } \\
\end{array}$ & $\begin{array}{l}44 \% .59 \% \\
\text { (uxcluded } \\
\text { acquantances) }\end{array}$ & & & & $46 \%$ \\
\hline $\begin{array}{l}\text { Fischer } \\
\text { (1982) }\end{array}$ & $\begin{array}{c}\text { Random Sample of N. Cattomia } \\
\text { Adunts } \\
n=1050\end{array}$ & 185 & & & & $\begin{array}{c}44 \% \\
(5 \text { most Important } \\
\text { network members, tes } \\
\text { required, no } \\
\text { acquainlanoes) }\end{array}$ & $\underset{\substack{10.6 \\
\text { tout of } 11 \text { support }}}{ }$ & & & $42 \%$ \\
\hline $\begin{array}{l}\text { A.tcalister \& } \\
\text { Fischer } \\
\text { (1978) }\end{array}$ & 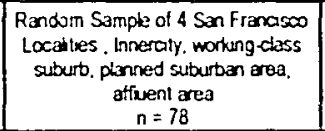 & 144.179 & & & & $\begin{array}{c}31.64 \% \\
\text { (only network members } \\
\text { mith tes. no } \\
\text { xcquantances) }\end{array}$ & & & $59 \%$ & \\
\hline $\begin{array}{l}\text { Gersid } \\
\text { (1988) }\end{array}$ & $\begin{array}{l}\text { Divoroed and Separated liken and } \\
\text { Women obtamed through court } \\
\text { records. referrats } 8 \text { snowbal } \\
\text { lectriques } \\
n=104\end{array}$ & 18 & & & & & & & \begin{tabular}{|l|}
$22 \%$ of Nibris \\
Networks. \\
$26 \%$ of Womenis \\
Networks
\end{tabular} & \\
\hline $\begin{array}{c}\text { Leste \& } \\
\text { Grady (1985) }\end{array}$ & \begin{tabular}{|c|}
$\begin{array}{c}\text { Reocenty Divorced litothers Randomity } \\
\text { Sebocted from Count Rscords } \\
n=38\end{array}$ \\
\end{tabular} & $\begin{array}{l}\text { Imited to the } 10 \\
\text { most important } \\
\text { network niembers } \\
\end{array}$ & & & & & & $\begin{array}{c}47 \text { on } 7 \text {-point tkent } \\
\text { scale. } 7=\text { very } \\
\text { similar }\end{array}$ & $63 \%$ & $32 \%$ \\
\hline 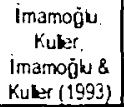 & $\begin{array}{l}\text { Partly Siratified Random Sample of } \\
\text { Turksh \& Swedish men and women } \\
\qquad \mathbf{n = 9 5 0}\end{array}$ & $\begin{array}{l}2879 \text { (Turksh } \\
\text { Women) } \\
2087 \text { (Swredish } \\
\text { Women) }\end{array}$ & & & & & & & & \\
\hline $\begin{array}{l}\text { 1.4kerdo } \\
(1989)\end{array}$ & $\begin{array}{c}\text { Adut Voluntisers } \\
n=50\end{array}$ & 228 & & & & & & & & $37 \%$ \\
\hline $\begin{array}{c}\text { van der Pool } \\
\text { (1993) }\end{array}$ & $\begin{array}{l}\text { Representative Sample of Dutch } \\
\text { Aduns age } 20.72 \\
n=902\end{array}$ & 99 & & & & & & & & $53 \%$ \\
\hline $\begin{array}{c}\text { Hanes \& } \\
\text { Hurber } \\
\text { (1992) }\end{array}$ & $\begin{array}{c}\text { Subsel of Fischer's (1982) randum } \\
\text { sample using only employed } \\
\text { recpondsents } \\
n=663\end{array}$ & 1974 & & & & & $\begin{array}{c}105 \\
\text { (out of } 9 \text { possible } \\
\text { support types) }\end{array}$ & & $58 \%$ & $40 \%$ \\
\hline
\end{tabular}


TABLE XXII

SUMMARY OF LITERATURE REVIEW OF NETWORK FUNCTION MEASURES

\begin{tabular}{|c|c|c|c|c|c|c|c|c|}
\hline Author(s) & Type of Sampie & $\begin{array}{l}\text { Ave Frequency of } \\
\text { Contact with Each } \\
\text { Network Member }\end{array}$ & $\begin{array}{l}\text { Ave. Number of } \\
\text { Network } \\
\text { Members } \\
\text { Contacted Each } \\
\text { Day }\end{array}$ & $\begin{array}{c}\text { Ave. Frequency } \\
\text { of Support } \\
\text { Provided by Each } \\
\text { Network Member }\end{array}$ & $\begin{array}{c}\text { Ave \# of } \\
\text { Network } \\
\text { Members Who } \\
\text { Give Support } \\
\text { Each Day }\end{array}$ & $\begin{array}{c}\text { Percent Reciprocal \& Nearly } \\
\text { Reciproca! }\end{array}$ & $\begin{array}{l}\% \text { Non-Reciprocal: Gave } \\
\text { Much More Than Receved }\end{array}$ & $\begin{array}{c}\text { \% Non-Reciprocal: } \\
\text { Received Much More Than } \\
\text { Gave }\end{array}$ \\
\hline $\begin{array}{l}\text { Present } \\
\text { Study }\end{array}$ & $\begin{array}{c}\text { Random Sample of } \\
\text { Women in Middle- } \\
\text { Class Moroccan } \\
\text { Neighborhood } \\
n=108\end{array}$ & $\begin{array}{l}1317 \text { days/month for } \\
\text { each network member }\end{array}$ & 78 & $\begin{array}{l}969 \text { days/ } \\
\text { month } \\
\text { (for all support } \\
\text { types) }\end{array}$ & 5.62 & $\begin{array}{c}59 \% \\
\text { (for all support types) }\end{array}$ & $\begin{array}{c}20 \% \\
\text { (for all support types) }\end{array}$ & $\begin{array}{c}12 \% \\
\text { (for all support types) }\end{array}$ \\
\hline $\begin{array}{c}\text { Lestie \& } \\
\text { Grady (1985) }\end{array}$ & $\begin{array}{c}\text { Recently Divorced } \\
\text { Mothers Randomly } \\
\text { Selected from Court } \\
\text { Records } \\
n=38\end{array}$ & & & \begin{tabular}{|l|} 
Emotional \\
Several \\
tumesMonth \\
Practical \\
Monthly \\
Financial. Yearly \\
\end{tabular} & & & & \\
\hline $\begin{array}{c}\text { Imamog̈lu. } \\
\text { Kuller. } \\
\text { İmamoğlu \& } \\
\text { Kuller (1993) }\end{array}$ & $\begin{array}{c}\text { Partly Stratified } \\
\text { Random Sample of } \\
\text { Turksh \& Swedish } \\
\text { men and women } \\
n=950\end{array}$ & \begin{tabular}{|c|}
1325 (Turkish Women) \\
11.22 (Swedish Women) \\
(scaled so $6=$ almost \\
never, $18=$ weekly, and \\
$30=$ dally)
\end{tabular} & & & & & & \\
\hline $\begin{array}{l}\text { Thomas. } \\
\text { Milburn, \& } \\
\text { Brown } \\
(1988)\end{array}$ & $\begin{array}{c}\text { Random sample of } \\
\text { Black Adults in } \\
\text { Richmond. VA } \\
n=451\end{array}$ & \begin{tabular}{|c|}
$529 \%$ Dally \\
$316 \% 2-3$ Times $/$ Week \\
$7.5 \%$ Weekly (but limited \\
to closesl network \\
members) \\
\end{tabular} & & & & $\begin{array}{c}25.7 \% \text { for Advice } \\
\text { GivingReceiving. } \\
173 \% \text { for Gring/Recening } \\
\text { Help }\end{array}$ & & \\
\hline $\begin{array}{c}\text { Ingersoll- } \\
\text { Dayton \& } \\
\text { Antonuca } \\
\text { (1988) }\end{array}$ & $\begin{array}{l}\text { National } \\
\text { Representative } \\
\text { Sample of Older } \\
\text { Adults } \\
n=718\end{array}$ & & & & & \begin{tabular}{|l|}
$81 \%$ (Spouses, Confiding) \\
$51 \%$ (Children, Confiding) \\
$56 \%$ (Friends, Confiding) \\
$85 \%$ (Spouses, Care When IIII) \\
$67 \%$ (Children, Care When III) \\
$63 \%$ (Friends. Care When III)
\end{tabular} & $\begin{array}{l}7 \% \text { (Spouses, Confiding) } \\
30 \% \text { (Children, Confiding) } \\
27 \% \text { (Frrends. Confiding) } \\
12 \% \text { (Spouses, Care When III) } \\
24 \% \text { (Children. Care When III) } \\
24 \% \text { (Friends. Care When III) }\end{array}$ & $\begin{array}{l}12 \% \text { (Spouses, Confiding) } \\
19 \% \text { (Children, Confiding) } \\
17 \% \text { (Friends, Confiding) } \\
3 \% \text { (Spouses, Care When II! } \\
9 \% \text { (Children. Care When III } \\
13 \% \text { (Friends. Care When III) }\end{array}$ \\
\hline $\begin{array}{c}\text { Wellman \& } \\
\text { Wellman } \\
\text { (1992) }\end{array}$ & \begin{tabular}{|c|} 
Small Subsample of \\
845 Randomly \\
Selected Toronto \\
Residents \\
\end{tabular} & & 11.58 & & & & & \\
\hline
\end{tabular}


most Western networks, density was high when compared to other reports (although this conclusion must be tempered by recognition of the methodological differences described), average network multiplexity for the Moroccan group was two to three times as high as for the other samples, and percentage of kin was greater for this group as well. Table XXII shows that average frequency of contact with network members for Moroccan respondents was much higher than that found in the other studies reviewed, as were the average numbers of network members with whom respondents had contact each day. The one comparison of average frequency of support indicates that the Moroccan group received more support than did the other group. For comparisons of reciprocity, levels among the Moroccan group appear fairly high and consistent with those sampled by Ingersoll-Dayton and Antonucci (1988), while both of these groups reported far greater reciprocity levels than did Thomas et al. (1988). The remainder of the reviewed results (where comparable) appear relatively consistent with the results of the present study. I believe these comparisons provide initial evidence that the group I studied had quite rich social networks and social support resources.

\section{Antecedent Predictors of Well-Being}

Age

From a conservation of resources perspective, age can be considered a "condition," and as such, increasing age may be associated 
with changes in resources. The results of these analyses suggest that this is in fact true. Older women were likely to have more physical difficulties as well as more severe illnesses, as would be expected during the aging process (Iezzoni, 1994). Yet age was only predictive for women reporting low stress levels and for the global analysis of the Illness Severity Index, perhaps indicating that high stress levels overwhelm its effects. At the same time, psychological function did not differ on the basis of age, a somewhat unexpected finding because some physical problems are known to increase psychological distress (Pugliesi \& Stoller, 1993). Since older women were more likely to be ill than younger women, it would be reasonable to hypothesize that such increases in illnesses might produce such distress. However, the number of chronic illnesses reported by respondents were not predictive of psychological problems among these women, providing further support that, for this population, neither age nor illnesses had an impact on psychological well-being.

There are a number of potential explanations for the lack of an association between age and psychological functioning. A COR analysis might suggest that these older women's networks remained rich in other resources and that such resources were able to compensate for those resources lost to illnesses, therefore reducing psychological strain. The overall high levels of support received for all age groups as well as the 
fact that increasing age was predictive of few measures of network structure and function provides evidence for this contention. Additionally, increases in illness with age may be considered normative, with older women expecting to be ill more than their younger counterparts. In this case, older women's expectations would be consistent with the illnesses they experience, resulting in little psychological distress. This explanation is compatible with Schulz and Rau's (1985) conception of statistically and temporally normative life events. These authors argue that normative events should reduce levels of subjective stress and negative well-being consequences that would be associated with the same events if they occurred during either a statistically and/or temporally non-normative period. In addition, support may be more easily mobilized and more forthcoming for normative events rather than for those that are nonnormative (Schulz \& Rau, 1985), and the ability of the support system to match the appropriate resources to the situation (Cohen, 1992) may be greater for normative events. Other authors have found evidence of an interaction between the expectations that people generally have about the effects of aging on health, and the responses of older people to their symptoms-both in terms of seeking health care and in coping with their symptoms (Keller, Leventhal, Prohaska \& Leventhal, 1989). These researchers argue that such beliefs may lead older people to expect both increases in the 
number of illnesses as well as increased severity and reduced possibilities of cure. But as Schulz and Rau (1985) have argued, as long as these expectations are widely held, older people are better able to cope with such problems because they are normative, even though one result may be that they are less likely to seek care than would a younger person experiencing the same event in a nonnormative circumstance.

From a social-network and social-support point of view, age was associated with several other factors that might have had negative effects on physical well-being. Increasing age was predictive of more negative life-events, fewer positive life events, reduced proportions of kin in the network, increased network dispersion, and reduced average frequencies of received support (see Tables VII, VIII, and X in the Results section). Any combination of these factors might reasonably be expected to affect well-being. Additionally, although increases in age were associated with larger support networks, this relationship was curvilinear, with the oldest and youngest respondents having smaller networks than middle-aged women. There are several possible explanations for a decrease in network size among the oldest respondents. Older women's networks may be smaller because network members die or become ill, or because the women themselves become unable to sustain the contacts and/or social obligations associated with network maintenance, particularly if their economic situation has 
deteriorated. Older women may have more difficulties visiting network members because they do not or can no longer drive, or must walk a distance to the nearest taxi stand or bus stop. In addition, Western researchers have found that women are particularly likely to be adversely affected by the negative events experienced by members of their networks (see Belle, 1987 for a review and theoretical implications; Fischer, 1982 for the impact on women of providing support to network members having difficulties). Because such events appear to increase with age, the probability of such events in an aging social network should be increased, with corresponding decreases in well-being.

\section{Level of Education}

In the present study, education appears to have played few important roles in the social-support process. Referring back to Tables VII, VIII and X in the Results section, education was predictive of reduced negative and increased positive life events, but with respect to the network measures, was associated with only reduced sizes in the mediation subnetwork and increased satisfaction with friends.

The above results are quite different from those found by Fischer (1982), who reported that of the personal characteristics he included in his California survey, education was the most consistent factor affecting the social networks of participants. He found that education was positively associated with increased companionship, intimacy and social 
activities, network size, and network dispersion, while educated respondents relied more on friends than on kin. In short, the more educated participants in Fischer's project had "broader, deeper and richer networks" (pp. 251), although network density was lower for those with more education. From a theoretical perspective, the networks Fischer studied were characterized by the kinds of structures and functions that ought to result in enhanced well-being. And, although it is interesting to note that the increased satisfaction with friends found in the present study may correspond loosely to Fischer's finding that more educated individuals relied more on friends than on kinship relationships, other similarities between these groups are not apparent.

A COR perspective would suggest that education should be considered a resource; however, it was not a consistent predictor of wellbeing in this study. Increased education was predictive of the number of illnesses reported by women with low stress levels during the six months prior to participation in the project, but was not predictive of any other outcome measures. Although it might be reasonable to expect that women with more education would have more information about how to remain healthy, know better how to access medical care, or detect important symptoms of health problems sooner, the lack of a consistent relationship between well-being outcomes and education level suggests 
that factors other than education were more important in determining well-being.

In general, compared to the roles of schooling in the lives of American respondents, education appears of little importance in the Moroccan setting. Formal instruction may remain less important in Morocco because the inclusion of women in the educational system is recent, and strains associated with playing non-traditional roles may equal any gains produced by increased training. Additionally, Moroccan society does not have a long history of the kinds of rewards Westerners associate with increased educational attainment. With unemployment so high and most positions filled on the basis of knowing the right people (i.e. patrons), the potential benefits of education may yet not be realizable.

\section{Frequency of Exercise}

Consistent with medical research on the beneficial effects of exercise (Blair, Kohl, Gordon \& Paffenbarger, 1992), frequency of exercise was one the most consistent predictors of physical well-being among these Moroccan women. It was associated with improved health in both global analyses as well as high- and low-stress conditions, although it was not predictive of psychological functioning. This latter finding is particularly interesting because, in American samples, exercise has been shown to positively affect psychological functioning as well (Raglin, 
1990). A COR perspective might suggest that exercise is an investment in a resource (i.e. enhanced health), but that it is not associated with psychological symptoms because other resources have been adequately mobilized to deal with respondents' psychological strain. It is also possible that American women are more concerned with bodily appearance than are Moroccan women, although my informal observations suggest that this is not the case, and Belarbi (1991) found that a large majority of her sample of Moroccan women were highly concerned with their body image and care, although it is possible that Moroccan women do not associate their body image with their level of exercise.

\section{Employment Status, the T-M Scale, and Working in the Public Sector}

Although employment status might be expected to play an important role in respondents' well-being, it was only predictive in one low-stress condition. Employed women were more likely to report more psychological symptoms if they had experienced low stress levels during the recent period. For conditions other than this particular instance, employment was not predictive of well-being. The larger number of psychological symptoms reported by this group as well as the increased psychological symptoms reported by women working in the public sector, do not replicate Western findings that working women generally benefit both psychologically and physically when compared to women 
who do not work outside the home (Barnett \& Baruch, 1987), although it is possible their presence in low-wage or underemployed positions was responsible for their increased symptoms. This suggests that employment may play different roles in the lives of Moroccan and American women.

Several reasons for these conflicting results can be suggested. It is possible that such an inconsistent finding as the association between employment and psychological symptoms for one low-stress group is a chance result. At the same time however, these results are consistent with the negative association found between women who worked in the public sector and psychological well-being. It is equally possible that the differences between the well-being of American and Moroccan women who work arise out of role-conflicts associated with the recent entry of women into Morocco's workforce and their movement away from more traditional female roles (see Abdalla, 1991 for an analysis of the effects of such changes on Kuwaiti women). However, if this were true, I would have expected to find more consistent associations between employment and reduced well-being as well as reductions in the well-being of more modern women, who I would expect to confront more role-related difficulties than their more traditional counterparts. The fact that more modern women reported less psychological distress under some lowstress conditions than did more traditional women provides tentative 
evidence that it is truly employment in the public sector, and not the more modern lifestyles that appear to covary with employment, that is associated with reduced well-being. In fact, it appears that modernity as measured in this study may be a COR "condition" that is associated with resource gains. I believe that the interpretation which follows has the most potential explanatory power for this constellation of results.

As mentioned above, women who worked in the pubic sector reported more psychological problems (as measured by the PST) and had higher scores on the GSI--a measure sensitive to both level of distress as well as number of symptoms. I believe this difference between private and public sector employment indicates that the public-sector workplace is more stressful than that of the private sector, therefore producing a drain on the resources of individuals working in that environment. In his review of occupational stress, Holt (1982) describes a number of workplace conditions which can produce such stress. Among these he includes organizational and adminisîrative irrationality (red tape), monotony, inequality of pay, and degree of control over work processes. I observed these factors at work whenever I interacted with any public agency in Morocco, and anecdotally, several of the women I interviewed made comments about the low pay they received when compared to men who did the same work. In addition, the bureaucratic nature of the 
public system is well-known. Combs-Schilling (1989) described the system accurately when she said:

"...the problems of bureaucratic bog are particularly damaging in former colonies, where bureaucracy was often developed with a degree of elaboration and red tape far beyond the norm in order to circumvent the possibilities of vitality, innovation, and creativity at the local levels. It is not happenstance that in Morocco, as in so many former colonies, every task has to be done in ten different offices with ten different signatures and ten different stamps. Bureaucratic gauntlet-running with its associated organizational exhaustion was, and is, a form of control that has reached frightening proportions. It not only slows the accomplishment of crucial tasks, it actively blocks their way (pp. 298)."

Such conditions appear to be a prescription for the occupational stress described by Holt (1982), and I believe such circumstances may be the most reasonable explanation for the increased psychological problems of women who work in the public sector. In addition, they may also account for the one analysis where employment itself was predictive, since working within the public sector was predictive of the same well-being measure. In addition, these types of workplace stressors 
may be compounded for female public-sector workers because jobs are extremely scarce, and men with families to support may be perceived as having rightful claims to these public-sector jobs.

\section{Family Matters: Marital Status, Marital Satisfaction (IMS Score), and}

\section{Number of Children}

The most important antecedent predictor of psychological wellbeing was marital satisfaction. The more dissatisfied respondents were with their marriages the more psychologically distressed they were. These results were quite consistent across all categories of analyses (global, high and low stress) and out of the 15 analyses conducted on the psychological outcome measures, it was predictive in 12. In addition, these results are consistent with Western research showing that although being married is generally associated with improved well-being, this effect is enhanced in high-quality marital relationships (see Schulz \& Rau, 1985 for a review). These results are also compatible with the COR point of view, which would suggest that distressed marriages are indicative of a serious resource drain in intimate support and therefore a major stressor. Interestingly, marital dissatisfaction was predictive of psychological problems alone and not physical health outcomes, as has been found repeatedly in the West.

At the same time that marital distress predicted reduced wellbeing, those respondents who were married appeared to be protected 
from psychological and physical distress, in particular during periods of high stress. These results are consistent with previous research showing that marriage is beneficial to both health and psychological functioning (see Argyle, 1992 and Schulz \& Rau, 1985 for reviews). However, interpretation of these results must be tempered by lack of a sample of never-married women, and the small number of respondents who were not married (9.3\% of the sample) at the time of the interview. Additionally, these results may be confounded by the social stigma attached to divorced or separated women in Morocco and the hardships caused by either of these states as well as by widowhood (CERED, 1990d; Naamane-Guessous, 1991).

Although the number of children a women had was not a consistent predictor of well-being, having more children was predictive of reduced numbers of illnesses in one low-stress condition. Because this result was not consistent across analyses and because it contradicts findings that women who have had more children have more health problems (Verbrugge, 1984, cited in Barnett \& Baruch, 1987), I am inclined to view it as anomalous and to suggest that further research needs to be completed before any conclusions are drawn about the effects of number of children in this context. 


\section{Number of Languages Spoken}

Those women who spoke the most languages in addition to their native tongue reported reduced psychological problems in one each of the high and low stress groups. Although these results are not consistent across groups, they are interesting and may warrant further study. Referring back to Table VIII of the regression analyses of antecedent and life-events measures on network structures, number of languages spoken was also predictive of reduced density and reduced proportions of kin in the network. These results suggest that women who spoke more languages may have had networks which included members who spoke languages that the respondents spoke (perhaps foreigners) but that were not spoken by other network members. This could result in the less dense networks suggested by the initial analyses of the model. In addition, if relationships with these network members replaced relationships with kin in networks, that could also result in different kinds and frequencies of support and negative interactions (proportions of kin were positively related to frequencies of negative interaction), perhaps resulting in reduced psychological symptoms. Additionally, COR theory might suggest that speaking multiple languages is a resource--perhaps enhancing an individual's sense of mastery or self-esteem, both of which have been shown to be associated with improved well-being (Hobfoll \& Freedy, 1993). 


\section{Socio-Economic Status}

In these analyses, SES was associated with enhanced psychological functioning, both in terms of numbers of reported symptoms as well as for the symptom/intensity measure (GSI). This is consistent with COR theorists' assertions that higher socio-economic status is an important resource, as well as with Fischer's (1982) findings that increased income (a component of the SES measure in this project) was associated with positive outcomes (increased free time, less hampering of social activities and psychological well-being by children, enhanced resources which could be used for entertaining as well as building and maintaining larger social networks, etc.). All were factors that Fischer found to be associated with improved psychological well-being. It is also consistent with Katchadourian and Churchill's (1973a) and El-Islam and El-Deeb's (1969) findings of an inverse relationship between education and mental illness among the patients presenting for psychiatric treatment in urban Lebanon, as well as their finding (1969) that the most severe mental illnesses were concentrated among the lower classes. Unfortunately, these latter studies all suffer from selection problems associated with the circumstances of data collection, i.e., that subjects in their studies presented themselves for treatment and were not necessarily representative of the actual population of people with mental disorders. In fact, these same researchers later $(1973 \mathrm{~b})$ found that members of the 
middle class had the lowest rates of mental illness for first-time treatment while members of both lower and upper classes had the highest rates of disorder. However, these results should also be interpreted with caution, for those members of the upper class most often have higher education levels which may make them more likely to seek psychiatric treatment than to see conventional healers or physicians.

An additional complication in interpreting these latter researchers' findings may be that the characteristics associated with significant mental disorders may make it difficult for those afflicted to complete their education or maintain jobs which would improve their class standings, with the final result being that their illnesses produced their class status rather than having reflected it. In fact, Katchadourian and Churchill (1973) report that re-admission rates for the different classes are overly concentrated among the lower classes, providing some support for the contention that one of the effects of the most severe mental illnesses is downward mobility.

Even with such cautionary statements about the interpretation of other research efforts, the results of this study represent analyses of the psychological adjustment of a sample of normally functioning individuals. The fact that increased SES is associated with enhanced psychological well-being does suggest that Katchadourian and 
Churchill's (1969) earlier results may be more accurate in the general population. In fact, the finding that SES was a positive predictor of increases in the patronage subnetwork suggests one way that SES may mediate psychological functioning (see discussions below).

Interestingly however, SES was not predictive of physical health. Because a number of researchers in the United States have found associations between lower SES and poorer health (see Iezzoni, 1994 for a short review), I expected to find similar associations in the Moroccan sample. In particular, I felt that SES would have important effects on respondents' physical health because those Moroccans who have money available for health care most often purchase it directly from private physicians, while those who do not have funds available must use the public health system--a cumbersome, underfunded and undersupplied program (Sabah, 1984) with serious problems associated with access (e.g. people may have to pay a bribe to health-care workers to get care in the first place, and even those who have been admitted to hospitals may not receive the care they need if they have not paid a bribe to the attending nurse). I expected that poorer people would avoid this system unless they were very ill, while higher SES respondents would see a doctor when necessary, therefore improving their overall health. Additionally, the ability of wealthier individuals to provide proper nutrition and housing for themselves and their families would suggest that SES should also play 
a role in this way as well. Perhaps, because Agdal is a middle-class area to begin with, most respondents had adequate access to health care as well as proper nutrition and housing, irrespective of the differences in SES levels within the group. That is, minimum resource requirements were met with respect to needs for physical health.

\section{Neighborhood Measures}

The length of time respondents had lived in their neighborhood was predictive of two of the psychological measures, but in opposite directions. Having lived in the neighborhood for longer periods was associated with increases in the intensity of psychological symptoms for the group who had experienced recent high stress, while longer periods in a neighborhood were predictive of fewer reported psychological symptoms among the low-stress group during the same period. The length of time someone lives in a neighborhood could be expected to reflect the opportunities people have to meet their neighbors and become involved with them--therefore providing a rough approximation of respondents' integration within their neighborhoods. A reasonable expectation for the effects of having lived for longer periods in a neighborhood would be that integration would increase, providing more support and therefore enhanced well-being. Additionally, if there were to be differences between the high- and low-stress groups, proponents of the buffering hypothesis would have predicted that having lived in a 
neighborhood for longer periods would provide insulating properties through ties with neighbors which would be most helpful during times of stress. However, the reverse appears to be true: Women who had low stress levels appeared to benefit from increased time spent living in their neighborhood while those with high stress levels appeared to be negatively affected. There seem to be two reasonable explanations for these differences. First, length of time lived in neighborhoods may be a poor measure of neighborhood integration, so its predictive ability may also be compromised, producing unreliable results. Conversely, if these seemingly contradictory relationships are in fact correct, it may be that social contacts (and therefore, expectations to entertain/visit with neighbors) may be beneficial during times of low stress but overly demanding during periods when stress is high and other necessities and time pressures are more salient.

The association between increased neighborhood activity levels and psychological distress is most likely an unreliable finding. Increased levels of neighborhood activity were only associated with increases in psychological distress for women who reported recent lowstress levels. However, if this result were to be borne out in future research, it is possible that such increased street activity could be considered a stressor in and of itself--particularly for women who must interact with the many men on the street who regularly make 
disparaging comments to female passersby. I know that I found this aspect of Moroccan life particularly distressing. Perhaps these culturally specific events are a type of stress which was not adequately measured by the LES, but which should be considered in future social support research carried out in Morocco.

\section{Life-Events Predictors of Well-Being}

The pattern of association between the life-events measures and well-being is very interesting. As found by Sarason et al. (1978) in their research, negative life events were better predictors of well-being than were positive changes: In the present study, positive life events were not associated with any outcome measures in any analyses. This was consistent with Hobfall and Lilly's (1993) first principle that "resource loss is more powerful, and more potent, than resource gain" (pp. 131). Consistent with COR theory and Western findings discussed previously, recent negative changes were associated with having had more (and more severe) physical health problems. What was most interesting was the lack of association between these same negative life events and psychological well-being, a relationship that has been well established in the West and which has found initial support in the Middle East (see Introduction). A number of potential explanations for this finding follow. 
COR theory suggests that problem-solving ability is an important personal resource. Supporting this contention, Thoits (1994) found that respondents who successfully solved stress-generating problems did not differ in psychological adjustment from those who had few or no such problems. Hobfall and Freedy (1990) reported that successful coping with problems may enhance an individual's sense of mastery and selfesteem, and they found that women who were higher in mastery received more instrumental support directed toward helping them with their problem than did those low in mastery. At the same time, other researchers have noted the proactive problem-solving abilities of women in Islamic countries (see Atiya, 1982; Davis, 1983; Friedl, 1989; Hays, 1987; and Mernissi, 1989 for just a few examples).

Although I did not study methods of problem solving as a whole, I collected information about how women solved a set of conflicts with their husbands and whether or not they used mediators in the process. In thinking about these results, I was reminded of two rather dramatic stories recounted to me by women who had severe problems with their husbands. The first told of a violent husbarid who eventually took a lover and, providing the lover with a house of her own, spent less and less time at home and reduced the amount of financial support he provided to his wife and children. The respondent eventually discovered the deception, and while her husband was out of town with the other 
woman, succeeded in obtaining the keys to the other house. She enlisted the help of some friends and family members who removed all the furniture from the house and sold it before her husband returned. When he finally asked her (almost a year later) whether or not she had been responsible for the act, she confirmed her involvement, and he left her. Although this may seem an unwelcome end, this respondent was able to support herself and her children and was happy that her husband was no longer in her life. From a COR perspective, this woman acted in several ways which would reduce the resource drain associated with the problem, while at the same time gaining resources from which she could draw in other difficult situations. She acted in a way which enhanced her personal feelings of power, self-esteem and mastery of the situation (as was evidenced by the relish with which she told the story); the husband (the cause of the problem) was eliminated without fuss in the end, and she collected a tidy sum from the sale of the furniture which ameliorated her financial situation. Therefore, although the situation was a stressful one, she appeared to have acted in ways which would enhance her self-esteem and feelings of mastery while eliminating her problem. COR theory suggests that people who are able to solve problems in a manner such as this one will fare far better in the face of stressors than will those whose interventions are less successful or less self-enhancing. 
The second account was told to me by an older respondent about an incident that had happened early in her marriage. She was her husband's fifth wife, he having divorced all but one of the previous women. ${ }^{9}$ Her husband decided that he wanted to divorce her as well, so she said to him "Come on, divorce me, let's go to the judge." They went to the judge, and her husband told the judge that she had been aggressive to him, in order to convince the judge that he should be given a divorce. She explained to the judge that it was not true, and told him that her husband was lying. The judge then "yelled" at her husband and the couple went home. Upon arriving at their house, the respondent said to her husband "See, you didn't gain anything by it." She reported that afterwards "there was no problem." I believe both of these accounts show the willingness of Moroccan women to use rather dramatic solutions to their problems--solutions that have the potential to make women feel more powerful (i.e., produce gains in resources) while solving their problems in ways that reduce the potential loss of resources that would continue if the problem had not been resolved. In addition, many of the other respondents reported both robust and innovative methods for problem solving, even when they appeared to be in positions that would make it difficult to act. The frequency with which these women

\footnotetext{
${ }^{9}$ Islam allows a man to have up to four wives if he treats them equally, but polygamous relationships are rare in Moroccan society.
} 
use such dramatic means suggests that they may have a greater sense of personal confidence, power and control-important personal resources in and of themselves--than do Western women (a finding consistent with Mernissi's [1987] analysis of male-female dynamics in modern Muslim societies). It is possible that, in a manner consistent with Thoit's (1994) findings, women's capability and willingness to deal with stressful situations in these ways may reduce the psychological problems associated with such stressors. At the same time such problem-solving efforts might be less likely to attenuate physical problems which most likely have their origins in the period before the stressful problem has been eliminated, perhaps explaining the ability of negative life events to predict physical but not psychological outcomes.

There are several additional explanations for this pattern of associations between life events and well-being, a number of which could operate within the general COR model. The first is provided by the work of Lin and Ensel (1989), who found that distinctive types of social support attenuate the effects of different stressors differently, with psychological resources buffering only psychological stressors. It is possible that the social networks of these Moroccan women were able to provide the support necessary to eliminate any psychological effects which might have occurred in the absence of support, but that such support did not eliminate the physical consequences associated with the 
stressors. A related explanation may also be that if these events were both statistically as well as temporally normative experiences (Schulz \& Rau, 1985), the respondents' cognitive appraisals of the events may have reduced their psychological impact, and their support systems may have been easier to mobilize than would be true in the case of non-normative stressors--further reducing their impact (see Cohen, 1992 for an analysis of this process).

Another COR interpretation has the potential to explain the differences in the patterns of results between the recent and remote stress periods (see Table XVIII - XIX). The sample was split based on stress level in order to determine if social network structure and support had direct effects on well-being or played only a buffering role during times of high stress. In fact, results were mixed with some measures predicting well-being during both high and low stress conditions and others predicting only in one or the other. Contrary to either direct- or buffering-effect hypotheses, network measures failed to predict wellbeing in the recent high-stress group, while they were predictive of the low-stress group alone for this period. These results were instead consistent with the COR postulate that high stress produces major resource loss, and that resource gains (in the form of social support) during such times would be insignificant in comparison to the losses. This explanation suggests reasons for the ability of network and support 
measures to predict well-being for the low-stress group as well as the lack of predictive ability of the same measures for respondents who experienced high-stress conditions. Additionally, some network and support measures were predictive of well-being in the high and lowstress groups during the remote stress period; their results, when taken together, were more consistent with the direct-effect hypothesis. COR theorists would suggest that this indicates that respondents had the necessary time to mobilize their networks and/or that their network members had sufficient opportunities to respond to respondents' stress levels, producing gains that were proportionally more important because the stress level was by then reduced.

Cultural differences in the expression of symptoms may also have been responsible for these unexpected results. A number of authors have found variations in the expression of psychological symptoms (see Al-Issa, 1982; Marsella, 1979 for reviews), and it is possible that such symptoms were expressed physically rather than psychologically--a possibility that may account for both the very low intensity of psychological symptoms reported, as well as the finding that recent negative events were predictive of physical health alone. However, respondents in this sample did report psychological symptoms--in fact, many more than American non-patient samples. At the same time however, there may be some differences in the expression of these 
psychological problems. For example, Moroccan psychiatrists report that it is more difficult to ask patients about low to moderate levels of depression than severe depression because the Moroccan Arabic words for depression describe only profound depression, and light or moderate depressions must be assessed by inquiring about a series of physical symptoms (N. Kadri, personal communication, August 9, 1994). This explanation appears to be a plausible hypothesis, but one that must be tested in future research.

Finally, an artifact of the data-collection process may also provide an explanation for these results. The life-events data (recent negative events) which were predictive of health outcomes, as well as the physical health data, were retrospectively collected for the same six-month period without differentiating between events which occurred first and those that occurred later. It is possible that illnesses were the cause of negative life-events rather than the reverse, and/or that the negative life events were illnesses, although this latter possibility seems more tenuous because only one question on the LES assessed whether or not respondents had become ill during the period, and that item specified only a serious illness. The former explanation seems the more likely of the two, and in this case, the lack of an association with psychological well-being must still be explained, and the other hypotheses for these findings then come into play. Further research to replicate this finding 
and to explore potential reasons for these differences could shed more light on this matter.

\section{Network Structure Predictors of Well-Being}

\section{Network Size: Global and Subnetworks}

The first hypothesis concerning network size stated that global network size would be associated with enhanced well-being to the point of diminishing returns (between five and 10 persons). However, the fact that the average global network size was far above this range is consistent with the lack of predictive ability of the measure. Both the hypothesis (because it states that effects will not be found after an adequate number of network members are available) and the results of the analysis were consistent with COR theory. A COR perspective would suggest that global network size was not predictive of well-being in this context because the smallest network consisted of nine members while the average network contained about 18 people. That is, the women in this sample had an adequate resource pool (with respect to the resources provided by large networks) available through their global networks, so network size was not predictive of well-being. At the same time, sizes of some of the subnetworks were predictive of well-being in some circumstances, indicating that some of the women may have lacked the support provided by particular types of subnetworks. 
As expected, increases in the size of the practical and emotional subnetworks were associated with enhanced well-being, although these results were far less consistent than I expected--showing up as predictors in only three of the twenty-five regression analyses. I believe these results are a function of the relatively large size of these subnetworks in general, that is, most respondents had enough people in each subnetwork upon whom they could rely for each type of support. Such an interpretation is consistent with the COR approach because its proponents argue that if resource pools are rich, the effects of stressful situations will be reduced and that there will be more opportunities to build resources, enhancing overall well-being. The fact that all subnetworks, with the exception of the patronage subnetwork, had means above five members provides support for this hypothesis, while the greater predictive ability of the patronage subnetwork with its average number of members at just over 3.5 may indicate that if on average, respondents have from five to ten persons upon whom they can rely for a specific type of support, that measure will no longer predict well-being outcomes. That is, it is the lack of the support (and the increased variance which may be associated with it) that allows prediction rather than the presence of a full complement of supportive people. This may explain why neither the size of the information nor mediation subnetworks were associated with well-being. It is plausible 
that only one or two people are necessary to provide adequate support of these types, and that having this basic need met was almost universal in the sample. This is similar to an idea proposed by El-Islam (1979) when he suggested that schizophrenics fare better in Middle-Eastern families than they do in the West because there are more members of the family who can share the burden of care. Additionally, it may be true that because the events which require informational or mediational support are less frequent, relying on one or two helpers neither overburdens them nor creates too many obligations, therefore reducing the resource loss that might be necessary to detect an association between information and mediation subnetwork sizes and well-being outcomes.

The size of the negative subnetwork, which might be expected to be a measure of potential resource loss, was predictive of reduced wellbeing as hypothesized, although it was only predictive in one condition. Consistent with COR theory, the lack of predictive ability of the size of this subnetwork may indicate that respondents' resource pools were sufficient for coping with such people. In addition, I suspect that the lack of a consistent association between the two is also a function of the fact that, in general, respondents appeared to be most likely to have negative interactions with the people who live in the same home, yet 
these same people were also responsible for a great deal of the positive interaction likely to ameliorate the effects of such negative interactions.

Finally, as outlined previously, there was an unexpected and fairly consistent association between the size of the patronage subnetwork and enhanced well-being. From an exchange theoretic perspective, I expected that such relationships would be non-reciprocal and therefore be negatively associated with well-being. However, increasing numbers of available patrons were associated with enhanced well-being, and the size of this subnetwork was predictive of psychological as well as physical outcomes, particularly for respondents who had experienced periods of high stress.

In an effort to explain the difference between expectations about the well-being effects of patronage relations and the results of analyses in the present study, I decided to further explore these relationships. The hypothesis that increasing numbers of patrons would be associated with reduced well-being was based on the assumption that relationships between patrons and clients would be asymmetric with respect to reciprocity. In order to find out whether on not this assumption was reasonable, I computed a cross-tabulation of network member as patron or non-patron by level of reciprocity.

The results of this analysis appear in Table XXIII, and as can be seen at first glance, the assumption that such relationships are 
inherently non-reciprocal was false. Almost $44 \%$ of relationships with identified patron network members were perceived as reciprocal in nature, about the same as those with non-patrons. However, it is also true that respondents' non-reciprocal relationships with patrons were different from those with non-patrons. In particular, the likelihood of respondents to "receive much more than they gave" from patrons was greater than from non-patrons $\chi^{2}(4, N=244)=56.8, p<.00000$, a result consistent with the initial hypothesis. Therefore, although there were more non-reciprocal relationships of the expected type among patrons, they were much less common than predicted explaining, at least in part, the lack of support for the patronage hypothesis. In addition, exchange theorists have also predicted that when non-reciprocal relationships are

\section{TABLE XXIII}

RESULTS OF CROSS-TABULATIONS OF PATRON VS. NON-PATRON NETWORK MEMBERS BY THE RECIPROCITY OF THEIR RELATIONSHIPS WTTH RESPONDENTS

\begin{tabular}{|c|c|c|c|c|c|c|}
\hline & $\begin{array}{l}\text { Respondent } \\
\text { Gave Much } \\
\text { More than } \\
\text { She Received }\end{array}$ & $\begin{array}{l}\text { Respondent } \\
\text { Gave a little } \\
\text { More than } \\
\text { She Received }\end{array}$ & $\begin{array}{c}\text { Relationship } \\
\text { was } \\
\text { Reciprocal }\end{array}$ & $\begin{array}{c}\text { Respondent } \\
\text { Received a } \\
\text { little More } \\
\text { than She } \\
\text { Gave }\end{array}$ & $\begin{array}{l}\text { Respondent } \\
\text { Received } \\
\text { Nuch Nore } \\
\text { than She } \\
\text { Gave }\end{array}$ & Row Total \\
\hline $\begin{array}{c}\text { Non-Patron } \\
\text { Network Nember }\end{array}$ & $\begin{array}{c}331 \\
(25.1 \%)\end{array}$ & $\begin{array}{c}1.48 \\
(11.2 \%)\end{array}$ & $\begin{array}{c}575 \\
(43.6 \%)\end{array}$ & $\begin{array}{c}116 \\
(8.8 \%)\end{array}$ & $\begin{array}{c}149 \\
(11.3 \%)\end{array}$ & $\begin{array}{l}1319 \\
80.6 \%\end{array}$ \\
\hline Patron & $\begin{array}{c}32 \\
(10.1 \%)\end{array}$ & $\begin{array}{c}29 \\
(9.1 \%)\end{array}$ & $\begin{array}{c}141 \\
(+4+320)\end{array}$ & $\begin{array}{c}51 \\
(16.036)\end{array}$ & $\begin{array}{c}65 \\
(20+4)\end{array}$ & $\begin{array}{l}318 \\
19.4 \%\end{array}$ \\
\hline Column Total & $\begin{array}{l}363 \\
22.2 \%\end{array}$ & $\begin{array}{l}177 \\
10.8 x\end{array}$ & $\begin{array}{l}716 \\
43.7 \%\end{array}$ & $\begin{array}{l}167 \\
10.2 \%\end{array}$ & $\begin{array}{l}214 \\
13.18\end{array}$ & $\begin{array}{l}1637 \\
100.0 \%\end{array}$ \\
\hline
\end{tabular}


the norm among compatriots, or when there are no other choices, people will remain in inequitable exchanges. In Morocco, it is certainly true that patronage relationships are the normative method for dealing with the all-encompassing governmental bureaucracies. However, the reasons for remaining in such relationships does not adequately explain the benefits associated with those relationships. It is possible that Western expectations suggesting that relationships should be reciprocal may be responsible for the oft made theoretical association between unbalanced ties and negative outcomes. It seems prudent to accept the idea that, since norms of reciprocity are variable across cultures, the interpretations (and consequences) of non-reciprocal relationships will also vary. Within contexts where patron-client ties are the norm, the benefits of such relationships may be great and what might be seen elsewhere as negative aspects of those ties would most likely be interpreted as the conventional pattern of social arrangements.

It is obvious that patronage relationships are more complicated than originally hypothesized. In addition to the potential consequences of differing cultural norms, patterns of patronage may be changing in Morocco as it modernizes. Whereas many traditional patron-client relationships involve close ties between the participants, with interactants often living together, and with clients functioning as servants/employees etc. (Maher, 1974), patronage among more modern 
groups, like the one I studied, may be more likely to reflect limited arrangements which are activated only when specific needs can be taken care of in no other way. For example, a parent who wants their child to attend a popular private school may find that the only way they can achieve this goal is to have a connection with someone who works at the school--a patron. In a situation such as this, the patron would be contacted and an effort made to obtain the child's entrance. If the arrangement worked out, a credit would be gained and a debt incurred, but neither would be as extensive as would be true in traditional patronclient relations where interdependence is much greater. This "limited patronage" approach to problem solving would be consistent with COR theory expectations that people will conserve resources whenever they are able. It is possible that only the more extensive and/or seriously non-reciprocal relationships are harmful while less extensive, more reciprocal relationships with patrons provide important benefits. These relationships may be particularly important when individuals must deal with heavy bureaucracies, thereby reducing stress and improving wellbeing. Stein (1984) makes the positive functions of patron-client relationships clear:

Mediating the social universe in behalf of his clients, the patron offers protection in the face of danger, greater security in an insecure world, greater predictability for the 
powerless, more resources for the resource-starved or deprived, reduction of stress, stability in the face of uncertainty, and reliability in an untrustworthy world. In short, if you cannot rely upon anyone else, at least you can count on the patron. If you yourself cannot act directly upon the bureaucracy or the state, the patron will intervene or intercede for you. (pp. 30-31) Sabah (1987) has noted that patron-client relations allow participants to deal with people who are known personally and with whom one can engage in an interpersonal mode of communication, thereby reducing the uncertainty associated with trying to solve problems (pp. 128), and she goes on to describe the potential help that patrons can provide in moving through the Moroccan bureaucracy, vastly reducing the levels of effort required. Other researchers have described the benefits of patronage systems to clients as well as patrons (see Brainard \& Zaharlick, 1989; Greenficld, 1987; and Rosen, 1984 for a few examples), although clients involved in these relationships pay a price for their involvement, both personally and in terms of the perpetuation of the system (Stein, 1984; Sabah, 1984). Sabah (1984) outlined the paradoxical nature of the problem when she described the outcomes of patronage systems: 
At the same time, it [patronagel puts individual and family in a situation of constant dependency, obligation, and subservience vis-à-vis kin and others. The family becomes actively dependent not only on those who have lent their services, but also on those who have a potential for doing so. This leads to a clientelistic mentality and areas of dependency become more and more numerous. An additional social cost of mediation [patronage] is that it undermines both the effectiveness and the credibility of formal channels. Mediation solves immediate problems for some, but creates conditions of blockage and marginality for others. At the same time, it mitigates against the creation of more viable social alternatives. (pp. 259-260).

In trying to understand the beneficial effects of patronage found in this project, it appears important to distinguish between levels of involvement in patron-client relations. The respondents in this study were in relatively strong economic positions in comparison to the majority of Moroccans. According to exchange theorists, people will engage in inequitable exchange relationships only when there are no alternatives available (Thibaut \& Kelley, 1986). Traditional patron-client relations develop between wealthy patrons and poor clients whose dependence upon the patron often become extreme, but who have no 
other resource options. In the case of this sample, the relatively high economic position of most respondents would seem to preclude such relationships, and in fact, the respondents' own relative wealth may make it more likely that they trade services at the same level then would be true for poorer participants in such relationships. This corresponds to Maher's (1974) finding that one form of patronage relations among the group she studied in Morocco was composed of arrangements between political equals. In the cases she described, patrons and clients were members of the same lineage, but it seems reasonable to suggest that in urban areas where tribal/lineage groups are separated, similar socio-economic statuses could become the basis for entering into such exchange relationships. In fact, increasing SES was associated with larger subnetworks of patrons in this sample. This would explain the number of reciprocal relationships with network members defined as patrons, as well as the beneficial outcomes associated with knowing patrons. Such relationships could be described as resource enriching, using the COR framework, rather than as resource drains. If patron-client relations among the middle and upper classes are frequently reciprocal as suggested here, then perhaps participants receive the benefits associated with a very serviceable type of relationship without placing themselves in positions of dependence that could be harmful. 
Another hypothesized relationship between subnetwork size and well-being was that increasing numbers of available mediators in networks would be beneficial to respondents. There was no evidence that the availability of such mediators had any beneficial effects on wellbeing. However, as I have reported elsewhere (Green, 1993), Moroccan couples who had an informal mediator help resolve serious disputes had better outcomes (as reported by the wives involved in the dispute) than did those with no mediator involved. Although this finding would appear to contradict the lack of predictability of the mediation subnetwork size, there are a number of potential reasons for these results. It is possible that because events which require a mediator are rare, effects would only be found in and around periods where a mediator was needed. Additionally, it is possible that the availability of only one mediator is the critical variable rather than associated benefits increasing as the number of such mediators increases. From a conservation of resources perspective, perhaps only a very small number of mediators are necessary to provide for basic needs, therefore reducing the predictive ability of this subnetwork size.

\section{Density, Multiplexity and Dispersion}

Density was predictive of enhanced physical health for those women who had experienced low levels of recent and remote stress. This was consistent with other findings that density may have 
differential effects depending on needs (House \& Kahn, 1985, and Schultz \& Rau, 1985 who briefly review this literature). In the case of the results of this study, density was associated with physical health alone, and only for women experiencing low stress levels. This may be a result of the identity maintenance functions that Walker, MacBride and Vachon (1977) have argued are potential benefits (or resources, from a COR perspective) of dense networks. It is possible that the effects of such maintenance functions may be most detectable under low-stress circumstances, where the drain of stressful situations is less likely to overwhelm any benefits. This interpretation is consistent with COR theorists' arguments that resource loss is more important than resource gain.

Neither multiplexity nor dispersion were associated with any of the well-being measures. It may be that multiplexity was unimportant because networks were so large that respondents had no real need for network members to provide multiple types of support since it would generally be possible to turn to other network members who could give the needed support, or because multiplexity was high. As for the lack of an effect of dispersion, it may be that respondents' higher SES levels allowed them to maintain the more distant relationships and still receive support when needed. If this were true, it would be consistent with 
Fischer's finding (1982) that dispersion was greater among high SES respondents.

\section{Homogeneity}

Two of the three measures of homogeneity were predictive of enhanced well-being in the hypothesized direction, but once again, each was associated with only one well-being measure. Increases in the average similarity of character between respondents and their network members were associated with enhanced psychological functioning, although such differences were not predictive of physical health. At the same time, the increased percentages of female network members were predictive of a reduction in psychological symptoms, but only for women who had experienced high stress during the remote period. This is consistent with the hypothesis that having more women in networks would enhance well-being, but the fact that it was not predictive of more well-being outcomes suggests that the relationship between female network members and well-being should be conceptualized differently for this group. Perhaps women are a more important resource during periods of high stress, and the relative availability of female network members (averaging more than $55 \%$ of network members) ensures adequate levels of the resources under most circumstances. This is consistent with Bell's (1987) suggestion that women are more likely to provide some types of support than are men. Conversely, it is also 
possible that rather than using the proportion of women in networks, a more appropriate measure would be the number of women available for supportive purposes.

The other measure of homogeneity--percentage of kin in the network--was not a predictor of well-being. However, as was true of percentages of women in the network, the average proportion of kin in respondents networks was very high (71\%), indicating that the types of support provided by kin should have been well represented. Future research efforts might explore whether there is a critical number of women or kin necessary in a network, and if resources below these levels are associated with reduced well-being.

Network Function Predictors of Well-Being

\section{Average Frequency of Contact and Support with Network Members}

As hypothesized, increased frequencies of contact were associated with enhanced well-being, although only in terms of reduced intensity of psychological symptoms. The lack of predictive ability of frequency of contact across analyses mirrors the contradictory results of other research efforts as well (see Berkman \& Syme, 1979; İmamoğlu, Küller \& Imamoğlu, 1993; Lieberman, 1982; Schwarzer \& Leppin, 1992; Thomas, Milburn, Brown \& Gary, 1988). From a COR perspective, these inconsistent results could be interpreted as reflecting the differences between rich versus poor resource pools under disparate demand levels 
brought about by stressful events. That is, frequency of contact may have no effect on well-being unless the frequency (the resource) is very low, or demands are very high, or there is some interaction between contact and demands and the presence or absence of other available resources. The high frequencies of contact reported by respondents in this sample may indicate that basic contact needs were being met, therefore reducing the measure's association with well-being.

Contrary to the hypothesized relationship that increased frequencies of support would be associated with better well-being, having had more support was predictive of lower well-being levels in one condition. However, as discussed in the Results section, this appears to be a statistical artifact. In either case, these analyses provided no support for a positive association between well-being and frequency of support, with the exception that COR theorists would argue that the consistent lack of effect is a function of the wealth of these two resources.

\section{Reciprocity in Relationships with Network Members}

Consistent with social exchange theory and with the hypothesis of a positive association between increased reciprocal relationships and enhanced well-being, increased proportions of reciprocal ties were consistently associated with reduced intensity of reported psychological symptoms. Interestingly, as with many of the other associations found 
in these analyses, the connection between the reciprocity measure and well-being supported the initial hypothesis, but the measure lacked the ability to predict different types of well-being. This inconsistency suggests that the link between the two measures is more complex than it had been conceptualized, and/or that the high reciprocity levels and low variation in the reciprocity measures reduces the possibility of finding such relationships.

Interestingly, the lack of an effect of non-reciprocal relationships would suggest that COR theory does not apply, for its proponents suggest that resource gains are less important than resource losses. With respect to reciprocity, the reverse appears to be true.

\section{Satisfaction with Family and Friends, and Feeling that the Most Important}

\section{Network Members Understand}

Satisfaction with family and friends were each predictive of one well-being measure. As was hypothesized, family satisfaction was associated with enhanced well-being, although it was a predictor in only one of the analyses, and that was for the severity of psychological symptoms during the remote high-stress condition. At the same time, feeling satisfied with friends was associated with more illnesses for those women with low stress levels during the remote period. The fact that the associations between either type of satisfaction were not consistent across analyses and that they were only predictive of a high- or low- 
stress group suggests that they are more likely to be statistical artifacts than real results. My interpretation of the association between satisfaction and well-being is that very little evidence for such a relationship exists, and that further research is necessary to determine whether such subjective global assessments are useful as predictors of well-being. In fact, future researchers might find they are more useful as dependent measures of a dimension of psychological adjustment rather than independent predictors of psychopathology.

As was true of the satisfaction measures, associations between respondents' beliefs that the most important members of their networks understood them and the well-being measures were inconsistent. This measure was predictive only of the number of psychological symptoms reported by women in the low-stress groups, although the relationship was consistent with the hypothesis that feeling that others understand would be associated with enhanced well-being. The fact that the result was consistent for both time periods for which stress levels were measured lends some credence to the finding, although the fact that it was predictive of only the one psychological measure suggests that further research is necessary before any conclusions can be drawn. Importance of Neighbors

Importance of neighbors was associated with the Illness Severity Index alone, although only for women who had experienced recent high 
stress levels. I suspect that this reflects the increased needs which people with more severe illnesses may have, particularly during periods of high stress. That is, neighbors may become more important if a person is very ill and under high stress. Again, because this finding was not consistent across groups, the need for further research to establish the existence of such a hypothesized relationship is necessary.

\section{Average Frequency of Negative Interactions}

Increases in the average frequency of negative interactions were predictive of overall psychological functioning (the GSI measure), but only for the group of women who had experienced low stress during the remote period. This was consistent with the hypothesized relationship, although as with many of the other measures, its predictive ability was far less across analyses than was expected. A number of other researchers have found that such negative interactions are consistently associated with decreased well-being (see Introduction), but that does not appear to be the case in the context of this project. COR theorists might suggest that the resource loss which should be associated with such interactions may have been tempered by the already strong resource pool which these respondents appear to possess.

\section{Feeling that Others Demand Too Much}

Feeling that others demanded too much was the most consistent predictor of well-being of all of the social support measures. This is 
probably the best measure of weak resource pools and/or resource drain included in the study. I would expect that women whose resources were stretched to the limit or who had generally poor resource pools would be the most likely to feel that others were too demanding of them, and as such, this measure should predict reduced well-being in the manner that it did. However, the fact that this measure was particularly predictive of the low-stress groups (in addition to the global measures of well-being) suggests that, at least among this sample, resources may either be more adequately mobilized for high stress situations than COR theory might suggest, or that network members increased their demands on respondents who they perceived to be under lower levels of stress. If this latter explanation is accurate, women with generally low stress levels but weak resource pools might account for these findings. Another possible interpretation of these results is that women who were already physically ill or mentally unstable found the regular demands of network members overwhelming. In either case, the consistent predictive ability of this measure suggests that further research into the processes of its association with well-being is warranted.

\section{Limitations of the Study}

The first set of potential limitations are related to the cultural differences that might have affected the results of this study. There are the obvious questions about threats to validity associated with applying 
theoretical concepts developed for one culture in a different cultural setting. In particular, these include potential problems associated with using instruments developed (like the BSI, LES \& SIRS-R) and standardized (the BSI) for use in a culture different from the one under study. In addition, there are risks that respondents were unwilling to tell the truth to a foreign interviewer (although my impression was that respondents were forthcoming even about the most uncomfortable pieces of information), or that the interviewer, working in a foreign language, misunderstood what respondents meant. In addition, it is possible that using different languages in interviews might produce different answers to the same questions, as was found by Bentahila (1983).

The second set of concerns are associated with the reliability and validity of the project. First, although the T-M and SES scales were probably more representative of urban Moroccan women than was the Agdal sample, the scales were nevertheless based on a sample that included larger numbers of women who were both more likely to live modern lifestyles and have more education and higher SES than the average population. In addition, the fact that I sampled a relatively homogenous group seems to have restricted the variance in the sample to a certain extent, although results did not change substantially when I included the non-random sample I had collected outside Agdal for 
purposes of scale construction (with the exception that the results of these analyses were statistically significant at higher levels). Another potential weakness of these results is associated with the number of variables used in analyses and the number of analyses completed. I have tried to draw attention to results that may capitalize on chance where that seemed the most reasonable option, and I also increased the significance requirements in order to reduce such chance results. However, the problem is still a concern and should be kept in mind by readers. In addition, there may be important validity and/or reliability problems within the measure of physical health. As described in the Method section, the average Moroccan's knowledge about illnesses was quite limited, and the symptom descriptions used to aid in understanding were certainly not as accurate as a diagnosis made by a physician and reported by a respondent. I tried to reduce these problems by enquiring about reported symptoms myself, but my qualifications do not include medicine.

Lastly, I was attempting to investigate an area in social science (social support) where what is known is often contradictory and/or inconsistent, and where effect sizes are weak and theoretical frameworks are either missing or severely underdeveloped. The concept of "social support" has yet to be adequately defined, and the scope of the field is so vast that it may never be possible to produce an adequate 
conceptualization. The fact that conservation of resources theory provided a way to conceptualize the pattern of results found in the study was a welcome addition, for it contributed to a more global understanding of the processes which I have tried to describe.

Although the above limitations must be kept in mind when interpreting the results of the present study, a number of findings were interesting and potentially significant. A summary of those findings follow.

\section{Summary of the Most Important and Interesting Conclusions Network Factors}

Several interesting findings emerged from a factor analysis of network structure and function variables. Of particular interest was the relationship between variables that represented reciprocity between network members and respondents. One might expect, if reciprocity were a continuum from giving more to receiving more, that variables which coded these relationships separately would load oppositely on the same factor, with variables coding reciprocal relationships falling somewhere in-between. What I found however, was that giving more and receiving more loaded on the same factor with the same sign, while reciprocal relationships loaded on the same factor with the opposite sign. This provides support for exchange theoretic contentions that the continuum ranges from reciprocity to non-reciprocity, and that non- 
reciprocal relationships of different kinds share important characteristics.

Consistent with recent arguments about the importance of density and social involvement in personal networks, the presence of factors representing social embeddedness and density suggests that such conceptualizations may be appropriately applied in very different social systems. Lastly, and perhaps most interesting, was the finding that measures of negative interactions and "feeling understood" both had their most significant loadings on the communication quality factor. This result suggests that future conceptualizations of the negative aspects of social interaction in networks might profit by including measures of communication among network members. It also implies that assessments of negativity in networks should incorporate measures of problems in interpersonal communication.

\section{Predictive Ability of the Overall Model}

Although the predictive ability of the full model (See Tables XIIIXVII) was satisfactory ( $\mathrm{R}^{21} \mathrm{~s}$ ranged from 35.5 to 49.5$)$, neither the measures of network structure nor those of network function by themselves accounted for very much of the variance in the final models (See Figure 15). Of these two types of measures, network functions fared better in their predictive ability than did measures of network structure, with functions accounting for some of the variance in both physical and 


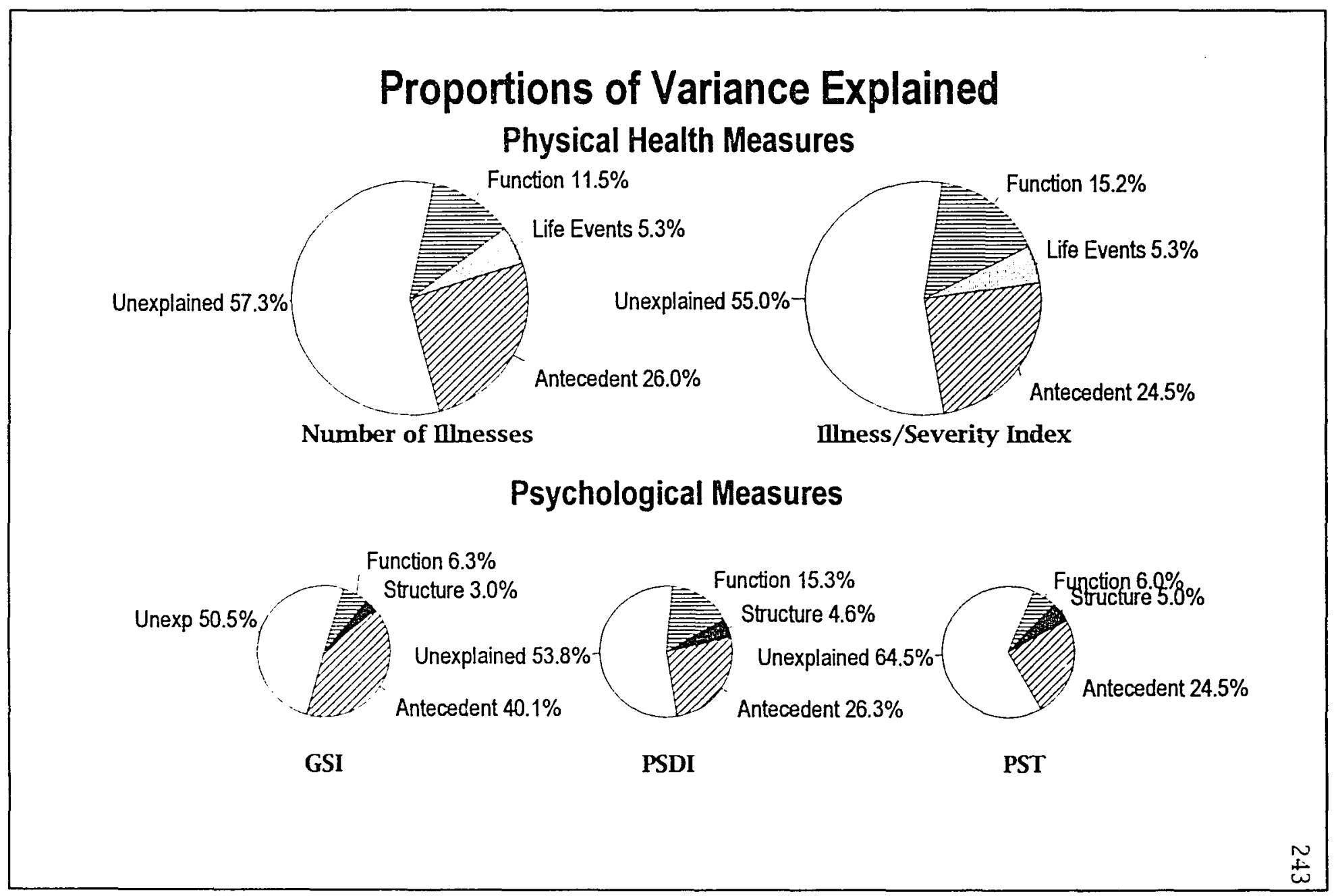

Figure 15. Percentage of variance accounted for by the full model in regression analyses with physical health and psychological functioning dependent measures. 
psychological well-being. Network structure measures accounted for a small percentage of the variance in the psychological measures but were not predictive in any of the equations predicting physical health. However, conservation of resources theory suggests that among rich, well-functioning networks, the predictive ability of such measures should be reduced. For this reason, the poor showing by the network measures may be less important than it might otherwise appear.

\section{The General Pattern of Results and Conservation of Resources Theory}

The general pattern of results describes a complex relationship between respondent characteristics, social networks and support, and well-being. I believe this pattern may be more interesting than the individual results themselves. Generally, results were consistent with hypotheses, indicating that the theoretical conceptualizations adopted were reasonable, yet the inconsistent predictive ability of most measures suggests that the initial model was incomplete. Conservation of resources theory provides a reasonable approach to understanding these seemingly inconsistent results and/or weak effects, and may explain some of the divergent results found by other social support researchers in previous work. Given the current state of theoretical development in the field of social support, the ability of any theory to predict and/or explain patterns of results within this literature is a welcome addition. 


\section{Interesting and Unexpected Findings}

There were a number of findings associated with particular measures which have theoretical significance, or which were somehow interesting or unexpected. A summary of these results follows.

\section{Antecedent Measures}

Several of the antecedent measures provided important information about social networks, social support and the processes associated with the maintenance of well-being. Contrary to the propositions of some theorists (see "Social Support and Modernization" in the Introduction) that more modern lifestyles should be associated with weakened ties and less well-functioning networks, I found little evidence of covariation between modernity and network structure, function or well-being. Where modernity did predict psychological outcomes, it was associated with enhanced rather than reduced functioning.

In general, as was true of modernity, SES was not an important predictor of either network structure or network functioning. The only associations between SES and network measures were findings that higher SES covaried with larger mediation and patronage subnetworks. However, having higher SES was fairly consistently associated with enhanced psychological well-being. 
Another unexpected finding was that public sector employment in Morocco was detrimental to psychological functioning. This result was unanticipated because government jobs are highly coveted and extremely secure, and I would have expected to find that those who had these jobs would benefit from both the status as well as the security associated with such employment. To the contrary, it appears that other factors associated with this work environment (such as public services' highly bureaucratic nature) overwhelm any positive effects the positions may provide.

As has been found elsewhere, marriage appears to have had a beneficial effect on well-being, although the small number of women in the sample who were not married should make this conclusion tentative. At the same time, increasing marital dissatisfaction was an important predictor of reduced psychological well-being, again consistent with Western research results, even in a setting where expectations for marital relationships are quite different ${ }^{10}$.

Of all the measures in the model, household size was the most consistent predictor of general network functioning and of negative interactions. The consistency of these findings, although not surprising,

\footnotetext{
${ }^{10}$ Many of the women told me during the course of their interviews that the most important aspect of their relationships with their husbands was mutual respect. I suspect that this focus on respect rather than love (the Western standard) comes out of the long tradition of arranged marriages, and remains the most important feature of the marital relationship even among those women who chose their husbands themselves.
} 
suggests that important information about the support process can be gained by a more intense focus on the support provided within households. This may be particularly true in the Moroccan setting because of the general importance of kinship relationships, but has the potential to be true in Western settings as well. In particular, the common prevalence of the nuclear family structure in both the West and within this sample suggests that family support systems may be more similar than different across these cultures.

\section{Life-Events Measures}

The most unexpected finding associated with the life-events measures was that although negative life events predicted physical health, there was no association between such events and psychological well-being. This is quite different from patterns reported by Western social support researchers who have generally found that negative life events have both psychological as well as physical effects (see Kessler \& McLeod, 1985 for a review). As explained previously, I believe that conservation of resources theory provides the best explanation for these results.

\section{Network Measures}

A number of the measures of network structure and function contributed interesting information about the support process in the 
Moroccan setting. A brief explanation of some of the more interesting of those results follows.

Female Network Members. Contrary to hypotheses that female network members would provide increased support, having proportionally more women in networks was associated with lower levels of average support, and having proportionally more women was only minimally associated with enhanced well-being. COR theory provides a possible explanation for these results (discussed previously) but I would like to propose that something like the "bystander effect" (Latané \& Darley, 1970) may be at work within these networks as well. Latané \& Darley (1970) have argued that as more people become available as potential helpers in emergency situations, individual bystanders become less likely to provide help. They propose that the responsibility for helping is diffused within the group, with individuals in larger groups having proportionally less responsibility for providing aid. If this process were found to operate in social networks as well, researchers should find that average levels of support become lower as the number of capable support providers increases. In a related finding, although I expected that increases in support would be predictive of enhanced well-being, there was no evidence that this was true. However, average support levels were high enough to suggest that increases may not have resulted in significant improvements, consistent with COR theoretic explanations. 
Mediators and Mediation. Although mediation produced improved dispute resolution outcomes for women in this sample (Green, 1993), the number of available mediators did not prove to be a predictor of wellbeing as expected. These contradictory results suggest that other measures or methods of studying mediation and mediators in social networks need to be implemented. Such methods should take into account the rare nature of events needing mediation as well as methods for studying the well-being of respondents who have been in situations where mediation could have been requested, following up by comparing those who used mediators to those who did not.

Patronage Relations. Increased numbers of patronage relationships were unexpectedly associated with enhanced psychological and physical well-being rather than the hypothesized reduced well-being. Additionally, although these relationships were less likely to be reciprocal than were relationships with other network members, respondents identified a large proportion of these relationships as reciprocal in nature. This may indicate either that reciprocity-in-kind is not as important as exchange theory would predict, or that patronage relationships among this group (more modern, middle class) are more likely to be characterized by reciprocity-in-kind than are traditional patron-client relations. I have suggested that the respondents in this sample, due to their higher levels of SES, employment, and education, 
might be better conceptualized as patrons themselves, maintaining relationships in which they exchange these types of services.

Reciprocity in Relationships. Another particularly interesting finding about reciprocity in relationships was the difference in levels of reciprocity between the network members who were respondents' children and the remainder of their networks. Relationships with nonchild network members were characterized by reciprocity, irrespective of the age of the respondent. Conversely, relationships with children were generally characterized as non-reciprocal, with younger respondents providing more support and help to their children than they received and older respondents (over age 60) receiving more help from their children than they gave. Of greatest interest was that there was no single respondent age group whose relationships with their children were characterized by even relative reciprocity. 


\section{REFERENCES}

Abdal-Ati, H. (1974). Modern problems, classical solutions: An Islamic perspective on the family. Journal of Comparative Family Studies, V(2), 37-54.

Abdalla, I. A. (1991). Social support and gender responses to job stress in an Arab culture. In P. L. Perrewé (Ed.) Handbook of job stress [Special Issue], Journal of Social Behavior and Personality, 6(7), 273288.

Abu-Lughod, J. L. (1980). Rabat: Urban apartheid in Morocco. Princeton, NJ: Princeton University Press.

Al-Issa, I. (1982). Does culture make a difference in psychopathology? In I. Al-Issa (Ed.), Culture and psychopathology, (pp. 3-29). Baltimore: University Park Press.

Al-Thakeb, F. T. (1985). The Arab family and modernity: Eviclence from Kuwait. Current Anthropology, 26(5), 575-580.

American Psychiatric Association. (1987). Diagnostic and statistical manual of mental disorders (3rd ed., rev.). Washington, DC: Author.

Antonucci, T. C. (1985). Social support: Theoretical advances, recent findings and pressing issues. In I. G. Sarason and B. R. Sarason (Eds.), Social support: Theory, research and applications (pp. 21-37). Boston: Martinues Nijhoff Publishers.

Agier, M. (1981). Etrangers, logeurs et patrons: L'improvisation sociale chez les commerçants soudanais de Lomé. Cahiers D'Etudes Africaines, 21(1-3), 251-265.

Argyle, M. (1992). Benefits produced by supportive social relationships. In H. O. F. Veiel \& U. Baumann (Eds.), The meaning and measure of social support (pp. 13-32). New York: Hemisphere Publishing Co.

Atiya, N. (1982). Khul-Khaal: Five Egyptian women tell their stories. Syracuse, NY: Syracuse University Press. 
Ayoub, V. F. (1965). Conflict resolution and social reorganization in a Lebanese village. Human Organization, 24(1), 11-17.

Ayoub, V. F. (1966). Resolution of conflict in a Lebanese village. In L. Binder (Ed.), Politics in Lebanon (pp. 107-126). New York: John Wiley.

Bates, D., \& Rassam, A. (1983). Peoples and cultures of the Middle East. Englewood Cliffs, NJ: Prentice-Hall.

Barakat, H. (1985). The Arab family and the challenge of social transformation. In E. W. Fernea (Ed.), Women and the family in the Middle East: New voices of change (pp. 27-48). Austin: University of Texas Press.

Barker, L. R., \& Whitfield, C. L. (1991). Alcoholism. In L. R. Barker, J. R. Burton \& P. D. Zieve, (Eds.), Principles of ambulatory medicine, Third Edition (pp. 204-231). Baltimore: Williams and Wilkins.

Barnett, R. C., \& Baruch, G. K. (1987). Social roles, gender, and psychological distress. In R. C. Barnett, L. Biener, \& G. K. Baruch (Eds.), Gender and stress (pp. 122-143). New York: Free Press.

Barrera, M. (1981). Social support in the adjustment of pregnant adolescents: Assessment issues. In B. H. Gottlieb, (Ed.), Social networks and social support (pp. 69-96). Beverly Hills: Sage Publications.

Belarbi, A. (1991). Soins corporels féminins: Entretien ou séduction. In A. Belarbi (Ed.), Approches: Corps au féminin (pp. 23-38).

Casablanca: Editions le Fennec, Imprimerie Najah Al Jadida.

Belle, D. (1982). The stress of caring: Women as providers of social support. In L. Goldberger \& S. Brenitz (Eds.), Handbook of stress: Theoretical and clinical aspects (pp. 496-505). New York: Free Press.

Belle, D. (1987). Gender differences in the social moderators of stress. In R. C. Barnett, L. Biener, and G. K. Baruch (Eds.), Gender and Stress (pp. 257-277). New York: The Free Press.

Bentahila, A. (1983). Language attitudes among Arabic-French bilinguals in Morocco. Clevedon, England: Multilingual Matters Ltd. 
Berkman, L. F. (1985). The relationships of social networks and social support to morbidity and mortality. In S. Cohen \& S. L. Syme, (Eds.), Social support and health (pp. 241-262). Orlando, FL: Academic Press.

Berkman, L. F., \& Syme, S. L. (1979). Social networks, host resistance and mortality: A nine year follow-up study of Alameda County residents. American Joumal of Epidemiology, 109, 186-20!.

Bernard, J. (1981). The female world. New York: Free Press.

Bigelow, G. E., \& Haines, C. S. (1991). Tobacco use and dependence. In L. R. Barker, J. R. Burton \& P. D. Zieve, (Eds.), Principles of ambulatory medicine, Third Edition (pp. 195-204). Baltimore: Williams and Wilkins.

Blair, S. N., Kohl, H. W., Gordon, N .F., \& Paffenbarger, R. S. (1992). How much physical activity is good for health? Annual Review of Public Health, 13, 99-126.

Blau, P. M. (1954). Patterns of interaction among a group of officials in a government agency. Human Relations, 7, 337-348.

Blau, P. M. (1964). Exchange and power in social life. New York: John Wiley \& Sons.

Boswell, D. M. (1969). Personal crises and the mobilization of the social network. In J. C. Mitchell, (Ed.), Social networks in urban situations: Analyses of personal relationships in Central African towns (24.5296). Manchester: Manchester University Press.

Bowen, D. L. (1985). Women and public health in Morocco: One family's experience. In E. W. Fernea (Ed.), Women and the family in the Middle East: New voices of change (pp. 134-144). Austin, TX: University of Texas Press.

Brainard, J., \& Zaharlick, A. (1989). Changing health beliefs and behaviors of resettled Laotian refugees: Ethnic variation in adaptation. Social Science and Medicine, 29(7), 845-852.

Centre d'Etudes et de Recherches Démographiques (CERED). (1990a). Atlas Démographique Maroc. Rabat: Royaume du Maroc, Premier Ministre, Ministere du Plan, Direction de la Statistique. 
Centre d'Etudes et de Recherches Démographiques (CERED). (1990b). Démographie régionale: Aspects socio-démographiques de la Wilaya de Rabat-Salé. Rabat: Royaume du Maroc, Premier Ministre, Ministere du Plan, Direction de la Statistique.

Centre d'Etudes et de Recherches Démographiques (CERED). (1990c). Mènages: Variables socio-démographiques. Rabat: Royaume du Maroc, Premier Ministre, Ministere du Plan, Direction de la Statistique.

Centre d'Etudes et de Recherches Démographiques (CERED). (1990d). Statut économique et social de la femme au Maroc: Recueil analytique des textes. Rabat: Royaume du Maroc, Premier Ministre, Ministere du Plan, Direction de la Statistique.

Centre d'Etudes et de Recherches Démographiques (CERED). (1991). Famille à Fès: Changement ou continuité?: Les réseaux de solidarités familiales. Rabat: Royaume du Maroc, Premier Ministre, Ministere du Plan, Direction de la Statistique.

Centre d'Etudes et de Recherches Démographiques (CERED). (1992). Niveau de vie des ménages 1990-91: Vol.1. Rapport de synthèse: Prémiers rèsultats. Rabat: Royaume du Maroc, Premier Ministre, Ministere du Plan, Direction de la Statistique, Division des Enquêtes auprès des Ménages.

Cleary, P. D. (1987). Gender differences in stress-related disorders. In R. C. Barnett, L. Biener, \& G. K. Baruch (Eds.), Gender and stress (pp. 39-72). New York: Free Press.

Cohen, J., \& Cohen, P. (1975). Applied multiple regression/correlation analysis for the behavioral sciences. Hillsdale, NJ: Lawrence Erlbaum Associates.

Cohen, J., \& Cohen, P. (1983). Applied multiple regression/correlation analysis for the behavioral sciences, Second Edition. Hillsdale, NJ: Lawrence Erlbaum Associates.

Cohen, S. (1992). Stress, social support and disorder. In H. O. F. Veiel \& U. Baumann (Eds.), The meaning and measure of social support (pp. 109-124). New York: Hemisphere Publishing Co. 
Cohen, S., \& Syme, S. L. (Eds.). (1985a). Social support and health. Orlando, FL: Academic Press.

Cohen, S., \& Syme, S. L. (1985b). Issues in the study and application of social support. In S. Cohen \& S. L. Syme, (Eds.). Social support and health (pp. 3-22). Orlando, FL: Academic Press.

Combs-Schilling, M.E. (1989). Sacred performances: Islam, sexuality, and sacrifice. New York: Columbia University Press.

Cook, K. S. (1982). Network structures from an exchange perspective. In P. V. Marsden \& N. Lin, (Eds.), Social structure and network analysis (pp. 177-199). Beverly Hills, CA: Sage Publications.

Corcoran, K., \& Fischer, J. (1987). Measures for clinical practice: A sourcebook. New York: The Free Press.

Cox, S. \& Radloff, L. S. (1984). Depression in relation to sex roles: Differences in learned susceptibility and precipitating factors. In C. Widom, (Ed.), Sex roles and psychopathology (pp. 123-143). New York: Plenum Press.

Dakof, G. A. \& Taylor, S. E. (1990). Victims' perceptions of social support: What si helpful from whom? Journal of Personality and Social Psychology, 58(1), 80-89.

Damis, J. (1991). America and the Maghrib. In I.W. Zartman \& W. M. Habeeb, (Eds.), Polity and society in contemporary North Africa. Boulder, CO: Westview Press.

Darlington, R. B. (1990). Regression and linear models. New York: McGrawHill.

Davis, J. A., \& Smith, T. W. (1989). General Social Surveys 1972-1989. Chicago: National Opinion Research Center.

Davis, S. S. (1978). Formal and nonformal roles of Moroccan village women. Unpublished doctoral dissertation, University of Michigan.

Davis, S. S. (1983). Patience and power: Women's lives in a Moroccan village. Rochester, VT: Schenkman Books. 
Davis, S. S. \& Davis, D. A. (1989). Adolescence in a Moroccan town: Making social sense. New Brunswick: Rutgers University Press.

Derogatis, L. R. (1983). Description \& bibliography for the SCL-90-R and other instruments of the Psychopathology Rating Scale Series. Unpublished manuscript.

Derogatis, L. R., Rickels, K., \& Rock, A. F. (1976). The SCL-90 and the MMPI: A step in the validation of a new self-report scale. British Journal of Psychiatry, 128, 280-289.

Durkheim, E. (1964). The division of labor in society. (G. Simpson, Trans.). New York: Free Press. (Original work published 1893).

Durkhcim, E. (1966). Suicide. (J. A. Spaulding \& G. Simpson, Trans.). New York: Free Press. (Original work published 1897).

Eisenstadt, S. N., \& Roniger, L. (1984). Patrons, clients, and friends: Interpersonal relations and the structure of trust in society. London: Cambridge University Press.

El-Islam, M F. (1979). A better outlook for schizophrenics living in extended families. British Journal of Psychiatry, 135, 343-347.

El-Islam, M. F., \& El-Decb, H. A. (1969). The education and occupational correlates of psychiatric disorder (A study at an Arab psychiatric clinic). International Joumal of Social Psychiatry, 15, 288-293.

El-Islam, M. F., Mohsen, M. Y. A., Demerdash, A. M., \& Malasi, T. H. (1983). Life events and depression in transit populations. International Journal of Social Psychiatry, 29(1), 13-20.

Festinger, L., Schachter, S., \& Back, K. (1950). Social pressures in informal groups. New York: Harper and Row.

Fischer, C. S. (1982). To dwell among friends: Personal networks in town and city. Chicago: University of Chicago Press.

Fischer, C. S. (1984). The urban experience, (2nd ed.). San Diego: Harcourt Brace Jovanovich.

Friedl, E. (1989). Women of Deh Koh: Lives in an Iranian village. Washington: Smithsonian Institution Press. 
Gans, H. J. (1962). The urban villagers: Group and class in the life of Italian-Americans. New York: The Free Press.

Geertz, C., Geertz, H., \& Rosen, L. (1979). Meaning and order in Moroccan society: Three essays in cultural analysis. London: Cambridge University Press.

Geertz, H. (1979). The meaning of family ties. In C. Geertz, H. Geertz, \& L. Rosen, (Eds.), Meaning and order in Moroccan society: Three essays in cultural analysis (pp. 315-391). London: Cambridge University Press.

Gellner, E. (1977). Patrons and clients. In E. Gellner \& J. Waterbury (Eds.), Patrons and clients in Mediterranean societies (pp. 1-6). London: Gerald Duckworth and Co.

Gerstel, N. (1988). Divorce and kin ties: The importance of gender. Journal of Marriage and the Family, 50(1), 209-219.

Gore, S. (1985). Social support and styles of coping with stress. In S. Cohen \& S. L. Syme, (Eds.) Social support and health (pp. 263-278). Orlando, FL: Academic Press.

Gottlieb, B. H. (Ed.).(1981). Social networks and social support. Beverly Hills: Sage.

Gottlieb, B. H. (1985). Social support and community mental health. In S. Cohen \& S. L. Syme, (Eds.) Social support and health (pp. 303-326). Orlando, FL: Academic Press.

Gove, W. R., Hughes, M., \& Style, C. B. (1983). Does marriage have positive effects on the psychological well-being of the individual? Journal of Health and Social Behavior, 24, 122-131.

Gram, M. E. (1974). Women of Tazoghrane. In J. Simmons, (Ed.), Village and the family: Essays on rural Tunisia (pp. 114-166). New Haven, CT: Human Relations Area Files.

Granovetter, M. S. (1973). The strength of weak ties. American Journal of Sociology, 8(6), 1360-1380. 
Green, C. A. (1993, April). The use of informal mediators by Moroccan women for marital dispute resolution. Paper presented at the meeting of the Pacific Sociological Association, Portland, OR.

Greenberg, M. S. \& Westcott, D. R. (1983). Indebtedness as a mediator of reactions to aid. In J. D. Fisher, A. Nadler, \& B. M. DePaulo (Eds.), New Directions in helping: Vol. 1. Recipient reactions to aid (pp. 85 112). New York: Academic Press.

Greenfield, S. M. (1987). The return of Dr. Fritz: Spiritist healing and patronage networks in urban, industrial Brazil. Social Science and Medicine, 24(12), 1095-1108.

Haines, V. A., \& Hurlbert, J. S. (1992). Network range and health. Journal of Health and Social Behavior, 33, 254-266.

Hall, A., \& Wellman, B. (1985). Social networks and social support. In S. Cohen \& S. L. Syme, (Eds.) Social support and health (pp. 23-41). Orlando, FL: Academic Press.

Harris, T. O. (1992). Some reflections on the process of social support and nature of unsupportive behaviors. In H. O. F. Veiel, \& U. Baumann, (Eds.), The meaning and measurement of social support (pp. 171190). New York: Hemisphere Publishing Co.

Hartley, J. M. (1985). The society and its environment. In H. D. Nelson (Ed.), Morocco: A country study (pp. 95-160). United States Government: Secretary of the Army.

Hatfield, E., \& Sprecher, S. (1983). Equity theory and recipient reactions to aid. In J. D. Fisher, A. Nadler, \& B. M. DePaulo (Eds.), New Directions in helping: Vol. 1. Recipient reactions to aid (pp. 113-141). New York: Academic Press.

Hays, P. A. (1987). Modernization, stress, and psychopathology in Tunisian women. Unpublished doctoral dissertation, University of Hawaii.

Haddad, M. (1988). Women and health in the Arab world. In N. Toubia (Ed.) Women of the Arab world (pp. 93-97). London: Zed Books, Ltd. 
Hessini, C. L. (1991). The hijab: An option for educated Moroccan women. Paper presented at the meeting of the American Institute of Maghrebi Studies on Women, the State and Development, October 10-13, Tangier, Morocco.

Hobfall, S. E. (1989). Conservation of resources: A new attempt at conceptualizing stress. American Psychologist, 44, 513-524.

Hobfall, S. E., \& Freedy, J. R. (1990). The availability and effective use of social support. Journal of Social \& Clinical Psychology: Special Issue: Social Support in Social and Clinical Psychology, 9, 91-103.

Hobfall, S. E., \& Lilly, R. S. (1993). Resource conservation as a strategy for community psychology. Journal of Community Psychology, 21, 128148.

Hobfall, S. E., Lilly, R. S., \& Jackson, A. P. (1992). Conservation of social resources and the self. In H. O. F. Veiel \& U. Baumann (Eds.) The meaning and measurement of social support (pp. 125-141). New York: Hemisphere Publishing Co.

Holmes, T. H., \& Rahe, R. H. (1967). The social readjustment rating scale. Journal of Psychosomatic Research, 11, 213-218.

Holt, R. R. (1982). Occupational stress. In L Goldberger \& S. Breznitz (Eds.), Handbook of stress: Theoretical and Clinical aspects (pp. +19 444). New York: Frec Press.

House, J. S. (1981). Work, stress, and social support. Reading, MA: AddisonWesley.

House, J. S., \& Kahn, R. L. (1985). Measures and concepts of social support. In S. Cohen \& S. L. Syme (Eds.), Social support and health (pp. 83108). Orlando, FL: Academic Press.

House, J. S., Umberson, D., \& Landis, K. R. (1988). Structures and processes of social support. Annual Review of Sociology, 14, 293318.

Hudson, W. W. (1982). The clinical measurement package: A field manual. Homewood IL: The Dorsey Press. 
Huxley, F. C. (1978). Wasita in a Lebanese context: Social exchange among villagers and outsiders. (Anthropological Paper No. 64). Ann Arbor, Michigan: University of Michigan, Museum of Anthropology.

tmamoğlu, E. O., Küller, R., tmamoğlu, V., \& Küller, M. (1993). The social psychological worlds of Swedes and Turks in and around retirement. Joumal of cross-cultural psychology, 24(1), 26-41.

Ingersoll-Dayton, B., \& Antonucci, T. C. (1988). Reciprocal and nonreciprocal social support: Contrasting sides of intimate relationships. Journal of Gerontology, 43(3), S65-S73.

Israel, B. A., \& Antonucci, T. C. (1987). Social network characteristics and psychological well-being: A replication and extension. Health Education Quarterly, 14(4), 461-481.

Israel, B. A. (1982). Social networks and health status: Linking theory, research, and practice. Patient Counseling and Health Education, $4(2), 65-79$.

Iezzoni, L. I. (1994). Dimensions of risk. In L. I. Iezzoni (Ed.), Risk adjustment for measuring health care outcomes, 29-118. ???: Health Administration Press.

Jacobs, J. (1961). The death and life of great American cities. New York: Random House.

Jones, D. C., \& Vaughan, K. (1990). Close friendships among senior adults. Psychology and Aging, 5(3), 451-457.

Kadushin, C. (1982). Social density and mental health. In P. V. Marsden \& N. Lin, (Eds.), Social structure and network analysis (pp. 147-158). Beverly Hills, CA: Sage Publications.

Kahn, R., \& Antonucci, T. (1980). Social networks in adult life questionnaire. Survey Research Center, Institute for Social Research, University of Michigan, Ann Arbor.

Kasriel, M. (1989). Libres femmes du Haut-Atlas?. Editions l'Harmattan: Paris.

Katchadourian, H. A., \& Churchill, C. W. (1969). Social class and mental illness in urban Lebanon. Social Psychiatry, 4, 49-55. 
Katchadourian, H. A., \& Churchill, C. W. (1973a). Education and mental illness in urban Lebanon. Social Psychiatry, 8, 152-161.

Katchadourian, H. A., \& Churchill, C. W. (1973b). Components in prevalence of mental illness and social class in urban Lebanon. Social Psychiatry, 8, 145-151.

Keller, M. S., Leventhal, H., Prohaska, T. R., \& Leventhal, E. A. (1989). Beliefs about aging and illness in a community sample. Research in nursing and health, (12), 247-255.

Kelley, H. H. (1979). Personal relationships: Their structures and processes. Hillsdale, NJ: Lawrence Erlbaum Assoc.

Kessler, R. C., \& McLeod, J. D. (1985). Social support and mental health in community samples. In S. Cohen \& S. L. Syme (Eds.), Social support and health (pp. 219-240). Orlando, FL: Academic Press.

Kiesler, C. A. (1985). Policy implications of research on social support and health. In S. Cohen \& S. L. Syme (Eds.), Social support and health (pp. 347-364). Orlando, FL: Academic Press.

Kessler, R. C., \& McLeod, J. D. (1985). Social support and mental health in community samples. In S. Cohen \& S. L. Syme (Eds.), Social support and health (pp. 219-240). Orlando, FL: Academic Press.

Kim, J., \& Mucller, C. W. (1978). Factor analysis: Statistical methods and practical issues. Beverly Hills: Sage Publications.

Knoke, D., \& Kuklinski, J. H. (1982). Network analysis. Sage University Paper series on Quantitative Applications in the Social Sciences, 28. Beverly Hills: Sage Publications.

Korte, C. (1978). Helpfulness in the urban environment. In A. Baum, J. A. Singer, \& S. Valins (Eds.), Advances in environmental psychology: Vol.1. The urban environment (pp. 85-109). Hillsdale, NJ: Lawrence Erlbaum Assoc.

Korte, C. (1983). Help-seeking in a city: Personal and organizational sources of help. In A. Nadler, J. D. Fisher, and B. M. DePaulo. (Eds.). New directions in helping: Vol. 3: Applied perspectives on helpseeking and receiving (pp. 255-271). New York: Academic Press. 
Kramer, J. (1970). Honor to the bride: A true story of Moroccan love and marriage customs. New York: Penguin Books.

Laireiter, A., \& Baumann, U. (1992). Network structures and support functions--theoretical and empirical analyses. In H. O. F. Veiel \& U. Baumann, (Eds.), The Meaning and measurement of social support (pp. 33-55). New York: Hemisphere Publishing.

Latané, B., \& Darley, J. (1970). The unresponsive bystander: Why doesn't he help? New York: Appleton-Century Crofts.

Leslie, L. A., \& Grady, K. (1985). Changes in mothers' social networks and social support following divorce. Journal of Marriage and the Family, 47(3), 663-673.

Levitt, M. J., Guacci, N., \& Weber, R. A. (1992). Intergenerational Support, relationship quality, and well-being: A bicultural analysis. Journal of Family Issues, 13(4), 465-481.

Lieberman, M. A. (1982). The effects of social supports on responses to stress. In L. Goldberger \& S. Breznitz, (Eds.), Handbook of stress: Theoretical and clinical aspects (pp. 764-783). New York: Free Press.

Lubeck, P. M. (1981). Islamic networks and urban capitalism: An instance of articulation from northern Nigeria. Cahiers D'Etudes Africaines, 21(1-3), 67-78.

Maazouzi, W. (1989). Les éléments d'une nouvelle politique de santé au Maroc. Rabat: Editions Okad.

Maher, V. (1974). Women and property in Morocco: Their changing relation to the process of social stratification in the Middle Atlas. London: Cambridge University Press.

Maher, V. (1976). Kin, clients, and accomplices: Relationships among women in Morocco. In D. L. Barker, \& S. Allen, (Eds.), Sexual divisions and society: Process and change (pp. 52-75). London: Tavistock Publications

March, K. S. \& Taqqu, R. L. (1986). Women's informal associations in developing countries: Catalysts for change? Boulder CO: Westview Press. 
Marsella, A. J. (1979). Cross-cultural studies of mental disorders. In A. J. Marsella, R. G. Tharp, and T. J. Ciboroski (Eds.), Perspectives on cross-cultural psychology. New York: Academic Press.

McCallister, L., \& Fischer, C. S. (1978). A procedure for surveying personal networks. Sociological Methods and Research, 7(2), 131-148.

Mernissi, F. (1987). Beyond the veil: Male-female dynamics in modem Muslim society, Revised edition. Bloomington, $\mathbb{N}$ : Indiana University Press.

Mernissi, F. (1989). Doing daily battle: Interviews with Moroccan women. New Brunswick, NJ: Rutgers University Press.

Milardo, R. M. (1987). Changes in social networks of women and men following clivorce: A Review. Journal of Family Issues, 8(1), 78-96.

Milardo, R. M. (1989). Theoretical and methodological issues in the identification of the social networks of spouses. Journal of Marriage and the Family, 51, 165-174.

Milardo, R. M. (1992). Comparative methods for delineating social networks. Journal of Social and Personal Relationships, 9, 447-461.

Mitchell, J. C. (1969). The concept and use of social networks. In J. C. Mitchell (Ed.), Social networks in urban situations: Analyses of personal relationships in Central African towns. Manchester: Manchester University Press

Naamane-Guessous, S. (1991). Au-delà de toute pudeur: La sexualité féminine au Maroc. Casablanca: l'Imprimerie de Fédala.

Newman, O. (1973). Defensible space: Crime prevention through urban design. New York: Macmillan.

Norušis, M. J. (1992). SPSS for Windows: Base system user's guide release 5.0. Chicago: SPSS Inc.

Olsen, M. E. (1968). The process of social organization. New York: Holt, Rinehart and Winston.

Parker, R. B. (1987). North Africa: Regional tensions and strategic concerns. New York: Praeger. 
Perkins, D. V. (1982). The assessment of stress using life events scales. In L. Goldberger \& S. Breznitz (Eds.), Handbook of stress: Theoretical and clinical aspects (pp. 320-331). New York: Free Press.

Pugliesi, K., \& Stoller, E. P. (1993, April). Physical health, social support and depression among the elderly: A panel analysis. Paper presented at the meeting of the Pacific Sociological Association, Portland, OR.

Rabkin, J. G. (1982). Stress and psychiatric disorders. In L. Goldberger \& S. Breznitz (Eds.), Handbook of stress: Theoretical and clinical aspects (pp. 566-584). New York: Free Press.

Radloff, L. (1975). Sex differences in depression: The effects of occupation and marital status. Sex Roles, 1, 249-266.

Raglin, J. S. (1990). Exercise and mental health: Beneficial and detrimental effects. Sports Medicine, 9, 323-329.

Rassam, A. (1980). Women and domestic power in Morocco. International Journal of Middle East Studies, 12, 171-179.

Rook, K. S. (1984). The negative side of social interaction: Impact on psychological well-being. Journal of Personality and Social Psychology, 46(5), 1097-1108.

Rook, K. S. (1992). Detrimental aspects of social relationships: Taking stock of an emerging literature. In H. O. F. Veiel, \& U. Baumann, (Eds.), The meaning and measurement of social support (pp. 157-169). New York: Hemisphere Publishing Co.

Rook, K. S., \& Pietromonaco, P. (1987). Close relationships: Ties that heal or ties that bind? In W. H. Jones \& D. Perlman (Eds.), Advances in personal relationships: Vol. 1. (pp 1-35). Greenwich, CT: JAI Press.

Rosen, L. (1972). The social and conceptual framework of Arab-Berber relations in Central Morocco. In E. Gellner \& C. Micaud, (Eds.), Arabs and Berbers: From tribe to nation in North Africa (pp. 1.55-173). Toronto: Lexington Books.

Rosen, L. (1984). Bargaining for reality: The construction of social relations in a Muslim community. Chicago: University of Chicago Press. 
Rosenberg, S. J., Hayes, J. R., \& Peterson, R. A. (1987). Revising the seriousness of illness rating scale: Modernization and restandardization. International Journal of Psychiatry in Medicine, $17(1), 85-92$.

Sabah, S. (1984). Mediation in a Moroccan setting. Unpublished doctoral dissertation. Purdue University, West Lafayette, IN.

Sabah, S. (1987). The interface between family and state. In I. W. Zartman (Ed.) The political economy of Morocco (117-140). New York: Praeger.

Sarason, I. G., Johnson, J. H., \& Siegel, J. M. (1978). Assessing the impact of life changes: Development of the life experiences survey. Journal of Consulting and Clinical Psychology, 46(5), 932-946.

Schulz, R. \& Rau, M. T. (1985). Social support through the life course. In S. Cohen \& S. L. Syme (Eds.), Social support and health (pp. 129-149). Orlando, FL: Academic Press.

Schwarzer, R., \& Leppin, A. (1092). Possible impact of social ties and support on morbidity and mortality. In H.O.F. Veicl \& U. Baumann (Eds.), The meaning and measurement of social support (pp. 65-83). New York: Hemisphere Publishing Co.

Sendiony, M. F. M., Abou-El-Azaem, M. G. M., \& Luza, F. (1977). Culture change and mental Illness. International Joumal of Social Psychiatry. 23, 20-25.

Selye, H. (1982). History and present status of the stress concept. In L. Goldberger \& S. Breznitz. (Eds.), Handbook of stress: Theoretical and clinical aspects (pp. 7-17). New York: Free Press.

Sixième Colloque de Démographie Maghrebine, (1985). La famille au Maghreb. Rabat: A.M.E.P.

Spanier, G. B. (1981). The role of extended kin in the adjustment to marital separation. Journal of Divorce, 5(1,2), 33-48.

Stein, H. F.. (1984). A note on patron-client theory. Ethos, 12(1), 30-36.

Steinmann, S. H. (1993). An historical analysis of migration and gender in the Todgha Oasis, Southern Morocco. Unpublished master's thesis, Clark University, Worcester, MA. 
Stevens, E. S. (1992). Reciprocity in social support: An advantage for the aging family. Families in Society, 73, 533-541.

Stuart, W. T. (1972). The explanation of patron-client systems: Some structural and ecological perspectives. In A. Strickon \& S. M. Greenfield, (Eds.), Structure and process in Latin America (pp. 1942). Albuquerque: University of New Mexico Press.

Sudman, S. (1976). Applied Sampling. San Diego: Academic Press, Inc.

Thamer, M. A., Stewart, K. G., \& Barker, L. R. (1991). Post-Myocardial Infarction care, cardiac rehabilitation, and physical conditioning. In L. R. Barker, J. R. Burton \& P. D. Zieve, (Eds.), Principles of ambulatory medicine, Third Edition (pp. 670-688).Baltimore: Williams and Wilkins.

Thibaut, J. W., \& Kelley, H. H. (1986 [1959]). The social psychology of groups. New Brunswick, NJ: Transaction Books.

Thoits, P. A. (1994). Stressors and problem-solving: The individual as psychological activist. Journal of Health and Social Behavior, 35, $143-159$.

Thomas, V. G., Milburn, N. G., Brown, D. R., \& Gary, L. E. (1988). Social support and depressive symptoms among blacks. The Journal of Black Psychology, 14(2), 35-45.

van der Poel, M. G. M. (1993). Delineating personal support networks. Social Networks, $15,49-70$.

Van Tilburg, T. (1992). Support networks before and after retirement. Journal of Social and Personal Relationships. 9, 433-14.5.

Vaux, A. (1992). Assessment of social support. In H. O. F. Veicl \& U. Baumann (Eds.), The meaning and measure of social support (pp. 193-216). New York: Hemisphere Publishing Co.

Vaux, A., Riedel, S. \& Stewart, D. (1987). Modes of social support: The social support behaviors (SS-B) scale. American Journal of Community Psychology, 15(2), 209-237. 
Walker, K. N., MacBride, A., and Vachon, M. L. S. (1977). Social support networks and the crisis of bereavement. Social Science and Medicine, 11, 35-41.

Walmyr Publishing Company. (1992). Walmyr assessment scales scoring manual. Tempe, AZ: Author.

Waltz, S. E. (1990). Another view of feminine networks: Tunisian women and the development of political efficacy. International Journal of Middle East Studies, 22(1), 21-36.

Waterbury, J. (1970). The commander of the faithful: The Moroccan political elite--a study in segmented politics. New York: Columbia University Press.

Wellman, B. (1981). Applying network analysis to the study of support. In B. H. Gottlieb, (Ed.), Social networks and social support (pp. 171-200). Beverly Hills: Sage Publications.

Wellman, B. (1979). "The community question". American Joumal of Sociology, 84, 1201-1231.

Wellman, B. (1985). From social support to social network. In I. G. Sarason \& B. R. Sarason, (Eds.), Social support: Theory, research and applications (pp. 205-222). Dordrecht: Nijhoff.

Weliman, B., \& Wellman, B. (1992). Domestic affairs and network relations. Journal of Social and Personal Relationships, 9 385-409.

Wellman, B., \& Wortley, S. (1989). Brothers' keepers: Situating kinship relations in broader networks of social support. Sociological Perspectives, 32(3), 273-306.

Wilcox, B. L., \& Birkel, R. C. (1983). Social networks and the help-seeking process: A structural perspective. In A. Nadler, J. D. Fisher, and B. M. DePaulo, (Eds.), New directions in helping: Vol. 3. Applied perspectives on help-seeking and receiving (pp. 235-253). New York: Academic Press.

Wills, T. A. (1983). Social comparison in coping and help-seeking. In B. M. DePaulo, A. Nadler, \& J. D. Fisher (Eds.), New directions in helping: Vol. 2. Help-seeking (pp. 109-141). New York: Academic Press. 
Wills, T. A. (1985). Supportive functions of interpersonal relationships. In S. Cohen, \& S. L. Syme, (Eds.), Social support and health (pp. 61-82). Orlando, FL: Academic Press.

Wirth, L. (1938). Urbanism as a way of life. American Journal of Sociology, $44,1-24$.

Wortman, C. B., \& Conway, T. L. (1985). The role of social support in adaptation and recovery from physical illness. In S. Cohen \& S. L. Syme (Eds.), Social support and health (pp. 281-302). Orlando, FL: Academic Press.

Wyler, A. R., Masuda, M. \& Holmes, T. H. (1968). Seriousness of illness rating scale. Journal of Psychosomatic Research, 11, 363-374.

Zimmer, C., \& Aldrich, H. (1987). Resource mobilization through ethnic networks: Kinship and friendship ties of shopkeepers in England. Sociological Perspectives, 30(4), 422-445.

Zurayk, H. (1987). The question of measurement in survey research in the Arab world. In M. A. Tessler, M. Palmer, T. E. Farah, \& B. L. Ibrahim (Eds.), The evaluation and application of survey research in the Arab world. Boulder, CO: Westview Press. 


\section{APPENDIX A \\ QUESTIONNAIRE: ENGLISH VERSION}

Copies of the French and Moroccan Arabic Questionnaires

are available through the author:

Sociology Department

Portland State University

Portland, Oregon 


\section{QUESTIONNAIRE: ENGLISH VERSION}

Instructions to Participants

First, I want to explain what this research project is about. I am interested in how people help each other, and how that help changes their physical health and emotional state. For example, many people find that having someone to help them when they need it, or someone to talk to when they have a problem, makes them feel better when they are under stress. I'm trying to find out how these kinds of help make life better.

I will be asking you to give me the first names and last initials of the people who help you. The only reason I need to have these names is so that I can make sure we are talking about the same person as we go through all the questions. I want you to know that your name will not be recorded anywhere, and that no information that could identify you or the people who help you will be made public. All the information that you share with me will be kept confidential.

I want you to know that you are free to withdraw from participating in this research project at any time, for any reason. If you do withdraw, you will not harm the project or your relationship with me in any way.

You may find that some of the questions make you feel uncomfortable, or that the interview takes a long time. Please let me know if you have these or other problems during or after the interview. I want to thank you for your willingness to participate. If you have any questions about the project or about the interview, please feel free to ask me now, or anytime later.

Interviewer _S G

Interview Session:

Date:

Location:

Start Time:

Stop Time:
Respondent Code:_100 $3+$ 
QUESTIONNAIRE \#1

Respondent Code: 100

\section{Part \#1: Demographics \& Life Style}

1. How long have you lived in Rabat? ..............

2. How long have you lived in this neighborhood?

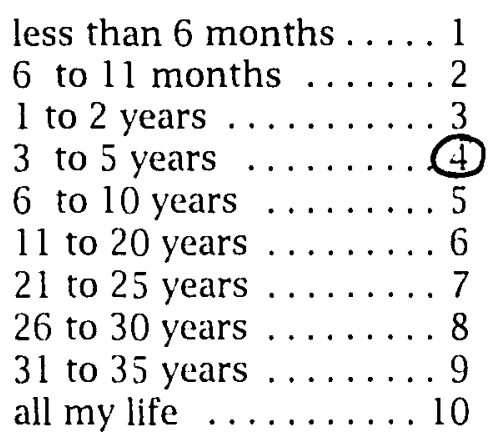

3. Before you lived here, where did you live? .....

[Prompt: Is it:]
a large city ....... 1
a mid-sized city ... 2
a small city ....... (3)
a small town .....
a rural area ......5

4. Have you ever lived in a rural area? [If yes], For how long? ...... . Yes.

[If yes] When did you leave?

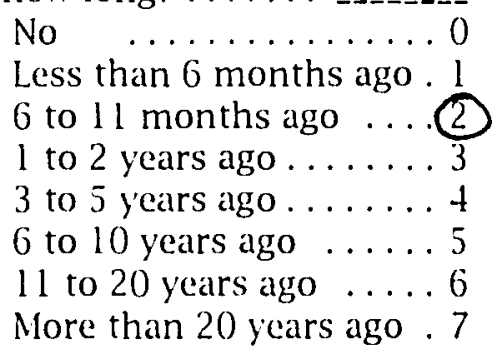

5. Do any members of your family or relatives live in rural areas?

[If Yes], How often do you have contact with them?

No family in rural areas. 0

Each week ........... (1)

Each month .........2

Each year .......... 3

Less than once a year . . 4 
6. Have you ever been to school? [If Yes], What type of school?

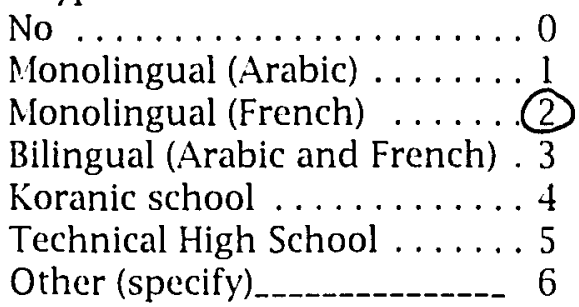

[If Yes] What was the last year of school you completed?

[If university] What was the name of your faculté?

All studies except medicine:

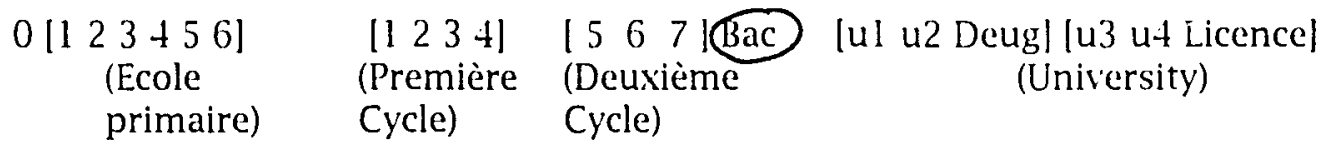

$\left[\begin{array}{l}567 \\ \text { [ Bac }\end{array}\right.$

(Lycée Technique)

[gl DEA, g2 g3 g4 DES]

(Troisième Cycle)

[dl d2 d3 d4 Doctorat]

Doctorat d'Etat
[ 12 ] Diplôme

(Les Instituts Supérieurs de Technologie)
Note: $\mathrm{Bac} \simeq$ High Sch. Diploma

Licence $\simeq \mathrm{BA} / \mathrm{BS}$

$\mathrm{DES} \simeq \mathrm{MA} / \mathrm{MS}$

Doctorat d'Etat $\simeq$ Ph.D.

Medical School: [ul u2 u3 u4 u5 u6 u7 DM spécialiste]

7. Last month, were you employed in a stable paid position, or were you a student, a housewife, looking for work, or something else?

[Code all that apply]

IIf she does not have a job and she is not looking, why?]

Employed ...........(1)

A Housewife ........ (1) Looking for work .... (D)

Not looking for work . 0 (1)

Other (specify) ............... 1

8. [If employed] How many hours each week do you normally work? . . _ _- 
9. [If employed] What kind of work do you do? ......

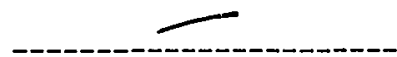

What sector do you work in? Private, public, or other (specify)?

10. Does you husband work? [If Yes] How many hours each week? (Unemployed $=0$ )

11. What kind of work does he normally do? [name of profession]. Teacher What sector does he work in?

Private, public, or other (specify)?

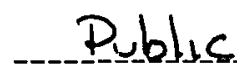

12. How many years have you been married? 7

Did you choose your husband yourself or did you have a traditional marriage?

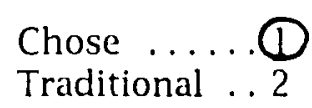

13. How old were you when you first married? .............. 19

14. How many children have you given birth to? Please count all children which were born living and those from previous marriages. . . . . . . 3

Could you tell me their first names?

\section{(LIST NAMES OF LIVING CHILDREN ON NETWORK MEMBER SHEET)}

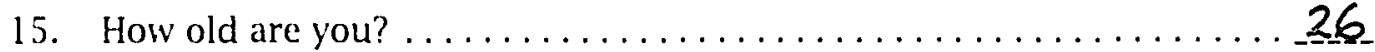

16. What is your religion?

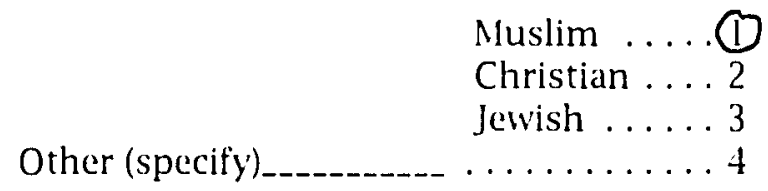


17. What languages do you speak? For [each language], do you speak [and then, do you read/write] a little, fairly well, or fluently/very well?

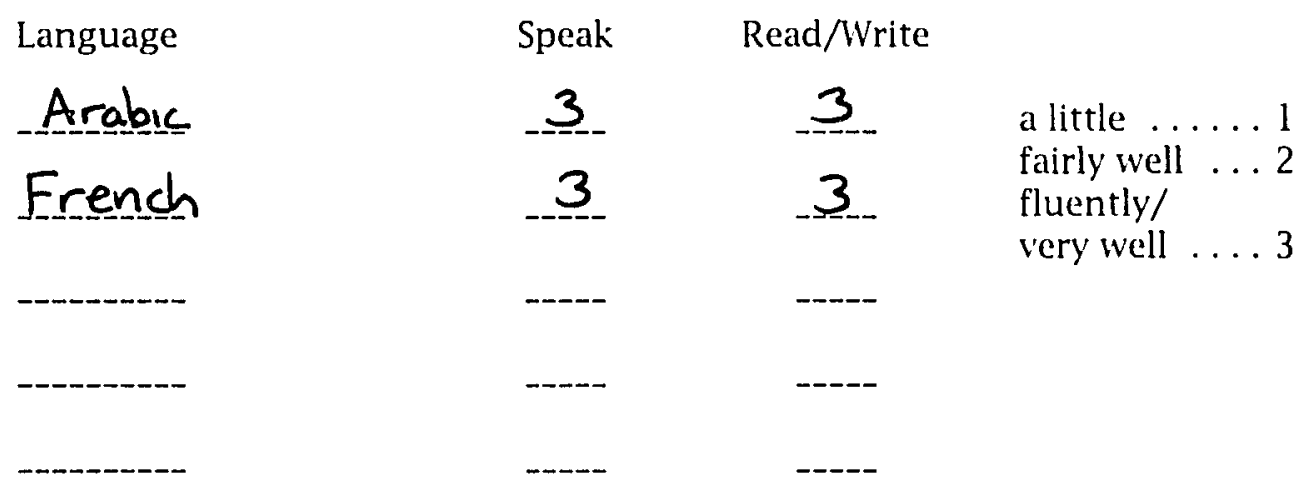

18. Who are the people that live with you now?

(LIST ON NETWORK MEMBER SHEET)

Do you have a maid? [If Yes] What is her name?

(LIST ON NETWORK MEMBER SHEET)

No ..... 0

Y'es ..... (1)

[If Yes] How many days does she work each week? . . _6 6

19. When you go into the city, how do you get there?

[Code all that apply]

Other (specify)

20. Do you and your husband have a car?

[If Yes], What kind? _... R4

Does it belong to both of you?

Do you have a motorbike?
On foot ...... 01

By car or taxi ... ()

By train ....... 1

Bus .........

Motorbike..... 1

$\ldots \ldots \ldots \ldots 2$

No ..... 0

Yes .... (1)

Yes ...........

To her Husband ... (2)

To her......... 3

Civil Service Car ...4

Other (specify)

No ..... 
21. Do you rent this (apartment, house)?

Yes $\ldots \ldots \ldots \ldots$ (1)

Own $\ldots \ldots \ldots \ldots \ldots 2$

Joint Ownership . . . . . 3

Mortgage .........4

Civil Service Housing . . . 5

Other (specify)

[If Yes] How much do you pay each month for the rent? . . . . . 2500

22. What is the monthly revenue of your household? .......... 10,000

23. When you leave the house, what do you normally wear?

[Code all that apply]

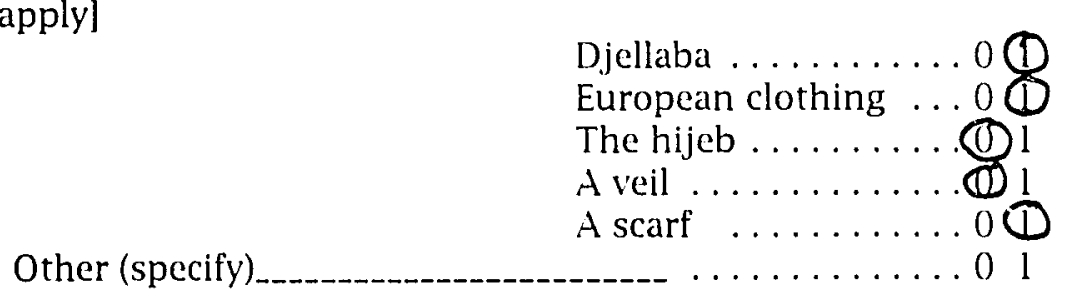

24. Do you exercise regularly? [If Yes] How many times each week and for how long each time? $($ No $=0)$

How many times ... 3

How long $30 \mathrm{~min}$

25. Do you drink tea or coffee? [If Yes] How many cups of each beverage do you drink each day, on average? $(\mathrm{No}=0)$

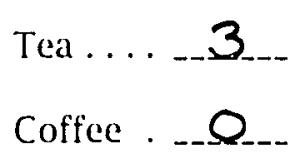

26. Do you smoke? [If Yes] How many packets each day on arerage? (No

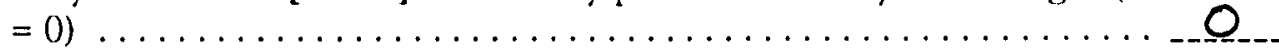
[If Yes], What brand?

27. Do you drink alcohol? [If Yes] How many glasses (of beer, wine or other) do you drink each week on average? $($ No $=0) \ldots \ldots \ldots \ldots$

28. In your daily life, would you say that your family and relatives are:

Very important for you ..... (1)

Not very important $\ldots \ldots \ldots . . . . . .3$

29. And your neighbors, would you say that they are:

Very' important for you ...... Somewhat important ....... (2)

Not very important ....... 3 
30. And your friends, are they:

Very important for you ...... (1)

Somewhat important ....... 2

Not very important ........ 3

\section{Part 2: Networks \& Support}

\section{GENERAL SUPPORT}

31. Who are the people in your life who are the most important to you? Think of your family, relatives, neighbors, friends, colleagues and acquaintances.

\section{(LIST NETWORK MEMBERS)}

32. In general, when you think of your friends, are you satisfied with your relationships and the things you do together?

Completely satisfied .... 1

Somewhat satisfied ....2

Somewhat unsatisfied . (3)

Completely unsatisfied . 4

33. Are you satisfied with your family life-the time you spend together and the things you do together?

Completely satisfied .... I

Somewhat satisfied .... 2

Somewhat unsatisfied . (3)

Completely unsatisfied , 4

34. When you think about the people who are the most important in your life, do you think they understand you most of the time, sometimes, or rarely?

$$
\begin{aligned}
& \text { Most of the time } \ldots \ldots \ldots \text { D } \\
& \text { Sometimes } \ldots \ldots \ldots \ldots \text { (2) } \\
& \text { Rarely } \ldots \ldots \ldots \ldots \ldots \text {. }
\end{aligned}
$$

35. How of ten do you have the impression that the people in your life demand too much from you?

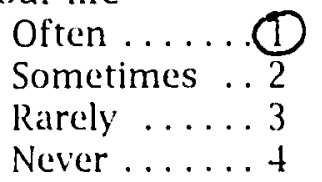

[If she does not speak french well, or if she does not want to finish the full interview (or cannot), Skip to Questionnaire \#3S] 
QUESTIONNAIRE \#2 Respondent Code:

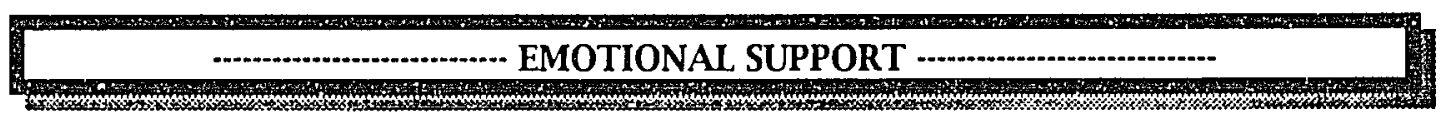

36. Now, I would like to talk about several types of support. First, I'm interested in the ways that people support and help each other emotionally. Here are some examples of this kind of support:
a)
listen when you need to talk about something, like a problem
b) make you feel understood
c) make you feel that you count in their lives
d) comfort you when you feel depressed
e) support you when you succeed
f) encourage you

Who are the people who support you the most in these ways?

\section{(LIST NETWORK MEMBERS)}

37. Are there people you can confide in about things that are important to you? [If Yes] Who?

\section{(LIST NETWORK MEMBERS)}

38. Are there people in your life who don't respect you?

(LIST NETWORK MEMBERS)

39. Are there people you talk with when you are upset, nervous or depressed?

40. (deleted)

(LIST NETWORK MEMBERS)

INSTRUMENTAL SUPPORT

41. Now, I would like to talk about another type of support. Sometimes, people can support or help you in a practical way. Here are some examples:
a) doing small favors
b) loan money or things
c) help you physically to accomplish a task
d) take care or your children, or you, when you are
e) provide transportation

Who are the people who help you the most in these ways?

(LIST NETWORK MEMBERS) 
42. Are there people who would take care of you if you were seriously ill or injured?

(LIST NETWORK MEMBERS)

Have you needed this kind of help during the last year?

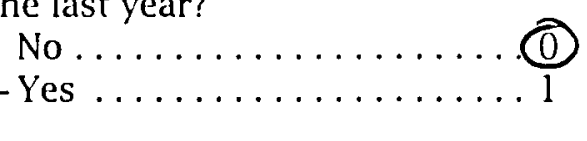

Did you get the help you needed?

No .............. 0

Yes, in part $\ldots \ldots \ldots \ldots 1$

Yes, totally $\ldots \ldots \ldots \ldots 2$

How long were you taken care of?

[Code $\mathbf{J}$ for days, $\mathbf{S}$ for weeks, $\mathbf{M}$ for months]

43. Suppose that you have some things to do at home that you can't do all by yourself. For example, if you needed someone to hold a ladder for you, help you move furniture or make some minor repairs, who would you ask for help?

\section{(LIST NETWORK MEMBERS)}

Have you needed this type of help during the last month?

No ................. 0

Yes $\ldots \ldots \ldots \ldots \ldots \ldots \ldots$ (1)

Did you get the help you needed?

No .............. 0

Yes, in part .........

Yes, totally $\ldots \ldots \ldots$ (2) 
44. Suppose that you had the flu, that you had to stay in bed for several days, and you needed someone to do the shopping for you. Who would you ask for help?

(LIST NETWORK MEMBERS)

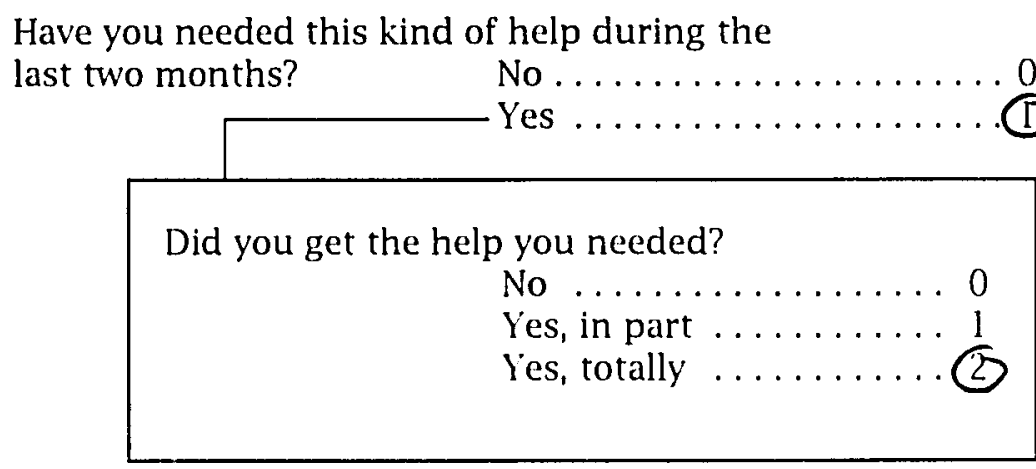

45. Suppose that you needed to borrow 5000DH or more for an important expenditure. Who would you ask for help? The bank .... 1

[Prompt: (If the bank) Is there anyone not associated with a bank that you could ask for a loan?]

\section{(LIST NETWORK MEMBERS)}

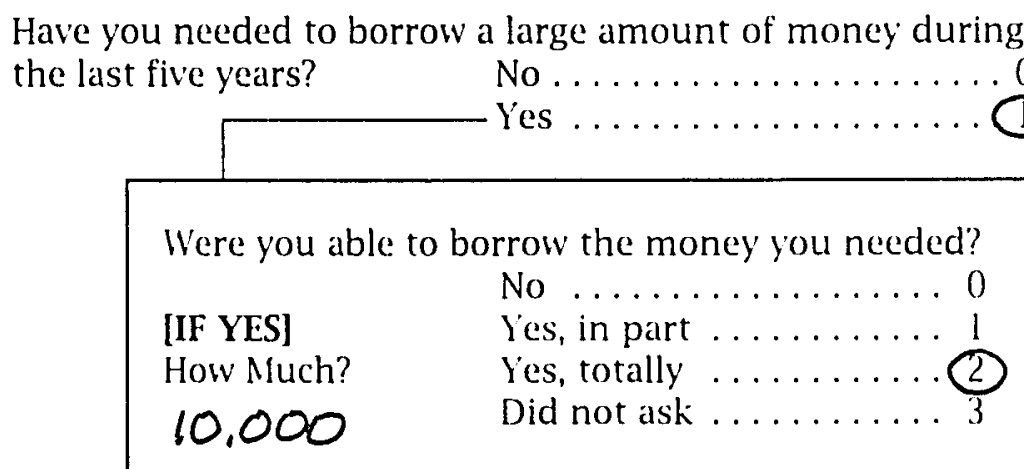

46. [If she has young children] Suppose that you needed someone to care for your children so that you could go to work or to the doctor. Who would you ask for help?

\section{(LIST NETWORK MEMBF.RS)}

No Children . 0

47. (Deleted)

48. [If she is less than $\mathbf{5 0}$ years old] If you gave birth to a child, is there someone who could come and stay with you to help you with the baby, or someone you could stay with while you recover from the birth?

\section{(LIST NETWORK MEMBERS)}




\section{INFORMATIONAL SUPPORT}

49. Now, I would like to talk about another type of help. The help people might give you if you needed information. Here are some examples of what I am talking about:

a)

b)

giving advice

problem

c) helping you find someone else who can give you

what you need

d) help you with your studies, or balancing your bank account

e) teaching you how to do something

Who are the people who help you the most in these ways?

\section{(LIST NETWORK MEMBERS)}

50. If you needed advice about something important, such as a legal problem or a business deal, who would you talk to?

\section{(LIST NETWORK MEMBERS)}

51. If you had problems with your family and you didn't know what to do about them, who would you ask for advice?

\section{(LIST NETWORK MEMBERS)}

52. Suppose you were very upset about a problem with your husband and hadn't been able to work it out with him. Who would you talk to about what to do?

(LIST NETWORK MEMBERS)

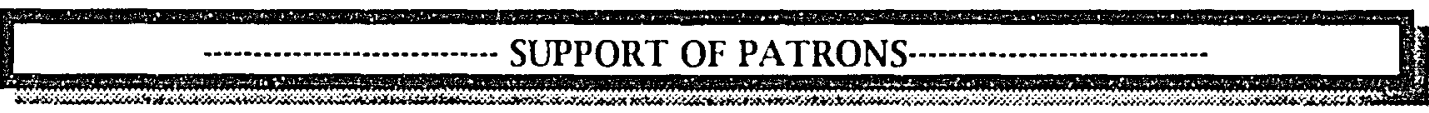

53. Another type of help and support that I am studying is the help provided by people who have connections. People with connections know how to get things done when the regular ways of doing things don't seem to work. Here are some examples of ways they might help you:

a) finding a job

b) getting a telephone

c) getting your son or daughter into a special school

d) helping get government or health services

e) helping you to buy something that is difficult to find or normally too expensive

f) help you to get a visa for traveling to another country 
53. (Continued) Now, thinking about the people in your life, who are the people you could go to if you need the help of someone who has connections?

54. (Deleted)

\section{(LIST NETWORK MEMBERS)}

55. If you needed to get medical help, but were having trouble getting an appointment, who would you ask to help you?

(LIST NETWORK MEMBERS)

56. If you needed to find a job for yourself or someone else in your family, is there someone who might be able to help you with getting one?

[PROMPT: Is there anyone else?]

\section{(LIST NETWORK MEMBERS)}

57. Do you know anyone who might be able to help you if you needed access to governmental agencies or public services?

58. (Deleted)

(LIST NETWORK MEMBERS)

\section{NEGATIVE INTERACTIONS}

59. Another type of interaction I am interested in are the times when people respond to you in unpleasant ways. In most relationships with family members, friends, colleagues and others, we frequently have negative interactions, even with people who support us. Here are some examples:
a)
b) people can make too many demands on you
c)
d)
e) people can refuse to support you in what you want to do
people can make you angry or upset
f) people with whom you have disputes

Now, thinking about the people in your life some more, who do you have negative interactions with?

\section{(LIST NETWORK MEMBERS)}

60. Thinking of the all people in you normally interact with, are there some people who you find make too many demands on your time, who ask you to do too many things, to do things that you aren't able to do, or who burden you in similar ways?

\section{(LIST NETWORK MEMBFRS)}

61. Are there people in your life who you feel you can really count on?

\section{(LIST NETWORK MEMBERS)}


62. Are there people in you life you tend to make you feel particularly angry, hurt, or upset? (LIST NETWORK MEMBERS)

63. Are there people in your life who you can trust?

(LIST NETWORK MEMBERS)

MEDIATIONAL SUPPORT

64. Another type of support I'm studying is mediational support. Sometimes people can play the role of an intermediary in cases of conflict or if there is a difficult or important situation. For example, people who could help by mediating are those people who you could ask to do things like these:
a) talk to someone on your behalf
b) help to resolve a quarrel between you and your husband
c) help solve a dispute between you and your family about who owned something, or about
d) help you to find a husband or wife for your daughter or son
e) help you if your husband decided to marry a second wife or it he wanted a divorce

Are there people you know who could intervene for you in these ways?

(LIST NETWORK MEMBERS) 
65. A few minutes ago, we discussed what you might do if you were very upset about a problem with your husband. Suppose that with the help of the people you spoke with, you decided to try several things in order to resolve the problem, but that nothing worked. Who could you ask to try to influence your husband?

\section{(LIST NETWORK MEMBERS)}

Have you ever had this type of problem?

No .....
Yes ....

Did you ask anyone for help?

No .......

les ....... 1

Did you get the help you needed?

No ........ 0

Yes, in part . 1

Yes, Totally . 2

When did this happen? .................

Can you tell me what happened? 
66. Suppose you and your husband are making a major purchase such as a house or car, and you find out that your husband is not going to put the purchase in both of your names, but just in his name. You tell him that you would like to have it put in both of your names, but he won't agree.

What would you do?

\section{Talk to my parents and ask them to talk to him}

Is there someone you could ask to try to influence his opinion?

[PROMPT: Is there anyone else?]

(LIST NETWORK MEMBERS)

Have you ever had this type of problem?

No ..... (1)

Yes .... I

Did you ask anyone for help? $\quad$ No . . . . . 0

Yes .......

Did you get the help you needed?

No .......

Yes, in part . 1

Yes, Totally. 2

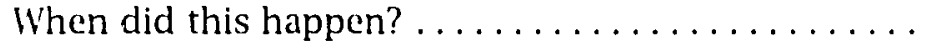

Can you tell me what happened? 
67. Suppose you and your husband have a bad fight, and that he hurts you physically, what would you do?

$$
\begin{aligned}
& \text { Go to my parents' house and wait } \\
& \text { until he comes to appologize }
\end{aligned}
$$

Is there someone that you could ask to intervene for you is this situation? [Prompt: Is there anyone else?]

\section{(LIST NETWORK MEMBERS)}


67. (continued) Have you ever had this type of problem?

No .....@

Yes .... 1

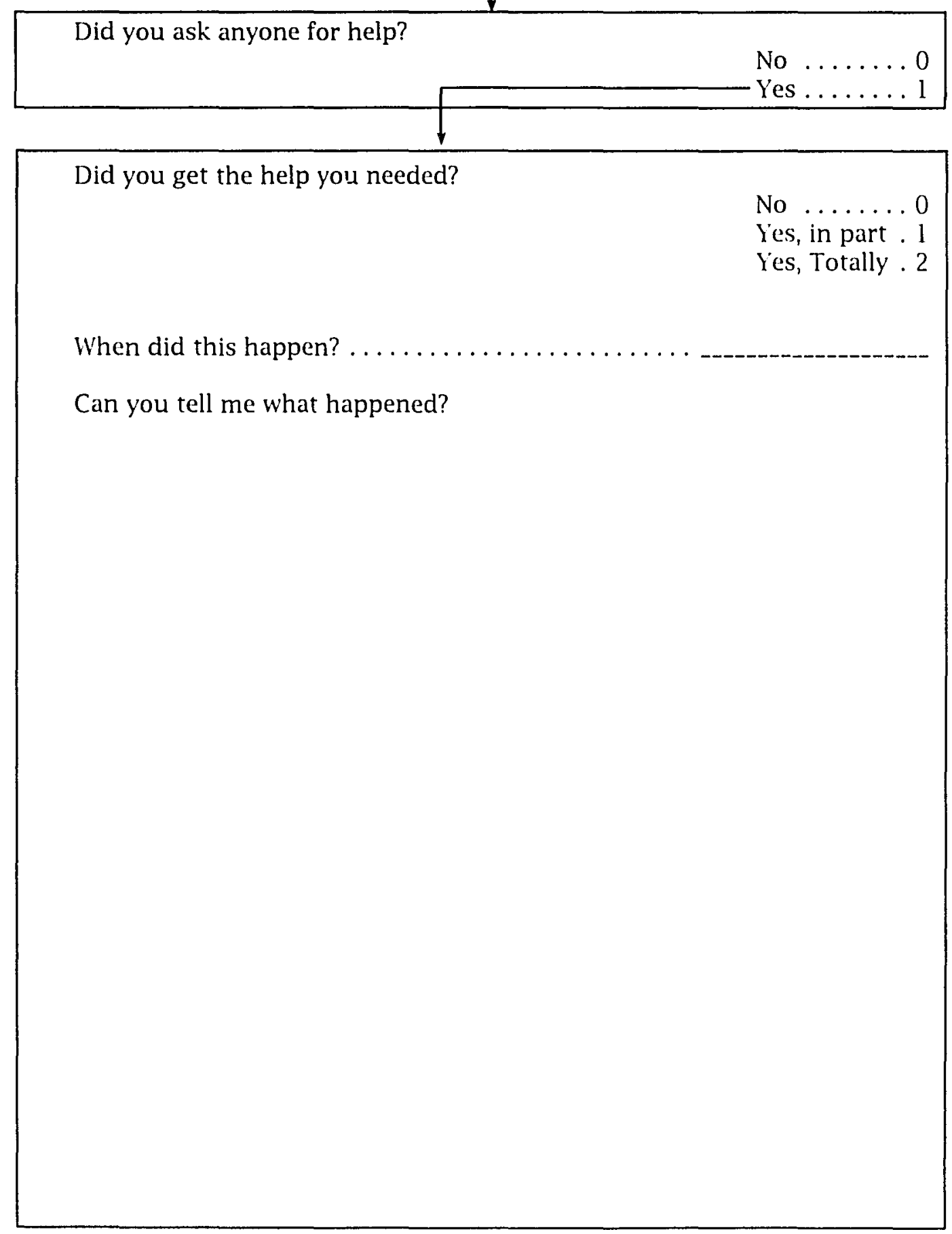


68. Suppose you are worried that your husband is drinking too much alcohol, and you want him to drink less, or stop drinking completely. What would you do?

$$
\text { Try to talk to him about it. }
$$

Is there someone you could ask to try to influence him?

[PROMPT: Is there anyone else?]

\section{(LIST NETWORK MEMBERS)}

Have you ever had this type of problem?

No ......(1)

Yes .... 1

Did you ask anyone for help?

No .......

Yes ....... 1

Did you get the help you needed?

No .......

Yes, in part . I

Y'es, Totally . 2

When did this happen? .

Can you tell me what happened? 
69. Suppose you discover or you are suspicious that your husband is having an affair with another woman. What would you do?

Try to find out if it's true and if it

is, confront him with it. If he refuses

to stop. I would leave

Is there someone you could ask to intervene on your behalf in this situation?

[PROMPT: Is there anyone else?]

\section{(LIST NETWORK MEMBERS)}

Have you ever had this type of problem?

No ..... (0)

I'es .... I

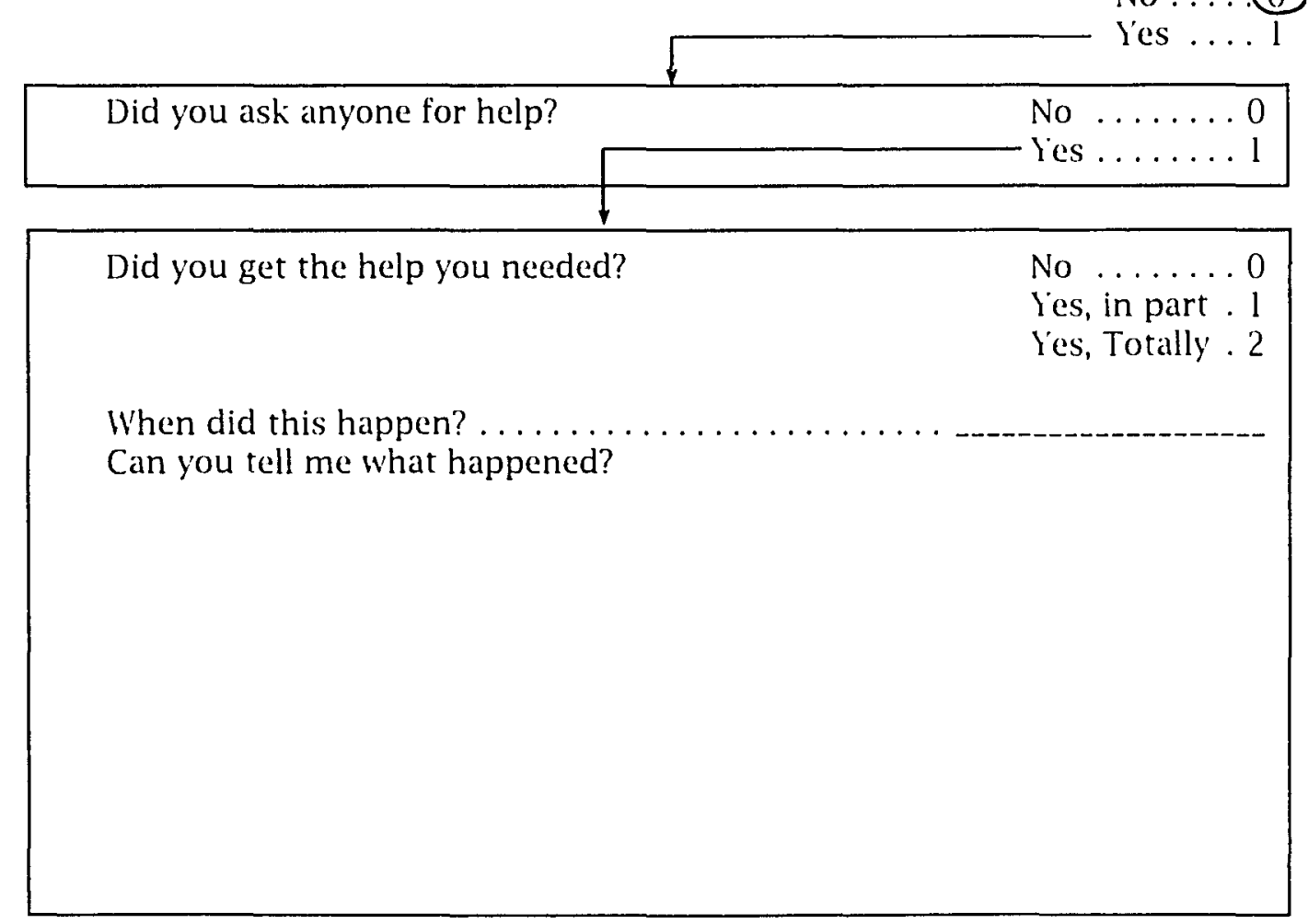




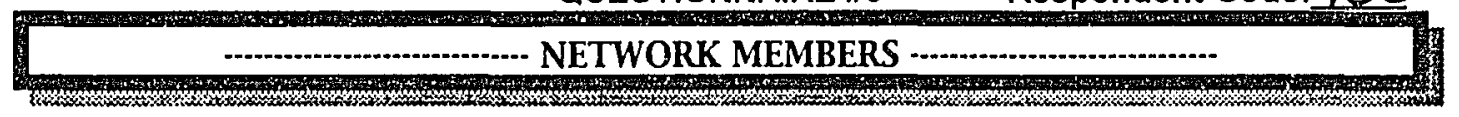

Now I want to ask you some more about the people you have named as your helpers and supporters. As I go down the list, I would like you to answer the same question for each person.

70. First, I want to be sure that I know the sex and age of each person...

71. Now could you tell me your relationship to each person?

Child .............. ENF

Husband .............MRI

Sister ................ S

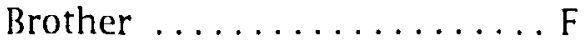

Sister's Husband . ........ MDS

Brother's Wife ......... FDF

Mother............ MER

Father ............. PER

Grand-mother ......... GM

Grand-father ........... GP

Maternal Aunt .......... TM

Maternal Uncle .......... OM

Paternal Aunt .......... TP

Paternal Uncle ......... OP

Husband's Mother ...... MDM

Husband's Father ........ PDM

Husband's Grand-mother . GMIN

Husband's Grand-father ... GPMI

Husband's Sister ......... SDM

Husband's Sister's Husband MISM

Husband's Brother ....... FDM

Husband's Brother's Wife .. FFM

Husband's Aunt . . . . . . TDM

Husband's Uncle ......... ODM

Father's Wife ......... FDP

Mother's Husband ........ BP

Half-Sister .......... DS

Half-Brother ......... DF

Other Family . .........AF

Other In-Laws ...........ABF

Friend $\ldots \ldots \ldots \ldots \ldots$ ANII

Acquaintance .......... CON

Husband's Friend ......... ADM

Colleague ............ COL

Neighbor ..............

Maid ............... BON

Other [please specify by giving a number and defining it above] $\ldots \ldots \ldots \ldots$ ? 
72. Thinking about your personality and the personality of each person, would you say that you are similar?

Not at all ...........

Somewhat $\ldots \ldots \ldots \ldots 2$

Very Similar ........ 3

73. Now, how often do you have contact with each person by telephone, mail or face to face?

Daily............. I

More than once a week . 2

Each week .......... 3

Each month ........4

74. (Deleted)

Less than once a month .5

75. (Deleted)

76. If you go to _-_-_._'s house, how long does it take to get there?

\section{(Code \#+ "M" for minutes \\ "H" for hours \\ "I" for days)}

\section{7.(Deleted)}

78.(Deleted)

79. In many relationships with family, friends and others, one person sometimes does more for another than that person does for him or her. In general, when you think about would you say that you: [Show Scale] [No support/help = 0]

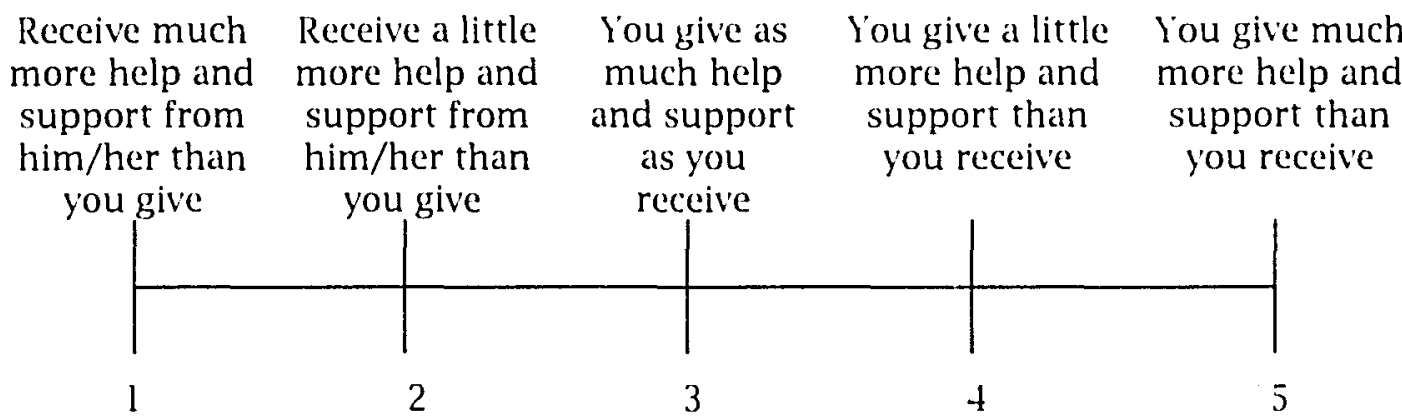

80. If you think about all the types of help and support that we have talked about, how of ten do you receive these kinds of support from each person? [show card]

Daily ................

More than once a week ..... . 2

Each month ........... 3

Each month ..........

Less than once a month .... . 5

Never .................

81. (Deleted) 
82. If you think about negative interactions, how of ten do you have this type of interaction with

Daily .................

More than once a week ..... 2

Each week ............ 3

Each month ..........4

Less than once a month ....5

Never..............6 6

83. In general, when you receive support or help from a member of your family, do you feel obliged to return the favor?

Always ......... 1

Often $\ldots \ldots \ldots 2$

Sometimes ......3

Rarely ..........

Never ......... 5

84. Do you find it difficult to return such help to the relatives who have helped you?
Always $\ldots \ldots \ldots$.....
Often .........2
Sometimes ......3
Rarely ..........
Never ..........5

85. In general, when you receive support or help from someone who is not a relative, do you feel obliged to return the favor?
Always .........
Often .........2
Sometimes ...... 3
Rarely ........4
Never .......... 5

86. Do you find it difficult to return such help to others who have helped you?

Always .........

Often ........2

Sometimes ...... 3

Rarely .........

87. Stop Time: $5: 30$

Never .........5

88. [DENSITY] Among the people that you have mentioned, who know's each other? 
APPENDIX B

SES AND T-M SCALES AND RELIABILITY ANALYSES 


\section{Reliability Analysis of the Socio-Economic Status (SES) Scale}

Final $\mathrm{N}$ of Cases in Scale $=131.0$

Final $N$ of Items in Scale $=6$

Scale Mean $=.1288$
Scale Variance $=15.6577$

Scale Standard Deviation $=3.9570$

Chronbach's Alpha $=.7690$

TABLE XXIV

ITEM-TOTAL STATISTICS FOR SES SCAIE RELIABIITY ANALYSIS

\begin{tabular}{|l|c|c|c|c|}
\hline $\begin{array}{l}\text { Variables } \\
\text { Included in } \\
\text { SES Scale }\end{array}$ & $\begin{array}{c}\text { Scale } \\
\text { Mean If } \\
\text { Item } \\
\text { Deleted }\end{array}$ & $\begin{array}{c}\text { Scale Variance } \\
\text { If Item Deleted }\end{array}$ & $\begin{array}{c}\text { Item-Total } \\
\text { Correlation }\end{array}$ & $\begin{array}{c}\text { Corrected } \\
\text { Alpha if } \\
\text { Item } \\
\text { Deleted }\end{array}$ \\
\hline $\begin{array}{l}\text { Level of } \\
\text { Education }\end{array}$ & .1018 & 10.6397 & .6237 & .7049 \\
\hline $\begin{array}{l}\text { Employment } \\
\text { Status }\end{array}$ & .0918 & 11.6691 & .4374 & .7548 \\
\hline $\begin{array}{l}\text { Owns } \\
\text { Automobile }\end{array}$ & .0891 & 11.5179 & .4597 & .7491 \\
\hline $\begin{array}{l}\text { Status Level of } \\
\text { Husband's Job }\end{array}$ & .1176 & 11.1189 & .5295 & .7306 \\
\hline $\begin{array}{l}\text { Total Revenue } \\
\text { Status Level of } \\
\text { Respondent's } \\
\text { Job }\end{array}$ & .1213 & 10.8566 & .5771 & .7176 \\
\hline
\end{tabular}




\title{
Reliability Analysis of the Traditionality-Modernity (T-M) Scale
}

Final $\mathrm{N}$ of Cases in Scale $=132$

Final $\mathrm{N}$ of Items in Scale $=19$

Scale Mean $=.2408$

\author{
Scale Variance $=172.5086$ \\ Scale Standard Deviation $=13.1343$ \\ Chronbach's Alpha $=.9402$
}

\section{TABLE XXV}

\section{ITEM-TOTAL STATISTICS FOR T-M SCALE RELIABIITYY ANALYSIS}

\begin{tabular}{|c|c|c|c|c|}
\hline Variables Included in Scale & $\begin{array}{l}\text { Scale Mean if } \\
\text { Item Deleted }\end{array}$ & $\begin{array}{l}\text { Scale Variance if } \\
\text { Item Deleted }\end{array}$ & $\begin{array}{l}\text { Corrected } \\
\text { Item-Total } \\
\text { Correlation }\end{array}$ & $\begin{array}{l}\text { Alpha if } \\
\text { Item } \\
\text { Deleted }\end{array}$ \\
\hline Respondent's Age & .2259 & 155.1824 & .6548 & .9370 \\
\hline Level of Education & .2491 & 149.9272 & .8760 & .9328 \\
\hline Employment Status & .2417 & 157.0053 & .5786 & .9384 \\
\hline Respondent is Homemaker & .2382 & 154.5257 & .6830 & .9365 \\
\hline Respondent Chose Husband & .2132 & 155.9010 & .6276 & .9375 \\
\hline Number of Children & .2088 & 158.2168 & .5446 & .9390 \\
\hline Reads Classical Arabic & .2645 & 157.8675 & $.5 \div 07$ & .9391 \\
\hline Reads English & .2350 & 155.7853 & .6313 & .9374 \\
\hline Reads French & .2184 & 150.0138 & .8803 & .9328 \\
\hline Speaks Classical Arabic & .2630 & 158.4439 & .5203 & .9395 \\
\hline Speaks English & .2286 & 156.1548 & .6120 & .9378 \\
\hline Speaks French & .2071 & 149.6718 & .8998 & .9324 \\
\hline $\begin{array}{l}\text { Respondent's Husband Was Chosen } \\
\text { by Her Family }\end{array}$ & .2088 & 154.3739 & .6956 & .9362 \\
\hline Respondent Wears the Djellaba & .2248 & 157.7594 & $.5+48$ & .9390 \\
\hline $\begin{array}{l}\text { Respondent Wears European Style } \\
\text { Clothing }\end{array}$ & .1980 & 154.3759 & $.70+9$ & .9361 \\
\hline $\begin{array}{l}\text { Respondent Wears a Scarf on Her } \\
\text { Head }\end{array}$ & .1987 & 155.8573 & .6491 & .9371 \\
\hline Respondent Wears the Veil & .2566 & 158.1279 & .5154 & .9396 \\
\hline $\begin{array}{l}\text { Respondent Wore a Scarf During } \\
\text { the Interview }\end{array}$ & $.23+1$ & 158.3210 & .5297 & .9393 \\
\hline $\begin{array}{l}\text { Respondent Wore European-Style } \\
\text { Clothing During the Interview }\end{array}$ & .2198 & 153.9903 & .7117 & .9359 \\
\hline
\end{tabular}


APPENDIX C

INTERVIEWER AND REFUSAL QUESTIONNAIRES 
89. Did the respondent have any difficulty hearing the questions?

Yes, great difficulty $\ldots \ldots \ldots \ldots \ldots \ldots \ldots$

Yes, some difficulty $\ldots \ldots \ldots \ldots \ldots \ldots 2$

No, none at all $\ldots \ldots \ldots \ldots \ldots$ (3)

90. Did the respondent have any difficulty understanding the questions?

Yes, great difficulty $\ldots \ldots \ldots \ldots \ldots \ldots$

Yes, some difficulty $\ldots \ldots \ldots \ldots \ldots \ldots 2$

No, none at all $\ldots \ldots \ldots \ldots \ldots \ldots$ (3)

91. What was the respondent's initial attitude about being interviewed?

Very interested or enthusiastic . ..........

Somewhat interested ................ (2)

Indifferent ..................

Somewhat reluctant $\ldots \ldots \ldots \ldots \ldots \ldots \ldots+$

Very reluctant $\ldots \ldots \ldots \ldots \ldots \ldots \ldots \ldots$

Hard to tell $\ldots \ldots \ldots \ldots \ldots \ldots \ldots$

92. What was the respondent's attitucie during the interview?

(Code all that apply) Friendly, eager, voluntecred information ... (1)

Cooperative, not particularly enthusiastic ... OD

Indifferent or bored $\ldots \ldots \ldots \ldots \ldots$ (D) 1

Irritated or hostile .................

Seemed anxious to get it over with $\ldots$. 1

Hard to tell ....................

93. Was anyone present during the interview?

Yes, for most of the interview ..........

Yes, for some of the interview ............ (2)

Yes, but only for a minute or two (Skip to \#95) 3

No, not at any time (Skip to \#95) ..........

94. If other was present for more than a minute or two: Who else was present? Son, age 3

95. Was there a language-based communication problem?

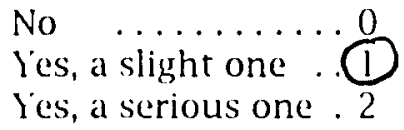


96. Did the respondent have any obvious physical limitations, disabilities or impairments, such as pregnancy, loss of a limb, paralysis, facial disfigurement, serious speech problems, palsy, or poor personal hygiene? (Code all that apply)

[If loss of limb, specify what limb]

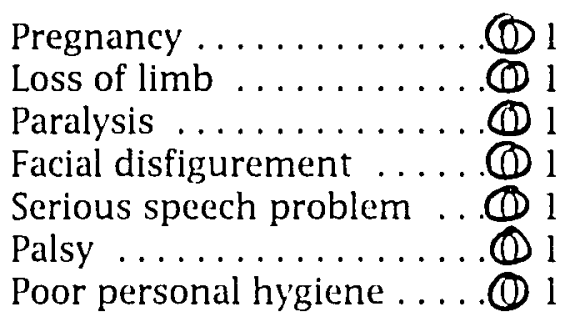

Other (specify)

97. In giving you names of people, did you get the impression that the respondent was exaggerating or underestimating the number of people in her network by giving you too many or too few names?

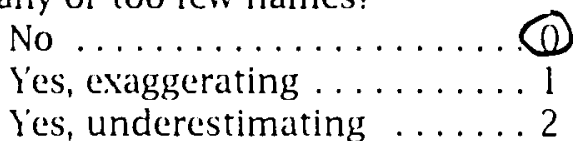

98. Aside from what she said in answer to the specific questions, is it your impression that the respondent leads a very busy' and active life; that she doesn't really have much to do; or that she is about average?

Very busy and active ....... (1)

Doesn't have much to do ....2

About average .......... 3

99. How open and forthcoming do you think the respondent was about her personal problems and feelings?

Open . . . . . . . . . . .
Alittle guarded $\ldots \ldots \ldots \ldots$ (2)
Was not honest $\ldots \ldots \ldots \ldots .3$

100. Did you observe any signs of tension or stress in the respondent's behavior?

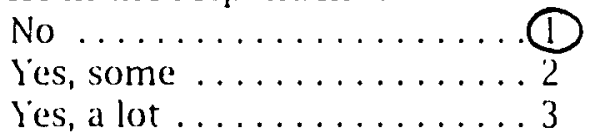




\section{Comments}

Please give a brief report of your contact with the respondent, including any information or impressions that you think might help me understand the respondent's household structure, situation in the neighborhood, social relations, and personal feelings. Also please note anything particular about the appearance of the respondent and her home and or any behavior that would help me understand the type of person she is. Please include a visual assessment of SES. (Code $0=$ no, $1=y e s, 2=$ unable to know)

$$
\begin{aligned}
& \text { VCR ....... } \\
& \text { Color TV ....... O } \$ 2 \\
& \text { Telephone ...... O } 0 \text { (12 } \\
& \text { Washing machine. } 0 \text { (1) } 2 \\
& 2 \mathrm{M} \ldots \ldots \ldots \ldots \mathrm{Q}_{2} \\
& \text { Stereo ........... o (1) } 2 \\
& \text { Furniture: } \\
& \text { very expensive ....... } \\
& \text { moderately expensive .. (2) } \\
& \text { about average ....... } 3 \\
& \text { slightly below average . . } 4 \\
& \text { very inexpensive . . . . . . } 5
\end{aligned}
$$

101. What kind of building does the respondent live in?

Single family attached (small) $\ldots \ldots \ldots \ldots \ldots$.

Single family attached (medium/large) . . . . . 2

Single family detached (small) ........... 3

Single family detached (medium/large) .....

Duplex or triplex ................. 5

Low-rise apartment (2 stories or less) . . . . . 6

High-rise apartment (3-stories or more) ... (7)

Other (specify)

102. What types of buildings are on the respondent's street (both sides of street on same block)? (Code all that apply)

Single family attached homes ......... (1)

Single family detached homes ........ (1) 1

Duplexes or triplexes .............. (1)

Low-rise apartments (2 stories or more) .... (D)

High-rise apartments(3 stories or more) ..... (1)

Commercial facilities ................ (1)

Industry (manufacturing) . . . . . . . . . (1) 1

Institutional structures (schools, mosques, hospitals etc.) ........ (1) 1

Other 
103. How far is the respondent's building from the nearest adjacent building--a few feet, no more than the width of a driveway, or more than that?

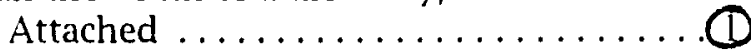

A few feet or less ...............

No more that the width of a driveway ... 3

More than that ...............

104. What does the front door of the respondent's house/apartment face?

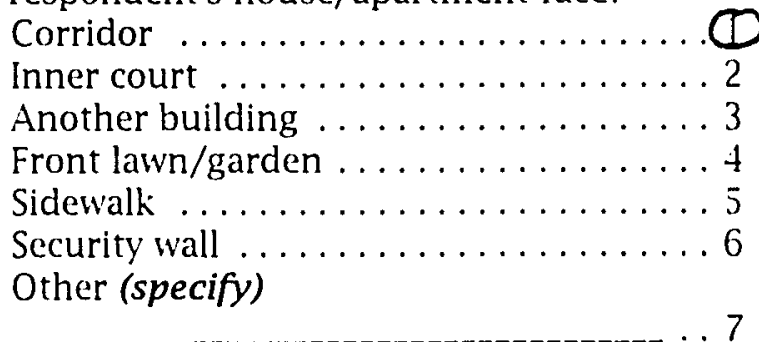

105. Did you see any of the following in the respondent's home or on its grounds? (Code all that apply)

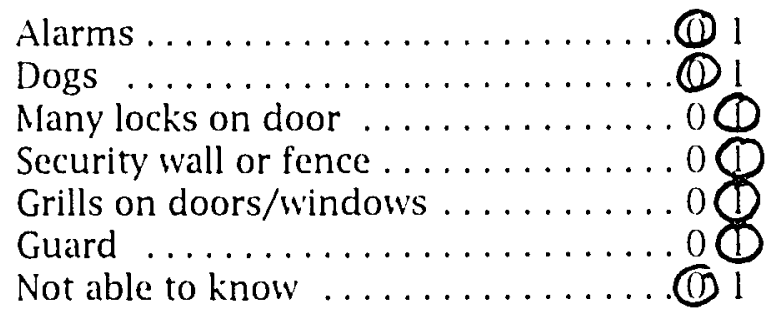

Other (Specify)

106. How well kept up is the outside of the respondent's house and yard/apartment building? Excellent condition ............

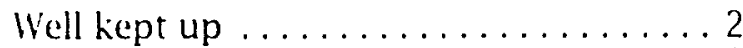

A bitworn down ............. (5)

Very poorly kept up ............ 4

A mixture of well kept up and poorly kept up ............ 5

107. How much activity--cars and people--was there on the street?

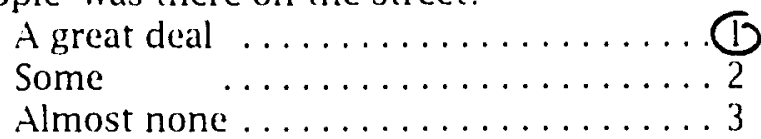

108. Time of day 
109. Area of city/neighborhood:

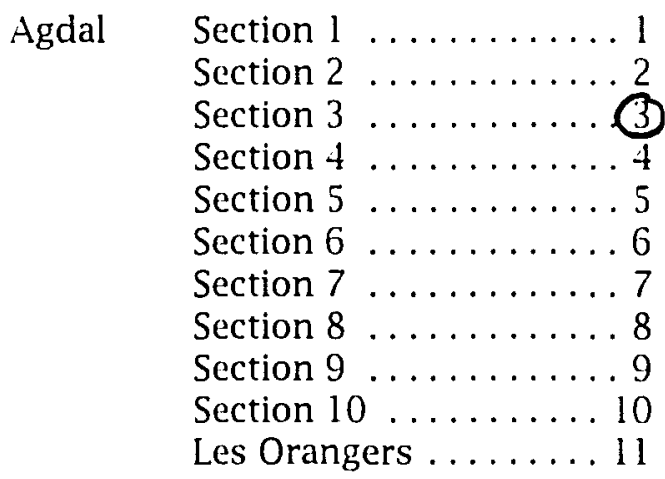

Other (specify)

110. Respondent's dress? (Code all that apply)

Western ................. (1)

Djellaba/Other traditional ....... 0

Hijeb ..................

Scarf/Other head covering .......1

Full veil with face covered .......(1) !

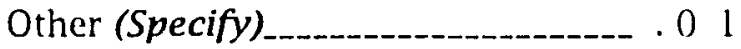


2. What was the respondent's approximate age?

$\begin{array}{lll}14-19 & \ldots & 1 \\ 20-29 & \ldots & 2 \\ 30-39 & \ldots & 3 \\ 40-49 & \ldots & 4 \\ 50-59 & \ldots & 5 \\ 60-69 & \ldots & 6 \\ 70-79 & \ldots & 7 \\ 80-89 & \ldots & 8\end{array}$

3. What was the reason given for the refusal?

\section{Not interested}

4. Were there small children obviously present?

No .......

Yes, some ... 1

Yes, many ... (2)

5. Did the respondent have any obvious physical limitations, disabilities or impairments, such as pregnancy, loss of a limb, paralysis, facial disfigurement, serious speech problems, palsy, or the like?

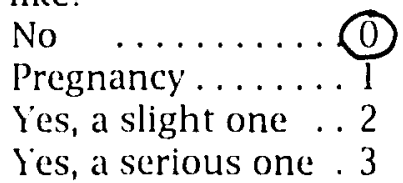

6. Did you observe any signs of tension or stress in the respondent's behavior?

No $\ldots . . . . .0$

Yes, some ... (1)

Yes, a lot ...2

7. Was someone else responsible for the refusal?

If yes, who (if known)?

$$
\begin{aligned}
& \text { No ..... (0) } \\
& \text { Yes .... }
\end{aligned}
$$

\section{Comments}

Please give a brief report of your contact with the respondent, including any information or impressions that you think might help me understand the respondent's household structure, situation in the neighborhood, social relations, and personal feelings. Also please note anything particular about the appearance of the respondent and her home and or any behavior that would help me understand the type of person she is. Please include a visual assessment of SES. VCR ......... O) 2

Color TV ....... 0 12

Telephone ....... 010

Washing machine. 01 (2) 
8. What kind of building does the respondent live in?

Single family attached $\ldots \ldots \ldots \ldots \ldots$.

Single family detached ............. 2

Duplex, town house, row house ....... 3

Low-rise apartment (2 stories or less) . . 4

High-rise apartment (3-stories or more) . (5)

Other (specify)

9. What types of buildings are on the respondent's street (both sides of street on same block)? (Code all that apply)

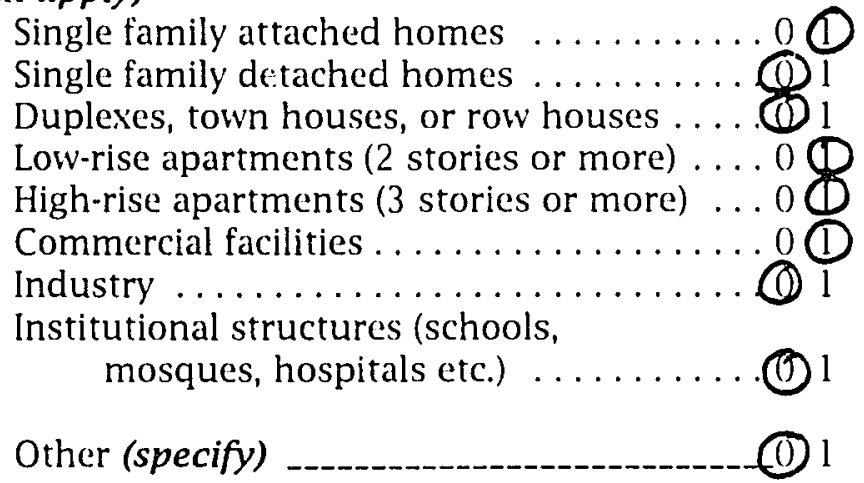

10. How far is the respondent's building from the nearest adjacent building-a few feet, no more than the width of a driveway, or more than that?

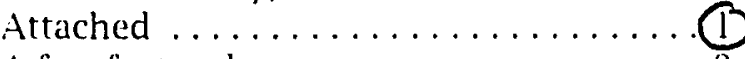

A few feet or less ..............

No more that the width of a driveway ... 3

More than that $\ldots \ldots \ldots \ldots \ldots \ldots \ldots$

11. What does the front door of the respondent's house/apartment face?

Corridor ................. (1)

Inner court ........... 2

Another building ........ 3

Front lawn/garden . . . . . . . 4

Sidewalk ............ 5

Security wall ..........6

Other (specify) _- . . 7 
12. Did you see any of the following in the respondent's home or on its grounds? (Code all that apply)

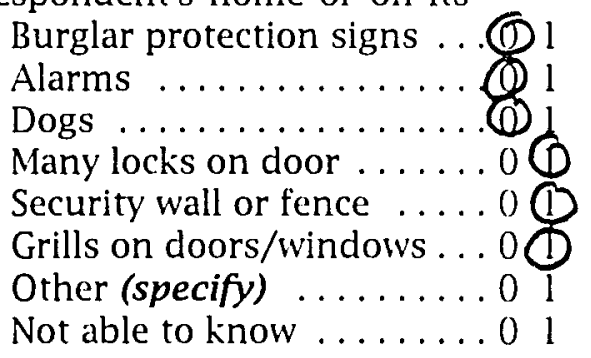

13. How well kept up is the outside of the respondent's house and yard/apartment building?

Very attractive .............

Well kept up ............. 2

A bit worn down ............... (3)

Very poorly kept up ..........

A mixture of well kept up

and poorly kept up $\ldots \ldots \ldots 5$

14. How much activity--cars and people--was there on the street?

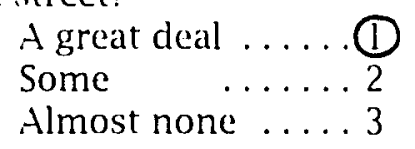

15. Area of city/neighborhood:

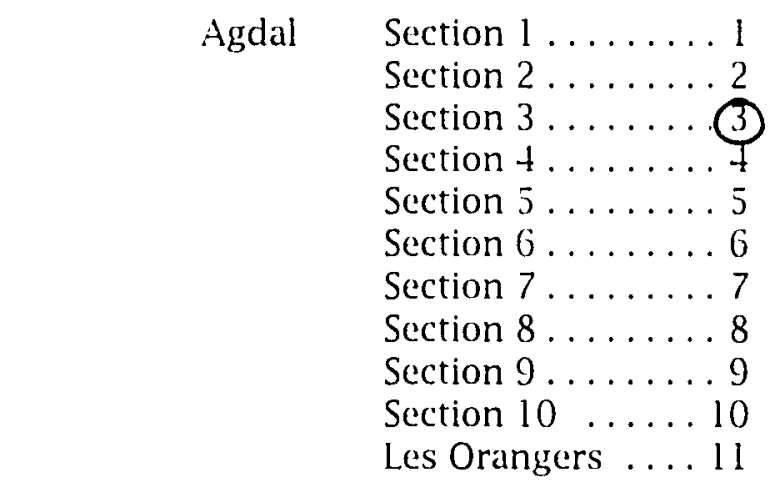

Other (specify)

17. Respondent's dress? (Code all that apply) Western ..........ळ

Djellaba/Other traditional . 0 (1)

Hijeb .............. (1)

Scarf/Other head covering (1) 1

Full veil with face covered. (1) 1 


\section{APPENDIX D \\ Brief Symptoms Inventory (BSI)}

Permission to create and use a variant version of the BSI was granted by Clinical Psychometric Research, Inc. and

Leonard R. Derogatis, Ph.D. on September 12, 1991.

A copy of the contract appears in this Appendix. 
This agreement is made as of the 12th day of September 1991 between Clinical Psychometric Research, Inc. and Leonard R. Derogatis, Ph.D. ("Licensor") and Carla Green ("Licensee"). The Licensor is the owner of the United States Copyright and Trademark on a psychological test known as the Brief symptom Inventory (BSI)

the "Test", and wishes to grant the Licensee the nonexclusive right to reproduce a variant version of the Test and use the variant version on the Test upon the terms and conditions hereinafter set forth.

1. Prior to its actual use in the research project for which it is intended, the Licensee agrees to provide the Licensor with a copy or "mock up" of the proposed variant version of the Test. The Iicenses also agrees to provide the Liverssor with a brief description of the project and its estimated start and completion dates.

2. The Licensee agrees that the name of the test RSI will appear prominently at the top of the first page of the version of the Test. The Licensee further agrees that the Licensor's name and copyright date will appear at the bottom of the first page as follows, "Copyright (C) 1975 by Leonard R. Derogatis, Ph.D., and further, that the message, "reproduced under license by the author" will also appear at the bottom of the first page.

3. The Licensee agrees that except for the specific variations in the test granted by this License, no alterations or changes will be made in the Test without the expressed written consent of the Licensor.

4. The Licensor herein grants to the Licensee a license to produce exactly _ _** copies of the variant version of the test as represented by the prototype identified in Paragraph 1 above.

5. The Licersee agrees to pay to the Licensor a rovalty of Eifty-cents (5.50) per variant version produced for a total royalty of _, the total amount payable within 30 days of receipt of an invoice for this amount.

6. The Licensee agrees that he will not sell, lease, distribute without payment, or in any other way disseminate, or allow to be disseminated by individuals in his/her employ, copies of the Test, except as specified herein. Further, the Licensee agrees that the use of the Test as licensed by this agreement is limited to the project identified in Paragraph 1 above, and that use of the Test in other contexts must be covered by a separate agreement.

*** Number of tests used will be supolied at end of study 
7. The Licensee agrees to provide the Licensor two (2) copies of the variant version of the Test for his files.
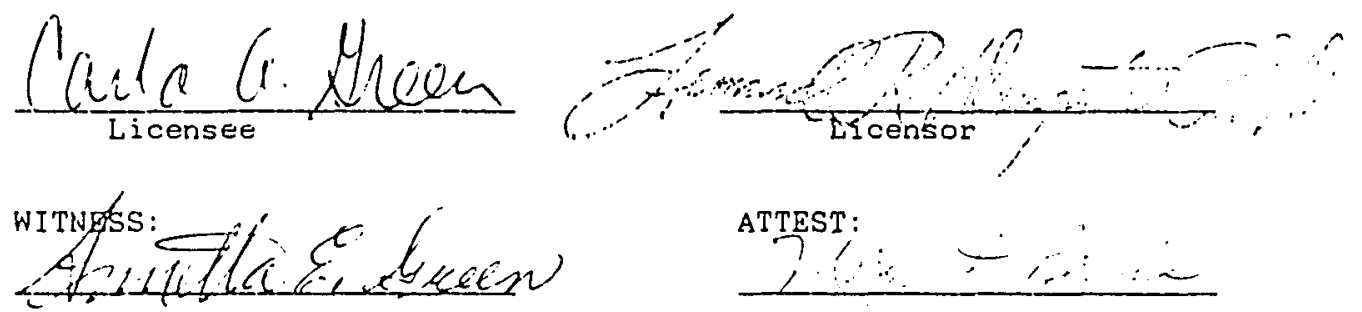

ATTEST:

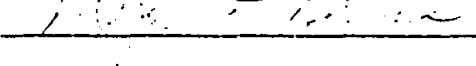




\begin{tabular}{|c|c|c|c|c|c|}
\hline \multicolumn{6}{|c|}{ Brief Symptoms Inventory (BSI) } \\
\hline \multicolumn{6}{|l|}{ Code number: 100} \\
\hline \multicolumn{6}{|c|}{ 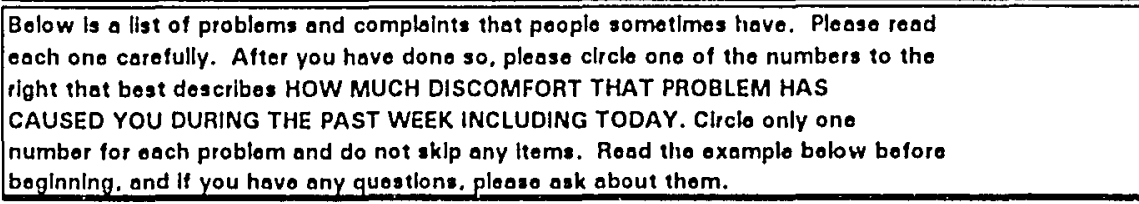 } \\
\hline How Much Were You Distressed By: & $\begin{array}{l}\overline{\bar{\alpha}} \\
\ddot{0} \\
\dot{0} \\
\underline{z}\end{array}$ & 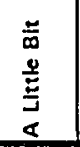 & $\begin{array}{l}\frac{7}{0} \\
\frac{0}{0} \\
\frac{0}{0} \\
\frac{0}{2} \\
\Sigma\end{array}$ & 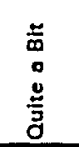 & 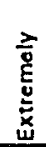 \\
\hline $\begin{array}{l}\text { Example: } \\
\text { Body Aches }\end{array}$ & 0 & 1 & 2 & 3 & 4 \\
\hline 1. Nervouenese or sliaklneers Instde & 0 & 3 & 2 & 3 & 4 \\
\hline 2. Fointness or dizziness & 0 & (1) & 2 & 3 & 4 \\
\hline $\begin{array}{l}\text { 3. The Idea that someone olse can } \\
\text { control your thoughts }\end{array}$ & (0) & 1 & 2 & 3 & 4 \\
\hline $\begin{array}{l}\text { 4. Foolling othors are to blamo for most } \\
\text { of your troubles }\end{array}$ & (0) & 1 & 2 & 3 & 4 \\
\hline 5. Trouble rememberlng things & 0 & (1) & 2 & 3 & 4 \\
\hline 6. Foeling easily annoyed or luritated & 0 & 1 & 2 & (3) & 4 \\
\hline 7. Pains In heart or chast & (0) & 1 & 2 & 3 & 4 \\
\hline 8. Foeling ofrald in open spoces & 0 & $\bar{T}$ & 2 & 3 & 4 \\
\hline 9. Thoughts of ending your lifo & (0) & 1 & 2 & 3 & 4 \\
\hline $\begin{array}{l}\text { 10. Feeling that most people cannot be } \\
\text { trusted }\end{array}$ & (0) & 1 & 2 & 3 & 4 \\
\hline 11. Poor appetito & (0) & 1 & 2 & 3 & 4 \\
\hline 12. Suddenly scared for no reoson & 02 & 1 & 2 & 3 & 4 \\
\hline $\begin{array}{l}\text { 13. Tomper outbursts that you could not } \\
\text { control }\end{array}$ & 0 & 1 & (2) & 3 & 4 \\
\hline $\begin{array}{l}\text { 14. Foeling lonely evon when you aro } \\
\text { with peoplo }\end{array}$ & 0 & (1) & 2 & 3 & 4 \\
\hline $\begin{array}{l}\text { 15. Fooling blocked in gotting things } \\
\text { dono }\end{array}$ & 0 & (1) & 2 & 3 & 4 \\
\hline 16. Feeling lonely & 70 & 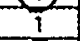 & 2 & 3 & 4 \\
\hline 17. Feelling blue & 0 & $\pi$ & 2 & 3 & 4 \\
\hline 18. Foeling no interest In things & 6 & $T$ & 2 & 3 & 4 \\
\hline 19. Foeling fearful & 02 & 1 & 2 & 3 & 4 \\
\hline 20. Your foelings being eosilly hurt & $(0)$ & 1 & 2 & 3 & 4 \\
\hline $\begin{array}{l}\text { 21. Feellng that people are unfriendly } \\
\text { or dislike you }\end{array}$ & 0 & (1) & 2 & 3 & 4 \\
\hline 22. Foeling Inferior to others & 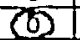 & 1 & 2 & 3 & 4 \\
\hline 23. Nauses or upset stomach & 0 & (1) & 2 & 3 & 4 \\
\hline $\begin{array}{l}\text { 24. Feeling that you aro wotched or } \\
\text { talked about by others }\end{array}$ & $\infty$ & 1 & 2 & 3 & 4 \\
\hline 25. Troublo falling asleep & 0 & 1 & 2 & (3) & 4 \\
\hline
\end{tabular}




\section{Brief Symptoms Inventory}

Page 2

\begin{tabular}{|c|c|c|c|c|c|}
\hline How Much Were You Distressed By: & $\sum_{0}^{\bar{\alpha}}$ & 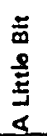 & $\begin{array}{l}\frac{7}{9} \\
\stackrel{0}{0} \\
\frac{0}{0} \\
\frac{\circ}{2}\end{array}$ & 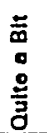 & 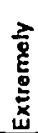 \\
\hline $\begin{array}{l}\text { 28. Hoving to chock and doublo-chock } \\
\text { what you do }\end{array}$ & 0 & & 2 & 3 & 4 \\
\hline 27. Difflculty maklng doclaion: & (a) & 1 & 2 & 3 & 4 \\
\hline $\begin{array}{l}\text { 28. Fooling ofrald to travol on buses. } \\
\text { subways, of tralne }\end{array}$ & & 1 & 2 & 3 & 4 \\
\hline 29. Trouble gettling your breath & (0) & 1 & 2 & 3 & 4 \\
\hline 30. Hot or cold spolts & 0 & & 2 & 3 & 4 \\
\hline $\begin{array}{l}\text { 31. Hoving to avold certaln things, } \\
\text { ploces, of activitios becouse they } \\
\text { frlghten you }\end{array}$ & & 1 & 2 & 3 & 4 \\
\hline 32. Yout mind going blank & 0 & & 2 & 3 & 4 \\
\hline $\begin{array}{l}\text { 33. Numbness or tingling In parts of } \\
\text { your body }\end{array}$ & 0 & & 2 & 3 & 4 \\
\hline $\begin{array}{l}\text { 34. The idea that you should be punlahed } \\
\text { for your ans }\end{array}$ & (6) & 1 & 2 & 3 & 4 \\
\hline 35. Feollng hopolese about the furure & 0 & & 2 & 3 & 4 \\
\hline 36. Troublo concontrating & 0 & & 2 & 3 & 4 \\
\hline 37. Fooling weak in parts of your body & (0) & & $\frac{5}{2}$ & 3 & 4 \\
\hline 38. Foeling tonse or keyod up & 0 & & 2 & 3 & 4 \\
\hline 39, Thoughts of death of dying & 0 & & 2 & 3 & 4 \\
\hline $\begin{array}{l}\text { 40. Hoving urges to beat, injure, or } \\
\text { harm someone }\end{array}$ & & 1 & 2 & 3 & 4 \\
\hline $\begin{array}{l}\text { 41. Having urges to break of emash } \\
\text { things }\end{array}$ & 0 & & 2 & 3 & 4 \\
\hline $\begin{array}{l}\text { 42. Feeling very colf-conscious with } \\
\text { others }\end{array}$ & & $i$ & 2 & 3 & 4 \\
\hline 43. Foeling uneasy In crowds & & 1 & $\frac{2}{2}$ & $\frac{5}{3}$ & 4 \\
\hline $\begin{array}{l}\text { 44. Never foeling close to another } \\
\text { person }\end{array}$ & & 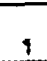 & 2 & 3 & 4 \\
\hline 45. Spolls of terror of pante & & 1 & 2 & 3 & 4 \\
\hline 46. Gotting Into froquent argumente & $\Omega$ & & 2 & 3 & 4 \\
\hline $\begin{array}{l}\text { 47. Fealing nervous whon you are beft } \\
\text { abno }\end{array}$ & & 1 & 2 & 3 & 4 \\
\hline $\begin{array}{l}\text { 48. Others not giving you proper crodit } \\
\text { for your achlovements }\end{array}$ & 0 & 1 & 2 & 3 & 4 \\
\hline $\begin{array}{l}\text { 49. Foeling oo restlose you couldn't sit } \\
\text { etlll }\end{array}$ & & 1 & 2 & 3 & 4 \\
\hline 50. Foelings of worthlessness & & 1 & 2 & 3 & 4 \\
\hline $\begin{array}{l}\text { 51. Foollng thet poople will take } \\
\text { advantage of you if you lot them }\end{array}$ & 0 & & 2 & 3 & 4 \\
\hline 52. Foelinga of guilt & 0 & 3 & $\frac{2}{2}$ & 3 & 4 \\
\hline $\begin{array}{l}\text { 63. The ldes that something to wrong } \\
\text { whth your mind }\end{array}$ & & 1 & 2 & 3 & 4 \\
\hline
\end{tabular}


APPENDIX E

Modified Life Experiences Survey (LES) 


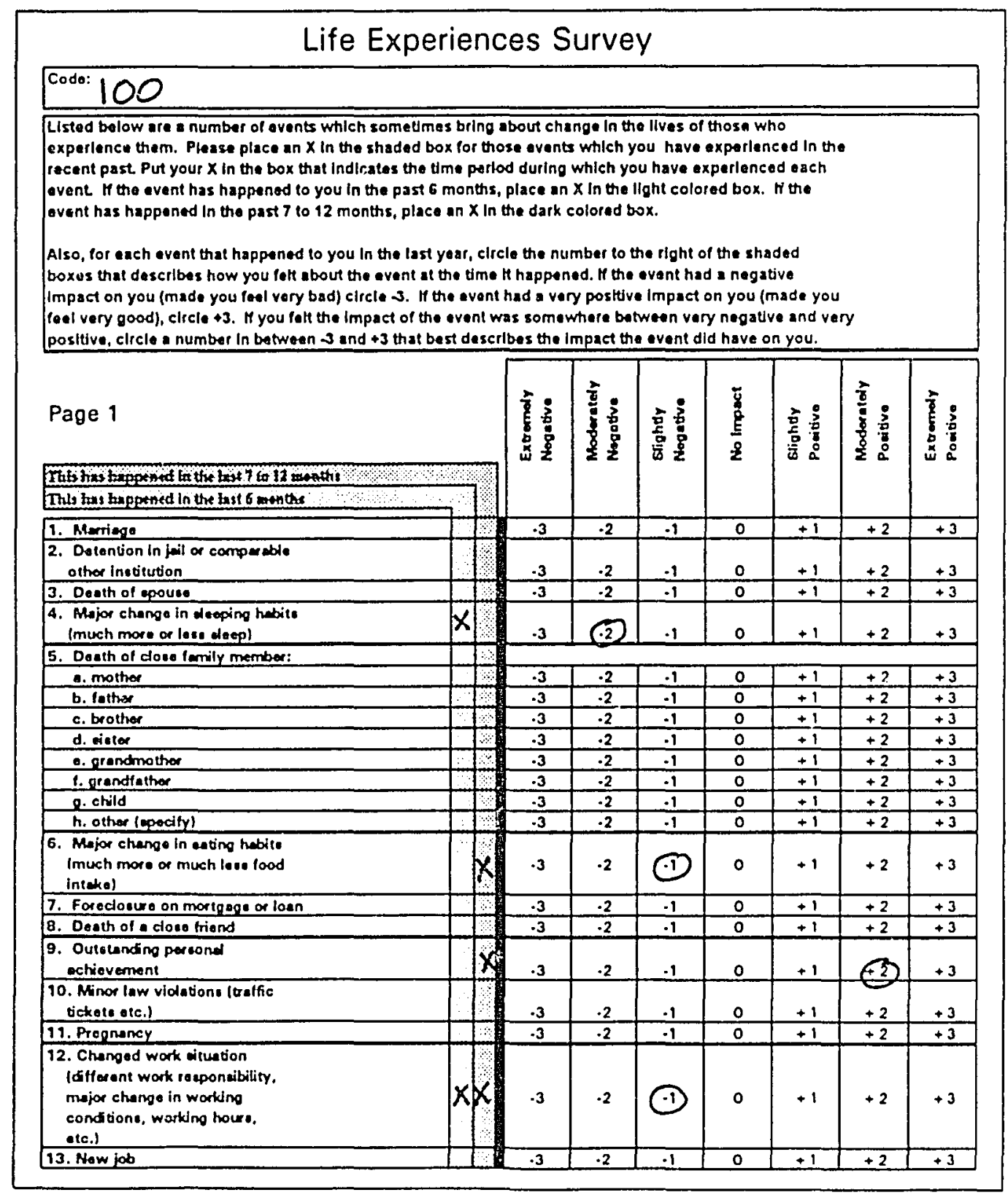




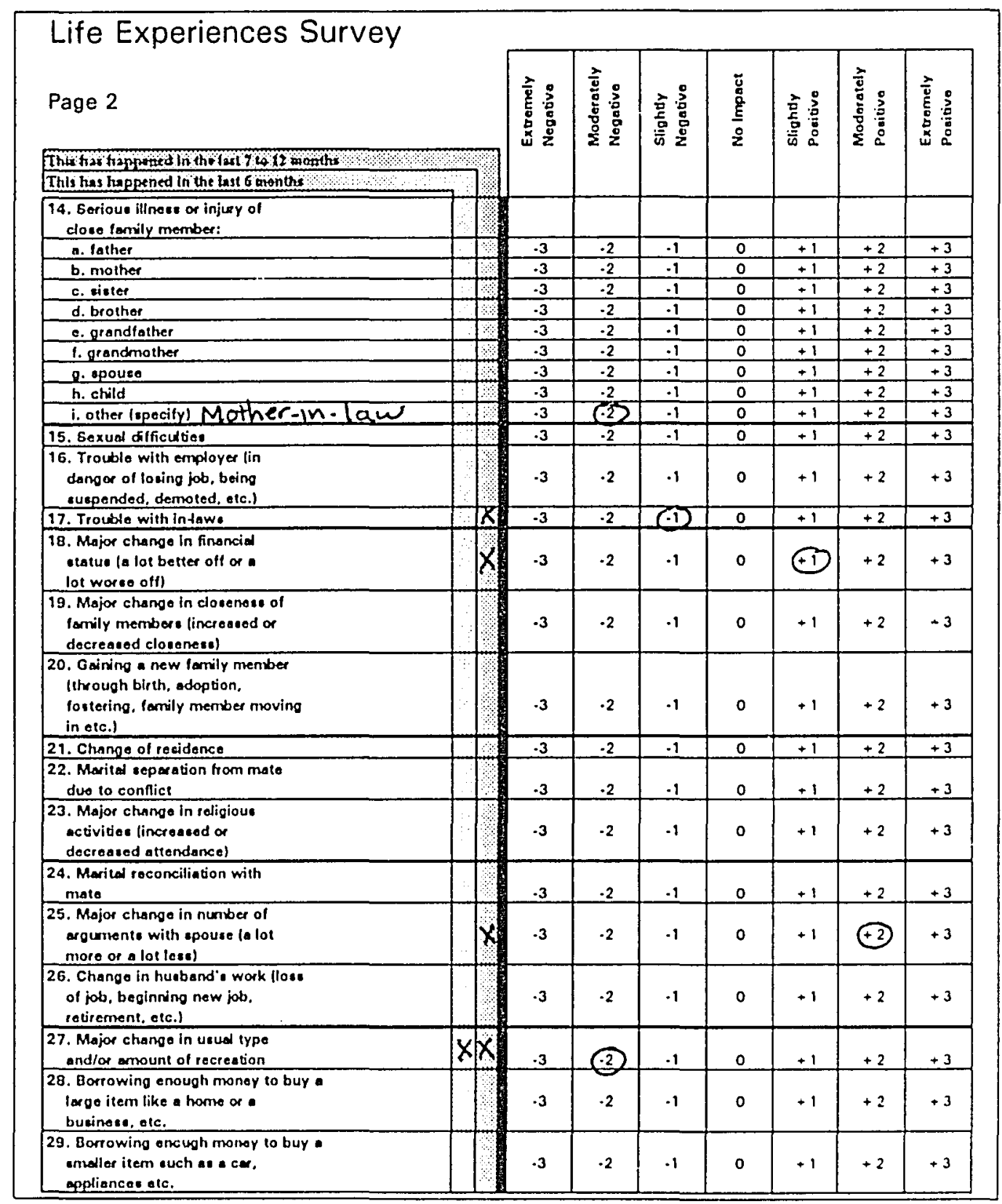




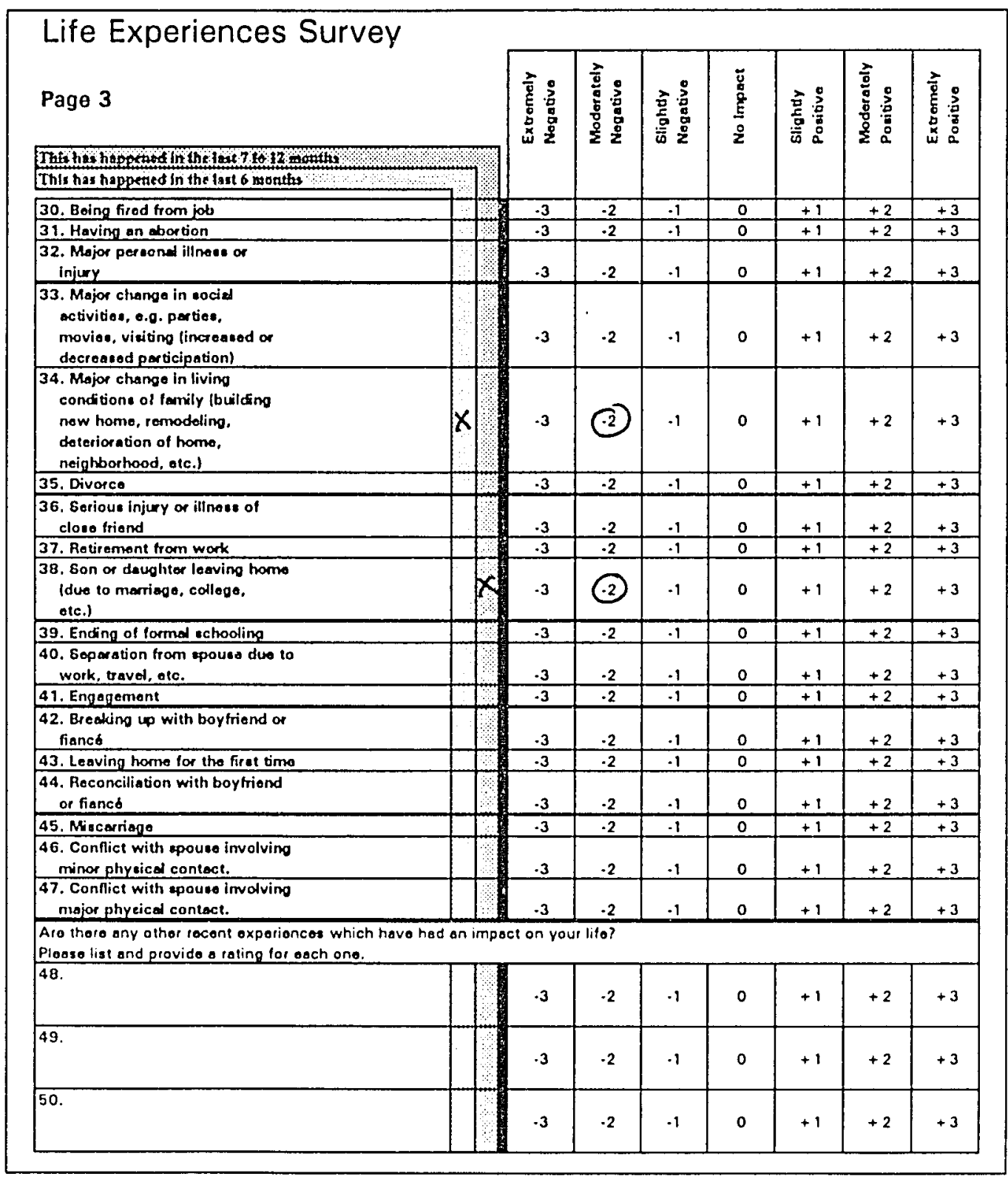




\section{APPENDIX F \\ Index of Marital Satisfaction (IMS)}

Permission to use and reproduce the IMS was granted by

Walter W. Hudson, Ph.D., in a letter dated January 11, 1994. 


\begin{tabular}{|c|c|c|c|c|c|}
\hline \multicolumn{3}{|c|}{ Index of Marital Satisfaction } & \multicolumn{3}{|c|}{ Code: 100} \\
\hline $\begin{array}{l}\text { This set of questions is about how satisfied you are with your } \\
\text { present marriage. Answer by circling the number of the } \\
\text { response which is closest to how you feel for each statement. }\end{array}$ & 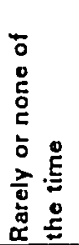 & 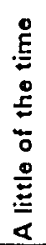 & 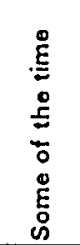 & 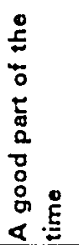 & 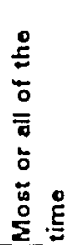 \\
\hline 1. I feel that my husband is affectionate enough. & 1 & 2 & 3 & (4) & 5 \\
\hline 2. I foel that my husband troats mo badly. & 3. & 2 & 3 & 4 & 5 \\
\hline 3. I feel that my husband really cares for mo. & 1 & 2 & 3 & (4) & 5 \\
\hline $\begin{array}{l}\text { 4. I foel that I would not choose the same husband if } \\
\text { I had it to do over. }\end{array}$ & 1 & 2 & 3 & 4 & (5) \\
\hline 5. I feel that / can trust my husband. & 1 & 2 & 3 & 4 & 5 \\
\hline 6. I feel that our relationship is breaking up. & & 2 & 3 & 4 & 5 \\
\hline 7. I feol that my husb and doesn' 1 understand mo. & 1 & 2 & (3) & 4 & 5 \\
\hline 8. I feel that our reletionship is a good one. & 1 & 2 & 3 & 4 & $(5)$ \\
\hline 9. I feel that ours is a very happy relationship. & 1 & 2 & 3 & क) & 5 \\
\hline 10. I feel that our life together is dull. & & 2 & 3 & 4 & 5 \\
\hline 11. I foel that we have a lot of fun together. & & 2 & (3) & 4 & 5 \\
\hline 12. I foel that my husband doesn't confide in me. & & 2 & 3 & 4 & 5 \\
\hline 13. I feel that ours is a very close relationship. & & 2 & 3 & 4 & 5 \\
\hline 14. I foel that I cannot rely on my partner. & & 2 & 3 & 4 & 5 \\
\hline $\begin{array}{l}\text { 15. I feel that wo do not have onough interests in } \\
\text { common. }\end{array}$ & & 2 & 3 & 4 & 5 \\
\hline $\begin{array}{l}\text { 16. I foel that we manage arguments and } \\
\text { disagreements very woll. }\end{array}$ & 1 & 2 & (3) & 4 & 5 \\
\hline $\begin{array}{l}\text { 17. I feel that we do a good job of managing our } \\
\text { finances. }\end{array}$ & 1 & 2 & (3) & 4 & 5 \\
\hline $\begin{array}{l}\text { 18. I feel that I should never have married my } \\
\text { purtner. }\end{array}$ & 1) & 2 & 3 & 4 & 5 \\
\hline $\begin{array}{l}\text { 19. I foel that my partner and I get along very well } \\
\text { together. }\end{array}$ & 1 & 2 & 3 & (4) & 5 \\
\hline 20. I feel that our relationship is very stable. & 1 & 2 & 3 & (4) & 5 \\
\hline $\begin{array}{l}\text { 21. I feel that my partner is pleased with me as a sex } \\
\text { partner. }\end{array}$ & 1 & 2 & (3) & 4 & 5 \\
\hline 22. I feal that we should do more things logether. & 1 & 2 & 3 & (4) & 5 \\
\hline $\begin{array}{l}\text { 23. I foel that the futuro looks bright for our } \\
\text { relationship. }\end{array}$ & 1 & 2 & 3 & (4) & 5 \\
\hline 24. I feel that our relationship is empty. & & 2 & 3 & 4 & 5 \\
\hline 25. I feel there is no excitement in our relationship. & & 2 & 3 & 4 & 5 \\
\hline
\end{tabular}




\section{APPENDIX G}

Modified Severity of Illness Rating Scale-Revised (SIRS-R) 


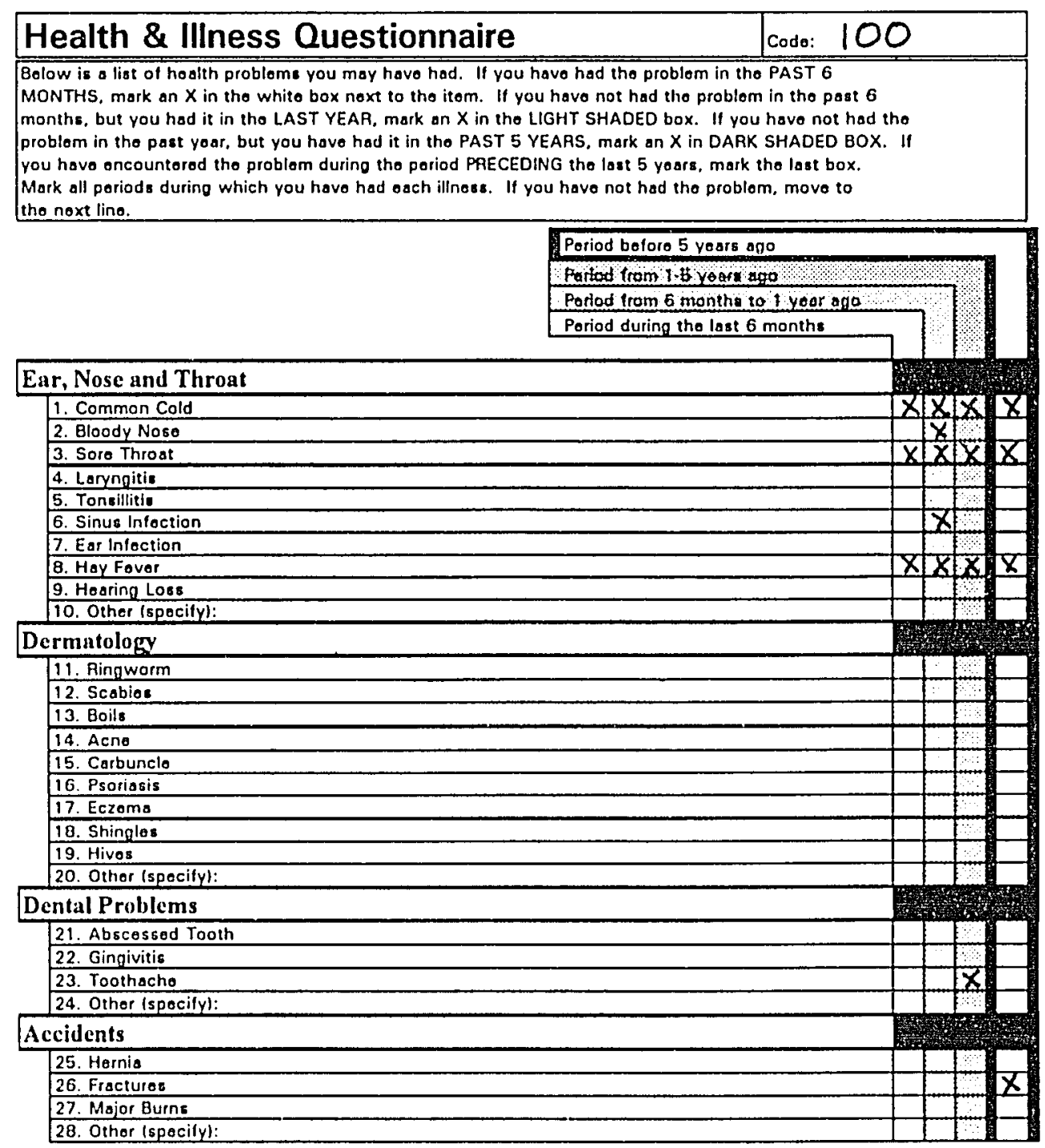




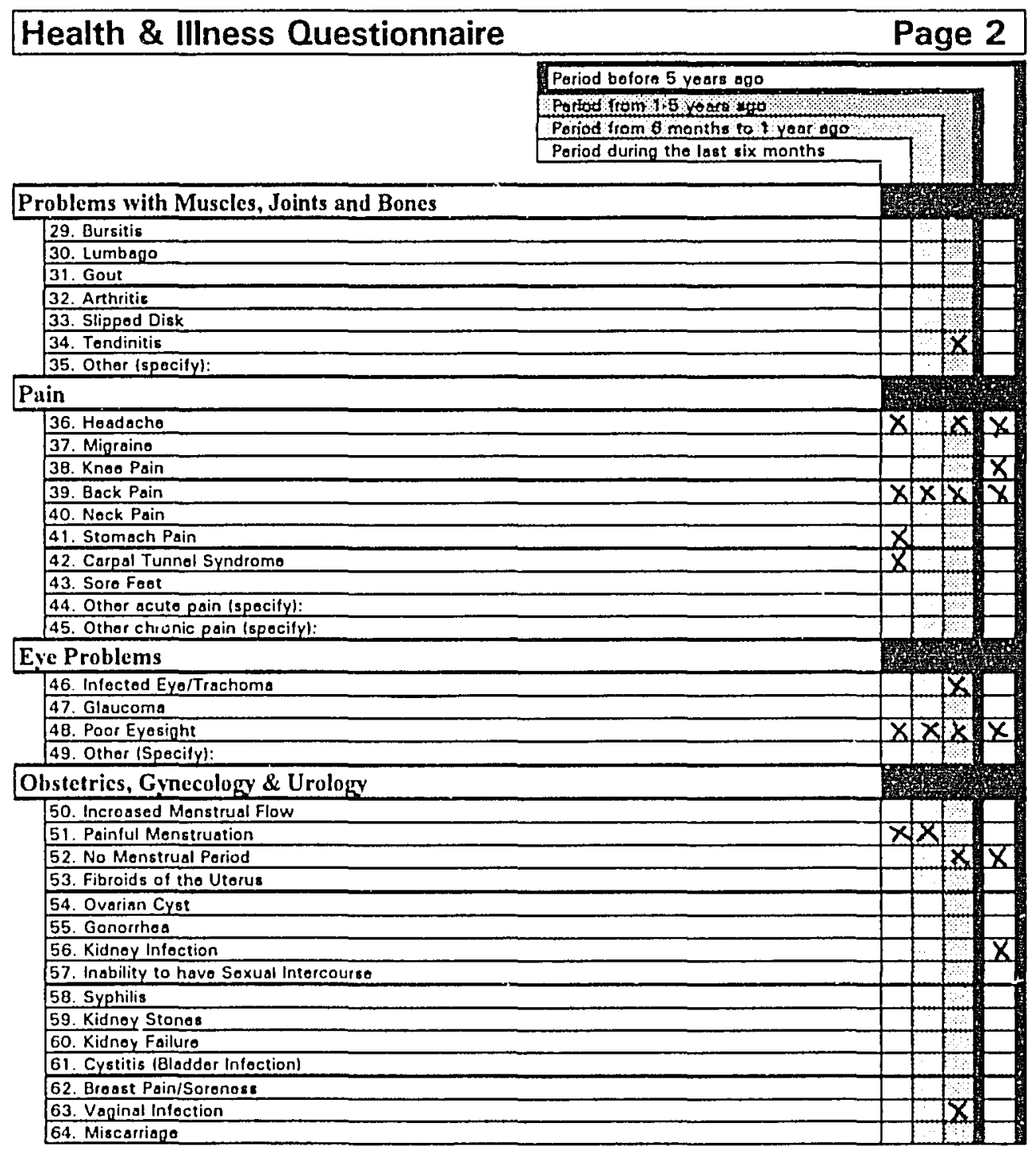




\begin{tabular}{|c|c|c|}
\hline Health \& Illness Questionnaire & & Page 3 \\
\hline & Poriod before 5 yoars ano & \\
\hline & Poriod from I s Yatgo sta & \\
\hline & Pariod from 8 monthe to 1 yoar apo & \\
\hline & Poriod during tho last 6 months & \\
\hline Obstetrics, Gynecology, \& Urology & & \\
\hline 65. Sterility & & \\
\hline 66. Complications during Labor & & \\
\hline 67. Complications during Pronnancy & & \\
\hline 68. Othor (specify): & & \\
\hline Digestive Problems & & \\
\hline 69. Constipation & & \\
\hline 70. Indigestion & & $\bar{x}$ \\
\hline 71. Diarrhoo & & \\
\hline 72. Hemornhoids & & \\
\hline 73. Ulcar & & \\
\hline 74. Gastroenteritis & & \\
\hline 75. Food Poisoning & & \\
\hline 76. Other (specify): & & \\
\hline Infectious or Contagious Illnesses & & \\
\hline 77. Chicken Pox & & \\
\hline 78. Mumps & & \\
\hline 79. Measles & & \\
\hline 80. Flu & & $\overline{x t}$ \\
\hline 81. Mononucloosis & & \\
\hline B2. Whooping Cough & & \\
\hline 83. Typhoid/Salmonello & & \\
\hline 84. Malaria & & \\
\hline 85. Chalera & & \\
\hline 86. Hepatitis & & \\
\hline 87. Totanus & & \\
\hline 88. Moningitis & & \\
\hline 89. Polio & & \\
\hline 90. Bilharia (schistosomiasis) & & \\
\hline 91. Other (specify): & & \\
\hline Lung Problems & & \\
\hline 92. Bronchitis & & x \\
\hline 93. Pneumonio & & \\
\hline 94 Asthma & & \\
\hline 95. Pulmonary Edema/Water on tho Lungs & & \\
\hline 96. Emphysema & & \\
\hline 97. Tuberculosis & & \\
\hline 38. Blood Clot in tho Lung & & \\
\hline 99. Other (specify): & & \\
\hline Problems with Internal Organs \& Glands & & \\
\hline 100. Goiter & & I. \\
\hline 101. Appendicitis & & 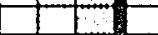 \\
\hline 102. Hyporthyroid & & \\
\hline
\end{tabular}




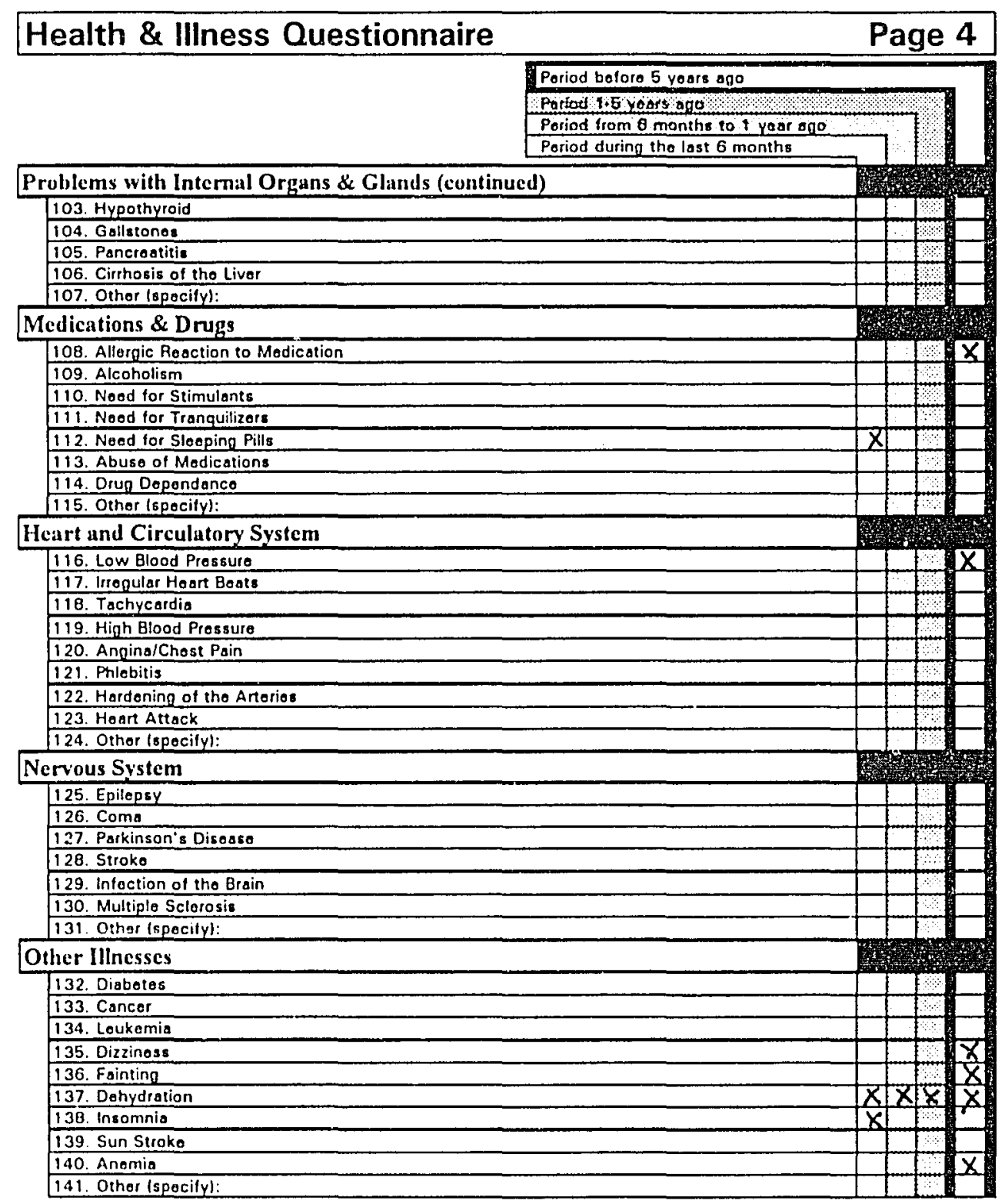

